Band XVIII Heft 3/4 (Schlußheft von Bd. XVIII) Dezember 1917

\title{
Versuche über die gametische Konstitution der Önotheren.
}

\author{
Von 0. Renner.
}

(Eingegangen am 20. Januar 1917.)

\section{Inhaltsübersicht.}

I. Die Materialien $\ldots . . . . . .128$

II. Das Verfahren bei der Aufzucht . . . . . . . . . . . . . . . 125

III. Die Beschaffenheit der Samen . . . . . . . . . . . . . . . . 130

IV. Die Beschaffenheit der Keimzellen . . . . . . . . . . . . . . 148

V. Die wesentlichen Unterscheidungsmerkmale der verwendeten Arten und der durch Kreuzung hergestellten Formen . . . . . . . . . . . . . 155

VI. Die Kennzeichen der verwendeten Arten . . . . . . . . . . . . 158

VII. Die Einzelergebnisse der Kreuzungsversuche . . . . . . . . . . . 165

1. Das Verhalten der Bastarde in der ersten Generation . . . . . . 165

2. Das Verhalten der Bastarde in den späteren Generationen . . . . 195

3. Kreuzungen der Bastarde mit den Elternarten . . . . . . . . . 203

a) Sesquireziproke Kreuzungen . . . . . . . . . . . . . . 203

b) Iterative Kreuzungen . . . . . . . . . . . . . . . . 209

4. Kreuzungen von zwei Zwillingsbastarden miteinander . . . . . . 213

VIII. Allgemeine Erfahrungen über die Vererbungserseheinungen . . . . . . 216

1. Die Zahlenverhältnisse . . . . . . . . . . . . . . . . . 216

2. Die Vererbung der Blütengröße . . . . . . . . . . . . . . 219

3. Die Vererbung der Griffellänge . . . . . . . . . . . . . 220

4. Die Vererbung der Anthokyanbildung . . . . . . . . . . . . 221

a) Die Farbe der Blattnerven . . . . . . . . . . . . . . 221

b) Die Färbung der Blütenkelche . . . . . . . . . . . . . 223

c) Die Färbung der jungen Früchte . . . . . . . . . . . . 224

d) Die rote Punktierung der Stengel und Fruchtknoten . . . . . 225

e) Die Färbung der Blumenkronen . . . . . . . . . . . . 226

5. Die Vererbung des Verhältnisses zwischen gesunden und tauben Samen 227

6. Die Vererbung der Habituscharaktere; die artunterscheidenden Merkmalskomplexe bezw. Faktorenkomplexe . . . . . . . . . . . . . 227

a) Komplexanalyse von O. Lamarckicna, muricata und biennis . . 228

b) Komplexanalyse von 0. suaveolens . . . . . . . . . . . . 285

c) Komplexanalyse einiger Bastarde . . . . . . . . . . . . 239 
7. Das Verhalten des Rotnervenfaktors gegenüber den artunterscheidenden Faktorenkomplexen . . . . . . . . . . . . . . . . . . 244

8. Die artunterscheidenden Faktorenkomplexe und die Mutationen . . . 248

9. Die Faktorenkomplexe einiger von de Vries verwendeten Arten . . 251

10. Das Verhältnis einiger Mutanten von $O$. Lamarckiana und $O$. biennis zu den Mutterarten . . . . . . . . . . . . . . . . . . 255

a) Die Mutanten der lata-Gruppe . . . . . . . . . . . . . 255

b) Die Mutanten der gigas-Gruppe . . . . . . . . . . . . . 257

c) O. Lamarckiana-brevistylis . . . . . . . . . . . . . . 259

d) Die Zwergformen . . . . . . . . . . . . . . . . . . 260

aa) O. Lamarckiana-nanella . . . . . . . . . . . . . . 260

bb) O. biennis-nanella . . . . . . . . . . . . . . . . 266

cc) O. Lamarckiana-gigas-nanella . . . . . . . . . . . . 266

e) O. Lamarckiana-rubrinervis . . . . . . . . . . . . . . . . . 267

f) O. Lamarckiana-oblonga . . . . . . . . . . . . . . . . . 271

11. Die Zahlenverhältnisse zwischen den Keimzelltypen . . . . . . . 271

12. Die Veränderung der artunterscheidenden Faktorenkomplexe in den

Bastarden . . . . . . . . . . . . . . . . . . . . . . 275

IX. Kreuzung und Artentstehung . . . . . . . . . . . . . . . . 280

X. Zusammenfassung der wesentlichen Ergebnisse . . . . . . . . . . 285

Nachschrift . . . . . . . . . . . . . . . . . . . . . . . 291

Zitierte Literatur. . . . . . . . . . . . . . . . . . . . . 292

\section{Die Materialien.}

Meine Versuche begannen im Sommer 1912 mit der Kreuzung vorhandener Materialien von O. biennis und Lamarckiana, deren Herkunft unbekannt ist. Die O. biennis war in mehreren gleichförmigen Exemplaren im alten botanischen Garten in München kultiviert und von der um München wild vorkommenden Form nicht za unterscheiden. Die O. Lamarckiana war im Hof des Zoologischen Instituts angepflanzt, typisch großblütig, mit rotstreifigem Kelch. Die Population wurde nicht genauer untersucht, weil die Absicht der Züchtung der Kreuzungen nicht bestand; leider wurde die Kultur der Pflanze an dem angegebenen Ort nicht fortgesetzt, und auch Samen sind nicht vorhanden. Das Ergebnis der Kreuzung biennis $\times$ Lamarckiana läBt aber nach den später gewonnenen Erfahrungen den Schluß zu, daß wenigstens das zu der Kreuzung verwendete Individuum rotnervig war; es soll mit Lamarckiana $\mathrm{X}$ bezeichnet werden. Die Kreuzung wurde im Nymphenburger botanischen Garten im Sommer 1914 zweijährig zur Blüte gebracht. Es waren die von de Vries beschriebenen Zwillinge laeta und velutina, und zwar 40 laeta, davon 25 weißnervig, 15 rotnervig, und 7 velutina, daron 5 weißnervig, 2 rotnervig. 
Weiter wurden 1914 und später in Kultur genommen:

O. biennis. Mehrere typische gleichförmige zweijährige Exemplare aus dem Nymphenburger Garten. Zu Bestäubungen diente als Vater und als Mutter ein Individuum biennis I1. Ein dreijähriges Exemplar derselben Population, biennis I 12, wurde 1915 verwendet. Aus selbstbefruchteten Samen von I1 wurden 1915 etwa 50 gleichförmige Pflanzen einjährig erzogen; von dieser Generation II dienten zu Bestäubungen die Individuen 1-5. Von 25 zweijährigen Pflanzen derselben Abstammung wurden 1916 verwendet: biennis II 51 und II 52.

O. muricata ${ }^{1}$ ). Generation I 1912 aus Samen, die Herr Geheimrat v. Goebel am Lido bei Venedig gesammelt hatte. Generation II 1914, einjährig erzogen, in 40 Individuen. Generation III 1915 einjährig in 30 Individuen und 1916 zweijährig in 10 Individuen. Ganz einförmig.

O. (biennis $\times$ muricata). Selbstbefruchtete Samen der $F_{3}$ (1909) und $F_{4}$ (1913), von Herrn Professor de Vries erhalten, gaben 1914 ein Exemplar der $\mathrm{F}_{4}$ und zwei Exemplare der $\mathrm{F}_{5}$. Alle drei Individuen waren einander ganz gleich.

O. (muricata $\times$ biennis). Selbstbefruchtete Samen der $\mathrm{F}_{3}$ von de Vries (1913) gaben 15 Individuen der $\mathrm{F}_{4}$ im Sommer 1914. 1915 erwuchs ein zweijähriges Exemplar aus einer überwinterten Seitenrosette. Von diesem gewonnene Samen lieferten 1916 die $F_{5}$ in 27 gleichförmigen Individuen.

O. suaveolens Desf. Samen von de Vries aus dem Forst von Fontainebleau bei Paris gaben 1914 die Generation I in 14 gleichförmigen und einem abweichenden rotnervigen Exemplar, das vielleicht ein Bastard suaveolens $\times$ biennis war. Zu Bestäubungen wurden verwendet I 1-5. Die Generation II, aus I4 gewonnen, wurde 1915 (etwa 100 Keimpflanzen, 25 Exemplare blühend) und wieder 1916 (27 Exemplare blühend) gezogen; Bestäubungen 1916 mit II 101-104.

O. Lamarckiana von de Vries. Selbstbefruchtete Samen von de Vries lieferten 1914 die Generation I in 30 weißnervigen Exemplaren, von denen eines eine Mutante war. Zu Bestäubungen wurden nur typische Individuen verwendet. Die Generation II, 1915 aus I 3 in 20 gleichförmigen Exemplaren.

1) Die Form ist mit der holländischen, von Bartlett (1914, S. 38) und danach auch von de Vries neuerdings als syrticola bezeichneten Art jedenfalls ganz nahe verwandt. Bevor Bartlett aber sein Urteil darüber abgegeben hat, möchte ich den älteren Sammelnamen muricata beibehalten. Zur genaueren Kennzeichnung wird der Biotypus gelegentlich, wie schon früher (Renner 1914), O. muricata-Venedig genannt werden. 
O. Lamarckiana von Heribert-Nilsson; im Text auch als schwedische Rasse bezeichnet. A weißnerviger Stamm, Reihe 71 a bei Heribert-Nilsson. Generation I 1914 in 30 blühenden Individuen erzogen, weißnervig, gleichförmig, einjährig; zu Bestäubungen verwendet Nr. 1-5. Von derselben Saat trieben zwei Rosetten erst 1915 Stengel; diese zweijährigen Exemplare heißen A I 31 und I32. Die Generation II, aus I 31 gewonnen, wurde 1916 einjährig erzogen in 40 gleichförmigen Individuen.

B rotnerviger, heterozygotischer Stamm $71 \mathrm{~b}$, aus derselben rotnervigen Mutter wie der weißnervige Stamm 71a. Generation I, 1914, einjährig, aus vier Rotnerven bestehend. Zur Bestäubung wurde B I 1 rotnervig verwendet.

C rotnerviger, heterozygotischer Stamm 75b. Generation I, 1914 , einjährig, besteht aus 16 Rotnerven und einem Weißnerv. Generation II, aus I rotnervig 3 gewonnen, 1915 einjährig erzogen, besteht aus 63 Rotnerven und 22 Weißnerven. Zur Bestäubung wurde ein Weißnerv C II weißnervig 1 verwendet.

O. rubrinervis, Mutante aus $O$. Lamarckiana. Selbstbefruchtete Samen von de Vries lieferten 1914 die Generation I in 50 weißnervigen Exemplaren. Generation II, aus I 1, 1915 gesät, 1915 in 25 einjährigen Individuen, 1916 aus im Topf überwinterten Rosetten in 12 Individuen erzogen; zur Bestäubung verwendet II 1 (1915) und II 26 (1916).

O. gigas, Mutante aus 0 . Lamarckiana. Selbstbefruchtete Samen von de Vries (1910) lieferten 1914 die Generation I in 50 und wieder 1915 in 20 weißnervigen Individuen.

O. gigantea Heribert-Nilsson ${ }^{1}$ ), Mutante aus O. Lamarckiana, Linie $22 \mathrm{~A}$. Selbstbefruchtete Samen einer zweijährigen Pflanze gaben 191417 Individuen, davon 15 rotnervig und 2 weißnervig. Ein Rotnerv blühte erst 1915, I rotnervig Nr. 15.

O. nanella, Mutante aus $O$. Lamarckiana. Samen von de Vries gaben 1914 die Generation I in 70 gleichförmigen Individuen, ebenso 1915 in 30 Exemplaren.

O. (Lamarckiana weißnervig $\times$ biennis) von Heribert-Nilsson. A. Samen einer kleinblütigen $\mathrm{F}_{2}$-Pflanze 56/8. Unter 15 blühenden Individuen der $\mathrm{F}_{3}$ waren 191414 Rotnerven und 1 Weißnerv; 1915

1) Heribert-Nilss on 1915 S. 54; 1912 S. 132 als "Kombination $7^{\text {" }}$ bezeichnet. $22 \mathrm{~A}$ ist eine Schwesterpflanze der Linie 22, $1912 \mathrm{~S} .168$ u. f. 
blühte ein zweijähriges rotnerviges Individuum, $\mathrm{F}_{3} \mathrm{Nr}$. 16. - B. Samen einer kleinblütigen $\mathrm{F}_{3}$-Pflanze 50/25; 1914 blühten 25 rotnervige Pflanzen der $\mathbf{F}_{4}$.

Die Überwachung der Kulturen ist durch meinen zeitweiligen Dienst im Heere mehrfach gestört worden. In den Sommern 1914 und 1916 konnte die Auszählung der entwickelten Pflanzen, im Frühjahr 1916 die Wartung der Keimlinge in den Töpfen und nach der Auspflanzung im Garten nicht so sorgfältig ausgeführt werden, wie es erwünscht gewesen wäre. Auch die Abfassung des Manuskripts ist unter recht erschwerenden Umständen zustande gekommen, woraus sich vor allem die wenig eingehende Behandlung der Literatur erklärt. Eine auch nur annähernd erschöpfende Besprechung der einschlägigen Literatur war übrigens von vornherein nicht beabsichtigt. Es sollen Versuche, Experimente mitgeteilt werden, die das Önotherenproblem auf eine neue Grundlage stellen. Bestätigungen aus den Ergebnissen anderer Züchter sind zur weiteren Sicherung meiner Schlüsse selten nötig, abgesehen natürlich von dem kaum auszuschöpfenden Versuchsmaterial von de Vries. Und ein immer wiederholter Hinweis darauf, daß sehr vieles, was über Oenothera geschrieben worden ist, in der Deutung der Erscheinungen weit vom Ziel trifft, wäre ein unfruchtbares Unternehmen.

Herrn Geheimrat v. Goebel bin ich für die freigebige Überlassung von Freiland im botanischen Garten in Nymphenburg zu großem Dank verpflichtet, desgleichen Herrn Inspektor Holfelder für vielfache Unterstätzung bei der Gartenarbeit.

\section{Das Verfahren bei der Aufzucht.}

Die Behandlung, die ich dem Züchtungsmaterial zuteil werden lasse, ist folgende. Die Samen werden in kleinen Esmarchschalen auf dauernd fencht gehaltenem Filtrierpapier ausgelegt und die Schalen, im Thermostaten oder in der Nähe des Heizkörpers, so lange bei $30-35^{\circ}$ gehalten, bis nach dem Auflaufen einer Anzahl Samen die Keimung zum Stillstand kommt. Dann werden die Schalen für einen oder zwei Tage in einen Raum mit $10-15^{\circ}$ gestellt, and hierauf geht nach der Zurückbringung in die höhere Temperatur die Keimung wieder einen oder mehrere Tage lang fort.' Die Behandlung mit 'wechselnder Temperatur wird etwa zwei Monate lang fortgesetzt, doch ist die Keimung 
gewöhnlich nach etwa vier Wochen beendet ${ }^{1}$ ). Das Auslegen der Samen geschieht, wenn die Pflanzen einjährig erzogen werden sollen, im Februar oder schon im Januar.

Die gekeimten Samen werden, sobald die Keimwurzel die ersten Wurzelhaare entwickelt hat, mit einer Pinzette aus den Schalen genommen und in große flache Töpfe mit gesiebter Erde pikiert; die Zahl der gekeimten Samen wird jeweils vor dem Pikieren gebucht. Läßt man die Keimlinge länger auf dem Papier, so wird die Samenschale oft von den Kotyledonen abgestreift, und der leere Balg kann dann leicht als tauber Same gezählt werden. Außerdem klebt sich die Wurzel auch bald fest an das Papier an oder bohrt sich gar in das Papier ein, so daß sie beim Abnehmen des Keimlings leicht beschädigt wird.

Neben jeden Samen, und zwar immer auf dieselbe Seite, wird beim Auspikieren ein kleines Holzstäbchen gesteckt, etwa $4 \mathrm{~cm}$ lang, $1 \mathrm{~mm}$ dick (Fig. 1). Mit dem Stäbchen wird vorher das Loch für die Wurzel gebohrt, wenn sie schon beträchtlichere Länge hat. Die Testa wird im allgemeinen nicht mit Erde bedeckt. Beim Begießen wird aber oft ein Same mit Erde zugeschüttet, und wenn ein schwäcblicher Keimling sich nicht durch die Erddecke herauszuarbeiten vermag, kann er oft dadurch gerettet werden, daß man neben dem Stäbchen an der Stelle, wo er versteckt sein muß, sorgfältig nachgräbt und die Kotyledonen freilegt. Dieses Nachgraben wird zu einer Zeit vorgenommen, wenn neben der Mehrzahl der Stäbchen die Keimblätter der gleichzeitig gepflanzten Sämlinge über der Erde erschienen sind. Ist ein Same nicht mehr zu finden oder wird er tot ausgegraben, so wird das Stäbchen schief eingesteckt, als Zeichen dafür, daß der Keimling überhaupt nicht über der Erde erschienen ist. Wenn ein Sämling nachträglich abstirbt, so ist das später in den Töpfen daran zu erkennen, daß ein aufrechtes Stäbchen ohne Pflanze dasteht. Sobald die Keimpflanzen mehrere Blätter gebildet haben, werden sie ebenso wie die leeren Stäbchen gezählt und alle Stäbchen entfernt. Nur schwächliche Pflanzen, bei denen das Eingehen noch zu befürchten ist, oder solche, die wegen irgendwelcher Merkmale öfter kontrolliert werden sollen, werden durch ein längeres Stäbchen deutlich gemacht, gelegentlich auch umgepflanzt.

1) De Vries empfiehlt als ein sehr rasch und sicher wirkendes Mittel zur Beschleunigung der Keimung das Einpressen von Wasser in die Samen bei 6-8 Atmosphären Druck für die Dauer von 2-3 Tagen (1915a, S. 190; 1915b). Vergl. auch Davis 1915a. 
Die Sämlinge werden gleich in solcher Entfernung pikiert, daß sie vor dem Auspflanzen in den Garten nicht umpikiert zu werden brauchen. Nur solche Individuen, die zwischen den Nachbarn zurückbleiben, werden umgepflanzt, damit sie nicht durch Beschattung geschädigt werden. Mitunter genügt es, von den kräftigeren Pflanzen die Blätter abzubrechen, die die schwächeren Sämlinge bedecken. Die Töpfe stehen in einem Gewächshaus bei etwa $15^{\circ}$.

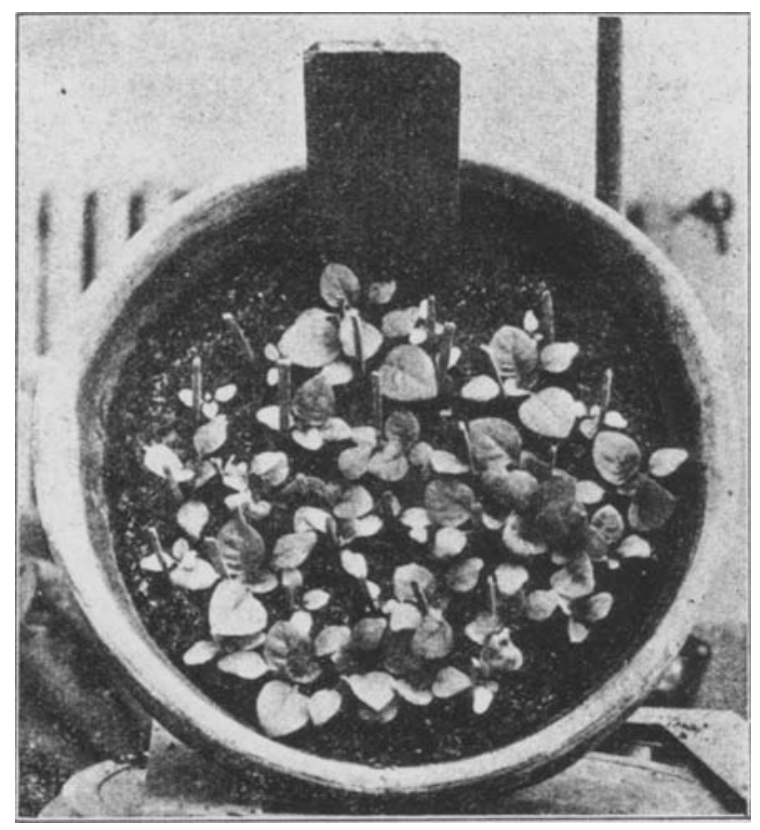

Fig. 1. Mehrere Wochen alte Keimpflanzen der $F_{1}$ der Kreuzung 0 . suaveolens $X$ biennis, jeder Keimling noch mit dem Holzstäbchen markiert. Die Schale enthielt die zuerst gekeimten Pflanzen; 21 Keimlinge sind groß und grün, redempta (= biennis), 16 sind schwach und gelb, flava.

Im April oder Mai pflanze ich die Sämlinge selber im Garten aus, die weiter entwickelten früher, die zurückgebliebenen später. Außer der Oenothera gigas kommen alle bis jetzt kultivierten Formen bei dieser Behandlung im ersten Jahr so zeitig zum Blühen, daß sie gut ausgereifte Früchte liefern. Auch auf den Beeten werden schwachwüchsige Individuen vor der Überwucherung durch kräftigere Nachbarn so gut wie möglich geschützt. 
Die Zahl der Keimlinge, die nicht einmal die Kotyledonen über der Erde entfalten, ist sehr gering, am größten noch bei schlecht ausgereiften Spätfrüchten, wie sie 1915 nach später Bestäubung mehrfach geerntet wurden. Es scheint also sicher, daß es keine Typen oder Klassen von Samen gibt, die zunächst wohl zu keimen vermögen, aber vor der Entfaltung der Keimblätter regelmäßig zugrunde gehen. Wenn ein gekeimter Same ausbleibt, so wird das auf zufälliger Schädigung beruhen. Dagegen sind Sämlingstypen, die mit winzigen weißen oder gelben Kotyledonen bald nach deren Entfaltung absterben, wohl vorhanden, z. B. bei der Kreuzung Lamarckiana $\times$ muricata.

Die nach Beendigung der Keimung in den Schalen zurückgebliebenen Samen werden zu gelegener Zeit mit einer Skalpellnadel geöffnet und auf das Vorhandensein oder Fehlen eines gut ausgebildeten Embryo untersucht. Es hat sich ergeben, dab die allermeisten nicht gekeimten Samen taub sind, keinen mit unbewaffnetem Auge sichtbaren Embryo enthalten. Es fehlen also auch solche durch zahlreiche Individuen dargestellte Samentypen, deren Embryo vollkommen entwickelt, aber nicht keimfähig wäre; wenn einzelne Samen mit voll ausgebildetem Embryo, wie es oft vorkommt, nicht zar Keimung zu bringen sind, so ist nicht zu entscheiden, ob es sich um nicht keimfähige Biotypen oder um zufällig gestörte Individuen handelt. Und es ist deshalb erlaubt, bei der Auszählung größerer Samenmengen, die dem umständlichen Keimverfahren nicht gut unterworfen werden können, jeden mit voll ausgebildetem Embryo ansgestatteten Samen als keimfähig anzusprechen.

In der Tabelle I sind einige Beispiele der Keimung ans dem Frühjahr 1915 zusammengestellt. Daß im folgenden Jahr die Keimprozente der keimhaltigen Samen gewöhnlich nicht ungünstiger ausfielen, ist aus den Einzelbeschreibungen der Versuche zu entnehmen. Schlecht keimte 1915 nur der Same von O. biennis $\times$ muricata; neben 108 gekeimten Samen blieben 59 ungekeimt, und davon hatten noch 39 einen Embryo, nur 20 waren taub. Noch schlechter keimte 1916 der Same von O. Lamarckiana $\times$ muricata.

Daß wenn möglich alle keimhaltigen Samen einer herausgegriffenen Probe mit allen Mitteln zur Keimung gezwungen werden müssen und der Keimversuch nicht vorzeitig abgebrochen werden darf, ist schon des öfteren ausgesprochen worden. Es ist ja bekannt, daß unter den Nachkeimern Abweicher verhältnismäßig häufig sind, und auch bei meinen Kulturen habe ich öfter die Erfahrung gemacht, daß die zuletzt gekeimten Samen "Mutanten" lieferten. Wo mehrere Typen in einer 
Tabelle I.

\begin{tabular}{|c|c|c|c|}
\hline & $\begin{array}{l}\text { Gekeimte } \\
\text { Samen }\end{array}$ & $\begin{array}{c}\text { Nicht } \\
\text { gekeimte } \\
\text { Samen }\end{array}$ & $\begin{array}{c}\text { Nicht } \\
\text { gekeimt, aber } \\
\text { keimhaltig }\end{array}$ \\
\hline O. biennis . . . & 190 & 36 & 1 \\
\hline O. biennis $\times$ Lamarckiana weißnervig. & 132 & 60 & 5 \\
\hline 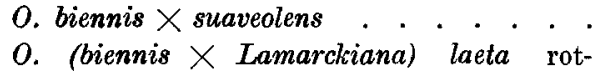 & 171 & 26 & 0 \\
\hline O. (biennis $\times$ Lamarckiana) velutina weib- & 241 & 84 & 1 \\
\hline$\underset{\text { O. biennis } \times(\text { biennis } \times \text { Lamarckiana) laeta }}{\text { nervig }}$ & 72 & 171 & 2 \\
\hline$\underset{\text { o.biennis } \times(\text { biennis }}{\text { weißnervig }} \times \dot{\text { Lamarckiana }) \text { velutina }}$ & 134 & 84 & 0 \\
\hline rotnervig $. \quad . \quad . \quad . \quad . \quad . \quad . \quad . \quad$. & 119 & 42 & 1 \\
\hline O. biennis $\times($ Lamarck $\times$ biennis $)$ fallax $\mathrm{F}_{\mathrm{s}}$ & 142 & 63 & 2 \\
\hline $\begin{array}{l}\text { O. (biennis } \times \text { muricata }) \times \text { biennis } \\
\text { O. Lamarckiana Heribert-Nilsson } \text { rot- }\end{array}$ & 69 & 9 & 2 \\
\hline O. Lamarckiana $\underset{\text { Heribert-Nilsson weiB- }}{\text { nervig }}$ & 95 & 172 & 0 \\
\hline o. Lamarckiana Heribert-Nilsson weib- & 166 & 119 & 0 \\
\hline o. Lamarckiana Heribert-Nilsson weiB- & 51 & 5 & 2 \\
\hline nervig $\times$ suaveolens...... & 317 & 6 & 2 \\
\hline o. rubrinervis. . . . . . & 167 & 81 & 2 \\
\hline O. rubrinervis $\times$ biennis . & 208 & 10 & 0 \\
\hline O. suaveolens . . . . . & 109 & 166 & 0 \\
\hline O. suaveolens $\times$ biennis . & 134 & 30 & 0 \\
\hline O. suaveolens $\times$ Lamarckiana . . . . . & 290 & 31 & 3 \\
\hline
\end{tabular}

Generation vorkommen, kann das Zahlenverhältnis zwischen den Typen bei den zuerst keimenden Samen ein anderes sein als bei den spät keimenden. Das war besonders auffällig bei der $F_{1}$ der Kreuzung $O$. suaveolens $\times$ biennis. Hier enthielt die erste Keimschale 21 grüne und 16 gelbe Keimlinge, 1 gekeimter Same blieb aus (vergl. Fig. 1); die zweite Schale enthielt 2 grüne und 40 gelbe Keimlinge; die dritte Schale enthielt 3 grüne und 37 gelbe Keimlinge, 3 gekeimte Samen blieben aus (vergl. Fig. 16, S. 171); in der vierten Schale waren nur gelbe Keimpflanzen, 7 an der Zahl. Man sieht, wie hier das Zahlenverhältnis zwischen dem grünen und dem gelben Typus gefälscht werden 
könnte, wenn man nur die Keimung eines kleinen Teils der Samen abwarten würde.

\section{Die Beschaffenheit der Samen.}

In einer früheren Mitteilung (1914) habe ich ausgeführt, daß die Vererbungserscheinungen der Önotheren in gewissen Fällen mit den Mendelschen Regeln einigermaßen in Einklang gebracht werden können, wenn man die besonders bei O. Lamarckiana seit lange bekannten tauben Samen als Repräsentanten gewisser lebensunfähiger zygotischer Kombinationen ansieht. Zur Prüfung der Hypothese war es vor allem nötig über die Konstanz des Zahlenverhältnisses zwischen gesunden und tauben Samen Erfahrungen zu sammeln. Die Untersuchung eines umfangreichen Samenmaterials hat nun ergeben, daß die sichere Trennung von gesunden und tauben Samen meistens viel schwieriger ist als es nach den ersten Proben den Anschein hatte. Die Musterung und Auszählung der Samen geschah auf weißen Porzellantellern, von denen auch die kleinsten Samenanlagen sich noch gut abheben.

In den Früchten sämtlicher untersuchten Materialien finden sich mindestens dreierlei Samentypen: erstens ansehnliche gesunde Samen mit harter Testa und vollentwickeltem Embryo, zweitens ansehnliche Samen mit harter Testa und winzigem abgestorbenem Embryo, drittens unentwickelte vertrocknete Samenanlagen, die ein feines bräunliches Pulver darstellen. Die Entscheidung, ob ein Same der ersten Kategorie zuzuteilen ist oder nicht, ist selten schwierig; nur ausnahmsweise kann man bei der Auszählung reifer Früchte zweifelhaft sein, ob ein Embryo, der beträchtlich kleiner ist als die normalen gesunden, aber auch größer als die knopfförmigen Embryorudimente der größeren tauben Samen, als gesund und keimfähig angesprochen werden soll. Dagegen ist es gewöhnlich schwer und häufig unmöglich, eine Grenze zwischen tauben Samen und ganz unentwickelten Samenanlagen zu finden $\left.{ }^{1}\right)$. Die größten tauben Samen sind oft so groß und prall, wie die größten gesunden, äußerlich von diesen in keiner Weise zu unterscheiden; nur die Testa erweist sich beim Anstechen mit der Nadel oft etwas weniger sklerosiert, was. sich bei solchen Samen am deutlichsten fühlbar macht, die einer frisch abgepflückten Frucht entriommen und noch nicht ausgetrocknet

1) Dieselbe Erfahrung scheint Davis gemacht zu haben; vergl. 1915b, S. 13 des Sonderabdrucks. - Die Photographie eines Sortiments tauber Samen von allen Größen bei Davis 1916 a; S. 224. 
sind. Solche großen Samen enthalten immer einen vielzelligen, mitunter mit bloßem Auge eben wahrnehmbaren Embryo. In sehr kleinen Samen mit noch gut entwickelter Testa ist in vorgerückterem Alter vom Embryo und rom Endosperm auch an Mikrotomschnitten oft keine Spur zu finden; der in seinen inneren Schichten zerstörte Nucellus umschließt einen leeren Hohlraum (vergl. 1914, S. 134), daß aber Befruchtung stattgefunden hat, zeigt häufig der in der Nucellusspitze erhaltene, an der Höhlung endigende Pollenschlauch an. Bei O. Lamarckiana sind nach Selbstbestäubung in solchen kleinen, schon ziemlich alten Samen einzellige Embryonen nebst 2-4 Endospermkernen gefunden worden. Daß so winzige Gebilde bei der Gewebeauflösung, die im Nucellus unter allen Umständen eintritt, vollständig verschwinden, ist nicht erstaunlich. Nicht selten werden die kleinen Samen mit ihrer schwach sklerosierten Testa von den benachbarten stärker wachsenden Samen flach zusammengepreßt, so daß die Nucellushöhle verschwindet, aber der Pollenschlauch ist auch hier noch lange zu sehen. In anderen Fällen - das ist besonders bei der Kreuzung O. muricata-Venedig $\times$ biennis beobachtet worden - greifen die Auflösungsvorgänge so weit um sich, daß auch die Nucellusspitze mit dem Pollenschlauch zerstört wird. Die allerkleinsten Samen erscheinen in eben ausgereiften, an der Spitze sich öffnenden Früchten als flache, weißliche, weiche Gebilde, die beim Austrocknen sich schwach bräunen. Und von solchen, nach zwei Dimensionen oft noch ganz ansehnlichen, bis $1 \mathrm{~mm}$ und darüber messenden Samenrudimenten finden sich nun häufig schrittweise Übergänge bis zu den ganz unentwickelten Samenanlagen hinunter. Noch in kaum vergrößerten Samenanlagen, die schon beträchtliches Alter hatten, sind Pollenschläuche gefunden worden; so bei der Kreuzung $O$. Lamarckiana $\times$ gigas, wo die Schläuche durch ihre Dicke sich besonders bemerkbar machen. - Auf Anzeichen apogamer Samenentwicklung bin ich nicht gestoßen, so wenig wie Heribert-Nilsson.(1915, S. 99).

Wir können also sagen: jede Samenanlage, die sich von den zweifellos unentwickelten durch ihre Größe deutlich abhebt, hat als befruchtet, als tauber Same zu gelten ${ }^{1}$ ). Im Einzelfall ist die Identifizierung der allerkleinsten Samen aus reifen Früchten so gut wie unmöglich, sogar auf mikroskopischem Weg, weil der Pollenschlanch zerstört werden kann. Höchstens in einem gewissen mittleren Alter wird sich an Mikrotomschnitten durch ganze Früchte ermitteln lassen, wie

1) Das hat schon Davis ( $1915 \mathrm{~b}$, S. 13 des Sonderabdrucks) vermutet. 
grob die Zahl der zwar befruchteten, aber sich kaum weiter entwickelnden Samenanlagen ist. Die Korrelation zwischen dem Wachstum des Embryo und der Ausbildung der Testa ist deutlich; je weiter der Embryo heranwächst, desto vollkommener entwickelt sich auch die Testa, und schon bei sehr kleinen kugeligen Embryonen wird die Testa fast so wie in gesunden Samen ausgebildet (z. B. bei O. suaveolens, O. [biennis $X$ muricata], O. [biennis $\times$ Lamarckiana] velutina). Wo die Integumente der Samenanlage kaum zu wachsen sich anschicken, kommt auch der Embryo über den einzelligen Zustand nicht hinaus, und die allerwinzigsten, schwer aufzufindenden Samen enthalten deshalb gerade die am allerstärksten gestörten Embryonen (beobachtet z. B. bei O. $\mathrm{La}$ marckiana, biennis).

Außer den befruchteten Samenanlagen, die sich mehr oder weniger weit entwickeln, kommen besonders in schwach bestäubten Früchten natürlich auch unbefruchtete vor, die ohne jede Vergrößerung vertrocknen und in der reifen Frucht, wie erwähnt, als feines bräunliches oder weißliches Pulver erhalten sind. Bei O. Lamarckiana handelt es sich dabei nach Geerts (1909, S. 177) nicht nur um solche Samenanlagen, die zufällig unbefruchtet bleiben, vielmehr soll etwa die Hälfte der Samenanlagen von vornherein steril, befruchtungsunfähig, mit rudimentären Megasporen ausgestattet sein und von Pollenschläuchen überhaupt nicht heimgesucht werden. Nach meinen eigenen zytologischen Beobachtungen besitzt auch die Rasse von Heribert-Nilsson zahlreiche Samenanlagen mit rudimentärem Embryosack. An einigen großen reifen Früchten dieser Rasse hat die sorgfältige Auszählung ergeben, daß die allerkleinsten Samenanlagen zahlreicher waren als die deutlich vergröBerten mit den eigentlichen Samen zusammen:

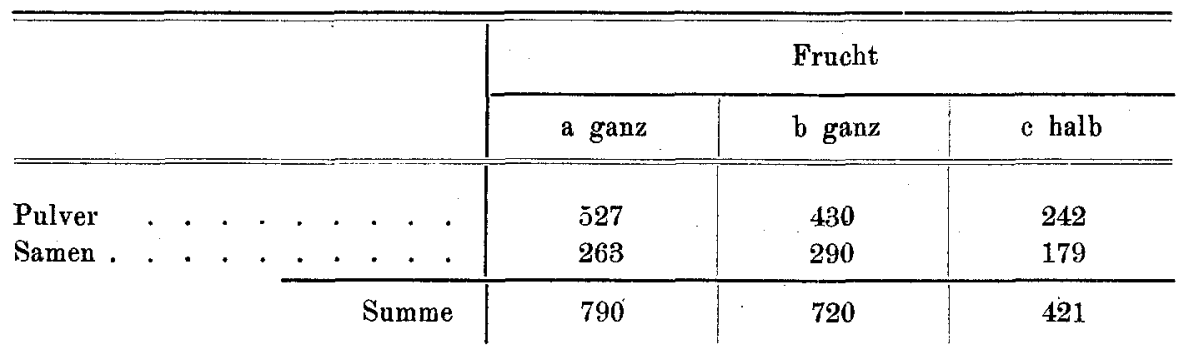

Unter den ganz kleinen Ovula, in dem Pulver, können also noch immer befruchtete Stücke verborgen sein, die sich kaum vergrößert 
haben; im Maximum könnte ja nach den Angaben von Geerts die Hälfte sämtlicher Samenanlagen befruchtet werden. Natürlich wird aber der Zufall anch bei der reichlichsten Bestäubung manche befruchtungsfähige Samenanlage von der Befruchtung ausschließen. $W_{0}$ größere Mengen von zweifellos unbefruchteten Samenanlagen vorkommen, wie regelmäßig im unteren Teil der von muricata-Pollen befruchteten Kapseln von O. Lamarckiana, sind sämtliche Ovula der betreffenden Fruchtgegend vollkommen gleich in der Größe. Die befruchtungsfähigen Samenanlagen entwickeln sich also, wenn die Befruchtung ausbleibt, nicht weiter als die von vornherein zur Sterilität bestimmten Ovula. Auch diese Beobachtung spricht neben den natürlich nur in verhältnismäBig geringer Zahl vorgenommenen mikroskopischen Prüfungen dafür, daß jede vergrößerte Samenanlage befruchtet ist.

Bei anderen Arten ist die relative Menge des Pulvers in samenreichen Früchten meist geringer. Bei O. muricata waren in einer halben Frucht (in zwei Fächern von vieren) enthalten: 70 ganz kleine Samenanlagen, 32 deutlich vergrößerte, also Samenrudimente, und 151 große Samen; zusammen $70 \mathrm{ganz}$ kleine auf 183 sicher befruchtete Samenanlagen. Das stimmt mit den Erfahrungen von Geerts überein, der etwa $25 \%$ sterile Orula fand. Noch weniger untangliche Samenanlagen scheint bei Geerts $O$. biennis gehabt zu haben, denn er sagt, daß sich der Prozentsatz nicht genan bestimmen ließ (S. 181, 183). Bei meinem Material ist die Menge des Pulvers größer als bei O. muricata, allerdings ist es teilweise ziemlich grob, so dab die Abtrennung von den Samen nicht sicher durchzuführen ist. Ich fand in einer halben Frucht 162 sehr kleine Samenanlagen auf 149 Samen, in einer zweiten 145 sehr kleine auf 172 Samen; die Ovula im empfängnisreifen Fruchtknoten habe ich noch nicht untersucht. Bei $O$. rubrinervis waren die Zahlen für je eine Hälfte von sechs Früchten:

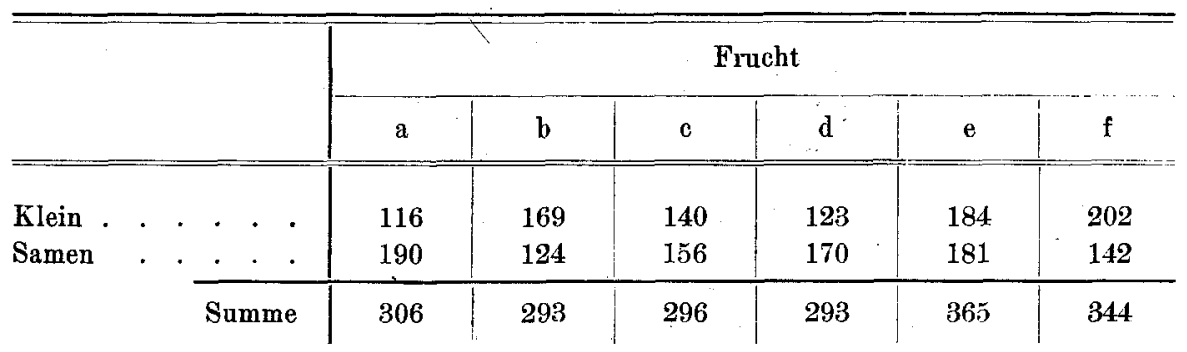


Bei O. suaveolens in drei ganzen Früchten:

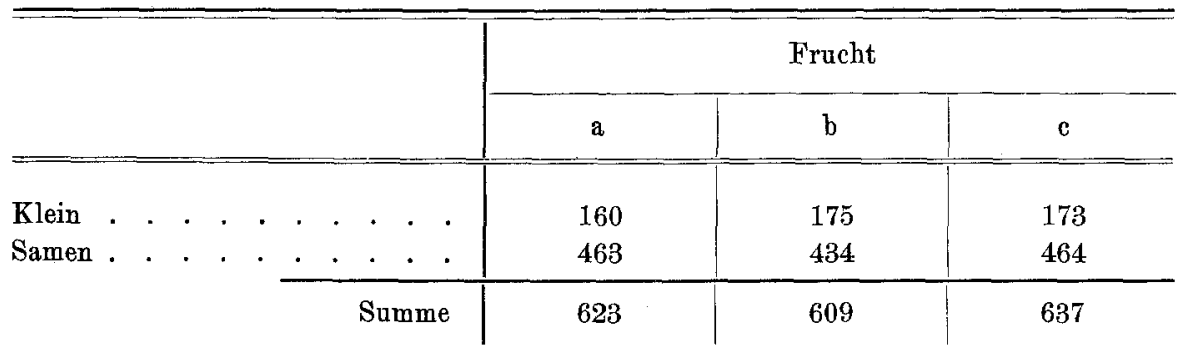

O. rubrinervis dürfte danach höchstens $38 \%$ sterile Samenanlagen besitzen (116 von 306), bei $O$. suaveolens dürfte etwa ein Viertel der Ovula steril sein.

Bevor die Beschaffenheit der Ovula in unbefruchteten Blüten zytologisch festgestellt ist, läßt sich nicht sagen, ob ein Teil der Samenanlagen notwendig unbefruchtet bleiben muß. Und auch dann, wenn die Häufigkeit der untauglichen Samenanlagen für eine Form ermittelt ist, wird es meistens unmöglich sein mit Sicherheit anzugeben, wie viele Samenanlagen in einer gegebenen Frucht befruchtet worden sind, weil einerseits eine Befruchtung sämtlicher tauglichen Ovula wohl selten erfolgt, andrerseits in dem „Pulver" noch befruchtete, sehr früh gehemmte Samenanlagen vorkommen können.

In der folgenden Tabelle II sind die Ergebnisse der Zählungen zusammengestellt. Die Abtrennung der „sehr kleinen“ Samen von dem Pulver ist so sorgfältig wie möglich vorgenommen worden, doch waren Willkürlichkeiten oft ganz unvermeidlich. Wenn möglich wurden für die Auszählung geschlossene Früchte verwendet. Bei großer Samenzahl wurden meist nicht sämtliche Samen der ganzen Frucht untersucht, sondern nur die in zwei von den vier Fruchtfächern enthaltenen Samen. Daß die vier Fruchtfächer sich in der genotypischen Beschaffenheit der Samen voneinander unterscheiden können, dürfte ansgeschlossen sein; wohl aber könnte der obere Teil jedes Fruchtfachs andere Samenklassen beherbergen als der untere (vergl. unten S. 151). Aus einer größeren Samenmenge einen Teil für die Untersuchung abzutrennen ist bedenklich, weil leicht eine Sortierung der Samen nach dem Gewicht oder nach der Größe eintreten kann, sobald die Samen aus der Frucht herausgenommen sind. Die Zahlen der "losen Samen" der Tabelle sind also am wenigsten zuverlässig.

In allen Fällen, die nicht als Kreuzungen gekennzeichnet sind, handelt es sich natürlich um kontrollierte Selbstbefruchtung. 
Tabelle II.

\begin{tabular}{|c|c|c|c|c|c|c|}
\hline \multirow{2}{*}{ Material } & \multirow{2}{*}{ Frucht } & \multicolumn{3}{|c|}{ Taube Samen } & \multirow{2}{*}{$\begin{array}{c}\text { Ge- } \\
\text { sunde } \\
\text { Samen }\end{array}$} & \multirow{2}{*}{$\begin{array}{c}\text { Ge- } \\
\text { sunde } \\
\text { Samen } \\
\text { in } \%\end{array}$} \\
\hline & & $\begin{array}{l}\text { sehr } \\
\text { klein }\end{array}$ & größer & $\mid \begin{array}{c}\mathrm{zu}- \\
\text { sammen }\end{array}$ & & \\
\hline \multirow[t]{4}{*}{ biennis I 1, zweijährig } & a) $\operatorname{ganz}$ & 15 & 44 & 59 & 204 & 77 \\
\hline & b) 1 . Hälfte & 11 & 42 & 53 & 74 & 58 \\
\hline & b) 2. Hälfte & 10 & 41 & 51 & 75 & 60 \\
\hline & c) $\operatorname{gan} z$ & 65 & 34 & 99 & 123 & 55 \\
\hline \multirow[t]{3}{*}{ II 1, einjährig } & a) fast ganz & 29 & 30 & 59 & 105 & 64 \\
\hline & b) ganz & 30 & 47 & 77 & 134 & 64 \\
\hline & c) nicht ganz & 15 & 19 & 34 & 79 & 70 \\
\hline \multirow[t]{2}{*}{ II 51, zweijährig } & a) groh, halb & 25 & 23 & 48 & 101 & 68 \\
\hline & b) groß, halb & 24 & 36 & 60 & 112 & 65 \\
\hline biennis II $51 \times$ Lamarckiana & a) mittelgroB, halb & 15 & 23 & 38 & 64 & 63 \\
\hline Her.-Nilss. weißnervig A II 1 & b) kleiner, halb & 25 & 14 & 39 & 65 & 63 \\
\hline biennis I $1 \times$ muricata II & mittelgrob, halb & 5 & 8 & 13 & 53 & 80 \\
\hline biennis II $51 \times$ muricata & a) mittelgroß, halb & 5 & 4 & 9 & 46 & 84 \\
\hline III 31 & $\begin{array}{l}\text { b) mittelgroh, mehr } \\
\text { als die Hälfte }\end{array}$ & 15 & 13 & 28 & 70 & 71 \\
\hline $\begin{array}{c}\text { biennis } \text { II } 52 \times \text { rubrinervis } \\
\text { II } 26\end{array}$ & mittelgroß, etwa $\% / s$ & 30 & 21 & 51 & 84 & 62 \\
\hline biennis I $1 \times$ suaveolens I5 & $\begin{array}{c}\text { mittelgroß, mehr als } \\
\text { die Hälfte }\end{array}$ & $?$ & 11 & - & 55 & 83 \\
\hline biennis II $51 \times$ suaveolens & a) ziemlich grob, halb & 15 & 8 & 23 & 82 & 80 \\
\hline II 101 & $\begin{array}{l}\text { b) ziemlich groß, mehr } \\
\text { als die Hälfte }\end{array}$ & 24 & 12 & 36 & 101 & 74 \\
\hline biennis $\mathrm{II} 51 \times($ biennis $\mathrm{I} 1 \times$ & a) nicht grob, halb & 23 & 7 & 30 & 48 & 62 \\
\hline Lam. A I 1) fallax $\mathrm{F}_{1} \mathrm{Nr} .18$ & b) groß, etwa $2 / s$ & 22 & 35 & 57 & 125 & 69 \\
\hline biennis I I $\times$ (bien. $\times$ Lam. & a) klein, ganz & $?$ & 26 & - & 45 & 63 \\
\hline X) laeta weißn. $\mathrm{F}_{1} \mathrm{Nr} .6$ & b) 218 lose Samen & $?^{\circ}$ & 84 & - & 134 & 61 \\
\hline $\begin{array}{l}\text { biennis I } 1 \times(\text { bien. } \times \text { Lam. } \\
\text { X) velutina rotn. } \mathrm{F}_{1} \text { Nr. } 1\end{array}$ & mittelgrob, ganz & 50 & 22 & 72 & 56 & 43 \\
\hline $\begin{array}{c}\text { biennis I } 1 \times(\text { Lam. } \times \text { bien. }) \\
\text { fallax H.-N. } \mathrm{F}_{3} \text { Nr. } 1 \\
\end{array}$ & klein, ganz & 38 & 34 & 72 & 51 & 41 \\
\hline $\begin{array}{l}\text { (bien. I } 1 \times \text { Lam. H.N. B I } \\
\text { rotn. 1) fallax } \mathrm{F}_{1} \text { Nr. } 1\end{array}$ & $\begin{array}{l}\text { mittelgroß, nicht ganz } \\
\text { vollständig }\end{array}$ & 8 & 135 & 143 & 50 & 26 \\
\hline (bien. I $1 \times$ Lam.H.-N. A I1) & a) grob, halb & 38 & 56 & 94 & 33 & 26 \\
\hline fallax $\mathrm{F}_{1} \mathrm{Nr} .18$, zweijährig & b) grob, halb & 28 & 58 & 86 & 32 & 27 \\
\hline
\end{tabular}


$\mathrm{Zu}$ Tabelle II (Fortsetzung von S. 135).

\begin{tabular}{|c|c|c|c|c|c|c|}
\hline \multirow{2}{*}{ Material } & \multirow{2}{*}{ Frucht } & \multicolumn{3}{|c|}{ Taube Samen } & \multirow{2}{*}{$\begin{array}{c}\text { Ge- } \\
\text { sunde } \\
\text { Samen }\end{array}$} & \multirow{2}{*}{$\begin{array}{l}\text { Ge- } \\
\text { sunde } \\
\text { Samen } \\
\text { in } \%\end{array}$} \\
\hline & & $\begin{array}{l}\text { sehr } \\
\text { klein }\end{array}$ & größer & $\mid \begin{array}{c}\text { zu- } \\
\text { sammen }\end{array}$ & & \\
\hline $\begin{array}{l}\text { (bien. I } 1 \times \text { Lam. B I rotn. 1) } \\
\text { fallax } \mathrm{F}_{2} \text {, rotnervig, klein- } \\
\text { blütig, aus } \mathrm{F}_{1} \mathrm{Nr} .1\end{array}$ & $\begin{array}{l}\text { a) grob, etwas mehr } \\
\text { als die Hälfte } \\
\text { b) ziemlich grob, } \\
\text { etwas mehr als die } \\
\text { Hälfte }\end{array}$ & $\begin{array}{l}43 \\
40\end{array}$ & $\begin{array}{l}134 \\
111\end{array}$ & $\begin{array}{l}177 \\
151\end{array}$ & $\begin{array}{l}46 \\
53\end{array}$ & $\begin{array}{l}21 \\
26\end{array}$ \\
\hline $\begin{array}{l}\text { (bien. I } 1 \times \text { Lam. B I rotn. } 1) \\
\text { fallax } \mathrm{F}_{1} \mathrm{Nr} .1 \times \text { bien. } \\
\text { (bien. I } 1 \times \text { Lam. A I } 1 \text { ) } \\
\text { fallax } \mathrm{F}_{1} \mathrm{Nr} .18 \times \text { bien. II } 51\end{array}$ & $\begin{array}{l}\text { nicht vollständig } \\
\text { a) mittelgrob, halb } \\
\text { b) ziemlich grob, halb }\end{array}$ & $\begin{array}{r}6 \\
18\end{array}$ & $\begin{array}{l}20 \\
53\end{array}$ & $\begin{array}{l}26 \\
71\end{array}$ & $\begin{array}{l}53 \\
59\end{array}$ & $\begin{array}{l}68 \\
45\end{array}$ \\
\hline $\begin{array}{l}\text { (bien. I } 1 \times \text { Lam. A I } 1) \\
\text { fallax } \mathrm{F}_{1} \mathrm{Nr} .18 \times(\text { Lam. A I } 1 \\
\times \text { bien. I 1) fallax } \mathrm{F}_{1} \mathrm{Nr} .1\end{array}$ & mittelgrob, halb & 19 & 65 & 84 & 20 & 19 \\
\hline $\begin{array}{l}\text { (bien. X Lam. X) laeta weib- } \\
\text { nervig } \mathbf{F}_{1} \text { Nr. } 6 \\
\text { (bien. } \times \text { Lam. X) laeta weiß- } \\
\text { nervig } \mathbf{F}_{1} \text { Nr. } 1\end{array}$ & $\begin{array}{l}\text { etwa halb } \\
\text { a) etwa halb } \\
\text { b) etwa halb }\end{array}$ & $\begin{array}{l}9 \\
8\end{array}$ & $\begin{array}{l}50 \\
47\end{array}$ & $\begin{array}{l}59 \\
55\end{array}$ & $\begin{array}{l}38 \\
51\end{array}$ & $\begin{array}{l}39 \\
48\end{array}$ \\
\hline $\begin{array}{c}\text { (bien. } \times \text { Lam. X) laeta weib- } \\
\text { nervig } \mathrm{E}_{1} \text { Nr. } 3 \times \text { bien. }\end{array}$ & grob, etwa halb & 29 & 52 & 81 & 68 & 46 \\
\hline $\begin{array}{l}\text { (bien. } \times \text { Lam. X) laeta weißn. } \\
\mathbf{F}_{1} \text { Nr. } 6 \times \text { Lam. Vries } 12\end{array}$ & $\begin{array}{l}\text { a) etwa halb } \\
\text { b) lose Samen }\end{array}$ & $\begin{array}{l}9 \\
7\end{array}$ & $\begin{array}{r}9 \\
52\end{array}$ & $\begin{array}{l}18 \\
59\end{array}$ & $\begin{array}{l}25 \\
81\end{array}$ & $\begin{array}{l}58 \\
58\end{array}$ \\
\hline $\begin{array}{l}\text { (bien. } \times \text { Lam. X) laeta weißn. } \\
\mathrm{F}_{1} \mathrm{Nr} .1 \times(\text { bien. } \times \text { Lam. } \mathrm{X}) \\
\text { velutina weißn. } \mathrm{F}_{1} \mathrm{Nr} .2\end{array}$ & $\begin{array}{l}\text { a) halb } \\
\text { b) halb }\end{array}$ & $\begin{array}{l}4 \\
6\end{array}$ & $\begin{array}{l}17 \\
23\end{array}$ & $\begin{array}{l}22 \\
29\end{array}$ & $\begin{array}{l}65 \\
62\end{array}$ & $\begin{array}{l}75 \\
68\end{array}$ \\
\hline $\begin{array}{c}\text { (bien. } \times \text { Lam. X) laeta rotn. } \\
\mathrm{F}_{1} \mathrm{Nr}, 3\end{array}$ & $\begin{array}{l}\text { a) fast } \operatorname{ganz} \\
\text { b) fast } \operatorname{ganz}\end{array}$ & $\begin{array}{l}? \\
?\end{array}$ & $\begin{array}{l}91 \\
89\end{array}$ & - & $\begin{array}{r}98 \\
113\end{array}$ & $\begin{array}{l}52 \\
56\end{array}$ \\
\hline $\begin{array}{c}\text { (bien. } \times \text { Lam. X) laeta rotn. } \\
\hat{\mathrm{F}}_{2} \text { aus } \mathrm{F}_{1} \text { Nr. } 3\end{array}$ & grob, halb & 23 & 53 & 76 & 50 & 40 \\
\hline $\begin{array}{l}{[(\text { bien. } \times \text { Lam. X }) \text { laeta weißn. }} \\
\mathrm{F}_{1} \mathrm{Nr} .3 \times \text { bien.] } \mathrm{F}_{1}=\text { bien. }\end{array}$ & mittelgrob, halb & 10 & 13 & 23 & 57 & 71 \\
\hline
\end{tabular}


Versuche über die gametische Konstitution der Önotheren.

$\mathrm{Zu}$ Tabelle II (Fortsetzung von S. 136).

\begin{tabular}{|c|c|c|c|c|c|c|}
\hline \multirow{2}{*}{ Material } & \multirow{2}{*}{ Frucht } & \multicolumn{3}{|c|}{ Taube Samen } & \multirow{2}{*}{$\begin{array}{c}\text { Ge- } \\
\text { sunde } \\
\text { Samen }\end{array}$} & \multirow{2}{*}{$\begin{array}{c}\text { Ge- } \\
\text { sunde } \\
\text { Samen } \\
\text { in } \%\end{array}$} \\
\hline & & $\begin{array}{l}\text { sehr } \\
\text { klein }\end{array}$ & größer & $\begin{array}{c}\text { zut- } \\
\text { sammen }\end{array}$ & & \\
\hline $\begin{array}{c}\text { (bien. } \times \text { Lam. } X) \text { velutina } \\
\text { weibnervig } \mathrm{F}_{1} \text { Nr. } 1\end{array}$ & $\begin{array}{l}\text { a) halb } \\
\text { b) halb } \\
\text { c) halb } \\
\text { d) halb } \\
\text { e) halb } \\
\text { f) etwas mehr als halb } \\
\text { g) halb } \\
\text { h) grob, ganz }\end{array}$ & $\begin{array}{r}10 \\
3 \\
3 \\
12 \\
15 \\
8 \\
9 \\
10\end{array}$ & $\begin{array}{r}191 \\
84 \\
87 \\
92 \\
113 \\
89 \\
111 \\
110\end{array}$ & $\begin{array}{r}201 \\
87 \\
90 \\
104 \\
128 \\
97 \\
120 \\
120\end{array}$ & $\begin{array}{r}116 \\
32 \\
34 \\
32 \\
41 \\
34 \\
39 \\
37\end{array}$ & $\begin{array}{l}37 \\
27 \\
28 \\
24 \\
24 \\
25 \\
25 \\
\mathbf{2 4}\end{array}$ \\
\hline $\begin{array}{l}\text { (bien. } \times \text { Lam. } \mathrm{X}) \text { velutina } \\
\text { rotnervig } \mathrm{F}_{1} \text { Nr. } 1 \\
\text { (bien. } \times \text { Lam. } \mathrm{X}) \text { velutina } \\
\text { rotnervig } \mathrm{F}_{1} \mathrm{Nr} .2\end{array}$ & $\begin{array}{l}\text { a) 1. Hälfte } \\
\text { 2. Hälfte } \\
\text { b) } 1 \text {. Hälfte } \\
\text { 2. Hälfte } \\
\text { c) halb } \\
\text { mittelgroß, halb }\end{array}$ & $\begin{array}{l}13 \\
18 \\
38 \\
51 \\
50 \\
16\end{array}$ & $\begin{array}{r}115 \\
112 \\
84 \\
75 \\
84 \\
88\end{array}$ & $\begin{array}{l}128 \\
130 \\
122 \\
126 \\
134 \\
104\end{array}$ & $\left.\begin{array}{l}50 \\
49 \\
24 \\
20 \\
46 \\
20\end{array}\right\}$ & $\begin{array}{l}28 \\
18 \\
26 \\
16\end{array}$ \\
\hline $\begin{array}{l}\text { (bien. I } 1 \times \text { Lam.rotn. H.-N. } \\
\text { B I 1) velutina weißn. } \mathrm{F}_{1} \text { Nr. } 1\end{array}$ & $\begin{array}{l}\text { a) groh, halb } \\
\text { b) mittelgrob, halb } \\
\text { c) klein, ganz } \\
\text { d) klein, ganz } \\
\text { a) groß, ganz } \\
\text { b) groB, fast ganz }\end{array}$ & $\begin{array}{l}0 \\
4 \\
1 \\
0 \\
2 \\
?\end{array}$ & $\begin{array}{r}87 \\
75 \\
44 \\
34 \\
197 \\
187 \\
\end{array}$ & $\begin{array}{r}87 \\
79 \\
45 \\
34 \\
199 \\
-\end{array}$ & $\begin{array}{r}36 \\
24 \\
9 \\
7 \\
74 \\
84 \\
81\end{array}$ & $\begin{array}{l}30 \\
23 \\
17 \\
17 \\
29 \\
30\end{array}$ \\
\hline $\begin{array}{l}\text { (bien, } \times \text { Lam. } \mathrm{X}) \text { velutina } \\
\text { rotn. } \mathrm{F}_{1} \text { Nr. } 1 \times \text { bien. }\end{array}$ & $\begin{array}{l}\text { a) klein, ganz } \\
\text { b) klein, ganz }\end{array}$ & $\begin{array}{l}32 \\
28\end{array}$ & $\begin{array}{l}68 \\
58\end{array}$ & $\begin{array}{r}100 \\
96\end{array}$ & $\begin{array}{l}16 \\
15\end{array}$ & $\begin{array}{l}14 \\
14\end{array}$ \\
\hline $\begin{array}{l}\text { (bien. } \times \text { Lam. X) velutina } \\
\text { weißn. } \mathrm{F}_{1} \text { Nr. } 1 \times \text { (bien. } \times \\
\text { Lam. X) laeta weißn. } \text { F }_{1} \text { Nr. } 2 \\
\end{array}$ & $\begin{array}{l}\text { a) etwa halb } \\
\text { b) etwa halb }\end{array}$ & $\begin{array}{l}6 \\
6\end{array}$ & $\begin{array}{l}1 \\
4\end{array}$ & $\begin{array}{r}7 \\
10\end{array}$ & $\begin{array}{l}68 \\
73\end{array}$ & $\begin{array}{l}91 \\
88\end{array}$ \\
\hline $\begin{array}{c}\text { (bien. } \times \text { Lam. } \mathrm{X}) \text { velutina } \\
\text { weißn. } \mathrm{F}_{2} \text { aus } \mathrm{F}_{1} \mathrm{Nr} .3 \\
\end{array}$ & ziemlich grob, halb & 3 & 88 & 91 & 42 & 32 \\
\hline (bien. $\times$ mur. $) \mathrm{F}_{1}$ Nr. 13 & $\begin{array}{l}\text { a) klein, ganz } \\
\text { b) klein, fast ganz }\end{array}$ & $\begin{array}{l}5 \\
6\end{array}$ & $\begin{array}{l}12 \\
23\end{array}$ & $\begin{array}{l}17 \\
29\end{array}$ & $\begin{array}{l}18 \\
16\end{array}$ & $\begin{array}{l}51 \\
37\end{array}$ \\
\hline $\begin{array}{c}(\text { bien. } \times \text { mur. }) \mathrm{F}_{1} \text { Nr. } 13 \times \\
\text { bien. II } 51\end{array}$ & $\begin{array}{l}\text { a) ziemlich groß, } \\
\text { halb } \\
\text { b) wie a) }\end{array}$ & $\begin{array}{l}6 \\
8 \\
\end{array}$ & $\begin{array}{l}4 \\
4\end{array}$ & $\begin{array}{l}10 \\
12 \\
\end{array}$ & $\begin{array}{l}46 \\
51 \\
\end{array}$ & $\begin{array}{l}82 \\
81\end{array}$ \\
\hline 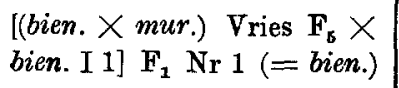 & $\begin{array}{l}\text { a) ganz } \\
\text { b) grob, halb }\end{array}$ & $\begin{array}{l}36 \\
38\end{array}$ & $\begin{array}{l}54 \\
12\end{array}$ & $\begin{array}{l}90 \\
50\end{array}$ & $\begin{array}{r}122 \\
88\end{array}$ & $\begin{array}{l}74 \\
64\end{array}$ \\
\hline
\end{tabular}

Induktive Abstammungs- und Vererbungslehre. XVIII. 
Zu Tabelle II (Fortsetzung von S. 137).

\begin{tabular}{|c|c|c|c|c|c|c|}
\hline \multirow{2}{*}{ Material } & \multirow{2}{*}{ Frucht } & \multicolumn{3}{|c|}{ Taube Samen } & \multirow{2}{*}{$\begin{array}{c}\text { Ge- } \\
\text { sunde } \\
\text { Samen }\end{array}$} & \multirow{2}{*}{$\begin{array}{l}\text { Ge- } \\
\text { sunde } \\
\text { Samen } \\
\text { in } \%\end{array}$} \\
\hline & & $\begin{array}{c}\text { sehr } \\
\text { klein }\end{array}$ & größer & $\begin{array}{c}\mathrm{zu}- \\
\text { sammen }\end{array}$ & & \\
\hline $\begin{array}{l}\text { (bien. I } 1 \times \text { suaveolens I } 5 \text { ) } \\
\text { suavis } \mathrm{F}_{1} \text { Nr. } 107 \\
\text { ebenso } \mathrm{Nr} .1\end{array}$ & $\begin{array}{l}\text { groh, halb } \\
\text { ganz }\end{array}$ & 12 & 105 & 117 & 66 & $\begin{array}{l}33 \\
36\end{array}$ \\
\hline $\begin{array}{c}\text { (bien. I } 1 \times \text { suaveolens I } 5) \\
\text { suavis } \mathrm{F}_{1} \mathrm{Nr} .107 \times(\text { suaveol. } \\
\times \text { bien.) redempta } \mathrm{F}_{1} \mathrm{Nr} .18, \\
\text { zweijährig }\end{array}$ & groß, etwa $1 / 3$ & 10 & 12 & 22 & 83 & 80 \\
\hline $\begin{array}{l}\text { (bien. I } 1 \times \text { suaveolens } \mathrm{I} 5 \text { ) } \\
\text { flava } \mathrm{F}_{1} \mathrm{Nr} .2\end{array}$ & halb & 17 & 45 & 62 & 98 & 61 \\
\hline Lamarckiana de Vries I 2 & ziemlich grob, halb & 12 & 87 & 99 & 69 & 41 \\
\hline $\begin{array}{c}\text { Lamarckiana Vries I } 1 \times \\
\text { biennis I } 1\end{array}$ & nicht groß, etwa $2 / 8$ & 4 & 17 & 21 & 80 & 79 \\
\hline $\begin{array}{l}\text { Lam. Vries I } 2 \times(\text { bien. } \times \\
\text { Lam.X) laeta weiBn. } \mathrm{F}_{1} \text { Nr. } 6\end{array}$ & 126 lose Samen & $?$ & 34 & - & 92 & 73 \\
\hline Lamarckiana Her.-Nilsson & a) halb & 24 & 82 & 106 & 53 & 33 \\
\hline weibnervig, & b) klein halb & 5 & 69 & 74 & 40 & 35 \\
\hline A I 1, einjährig & c) halb & $?$ & 69 & - & 66 & 49 \\
\hline & d) ganz & 3 & 123 & 126 & 61 & 33 \\
\hline A I 3, einjährig & a) ziemlich grob, ganz & $?$ & 79 & - & 73 & 48 \\
\hline & b) halb & $?$ & 53 & - & 41 & 44 \\
\hline & c) klein, halb & $?$ & 39 & - & 25 & 40 \\
\hline & d) klein, ganz & 5 & 51 & 56 & 32 & 36 \\
\hline A I 31, zweijährig & a) $\operatorname{ganz}$ & 78 & 108 & 186 & 78 & 30 \\
\hline & b) $\operatorname{ganz}$ & 39 & 103 & 142 & 118 & 45 \\
\hline A II 1, einjährig & a) sehr groß, halb & 5 & 75 & 80 & 75 & 48 \\
\hline & b) sehr groß, halb & 8 & 87 & 95 & 79 & 45 \\
\hline & c) ziemlich grob, halb & 6 & 63 & 69 & 47 & 40 \\
\hline A II 2, einjährig & sehr grob, halb & 4 & 79 & 83 & 67 & 45 \\
\hline Lamarckiana Her.-Nilsson & a) nicht grob, halb & 7 & 68 & 75 & 22 & 23 \\
\hline C II rotnervig 1 & b) groß, halb & 20 & 96 & 116 & 42 & 27 \\
\hline Lamarckiana Her.-Nilsson & a) & - & 73 & - & 77 & 51 \\
\hline A I $1 \times$ biennis I 1 & b) & - & 31 & - & 32 & 51 \\
\hline & c) & - & 43 & - & 36 & 46 \\
\hline & d) & - & 74 & - & 92 & 55 \\
\hline
\end{tabular}


Versuche über die gametisehe Konstitution der Önotheren.

Zu Tabelle II (Fortsetzung von S. 138).

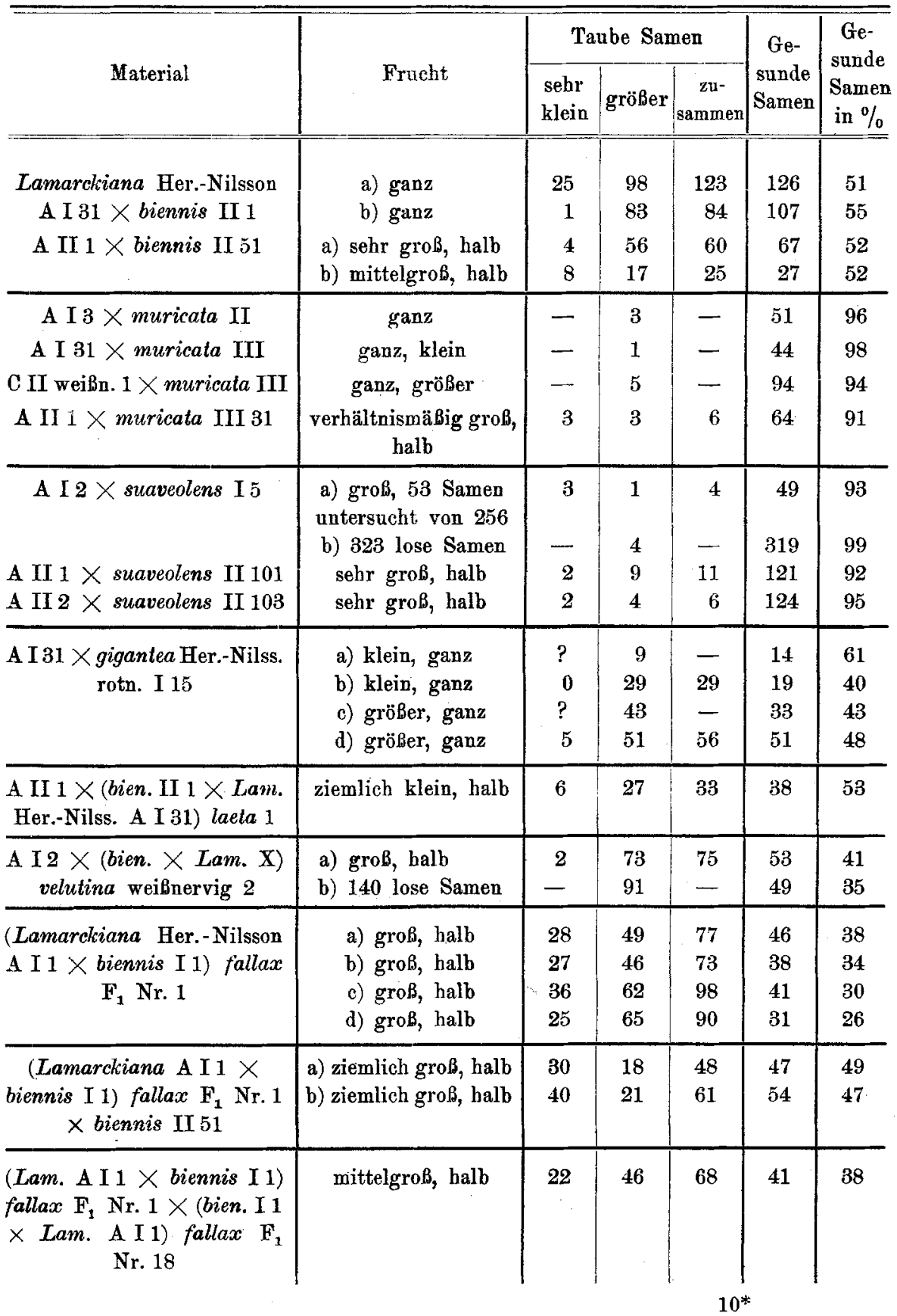


$\mathrm{Zu}$ Tabelle II (Fortsetzung von S. 139).

\begin{tabular}{|c|c|c|c|c|c|c|}
\hline \multirow{2}{*}{ Material } & \multirow{2}{*}{ Frucht } & \multicolumn{3}{|c|}{ Taube Samen } & \multirow{2}{*}{$\begin{array}{c}\text { Ge- } \\
\text { sunde } \\
\text { Samen }\end{array}$} & \multirow{2}{*}{$\begin{array}{c}\text { Ge- } \\
\text { sunde } \\
\text { Samen } \\
\text { in } \%\end{array}$} \\
\hline & & $\begin{array}{l}\text { sehr } \\
\text { klein }\end{array}$ & größer & $\left|\begin{array}{c}\text { zu- } \\
\text { sammen }\end{array}\right|$ & & \\
\hline $\begin{array}{c}\text { (Lam. } \times \text { bien.) fallax } \mathrm{H} .-\mathrm{N} . \\
\mathrm{F}_{\mathrm{s}} \text { Nr. 1, einjährig } \\
\text { Nr. } 16, \text { zweijährig }\end{array}$ & $\begin{array}{l}\text { ziemlich klein, nicht } \\
\text { ganz vollständig } \\
\text { a) ganz } \\
\text { b) ganz } \\
\text { c) ganz } \\
\text { d) ganz }\end{array}$ & $\begin{array}{r}9 \\
15 \\
11 \\
22\end{array}$ & $\begin{array}{l}152 \\
\\
285 \\
188 \\
207 \\
248\end{array}$ & $\begin{array}{l}155 \\
\\
244 \\
203 \\
218 \\
270\end{array}$ & $\begin{array}{l}6 \\
\\
22 \\
21 \\
20 \\
18\end{array}$ & $\begin{array}{l}4 \\
8 \\
9 \\
8 \\
7\end{array}$ \\
\hline $\begin{array}{c}(\text { Lam. } \times \text { bien. }) \text { fallax } \mathrm{H} . \mathrm{N} . \\
\mathrm{F}_{\mathrm{s}} \text { Nr. } 1 \times \text { biennis } \mathrm{I} 1\end{array}$ & $\begin{array}{l}\text { nicht ganz } \\
\text { vollständig }\end{array}$ & 10 & 37 & 47 & 69 & 59 \\
\hline $\begin{array}{c}(\text { Lam. } \times \text { bien.) fallax } \mathrm{H} . \mathrm{N}, \\
\mathrm{F}_{3} \text { Nr. } 1 \times \text { Lam. A I } 1 \\
\end{array}$ & mittelgrob, etwa halb & 0 & 48 & 48 & 22 & 31 \\
\hline $\begin{array}{l}\text { muricata II } 1 \\
\text { III } 1 \\
\text { III } 31\end{array}$ & $\begin{array}{l}\text { grob, etwa halb } \\
\text { grob, halb } \\
\text { a) groh, halb } \\
\text { b) klein, ganz }\end{array}$ & $\begin{array}{r}7 \\
12 \\
18 \\
5\end{array}$ & $\begin{array}{r}22 \\
55 \\
20 \\
3\end{array}$ & $\begin{array}{r}29 \\
67 \\
38 \\
8\end{array}$ & $\begin{array}{r}153 \\
116 \\
115 \\
52\end{array}$ & $\begin{array}{l}83 \\
63 \\
75 \\
87\end{array}$ \\
\hline $\begin{array}{c}\text { muricata ILI } 1 \times \text { Lamarck. } \\
\text { H.-N. weißn. A I } 31 \\
\text { muricata III } 31 \times \text { Lamarck. } \\
\text { H.-N. weißn. A II } 1\end{array}$ & $\begin{array}{l}\text { ziemlich grob } \\
\text { a) ziemlich klein, halb } \\
\text { b) wie a) }\end{array}$ & $\begin{array}{l}50 \\
10 \\
10\end{array}$ & $\begin{array}{r}31 \\
9 \\
14\end{array}$ & $\begin{array}{l}81 \\
19 \\
24\end{array}$ & $\begin{array}{l}74 \\
77 \\
92\end{array}$ & $\begin{array}{l}48 \\
80 \\
80\end{array}$ \\
\hline $\begin{array}{c}\text { (muricata III } 1 \times \text { Lamarek. } \\
\mathrm{A} \text { I 31) velutina } \mathrm{F}_{1} \mathrm{Nr} .1\end{array}$ & nicht grob, halb & 10 & 45 & 55 & 42 & 43 \\
\hline $\begin{array}{c}(\text { muricata } \times \text { biennis }) \mathbf{F}_{4} \text { von } \\
\text { de Vries }\end{array}$ & $\begin{array}{l}\text { a) ganz } \\
\text { b) ganz }\end{array}$ & $\begin{array}{l}20 \\
20\end{array}$ & $\begin{array}{l}44 \\
68\end{array}$ & $\begin{array}{l}64 \\
88\end{array}$ & $\begin{array}{l}29 \\
38\end{array}$ & $\begin{array}{l}31 \\
30\end{array}$ \\
\hline rubrinervis $I 1$ & $\begin{array}{l}\text { a) grob, halb } \\
\text { b) grob, halb } \\
\text { c) kleiner, halb } \\
\text { d) } 248 \text { lose Samen } \\
\text { halb } \\
\text { mittelgrob, halb }\end{array}$ & $\begin{array}{r}4 \\
10 \\
5 \\
- \\
9 \\
5\end{array}$ & $\begin{array}{l}47 \\
39 \\
38 \\
79 \\
46 \\
78\end{array}$ & $\begin{array}{l}51 \\
49 \\
43 \\
- \\
55 \\
83\end{array}$ & $\begin{array}{r}139 \\
106 \\
.81 \\
169 \\
115 \\
120\end{array}$ & $\begin{array}{l}73 \\
68 \\
65 \\
68 \\
68 \\
59\end{array}$ \\
\hline $\begin{array}{l}\text { rubrinervis } \text { I } 2 \times \text { biennis } \text { I } 1 \\
\text { rubrinervis II } 26 \times \text { biennis } \\
\text { II } 52\end{array}$ & $\begin{array}{c}\text { lose Samen } \\
\text { nicht grob, etwas mehr } \\
\text { als die Hälfte }\end{array}$ & $\begin{array}{l}? \\
6\end{array}$ & $\begin{array}{r}10 \\
4\end{array}$ & $\overline{10}$ & $\begin{array}{l}208 \\
171\end{array}$ & $\begin{array}{l}95 \\
94\end{array}$ \\
\hline $\begin{array}{c}\text { rubrinervis I } 4 \times \text { Lamarck. } \\
\text { H.-N. A I } 2\end{array}$ & $\begin{array}{l}\text { a) ziemlich klein, } \\
\text { etwa } 1 / 4 \\
\text { b) groß, halb } \\
\text { c) groß, halb }\end{array}$ & $\begin{array}{l}4 \\
20 \\
20\end{array}$ & $\begin{array}{l}19 \\
77 \\
56\end{array}$ & $\begin{array}{l}23 \\
97 \\
76\end{array}$ & $\begin{array}{r}33 \\
121 \\
105\end{array}$ & $\begin{array}{l}59 \\
55 \\
58\end{array}$ \\
\hline
\end{tabular}


Versuche über die gametische Konstitution der Önotheren.

$\mathrm{Zu}$ Tabelle II (Fortsetzung von. S. 141).

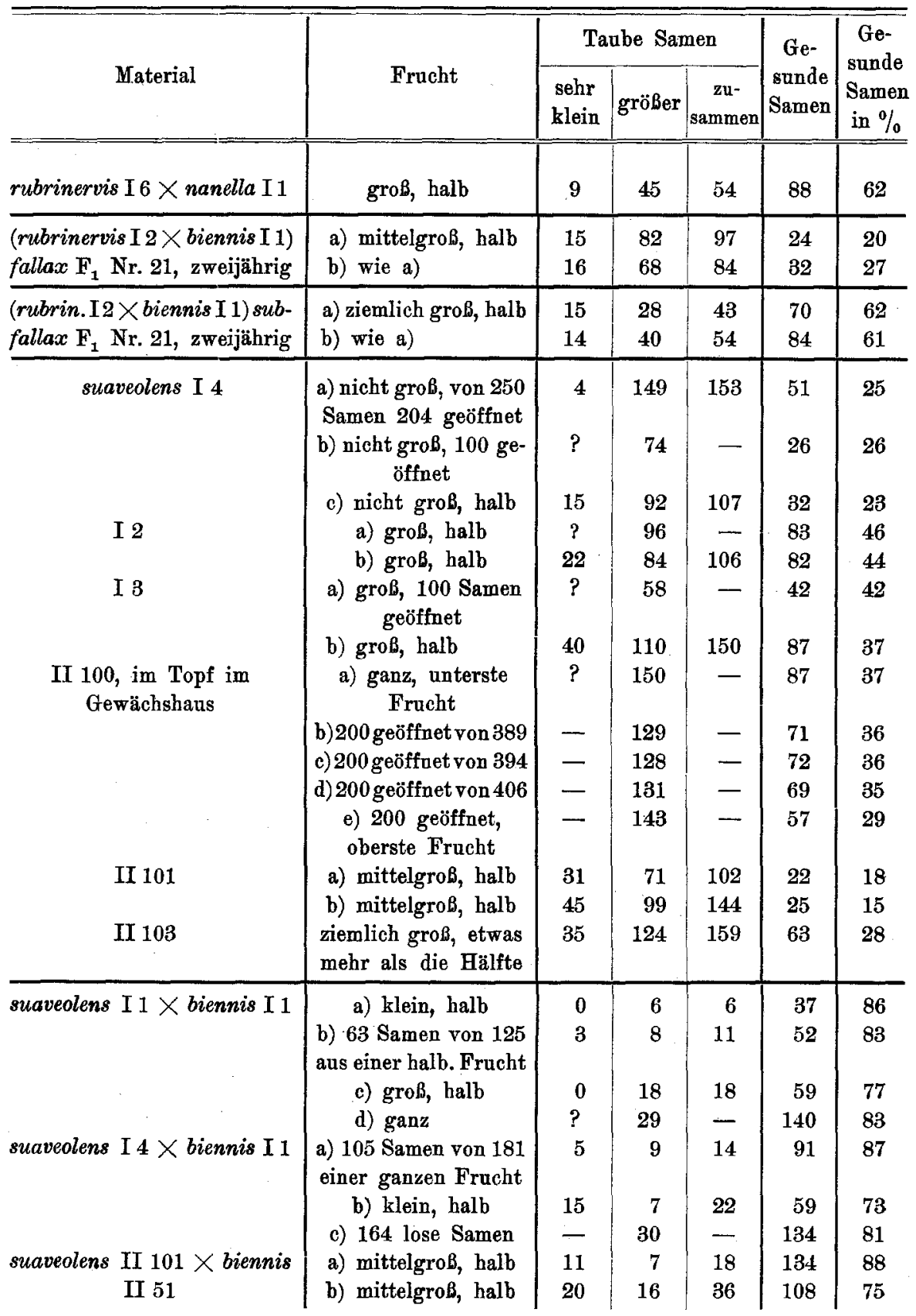


Zu Tabelle II (Fortsetzung von S. 141).

\begin{tabular}{|c|c|c|c|c|c|c|}
\hline \multirow{2}{*}{ Material } & \multirow{2}{*}{ Frucht } & \multicolumn{3}{|c|}{ Taube Samen } & \multirow{2}{*}{$\begin{array}{c}\text { Ge- } \\
\text { sunde } \\
\text { Samen }\end{array}$} & \multirow{2}{*}{$\begin{array}{l}\text { Ge- } \\
\text { sunde } \\
\text { Samen } \\
\text { in } \%\end{array}$} \\
\hline & & $\begin{array}{l}\text { sehr } \\
\text { klein }\end{array}$ & größer & $\begin{array}{c}\mathrm{zu}- \\
\text { sammen }\end{array}$ & & \\
\hline $\begin{array}{c}\text { suaveolens I } 5 \text { × Lamarck. } \\
\text { Her.-Nilss. A I } 2 \\
\text { suaveolens II } 103 \times \text { Lamarck. } \\
\text { Her.-Nilss. A II } 1\end{array}$ & $\begin{array}{l}\text { a) mittelgroß, halb, } \\
176 \text { Samen, davon } \\
102 \text { untersucht } \\
\text { b) } 321 \text { lose Samen } \\
\text { groh, halb }\end{array}$ & - & $\begin{array}{r}28 \\
4\end{array}$ & - & $\begin{array}{l}293 \\
129\end{array}$ & $\begin{array}{l}91 \\
93\end{array}$ \\
\hline $\begin{array}{l}\text { (suaveolens } \mathrm{I} 4 \times \text { biennis } \mathrm{I} 1 \text { ) } \\
\text { redempta } \mathrm{E} 1 \mathrm{Nr} .1\end{array}$ & etwa halb & 15 & 23 & 38 & 90 & 70 \\
\hline $\begin{array}{l}\text { (suaveolens I } 5 \times \text { Lamarck. } \\
\text { A I 2) bienni-laeta } \mathrm{F}_{1}\end{array}$ & groh, etwa halb & 20 & 51 & 71 & 30 & 30 \\
\hline $\begin{array}{c}\text { (suaveolens } \times \text { Lamarckiana) } \\
\text { bienni-velutina } \mathrm{F}_{1}\end{array}$ & mittelgroß, halb & 7 & 78 & 85 & 30 & 26 \\
\hline $\begin{array}{c}\text { (suaveolens } \times \text { Lamarckiana) } \\
\text { suavi-laeta } \mathbf{F}_{1}\end{array}$ & ziemlich groß, halb & 3 & 46 & 49 & 88 & 64 \\
\hline $\begin{array}{c}\text { (suaveolens } \times \text { Lamarckiana) } \\
\text { suavi-velutina } \mathrm{F}_{1}\end{array}$ & groß, halb & 2 & 63 & 65 & 53 & 45 \\
\hline
\end{tabular}

In der folgenden Tabelle III sind die Daten der Tabelle II noch einmal in gekïrzter übersichtlicherer Form dargestellt, und zwar sind nur die Prozentzahlen der keimhaltigen Samen angegeben, an erster Stelle die von mir beobachteten, an zweiter Stelle zum Vergleich die von de Vries (1916b) mitgeteilten Zahlen.

Tabelle III.

\begin{tabular}{|c|c|c|c|c|c|}
\hline & & & & $\begin{array}{c}\text { Selbst } \\
\text { beobachtet }\end{array}$ & $\begin{array}{c}\text { Von de Vries } \\
\text { mitgeteilt }\end{array}$ \\
\hline biennis & . . . & . . . . & & $5 \check{5}-7.7$ & $82-96$ \\
\hline$n$ & $\times$ Lamarckiana . . & . . . . . . . . . . & . & 63 & $82-94$ \\
\hline$"$ & $\times$ muricata. . . . & . . . . . . . . & . & $71-84$ & 93 \\
\hline$"$ & X rubrinervis . . . . & . . . . . . . . & . & 62 & $\dot{-}$ \\
\hline$"$ & $X$ suaveolens & . & . . & $74-83$. & 93 \\
\hline$n$ & $\times($ biennis $\times$ Lamarckiana $)$ & fallax. & & $62-69$ & - \\
\hline$n$ & $n$ & laeta weißnervig. & & $61-63$ & - \\
\hline$"$ & $n$ & velutina rotnervig & & 43 & - \\
\hline
\end{tabular}


Zu Tabelle III (Fortsetzung von S. 142):

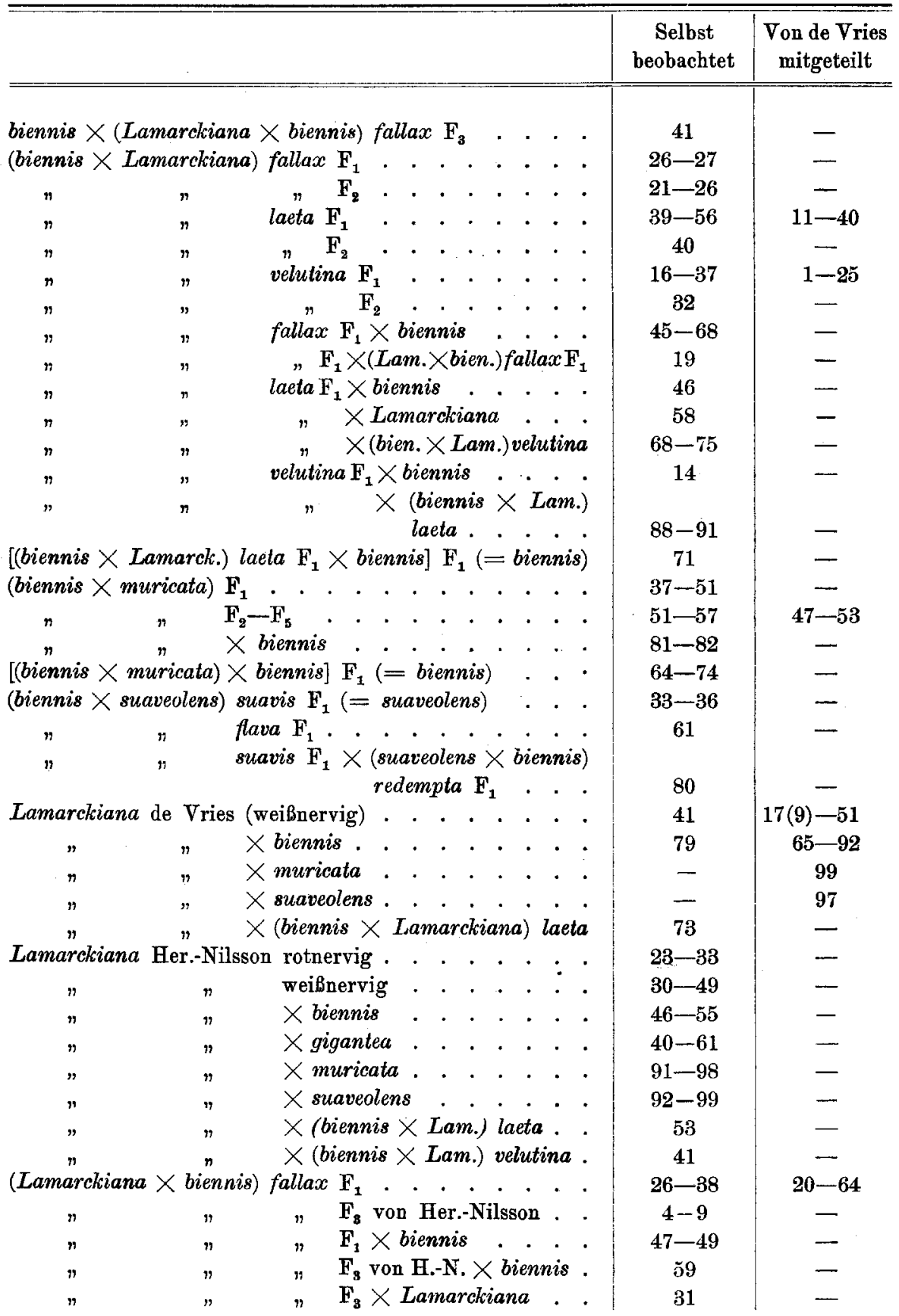


Zu Tabelle III (Fortsetzung von S. 143).

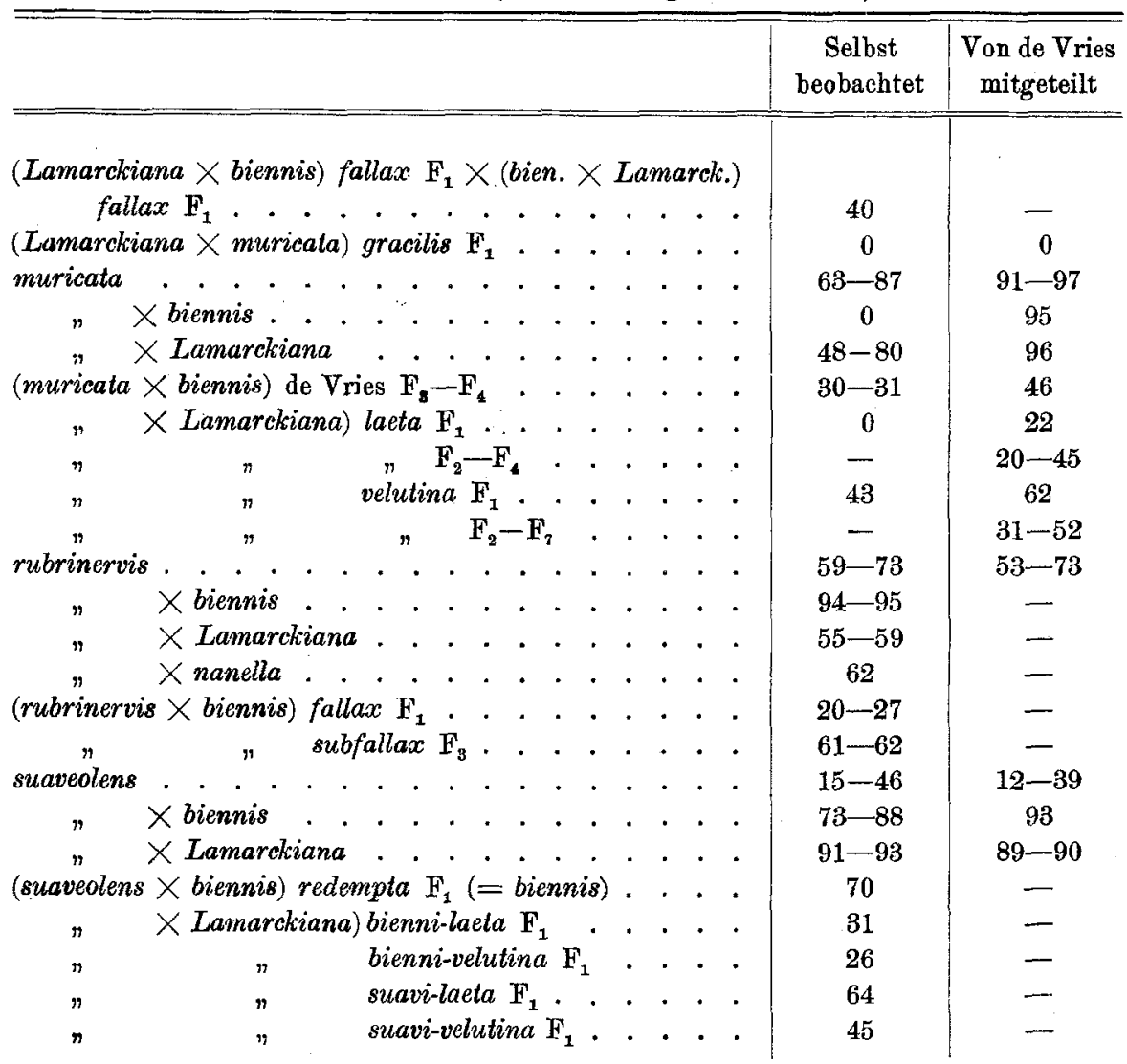

Die in den Tabellen II und III zusammengestellten Zählungen lassen folgende Tatsachen erkennen. 1. In den beiden Fälften einer und derselben Frucht (jede Hälfte umfaßt zwei von den vier Fruchtfächern) ist sowohl die absolute Zahl der Samen wie auch das Verhältnis zwischen gesunden und tauben Samen sehr übereinstimmend; man vergleiche die Angaben für biennis, S. 135, und für (biennis $\times L a$ marckiana $\mathrm{X}$ ) velutina rotnervig 1, S.137. 2. In verschiedenen Früchten eines und desselben Individuum dagegen ist bei Selbstbestänbung oder bei Bestäubung mit dem Pollen desselben fremden Individuum das Verhältnis zwischen gesunden und tauben Samen gewöhnlich nichts weniger als konstant; verhältnismäßig weit geht die Konstanz bei dem im Topf zur Blüte gebrachten Exemplar II 100 von O. suaveolens und bei (biennis $\times$ Lamarekiana $\mathrm{X}$ ) velutina weißnervig 1 . Früchte, in denen 
die absolute Zahl der gesunden Samen ungefähr die gleiche ist, haben auch oft einen ähnlichen Prozentsatz an gesunden Samen. Am höchsten ist die Zahl der gesunden Samen im Verhältnis za der der tauben Samen in großen Früchten, die eine große absolute Zahl von gesunden Samen enthalten; am kleinsten ist der Prozentsatz von gesunden Samen bei geringer absoluter Zahl der gesunden Samen, in kleinen Früchten. 3. Größer als zwischen Früchten, die an einem Individuum bei Bestäubung mit demselben Pollen gebildet worden sind, erweisen sich die Unterschiede bei Verwendung des Pollens verschiedener Sippen. O. Lamarckiana bildet bei Selbstbestäubung $30-49 \%$ keimhaltiger Samen, bei Bestäubung mit dem Pollen von $O$. biennis $46-55 \%$, bei Bestäubung mit dem Pollen von $O$. muricata und von $O$. suaveolens $91-99 \%$. O. suaveolens erzeugt bei Selbstbestäubung $15-46 \%$ gesunder Samen, bei Kreuzung mit biennis $\sigma^{7}$ $73-88 \%$, und mit Lamarckiana $\sigma^{7} 91$ bis $93 \%$. O. rubrinervis hat nach Selbstbestäubung 59-73\%, nach Bestäubung mit dem Pollen von O. biennis 94-95\% gesunder Samen. In allen Fällen, in denen durch Verwendung des Pollens einer fremden Sippe der Prozentsatz der gesunden Samen beträchtlich gesteigert wird, ist die Nachkommenschaft zweiförmig, während sie bei einer Kreuzung, die den Gehalt an gesunden Samen nicht erhöht (z. B. O. Lamarckiana $\times$ biennis), ebenso wie bei Selbstbestäubang einförmig ist. Es ist also nicht mehr daran zu zweifeln,

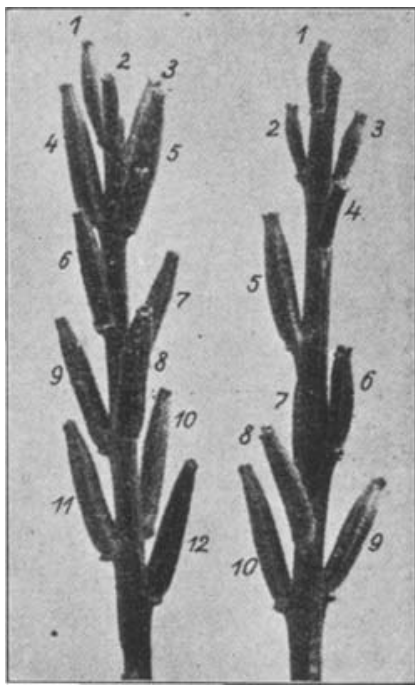

Fig. 2. Früchte der O. Lamarckiana-weibnervig von $\mathrm{H}$ eribert-Nilsson, nach Bestäubung mit verschiedenem Pollen, 1916. Von oben nach unten: links Frucht 1-3: Lam. $\times$ muricata (kurz und dünn); 4, 5, 8: gleichzeitig $X$ suaveolens und $X$ biennis (lang und dick); 6 und 7 : $\times$ biennis (deutlich kleiner); 9 and 10: $\times$ suaveolens; 11 und 12 : selbstbestäubt; rechts $1-3$ : $\times$ muricata (wieder kurz und dünn); 4: $\times$ biennis (nicht viel größer); 5, 6, 7: gleichzeitig $X$ suaveolens und $X$ biennis; $8,9,10: \times$ suaveolens.

daß die tauben Samen genotypische Bedeutung haben, mindestens zum Teil als Repräsentanten lebensunfähiger zygotischer Kombinationen angesehen werden müssen. Dieselben Samenanlagen, die bei Befruchtung durch den Pollen der einen Art taube Samen liefern, ent- 
wickeln sich bei Verwendung des Pollens einer anderen Art zu keimfähigen Samen.

Die Früchte eines Individuum sind in derselben Region des Fruchtstandes natürlich um so größer, je zahlreicher und je größer die Samen sind. Wenn wir bei $O$. Lamarckiana die bei Selbstbefruchtung erreichte Fruchtgröße als die normale ansehen, so wird durch Bestäubung mit dem Pollen der O. suaveolens die Dicke der Früchte vielleicht etwas gesteigert, weil jetzt die allermeisten Samen voll ansgebildet werden, nicht ein größerer Teil sehr früh gehemmt wird. Kleiner als bei Selbstbefruchtung sind die Früchte nach Bestäubung mit biennis-Pollen (Fig. 2); das Verhältnis zwischen großen gesunden und kleinen tauben Samen bleibt ungefähr das gleiche, aber die Zahl der befruchteten Samenanlagen scheint bei Kreuzung mit biennis $\sigma^{\text {t }}$ meist geringer zu sein als bei Selbstbestäubung. Auffallend klein sind die Früchte der $O$. Lamarckiana immer nach Bestäubung mit dem Pollen der O. muricata (Fig. 2); zwar sind alle Samen gesund und sehr groß, aber die absolute Zahl der Samen ist klein, weil die Samenanlagen nur in der oberen Hälfte des Fruchtknotens befruchtet werden (vergl. unten S. 151). An zwei Hauptstengeln, im unteren Teil der Infloreszenz (die Stücke sind in Fig. 2 wiedergegeben), wurden folgende Längen der Früchte gemessen: $O$. Lamarckiana selbstbestäubt $42,41,43,40,42 \mathrm{~mm} ; L$. $\times$ suaveolens $43,41,43,39,37 \mathrm{~mm}$; $L$. gleichzeitig mit dem Pollen von suaveolens und von biennis bestäubt 40,42,40,42,39,38,33 mm;L. $\times$ biennis $34,39,36,20 \mathrm{~mm} ; L$ : $\times$ muricata $27,20,30,23,20,21 \mathrm{~mm}$.

Die Frage, warum das Verhältnis zwischen gesunden und tauben Samen bei gleichartiger Bestäubung so auffallend inkonstant ist, läßt sich vorerst nicht mit Sicherheit beantworten. Vermutlich werden gelegentlich einzelne Embryonen, die nach ihrer genotypischen Konstitution voll entwicklungsfähig wären, durch zufällige Störungen physiologischer Art gehemmt. Hierfür sprechen Erfahrungen, die de Vries (1915 b) mitteilt. Er findet nämlich bei $O$. Lamarckiana, wenn sie auf gut gedüngtem Boden kultiviert wird, $43-46 \%$ gesunder Samen, bei weniger günstigen Bedingungen fällt dieser Gehalt auf $32-39 \%$ (S. 171, 172). Eine neue rubrinervis-artige Mutante lieferte ihm auf kräftigen gut ernährten Pflanzen bis $97 \%$ keimhaltiger Samen, auf schwachen schlecht ernährten nur etwa $25 \%$ (S. 175 $\left.{ }^{1}\right)$. - Eine andere wichtige Fehlerquelle liegt wahrscheinlich, wenigstens bei gewissen Kombinationen, in der Un-

1) Ob das wirklich demselben Genotypus angehörende Individuen waren? 
sicherheit, mit der die Trennung der tauben Samen von den unbefruchteten Samenanlagen behaftet ist. Und die erwähnte relative $\mathrm{Zu}$ nahme der tauben Samen mit der Abnahme der absoluten Zahl der gesunden Samen könnte vielleicht so gedeutet werden: wo wenige Samen sich voll entwickeln, ist die Konkurrenz um die Nahrung für die schwächeren und schwächsten Embryonen weniger gefährlich, so daß viele oder alle befruchteten Samenanlagen bis zu kleinen Sämchen heranwacbsen, während beim Wettbewerb zahlreicher gesunder Embryonen und Endosperme die allerungünstigsten zygotischen Kombinationen überhaupt nicht in die Embryoentwicklung einzutreten vermögen ${ }^{1}$ ). Über diesen Punkt kann die zytologische Untersuchung natürlich vollkommene Klarheit bringen. - Ein weiterer Faktor, nämlich verschiedene Wachstumsgeschwindigkeit der genotypisch verschiedenen Pollenschlänche, kann den Gehalt an tanben Samen z. B. dann in variabler Weise beeinflussen, wenn das Gen für Rotnervigkeit, das in positiven Homozygoten nicht existenzfähig ist, ins Spiel kommt; das wird im nächsten Abschnitt (S. 155) auseinandergesetzt. - Vorläufig bin ich außerstande in einem gegebenen Fall zu entscheiden, welcher Prozentsatz von tauben Samen die Verbältnisse der Keimzellen am ehesten wiedergibt.

In einer eingehenden Studie hat de Vries sich neuerdings mit den tauben Samen der Önotheren beschäftigt (1916b). Im großen und ganzen stimmen seine Befunde mit den meinigen recht gut überein, wie die Tabelle III ersehen läßt, doch sind seine Zahlen mit den meinigen wohl nicht genau vergleichbar, weil er wahrscheinlich die allerkleinsten Samenrudimente nicht als taube Samen gezählt hat. $\mathrm{Er}$ reinigt nämlich das auszuzählende Samenmaterial "durch Abblasen" von dem Pulver der sterilen Samenanlagen (S. 243), und dabei mögen die kleinsten Samen mitunter schon vor der Zählung beseitigt werden. Nach seinen Protokollen ist der Prozentsatz der keimhaltigen Samen im unteren Teil der Fruchtähren mitunter deutlich größer als gegen die Spitze (bei O. Lamarckiana S. 256, O. rubrinervis und erythrina S. 263, O..suaveolens S. 276; dazu stimmt auch mein Befund an O. suaveolens II 100, S. 141), und „um so höher, je besser die Kultur und je größer die dadurch erzielte individuelle Kraft der Pflanzen ist" (S. 259). - De Vries lehnt die Deutung, die ich (1914) für das Auftreten der tauben Samen gegeben habe, durch-

1) De Vries (1916 b, S. 256) meint, daß in kleinen Früchten der O. Lamarckiana die tauben Samen kleiner sind als in großen samenreichen Kapseln; eine Verschiedenheit der Zahlenverhältnisse hebt er nicht hervor. 
aus ab und macht für diese Eigentümlichkeit bei $O$. Lamarckiana und suaveolens eine erbliche "semiletale Eigenschaft" verantwortlich, während er in anderen Fällen eine zufällige Hemmung der jungen Samen annimmt. Ich habe auf seine Ausführungen schon kurz geantwortet (1916) und möchte hier meine Argumente nicht wiederholen ${ }^{1}$ ).

\section{Die Beschaffenheit der Keimzellen.}

Wie die Samenanlagen, so sind auch die Pollenkörner häufig zu einem großen Teil steril. O. Lamarckiana und biennis haben nach Geerts (S. 179, 183) etwa 50\%, muricata nach Geerts (S. 183) und Davis (1915 b, S. 7 des Sonderabdrucks) noch mehr untaugliche Pollenkörner; Gates (1915) hat bei O. Lamarckiana 24,9-57,6\% guten Pollen gefunden (zitiert nach Winkler 1916, S. 509). Daß teilweise Unfruchtbarkeit des Pollens und der Ovula als ein Zeichen von Heterozygotie gedeutet werden kann, haben z. B. Jeffrey (1914) und Davis (1915 b) nachdrücklich betont. Ein Beweis für oder gegen diese Auffassung, die z. B. de Vries ablehnt (1915a, S. 176), wird sich schwerlich erbringen lassen. Aber nehmen wir einmal an, die sterilen Pollenkörner seien tatsächlich genotypisch anders konstituiert als die gesunden, so läßt sich etwa aus dem einfachsten Zahlenverhältnis $1: 1$ der Schluß ziehen, daß ebensoviele haploide Genotypen im Pollen beseitigt werden als in anscheinend keimfähigem Zustand erhalten bleiben. Bei den Samenanlagen ist die Beurteilung schwieriger, weil bei ihrem Sterilwerden ganze Sporentetraden verworfen werden, nicht Einzelsporen wie im Pollen. Im allgemeinen hängt die Entscheidung darüber, ob eine Megaspore sich zum Embryosack entwickeln soll, von der Lage der betreffenden Zelle in der Reihe der vier Sporen ab. Wenn nun, im einfachsten Fall, zweierlei Megasporen gebildet werden, entwicklungsfähige und zur Sterilität verurteilte, so muß nur dann die Hälfte der Samenanlagen steril werden, falls entweder die oberste Spore zum Embryosack heranreift oder überhaupt keine. Es ist aber sehr wohl denkbar, daß bei Unterschieden in der Entwicklangsfähigkeit der Megasporen die Lage der einzelnen Zelle nicht dasselbe Gewicht hat wie bei homozygotischen Formen, und falls von den gesunden Megasporen immer eine begünstigt

1) In der Zwischenzeit hat de Vries (1917) auf Grund neuer Erfahrungen, ohne meine Mitteilung in den Berichten 1916 zu kennen, seine Auffassung in einem Sinn modifiziert, daß sie sich mit der von mir vorgeschlagenen praktisch deckt; vergl. die Nachschrift. 
wird, auch wenn sie nicht.am Ende der Tetrade liegt, so werden sämtliche Samenanlagen gesund. Die zu partieller Sterilität führende Spaltung, die sich im Pollen nicht verheimlichen läßt, könnte in den Samenanlagen ganz wohl verheimlicht werden ${ }^{1}$ ). Vielleicht beruht das Auftreten von $25 \%$ steriler Ovula bei O. muricata, gegenüber dem Sterilwerden von $50 \%$ des Pollens, auf einer gewissen Bevorzugung der zu weiterer Entwicklung befähigten Megasporen gegenüber den genotypisch untauglichen. Zytologische Untersuchung könnte leicht Klarheit über diese Frage bringen. Daß gerade $25 \%$ statt $50 \%$ der Megasporen steril werden, könnte durch die Annahme gewisser Beziehungen zwischen Reduktionsteilung und Spaltung ohne Schwierigkeit plausibel gemacht werden, doch sind solche Phantasien müßig, bevor der Nachweis geführt ist, daß tatsächlich andere Megasporen als die oberste zur Entwicklung zugelassen werden.

Niemand zweifelt mehr daran, daß es unerlaubt ist, aus der $\mathrm{Zu}$ sammensetzung der in Form voll entwickelter Individuen erzogenen Nachkommenschaft auf die Zahl der in den Eltern gebildeten verschiedenen Keimzelltypen ohne weitere Kautelen zu schließen. Wir verdanken die Entdeckung der aus den Mendelschen Regeln erschlossenen Vererbungsgesetze dem glücklichen Zufall, daß bei Kreuzungen von Rassen, die sich nur durch Farbmerkmale und ähnliches unterscheiden, sämtliche gametischen (haploiden) Faktorenkombinationen in gleicher Weise funktionstüchtig und sämtliche zygotischen (diploiden) Kombinationen in gleicher Weise entwicklungsfähig sind, so daß das Aufspalten der Keimzellen noch in der diploiden $\mathrm{F}_{2}$-Nachkommenschaft sich ohne Fälschung abbildet. Sobald wir regelmäßig einen Teil der Samen taub finden, müssen wir mit der Möglichkeit einer genotypisch bedingten Zygotenausschaltung rechnen, und sobald wir einen Teil des Pollens (und der Samenanlagen) steril finden, müssen wir die Möglichkeit einer Eliminierung gewisser Gametentypen im Auge behalten. Aber mit der Berücksichtigung dieser Momente ist noch nicht alles getan. Wir müßten uns z. B., um ganz exakt zu sein, vergewissern, ob alle gesund scheinenden Pollenkörner auch wirklich Pollenschläuche zu treiben vermögen, die die Samenanlagen erreichen. Weiter ist es stillschweigende, aber durch nichts bestätigte, ja nicht einmal geprüfte Annahme der meisten Vererbungsforscher, daß alle Pollenschläuche eines Andröceum gleiche durchschnittliche Keimungs- und Wachstumsgeschwindig-

1) Diese Möglichkeit deutet schon Tischler an (diese Zeitschrift, 1911, Bd. 5, S. 328). 
keit haben, auch wenn sie verschiedene haploide Genotypen repräsentieren. Zwischen verschiedenen Arten bestehen in Hinsicht auf die Ausgiebigkeit und die Geschwindigkeit des Längenwachstums der männlichen Prothallien zweifellos mitunter Verschiedenheiten. Von O.muricata erreichen nur wenige Pollenschläuche mit knapper Not die Samenanlagen der $O$. Lamarckiana, deren langer Griffelweg offenbar fast über die Kräfte des auf eine viel kürzere Wanderung eingerichteten muricata-Pollens geht ${ }^{1}$ ); denn auch bei der reichlichsten Bestäubung mit dem Pollen der O. muricata bleiben die Samenanlagen in der unteren Hälfte des Fruchtknotens von $O$. Lamarckiana immer unbefruchtet, die Früchte klein und am Grunde dünn. Auch mit dem Pollen von $\hat{O}$. biennis bildet $O$. Lamarckiana meistens keine sehr großen und samenreichen Früchte. Bei gleichzeitiger reichlicher Bestäubung der O. Lamarckiana mit dem Pollen der O. biennis und dem der O. suaveolens scheint suaveolens allein oder wenigstens fast allein zur Befruchtung zu gelangen, biennis zurückzubleiben. Ich habe die so gewonnenen Samen noch nicht ausgesät, aber ihre Beschaffenheit gibt eine klare Antwort. O. Lamarckiana erzeugt nämlich mit dem Pollen der O. suaveolens fast lauter gesunde Samen, mit dem von $O$. biennis zur Hälfte taube. Bei gleicher Menge und gleicher Wachstumsgeschwindigkeit der beiden Pollenarten müßten die Samen also ungefähr zu $3 / 4$ gesund und $\mathrm{zu}^{1 / 4}$ taub ausfallen, tatsächlich ist der Prozentsatz der gesunden (bei einer Zählung 154 auf 15 taube) aber so hoch, wie wenn der Pollen der O. suaveolens allein auf die Narbe gebracht wird. Bei spärlicher Pollinierung müßte auch der langsamer wachsende Pollen zur Befruchtung zugelassen werden, das wurde aber dadurch verhindert, daß zwei Narbenschenkel mit dem einen und zwei mit dem anderen Pollen so dicht wie möglich eingepndert wurden. - Auf etwas andere Weise hat Heribert-Nilsson ermittelt, daß die Pollenschlänche der O. Lamarckiana im eigenen Griffel rascher wachsen als die Pollenschläuche der $O$. gigas im Lamarckiana-Griffel (1911, S. 25).

Wenn nun eine Art wie $O$. Lamarckiana oder ein künstlich erzeugter Bastard zweierlei Pollen erzengt, so brauchen die beiden Pollentypen unter gleichen Außenbedingungen nicht notwendig gleich rasch zu keimen und zu wachsen, und die Keim- und Wachstumsgeschwindig-

1) Jost (1907, S. 107) findet ja auch, dab man Pollenschläuche von Hippeastrum aulicum and von Lilium Martagon durch Aneinanderfügen von zwei Griffeln nicht dazu bringen kann, den zweiten Griffel auch noch ganz zu durchwachsen. 
keiten der beiden Typen brauchen durch die Variation gewisser Außenbedingungen, etwa der Temperatur, nicht in genau derselben Weise beeinflußt zu werden. Außer von dem Verhältnis der Wachstumsgeschwindigkeiten der Pollenschläuche ist die Zusammensetzung der Nachkommenschaft auch von der Menge der die Samenanlagen erreichenden Pollenschläuche abhängig. Wenn nicht mehr Pollenschläuehe als Samenanlagen vorhanden sind, müssen auch die langsamsten Schlänche noch unbefruchtete Ovula finden. Die betreffenden Samen dürften dann zur Hauptsache im unteren Teil der Frucht liegen (vergl. oben S. 134). Je mehr aber die Zahl der entwicklungskräftigen Pollenkörner über die der Samenanlagen überwiegt, desto ungünstiger werden die Aussichten, zur Befruchtung zu kommen, für den langsamer wachsenden Pollentypus. Bei Selbstbestäubung der weißnervigen 0 . Lamarckiana bleiben solche Unterschiede in den physiologischen Konstanten der Pollensorten, wenn sie vorhanden sind, ohne Wirkung auf die Zusammensetzung der Nachkommenschaft. Die genannte Art bildet Samenanlagen $L$ und $\mathrm{l}$, beide Typen wenigstens bei gewissen Rassen in gleicher Anzahl, und ebenso Pollenkörner L und l. Lebensfähig sind nur die Heterozygoten Ll, die Homozygoten LL und 11 sterben frühzeitig. Wenn die Pollensorten L und 1 die gleiche Aussicht haben die Befruchtung auszuführen, entstehen $50 \%$ gesunde Ll-Samen, $25 \%$ taube LL- und $25 \%$ 11-Samen. Bleibt der Pollen 1 hinter dem Pollen $L$ weit zurück, so werden alle Samenanlagen von dem Pollen $\mathrm{L}$ befruchtet. Es entstehen wieder $50 \%$ gesunde Samen und $50 \%$ taube; die letzteren stellen zwar alle die Kombination LL dar, doch fällt das Fehlen der ebenfalls tauben 11-Samen nicht auf. Wird aber O. biennis mit dem Pollen der O. Lamarckiana belegt, so hängt das Zahlenverhältnis der Zwillinge laeta und velutina bei reichlicher Bestänbung von dem Verhältnis derWachstumsgeschwindigkeiten der beiden Pollentypen ab; von verschiedener Entwicklungs- und Keimfähigkeit der erzeugten Samentypen wollen wir absehen. Die Wachstumsgeschwindigkeiten der laeta (L) und der velutina (l) erzeugenden Pollenschläuche brauchen nicht bei jeder Witterung und bei jedem Alter des Pollens dasselbe Verhältnis zu haben, anßerdem wird die Bestäubung nicht immer gleichmäßig reichlich ausfallen, und so können Schwankungen in den Verhältniszahlen der Zwillinge vorkommen, wie sie tatsächlich beobachtet werden; daß diese Schwankungen auf die angedeutete Weise und nicht anders zustandekommen, soll natürlich nicht behauptet werden.

$\mathrm{Zu}$ den Außenbedingungen gehört auch das Substrat, $d$. h. das Leitnngsgewebe im Griffel, und wenn ein Pollen a in einem Griffel A 
rascher wächst als der Pollen b, so kann in einem Griffel B der Pollen b rascher wachsen. Das Verhältnis der Wachstumsgeschwindigkeiten zweier Pollenklassen braucht also bei Verbindung mit verschiedenen als Weibchen verwendeten Biotypen nicht immer das gleiche zu sein.

Schon vor langer Zeit (1902) hat Correns, als er in der $\mathrm{F}_{2}$ einer Maiskreuzung auf unerwartete Zahlenverhältnisse $(15,6-18 \%$ runzlige Dextrinfrüchte statt $25 \%$ ) stieß, die Ursache für die Abweichung im Pollen des $\mathrm{F}_{1}$-Bastardes gefunden. Durch Rückkreuzung des Bastardes $ᄋ$ mit dem rezessiven Elter $\sigma^{7}$ stellte er fest, daß die beiden Klassen von Eizellen im Bastard in gleicher Zahl gebildet werden. Er glaubte schließen zu dürfen, daß für den Pollen dasselbe gilt, daß aber die Bildung der rezessiven Homozygoten weniger leicht gelingt als die der übrigen möglichen Kombinationen. Er scheint dabei an selektive Befruchtung gedacht zu haben, und Baur (1914, S. 152) schließt sich dieser Vermutung an. Johannsen dagegen meint bei der Besprechung des Falles (1913, S. 519): „Offenbar konnten die Pollenkörner mit dem hier Stärkebildung bedingenden Gene oder Faktor schneller keimen oder sonst schneller wirken als die anderen Pollenkörner" (nämlich als die mit dem rezessiven Faktor für Dextrinbildung im Endosperm). Correns hat klar gesehen, daß dem beweglichen Pollen, sobald er mehr als einen Typus umfaßt, mit den üblichen statistischen Methoden nicht sicher beizukommen ist. Bateson übersieht den springenden Punkt, wenn er meint, das Ergebnis der Rückkreuzung sei das gleiche, wenn vom Bastard der Pollen und vom rezessiven Elter die Eizellen verwendet werden (S. 164). Warum das nicht sein kann, wie das Experiment ja aueh ergibt (Bastard $Q \times$ Elter $\sigma^{7}$ gibt $49,24 \%$ Dextrinsamen unter 1769, Elter 우 $\times$ Bastard $\sigma$ 41,99\% unter 331 Samen), das setzt Correns ausführlich auseinander. Die Rückkreuzung mit dem rezessiven Elter hat keinen anderen Zweck als den, einheitliches Pollenmaterial zu erhalten. Sobald der Pollen vom Bastard genommen wird, sind die Befruchtungsverhältnisse bei der Rückkreazung mit dem Elter dieselben wie bei der Selbstbestäubung des Bastards.

Nebenbei bemerkt, hat Correns anch Störungen der Mendelzahlen durch ungleiche Entwicklungsfähigkeit der Zygoten in der Erwartung schon vorweggenommen (1902, S. 171).

Den Gedanken an eine selektive Befruchtung hat Heribert-Nilsson (1915, S. 30) mit Entschiedenheit aufgegriffen zur Erklärung der Spaltungszahlen bei den rotnervigen Stämmen von O. Lamarckiana. Diese Rotnerven spalten immer Weißnerven ab, sind also nur im heterozygotischen Zustand existenzfähig (Heribert-Nilsson 1912, 1915). 
Wenn nun die Homozygoten RR ebenso oft gebildet würden wie die anderen lebensfähigen Kombinationen $\mathrm{Rr}$, rR und $\mathrm{rr}$ und erst nachträglich zngrunde gingen, dann müBte das Verhältnis Rotnerven : Weibnerven $=2: 1$ sein. Tatsächlich findet Heribert-Nilsson ein Verhältnis, das sich mehr dem Wert 3:1 nähert, nämlich im Mittel 2,68:1. Er erklärt den Befund durch die Annahme, daß die R-Pollenschläuche von den R-Samenanlagen abgestoßen, an der Befruchtung gehindert werden, so daß später anlangende r-Pollenschläuche die Befruchtung noch vollziehen können. Statt der Eliminierung lebensunfähiger RR-Zygoten soll "Prohibition" der positiven Homozygoten Platz greifen. Fürs erste sind alle Zahlen von Heribert-Nilsson nicht zuverlässig, weil nicht sicher ist, ob bei seinem Zuchtverfahren alle keimfähigen Samen wirklich zur Keimung und Weiterentwicklung gebracht wurden; in einzelnen Fällen von besonders anffallenden Spaltungszahlen sucht er selber die Ursache in "äußeren Faktoren", die eine ungewollte Selektion bewirkt haben könnten (1915, S. 19). Bei der einzigen besser kontrollierten Aussaat, die ich selber (1915) gemacht habe, fand ich aber auch das Verhältnis $3: 1$, nämlich 63 Rotnerven und 22 Weißnerven. Nehmen wir also einmal an, das Verhältnis 3:1 sei das normal vorkommende, und suchen wir die Hypothese der Prohibition zu prüfen.

Außer im Faktor für die Nervenfarbe ist die rotnervige $O$. Lamarckiana auch im L-Faktor heterozygotisch, wie ich 1914 auseinandergesetzt habe; daßs es sich dabei in Wirklichkeit nicht um ein einzelnes Gen handelt, stört uns hier nicht. Bei ganz gleichmäBiger Zygotenbildung würde das Schema I gelten. Die als taube Samen ausgeschalteten Homozygoten RR, LL und 11 sind durch Striche bezeichnet, die lebensfähigen doppelt heterozygotischen Rotnerven $\mathrm{RrLl}$ sind nur doppelt so zahlreich wie die Weißnerven $\mathrm{rrLl}$, und das Verhältnis der gesunden Samen zu den tauben ist $6: 10$, die Samen sind also zu $37,5 \%$ gesund.

Schema I.

\begin{tabular}{|c|c|c|c|c|}
\hline & RL & $\mathrm{Rl}$ & $\mathrm{rL}$ & $\mathrm{rl}$ \\
\hline RL & - & - & - & RrLl \\
\hline Rl & - & - & $\operatorname{Rr} \mathrm{Ll}$ & $\ldots$ \\
\hline $\mathrm{rL}$ & - & $\operatorname{RrLl}$ & - & $\mathrm{rrLl}$ \\
\hline $\mathrm{rl}$ & $\mathrm{RrLl}$ & - & $\mathrm{rr} \mathrm{Ll}$ & - \\
\hline
\end{tabular}

Wenn nun Heribert-Nilssons Vorstellung das Richtige trifft, müssen wir das Schema II so schreiben, dah die R-Samenanlagen nur yon r-Pollenschläuchen befruchtet werden; unter einander stehen die $O$, neben einander die $\sigma^{7}$ Gameten.

Schema II.
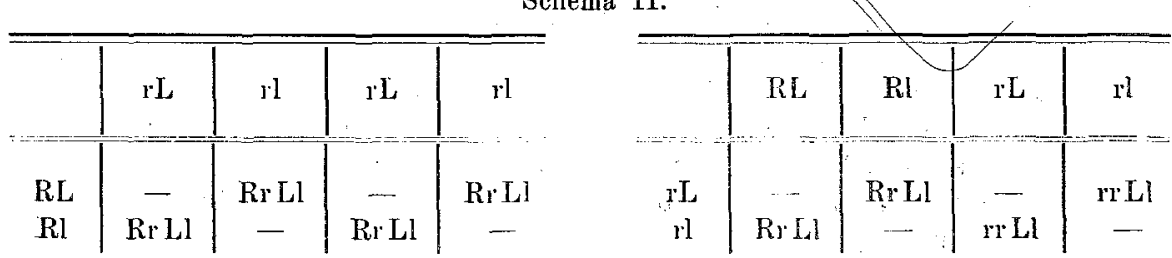

Induktive Abstammungs- und Vererbungslehre. XVIII. 
Das Verhältnis Rotnerven: Weibnerven wird nun wie verlangt $3: 1$, und die gesunden Samen sind ebenso häufíg wie die tauben. In der Tabelle II (S. 138) ist verzeichnet, daB bei der rotnervigen 0 . Lamarckiana C II 1 nur 23 und $27 \%$ gesunde Samen gefunden worden sind. Zur größeren Sicherheit habe ich noch ein paar Früchte untersucht; C I 3 ist das Exemplar, dessen Nachkommen 1915 aufgezogen wurden.

\begin{tabular}{|c|c|c|c|c|c|c|c|c|}
\hline \multirow{2}{*}{\multicolumn{3}{|c|}{$\begin{array}{c}\text { Lamarckiana } \\
\mathrm{H} . \mathrm{N} . \\
\text { rotnervig }\end{array}$}} & \multirow[b]{2}{*}{ Frucht } & \multicolumn{3}{|c|}{ Taube Samen } & \multirow{2}{*}{$\begin{array}{c}\text { Gesunde } \\
\text { Samen }\end{array}$} & \multirow{2}{*}{$\begin{array}{c}\text { Gesunde } \\
\text { Samen } \\
\text { in } \%\end{array}$} \\
\hline & & & & sehrklein & größer & $\begin{array}{c}\mathbf{z u}^{-} \\
\text {sammen }\end{array}$ & & \\
\hline C I 1 & & . & grob, halb & 12 & 87 & 99 & 50 & 33 \\
\hline C I 2 & & . . & $\begin{array}{c}\text { grob, nicht ganz } \\
\text { halb }\end{array}$ & 12 & 85 & 97 & 35 & 27 \\
\hline $\mathrm{C}$ I 3 & . & & grob, fast halb & 6 & 108 & 114 & 37 & 25 \\
\hline C I 4 & & . & $\begin{array}{l}\text { mittelgroß, nicht } \\
\text { ganz halb }\end{array}$ & 12 & 61 & 73 & 24 & 25 \\
\hline B I 1 & & . & $\begin{array}{l}\text { ziemlich grob, } \\
\text { etwa } 1 / 3\end{array}$ & 16 & 73 & 89 & 39 & 30 \\
\hline
\end{tabular}

Die Prozentzahlen der gesunden Samen halten sich durchweg weit unter $50 \%$, und damit seheint die Hypothese der Prohibition widerlegt. Nehmen wir nun an, dab doppelt so viel R- als $r$-Pollenschläuche zur Befruchtung kommen, so erbalten wir das folgende Schema.

Schema III.

\begin{tabular}{|c|c|c|c|c|c|c|}
\hline & $\mathrm{RL}$ & RL & $\mathbf{R l}$ & $\mathrm{Rl}$ & $\mathrm{rL}$ & $\mathrm{rl}$ \\
\hline RL & - & - & - & - & - & $\operatorname{RrLl}$ \\
\hline $\mathbf{R l}$ & - & - & - & - & $\mathrm{RrLl}$ & - \\
\hline $\mathrm{rI}$ & - & $\ldots$ & $\operatorname{RrLI}$ & $\operatorname{RrLl}$ & - & $\operatorname{rrLl}$ \\
\hline $\mathrm{rl}$ & $\operatorname{RrLl}$ & RrLl & - & - & $\operatorname{rrLl}$ & - \\
\hline
\end{tabular}

Danach entstehen wieder dreimal so viele Rotnerven als Weißnerven und 8 gesunde auf 16 taube Samen, also $33 \%$ gesunde Samen. Das entspricht ungefähr dem tatsächlichen Befund. $\mathrm{Zu}$ prüfen wäre diese Zurechtlegung durch die Kreuzung weißnervig $Q \times$ rotnervig $\delta$, wie sie Heribert-Nilsson schon ausgeführt hat. Er fand (1915, S. 24, Tabelle II, Nr. 100) 76 Rotnerven auf 35 Weißnerven, also das Verhältnis 2,2:1 anstatt des zu erwartenden Wertes 2:1. Die Spaltung der Nachkommenschaft des betr. Rotnerven bei Selbstbefruchtung in 1,8 Rotnerven : 1 Weißnerv stimmt damit freilich gar nicht überein. Aber wie schon hervorgehoben ist auf die Zahlen von Heribert Nilsson leider kein Verlaß, einerlei ob sie mit einem einfachen Mendelschen Schema stimmen oder nicht. 
Wenn es sich bestätigen sollte, daß mehr R- als r-Spermazellen in Aktion treten, müßte erst noch entschieden werden, ob die R-Pollenkörner infolge eines "Reduplikations"-Vorgangs in größerer Zahl gebildet werden als die r-Pollenzellen, oder ob die Pollenschläuche mit dem R-Faktor rascher wachsen als die ohne diesen Faktor. Im zweiten Fall wäre jedenfalls eine hohe Variabilität in den Zahlenverhältnissen der Zygoten zu erwarten.

Es läßt sich nicht leugnen, daß die Vererbungsforschung, trotz der klaren Einsicht einzelner Forseher, in der Praxis in mancher Beziehung noch zu grob statistisch arbeitet und viel mehr biologisch arbeiten muß. Bevor wir aus der Zusammensetzung einer Nachkommenschaft auf die genotypische Konstitution der Eltern und Großeltern zu schließen wagen, müssen wir streng genommen die ganze Entwicklungsgeschichte der Keimzellen und der Zygoten kennen. Über das Schicksal der Megasporen und der Zygoten erhalten wir leicht und sicher AufschluB; die Samenanlagen sind ja unverlierbar im Gynäzeum geborgen. Aber was bei dem Wettlauf der männlichen Prothallien von der Narbe bis zum Embryosack geschieht, darüber wissen wir vorerst nichts, abgesehen von den Studien von Jost, die ein kleines aber sehr wichtiges Gebiet geklärt haben, und es wird auch im einzelnen Fall schwer sein, davon Kenntnis zu bekommen. An der Vernachlässigung dieses Stücks der Lebensgeschichte selbst viel studierter Samenpflanzen ist wohl zu einem guten Teil eine Nachlässigkeit der in der Vererbungslehre gebräuchlichen Terminologie schuld. Wer gewohnt ist die Pollenkörner einer Blütenpflanze. Gameten zu nennen ${ }^{1}$ ), vergißt zu leicht, daß der Weg von der Mikrospore zur kopulierenden Spermazelle weit, mitunter mit dem Zentimetermaß zu messen ist. Eine nomenklatorische Ungenauigkeit ist vielleicht $\mathrm{zu}$ einem Schaden für die experimentelle Methodik geworden.

\section{Die wesentlichen Unterscheidungsmerkmale der verwendeten Arten und der durch Kreuzung hergestellten Formen.}

Die von anderen Autoren gegebenen ausführlichen Beschreibungen der bisher beobachteten Formen werden als bekannt vorausgesetzt. Es

1) In einem Aufsatze "Zur Terminologie des pflanzlichen Generationswechsels" (Biolog. Centralbl. 1916, Bd 36, S. 337) bin ich anf diesen Gebrauch des Terminus Gamet nicht eingegangen, weil es zu klar ist, daß der Usus für vergleichend morphologische Betrachtung als Mißbrauch erscheint. 
sollen nur solche Charaktere hervorgehoben werden, die mir für die Unterscheidnng und Gruppenbildung in meinen Kulturen besonders wertvoll erschienen, vor allem deshalb, weil es sich dabei oft um reine Alternativen handelt, nicht um quantitative, nur durch Messungen festzustellende Unterschiede. Solche Merkmale sind:

1. Vorhandensein oder Fehlen roten Anthokyans in den kleinen Gewebehöckern, die als Träger der stärkeren Haare ${ }^{1}$ ) an Stengel und an den Fruchtknoten über die Oberfläche der betreffenden Organe vorspringen und bei makroskopischer Betrachtung nur im Falle der Rotfärbung als kleine, scharf umgrenzte Tupfen hervortreten, falls der Grund, auf dem sie stehen, grün ist. Ob die Fruchtknoten und ebenso die Sproßachsen, besonders in den oberen Teilen, rot getupft sind oder nicht, gehört zu den wichtigsten Kennzeichen einer Form. Ohne Bedeutung ist die Rotfärbung der Haarpolster, wenn sie nur an gleichmäßig rot überlaufenen Stengelteilen auftritt.

2. Vorhandensein oder Fehlen roten Anthokyans in der Epidermis der stärkeren Blattnerven. Vorhandensein bedingt "Rotnervigkeit", Fehlen "Weißnervigkeit" (Heribert-Nilsson). Erwachsene Rosetteu und junge Stengel zeigen die Rotfärbung der Nerven, wenn sie vorhanden ist, am deutlichsten; gegen Ende der Blütezeit oder sogar schon früher blaßt die Nervenfarbe meistens stark aus (vergl. dieselbe Beobachtung bei Heribert-Nilsson an O. Lamarckiana, 1915 S. 13). Außerdem können Stengel und Zweige, die im Schatten aufwachsen, sehr schwache Pigmentierung der Blätter besitzen, und umgekehrt können Pflanzen, die in Dichtsaat in Töpfen heranwachsen, auch dann rote Nerven an den Rosettenblättern zeigen, wenn die betreffende Form bei Kultur im Gartenfreiland nie die schwächste Nervenfärbung erkennen läßt (bei $O$. suaveolens beobachtet). Zu der Ermittlung der Nervenfarbe müssen die Pflanzen also bei guter Wurzelernährung und im hellen Licht erzogen und weder zu früh noch zu spät gemustert werden.

3. Vorhandensein oder Fehlen eines rotbraunen oder braunroten Farbstoffs in den Kelchblättern, und zwar. auf der Außenseite. Von rein grünen Kelchen bis zu solchen vom rubrinervis-Typus, bei dem

1) De Vries erwähnt diese Gebilde bei O. rubrinervis in Mutationstheorie I, S. 235: „namentlich sind die kleinen Hügel, auf denen die größeren Haare stehen, in der Mehrzahl rötlich". Davis nennt die Höcker seit 1913 Papillen; bis 1912 nennt er sie papillate glands und schreibt ịhnen befremdender Weise die Funktion von Schleimausscheidung zu (1912, S. 386). Auch Klebah a beachtet die "roten Höcker" und stellt sie auf Taf. IV, IX, X dar, bei O. rubricaulis Kleb. 
nur die Mittelnerven, die äußersten Ränder und die dünnen Spitzen der Kelchblätter grün, alle übrigen Teile tief rot sind, finden sich alle Übergänge ${ }^{1}$ ). Bei schwacher Pigmentierung trägt jedes Kelchblatt zu beiden Seiten des Mittelnervs je einen schmalen und kurzen rötlichen Streifen, und diese Streifen können an Breite und Länge so zunehmen, daß das Grïn nur an den genannten Stellen der Kelchblätter sichtbar bleibt. Die Rotfärbung der Kelche wird mit zunehmender Entwicklung der Infloreszenzen stärker; sind die Kelche der oberen Blüten nur leicht rot gestreift, so können die der unteren Blüten ganz grün bezw. gelbgrün sein.

4. Vorhandensein oder Fehlen eines rotbraunen oder braunroten Farbstoffs in der Epidermis der jungen Früchte, abgesehen von gefärbten, als rote Tupfen erscheinenden Haarpolstern. Die Färbung wird bald nach der Befruchtung deutlich, nimmt eine Zeitlang zu bis zur Bildung von vier breiten dunklen Streifen und verschwindet dann früher oder später wieder ${ }^{2}$ ). Die Rotfärbung der Früchte kommt nur bei Rotfärbung des Kelchs vor; sie kann sehr kräftig sein bei ganz leichter Streifung des Kelchs $(O$. [rubrinervis $\times$ biennis] subfallax $)$ und sie kann nur eben angedeutet sein bei ziemlich kräftiger Färbung des Kelchs (O. [biennis $\times$ Lamarekiana] velutina).

De Vries hat die Unterschiede in der Anthokyanbildung sehr gering bewertet und vielfach ganz unberücksichtigt gelassen. So war es ihm möglich bei gewissen Bastardgenerationen Formen zusammenzufassen, die weit verschieden sind, z. B. die in der Kreuzung $O$. (biennis $\times$ Lamarckiana) velutina $\times$ (biennis $\times$ Lamarckiana) laeta auftretenden laeta und Lamarckiana beide als laeta zu bezeichnen, trotzdem die laeta grüne Kelche, grüne Früchte und ungetupfte Stengel, die Lamarckiana rotgestreifte Kelche, rotgestreifte Früchte und rotgetupfte Stengel besitzt.

5. Das Verhältnis zwischen der Länge des Griffels und der Länge der Staubblätter. Der Griffel ist "kurz", wenn die Narben ganz oder großenteils von den Antheren gedeckt werden; er ist „mittellang“", wenn die Antheren die Narben im unteren Teil noch erreichen; er ist "lang“", wenn die Narben die Antheren nicht mehr erreichen, so daß keine Selbstbestäubung in der Knospe möglich ist; er ist "sehr lang“, wenn die Narbenbasen deutlich über die Antheren hinausgeschoben sind. Die

1) Vergl. de Vries 1913, Taf. XVIII, XXI.

2) Vergl. de Vries 1913, Taf. II, XVIII, XXI. 
relative Griffellänge pflegt an den unteren Blüten einer Infloreszenz geringer zu sein als an den oberen ${ }^{1}$ ), und die Unterschiede zwischen lang- und kurzgriffeligen Individuen sind an den oberen Blüten meist auffallender als an den unteren.

6. Überhängende Gipfel der wachsenden Hauptstengel und Seitenäste charakterisieren die 0 . muricata und ihre Pollenbastarde gegenüber den übrigen Formen mit geraden, nicht nutierenden Sprossen. Mit dem Abschluß des Längenwachstums strecken sich die vorher nutierenden Infloreszenzspitzen gerade.

7. Beträchtliche Unterschiede finden sich in der Gestalt der jungen, etwa drei Wochen alten Keimpflanzen ${ }^{2}$ ). Typus von O. biennis: dichte Rosetten aus kleinen, ziemlich breiten, flach nieder- und aneinandergedrückten Blättern. Typus von $O$. Lamarckiana: ziemlich flache Rosetten aus bedeutend größeren, länger gestielten, breiten Blättern. Typus von $O$. (biennis $\times$ Lamarckiana) velutina: sehr lockere aufgerichtete Rosetten aus wenigen, ziemlich großen, lang gestielten, elliptischen, glatten Blättern. Typus von O. rubrinervis: Keimpflanzen mit gestreckten Internodien und lang gestielten eiförmigen Blättern, nicht rosettenartig. - Andere weniger scharf gekennzeichnete Typen lassen sich nicht mit wenigen Worten charakterisieren. - Sehr wichtig ist dás Auftreten von langsam wachsenden gelben und von bald absterbenden gelblichen oder weißen Keimpflanzen neben den grünen.

8. Zu den Eigentümlichkeiten, die eine Form kennzeichnen, gehört auch das Verhältnis zwischen gesunden und tauben Samen. Wie dieses zu ermitteln ist und wie vorsichtig die gefundenen Zahlen zu beurteilen sind, ist oben auseinandergesetzt worden.

\section{Die Kennzeichen der verwendeten Arten.}

O. biennis (Fig. 3). Die Rasse, die ich 1914 im botanischen Garten in Nymphenburg in Kultur fand, ist von der um München wild vorkommenden Form nicht zu unterscheiden. Blattrosette stark. Blätter

1) Vergl. dazu Gates, 1911, S. 595.

$\left.{ }^{2}\right)$ Die hervorgehobenen Unterschiede waren am schärfsten ausgeprägt bei den ausgedehnten Kulturen im Frähjahr 1916, bei denen die Töpfe mit den Sämlingen in einem ziemlich kühlen Raum gehalten wurden. Die Erde war nicht sehr kräftig gedüngt. Im Jahr 1917, bei Kultur in fetter schwarzer Gartenerde und in einem sonnigen Gewächshans, waren die Unterschiede z. B. zwischen biennis- und Lamarckiana-Keimpflanzen viel schwächer. 
glatt, dunkelgrün, rotnervig, die der Rosette meist rot gefleckt. Stengel und Fruchtknoten ohne rote Tupfen, mit rauhen Haaren. Brakteen flach, ziemlich kein. Kelch und Frucht grün. Äußerste Spitzen der Kelchzipfel und der Brakteen kräftig rot. Kronblätter der unteren Blüten $28 \mathrm{~mm}$ lang, tiefgelb. Griffel meistens kurz, seltener mittellang. Antheren ziemlich arm an Pollen. Früchte rauh behaart (Fig. 8). Samen zu 55-77\% ge-

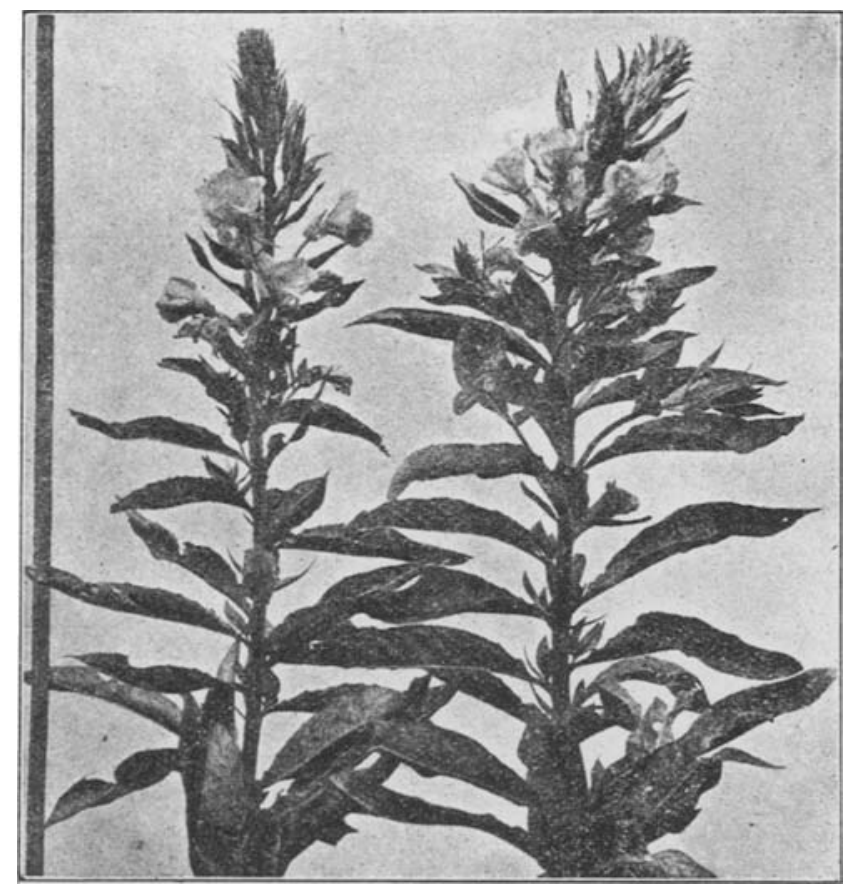

Fig. 3. Rechts 0 . biennis, zweijäbrig erzogen, links 0 . (suaveolens $\times$ biennis) redempta, zweijährig. Am 1. 7. 1916 aufgenommmen. Beide Formen sind einander vollkommen gleich. ${ }^{1}$ )

sund, unter den tauben sehr kleine mit typisch gestörtem Embryo und Endosperm. Solche kranken Samen wurden auch bei der um München wild wachsenden Form gefunden, die aber weniger taube Samen bildet. -

1) Der bei den meisten Bildern mitphotographierte zusammenlegbare Mabstab ist im ganzen $100 \mathrm{~cm}$ lang (vergl. z. B. Fig. 4, 9). Wo die Zentimeterteilung (vergl. Fig. 8) in den Reproduktionen nicht wahrnehmbar ist," sind wenigstens die $10 \mathrm{~cm}$ voneinander entfernten Knöpfe zu erkennen. 
Solange noch Blütenknospen in größerer Zahl vorhanden sind, ist das Bild des flach abgestutzten Infloreszenzgipfels mit den rot gespitzten Kelchzipfeln and Brakteen sehr charakteristisch. Stengelhöhe der einjährig erzogenen Individuen etwa $110 \mathrm{~cm}$, der zweijährigen größer ${ }^{1}$ ). Unter den zahlreichen Individuen, die ich in zwei Generationen erzog, war nicht ein abweichendes.

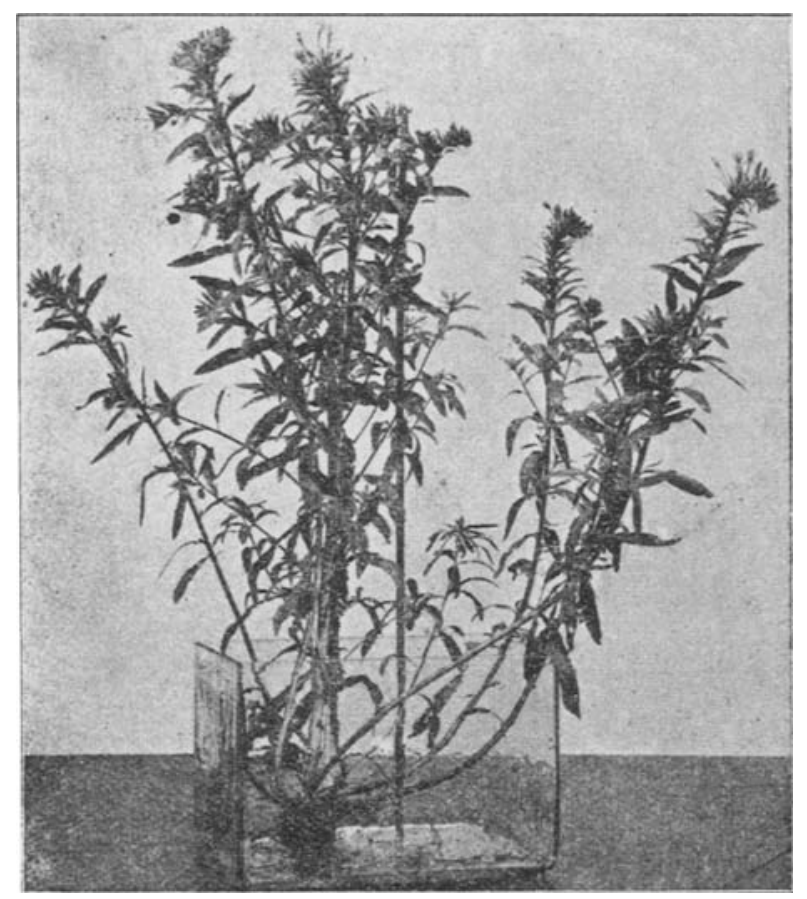

Fig. 4. O. muricata von Venedig, einjährig, 6.9.15.

O. muricata-Venedig (F. 4, 5, 10). Blattrosette stark, zur Zweijährigkeit neigend. Blätter lang und schmal, bläulichgrün, fein behaart, rotnervig. Stengelspitzen einige Zeit vor Beginn der Blüte bis zum Abschluß der Blüte überhängend. Beginn der Blüte spät, Ende Juli. Stengel unten rot überlaufen. Stengel und Fruchtknoten fein rot ge-

1) Die Stengelhöhen sind alle im Sommer 1916 gemessen an Pflanzen, die auf ziemlich gleichmäßig behandeltem, nicht gerade sehr reichem Boden erwachsen waren. In guter Gartenerde können die Pfianzen sicher höher werden, aber die Maße sind untereinander alle vergleichbar. 
tupft. Brakteen groß, schmal, flach. Kelch in seiner ganzen Ausdehnung leicht rötlich gefärbt, auch die Kelchröhre; Spitzen der Kelchzipfel kurz und dick. Kronblätter $15 \mathrm{~mm}$ lang und breit, blaßgelb. Griffel sehr kurz, mit kurzen, dicken Narben. Antheren kurz, arm an Pollen. Früchte eine Zeitlang rotstreifig, am Grund sehr dick, kegelförmig verjüngt (Fig. 10). Samen zu $63-87 \%$ keimhaltig. - Abweichende Individuen wurden weder in den Keimschalen noch blühend im Garten beobachtet.

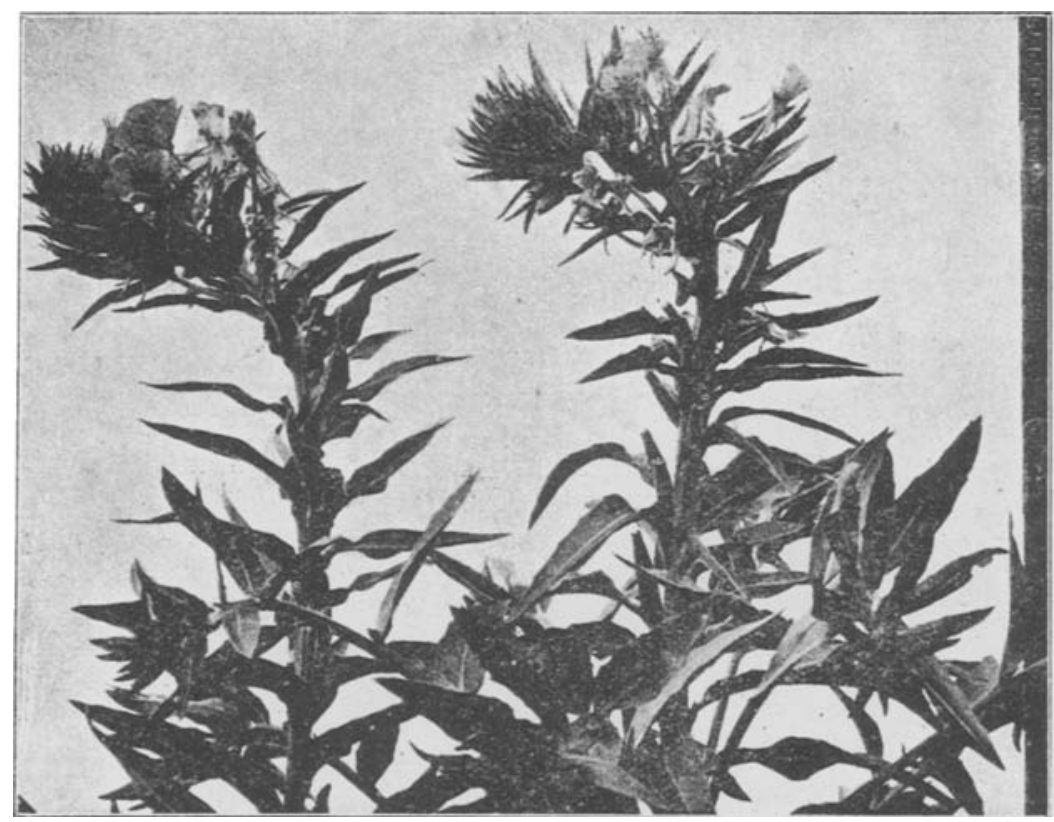

Fig. 5. Rechts $O$. muricata von Venedig, links $O$. (biennis $\times$ muricata-Venedig) $\mathrm{F}_{1}$, beide einjährig. 31.7.16. In der Photographie unterscheidet sich der patrokline Bastard von dem Vater nur durch die größeren Blüten.

O. suaveolens Desf. (Fig. 6, 7, 8). Ohne ausgeprägte Blattrosette, typisch einjährig. Stengel unten rot überlaufen, von unten an reich verzweigt, bis $140 \mathrm{~cm}$ hoch, Wuchs buschig. Blätter rein grün, breit, fein gezähnt, weißnervig, weich und fein behaart, sehr leicht welkend. Brakteen groß, breit, flach. Stengel und Fruchtknoten nicht rot getupft. Kelch grün, mit schlanken Zipfelspitzen. Kronblätter 35-38 mm lang, schwefelgelb. Griffel kurz. Antheren reich an Pollen. Früchte grün, lang unả schlank, fein behaart (Fig. 7). Samen zu $15-46{ }^{\circ}{ }_{0}$ keim- 
haltig. - In der ersten Generation, die aus frei bestäubten Früchten (vom natürlichen Standort) erzogen war, fand sich unter 15 Individuen ein abweichendes, mit roten Blattnerven und kurzen Früchten, wahrscheinlich ein Bastard aus einer rotnervigen Form. In der zweiten Generation

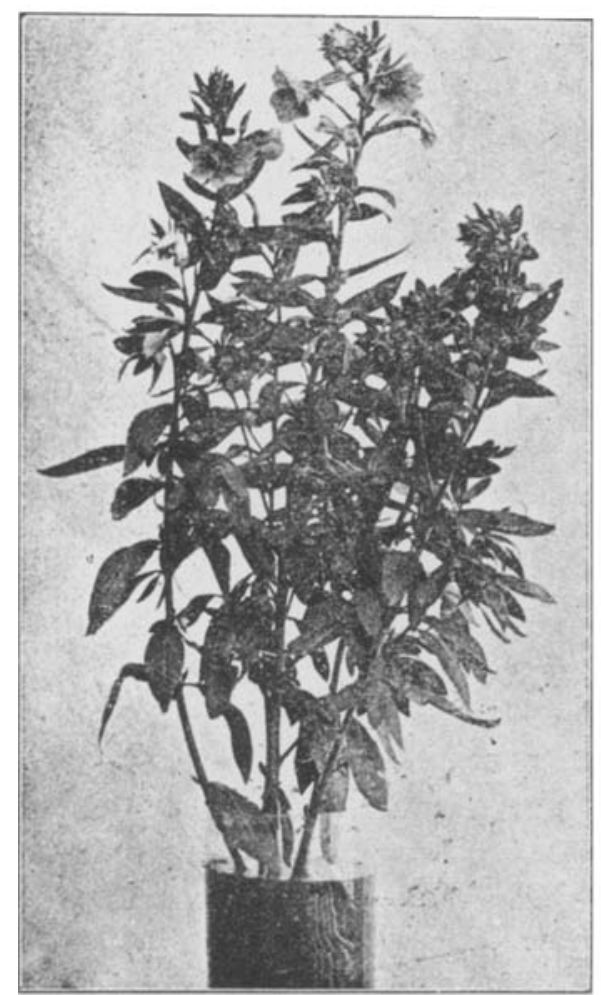

Fig.6. O. (biennis $\times$ suaveolens) suavis $\mathbf{F}_{1}$, mit $O$. suaveolens identisch, beim Beginn der Blüte, einjährig, Anfang Juli 1915.

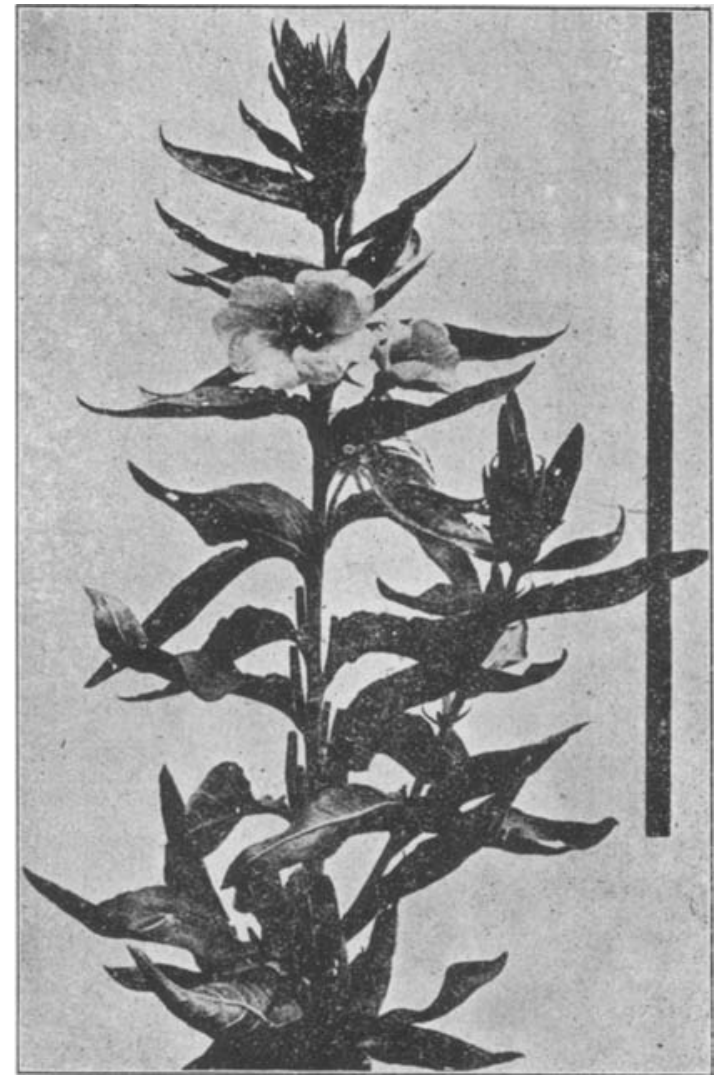

Fig. 7, O. suaveolens, einjährig, bald nach dem Beginn der Blüte, 20. 7. 16. Die Figuren 11,6, 7, 12, 13, 8 links können als aufeinanderfolgende Stadien von O. suaveolens ebensogut wie von $O$. (biennis $X$ suaveolens) suavis gelten.

traten unter 109 Keimpflanzen als Nachkeimer zwei Individuen mit gelben Kotyledonen auf, die im Topf erzogen sich zu schwachen Pflanzen mit sehr dünnen, gelblichgrünen, weißnervigen Blättern entwickelten; sie entsprechen wohl der Mutante lutescens, die de Vries (1916a, S. 7) 
erwähnt. In einer zweiten Saat derselben Generation war unter 27 Exemplaren kein Abweicher.

O. Lamarckiana von de Vries. Blattrosette stark. Blätter graulichgrün, sehr bucklig, weißnervig. Stengel und Fruchtknoten kräftig rot

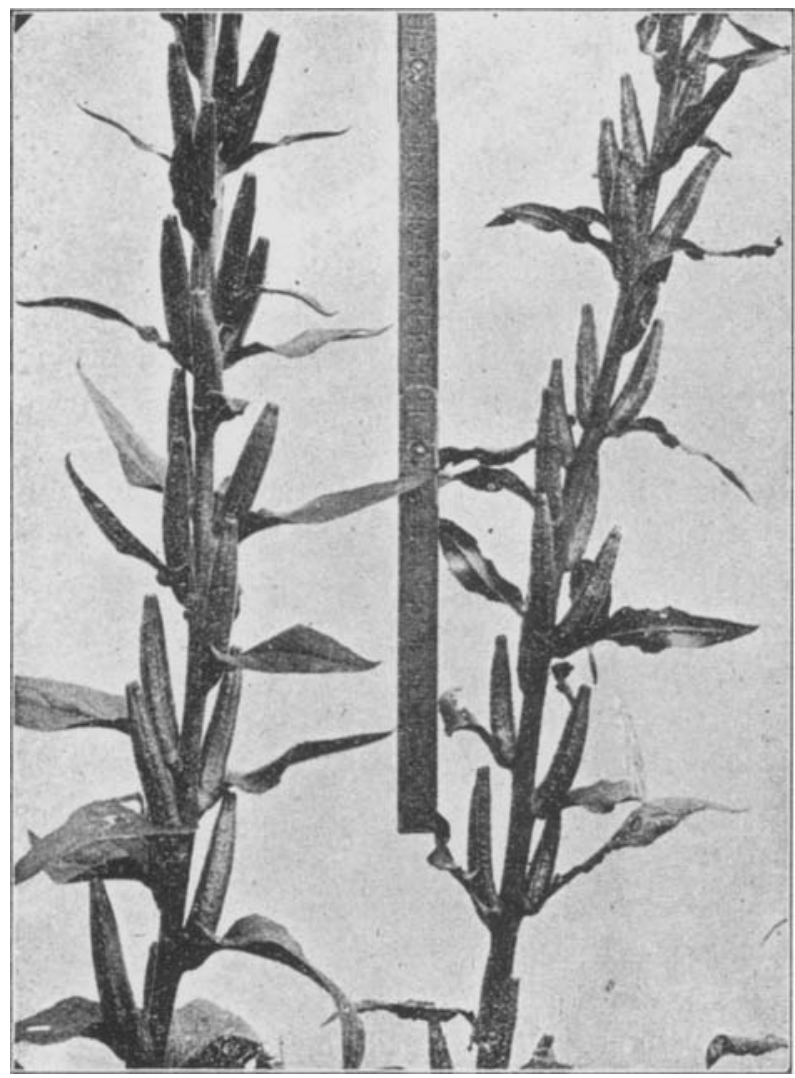

Fig. 8. Fruchtstände einjähriger Pflanzen, links von $O$. (biennis $\times$ suaveolens) suavis (= suaveolens; Früchte lang, fein behaart), rechts von $O$. (suaveolens $\times$ biennis) redempla (= biennis: Früchte kurz, grob behaart). 16.9.15.

getupft. Brakteen groß, rinnig, abwärts gebogen, leicht gewellt. Kelch breit rotstreifig. Kronblätter $48 \mathrm{~mm}$ lang, blaßgelb. Griffel sehr lang. Antheren reich an Pollen. Früchte breit und tief rotstreifig. Samen zu 17-51\% keimhaltig. Für den Habitıs charakteristisch sind starke, erst niederliegende, dann bogig aufsteigende Äste am Grund des Haupt- 
stamms; vergl. de Vries 1913 Tafel I. Stengel einjährig bis $145 \mathrm{~cm}$ hoch. - In der ersten Generation war unter 30 Individuen ein breitblättriges spät blübendes. Die zweite Generation, aus 20 Individuen bestehend, war einförmig.

O. Lamarckiana von Heribert-Nilsson. Die weißnervigen Individuen sind von der de Vriesschen Form kaum verschieden; die Kronblätter sind etwas größer, bis $55 \mathrm{~mm}$ lang; Samen zu $30-49 \%$ keimhaltig. Die rotnervigen Individuen, die immer Weißnerven abspalten ${ }^{1}$ ), haben weniger bucklige Blätter; Samen zu $23-27 \%$ keimhaltig; über andere Unterschiede berichtet Heribert-Nilsson ${ }^{2}$ ). Mutanten sind in meinen allerdings ziemlich wenige Individuen umfassenden Kulturen nicht aufgetreten.

O. gigas von de Vries. Die Blätter sind weißnervig, Stengel und Fruchtknoten sind rot getupft, die dicken Narben liegen über den Antheren. Antheren sehr pollenreich. - Abweicher sind zahlreich; unter 30 Individuen der ersten Generation waren mehrere, die mit dem eigenen Pollen keine Früchte ansetzten, und drei Individuen mit sehr schmalen spitzen Blättern, deren Stengel sehr spät schossen und sich kaum verzweigten.

O. gigantea von Heribert-Nilsson. Heterozygotisch rotnervig, Weißnerven abspaltend. Stengel und Fruchtknoten rot getupft. Auffallende Abweicher fehlten.

O. nanella von de Vries. Blätter weißnervig. Stengel und Fruchtknoten rot getupft.

O. rubrinervis von de Vries. Blattrosetten schwach, typisch einjährig. Blätter schmal, leicht bucklig, fein gezähnelt, weißnervig. Stengel $1 \mathrm{~m}$ hoch, wie die Fruchtknoten rot getupft. Achse zwischen den Blüten geschlängelt. Der Fruchtknoten fast wagrecht abstehend, die Kelchröhre wieder fast senkrecht aufgerichtet. Knospen sehr dick. Der Kelch fast ganz rot. Die Kronblätter in der Knospe zerknittert, fast wie bei Papaver rhoeas, sehr groß, dunkelgelb. Griffel lang; Narben dick, ziemlich kurz. Antheren anßerordentlich pollenreich. Früchte groß und dick, breit rotgestreift. Samen zu 59-73\% keimhaltig. - Alle Teile sehr spröde und brüchig.

\footnotetext{
1) Vergl. oben S. 152.

2) 1912 S. $103,1.915$ S. 37.
} 


\section{Die Einzelergebnisse der Kreuzungsversuche.}

\section{Das Verhalten der Bastarde in der ersten Generation.}

Das erste, was von einer Kreuzung sofort nach dem Ausreifen der Früchte festgestellt werden kann, ist die Beschaffenheit der Samen, aus denen die erste Bastardgeneration hervorgehen soll. Es werden

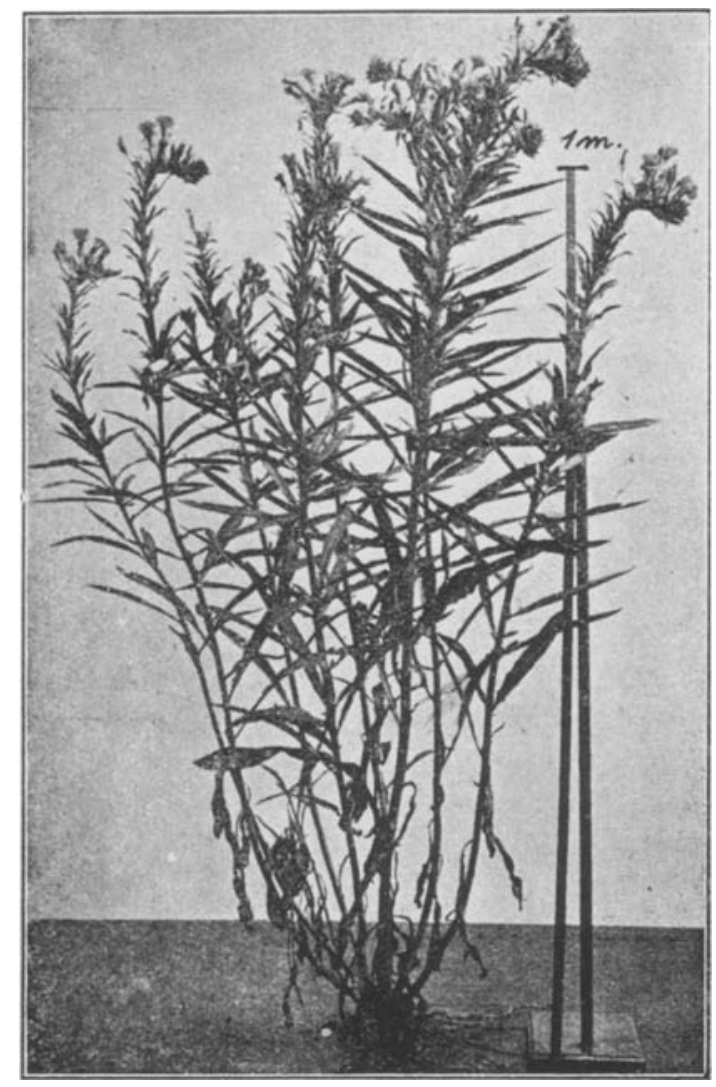

Fig. 9. 0. (biennis $\times$ muricala) $\mathrm{F}_{1}$, einjährig, 3.9.15.

also im folgenden die Beschreibungen der Kreuzungen beginnen mit der Angabe des beobachteten, schon in der Tabelle III mitgeteilten Verhältnisses zwischen gesunden und tauben Samen. Daran schließt sich die Beschreibung der Sämlinge, falls in den Keimschalen bemerkenswerte Eigentümlichkeiten zutage treten, weiter folgt die Schilderung der erwachsenen Bastardpflanzen. Den Beschluß macht die Auszählung der 
nach Selbstbestäubung der $F_{1}$-Generation gewonnenen Samen, welche die $\mathrm{F}_{2}$ liefern sollen.

O. biennis $\times$ muricata (Fig. 5, 9, 10). Samen zu $71-84 \%$ keimhaltig. Außer gesunden Keimpflanzen treten gelblichweiße Keimlinge

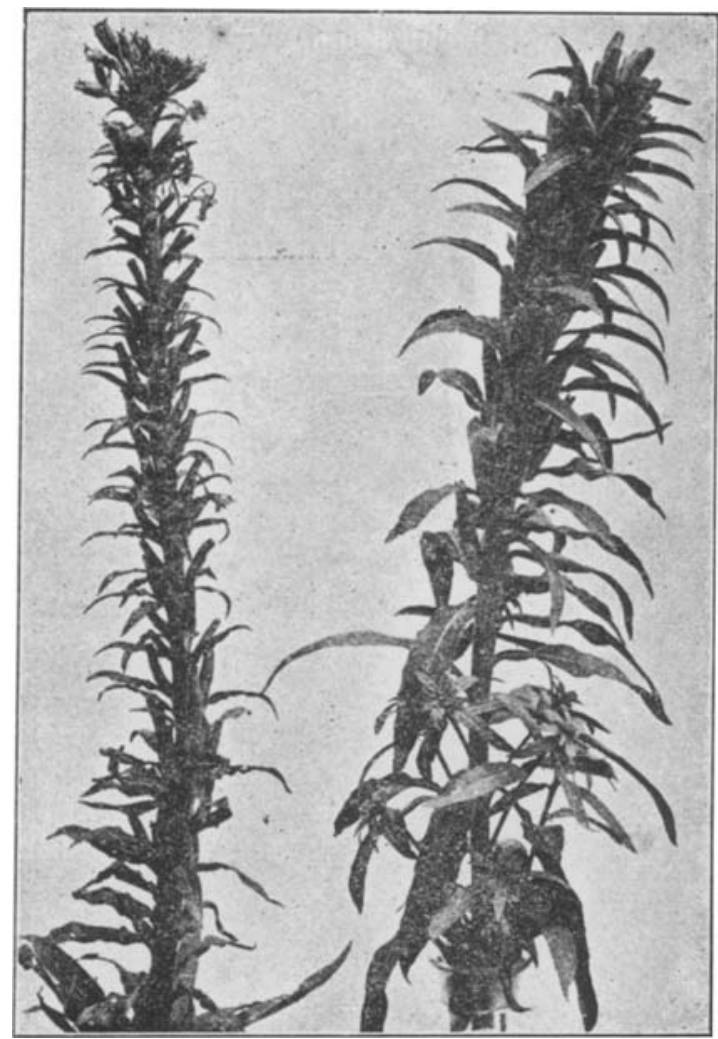

Fig. 10. Fruchtstände, rechts von 0. muricata, links von $O$. (biennis $\times$ muricata) $F_{1}$. Einjährig 26.10. 15. In diesem Zustand ist der Bastard von der Vaterart stark verschieden. Bei O. muricata stellt die Infloreszenzspitze ihr Wachstum bald ein, wohl infolge der Ausbildung der großen dicken Früchte, beim Bastard werden über den dünnen Früchten noch lange Blüten entialtet.

anf, die mit winzigen Kotyledonen zugrunde gehen, ohne Primärblätter zu bilden; über diese Zweiförmigkeit der $F_{1}$ vergleiche unten S. 234 . Die erwachsenen Pflanzen sind in allen Stadien stark patroklin, der $O$. muricata sehr ähnlich in Wuchs, Form der Blätter, Knospen, Blüten, Narben, in" der Behaarung. Die Stengelspitzen nicken zur Blütezeit 
ebenso stark wie die der muricata, fangen aber später an zu nutieren, sind zu Beginn der Blüte noch gerade; Stengel bis $110 \mathrm{~cm}$ hoch. Die Blüte beginnt etwa gleichzeitig mit der der biennis, früher als die der muricata. Stengel unten rot überlaufen, oben wie die Blätter hellgrün, nicht bläulichgrün. Blattnerven weiß, nur an den unteren Stengelblättern später rötlich. Rote Punktierung am Stengel und an den Fruchtknoten fehlt, höchstens tritt gegen Ende der Blütezeit am Sproß-

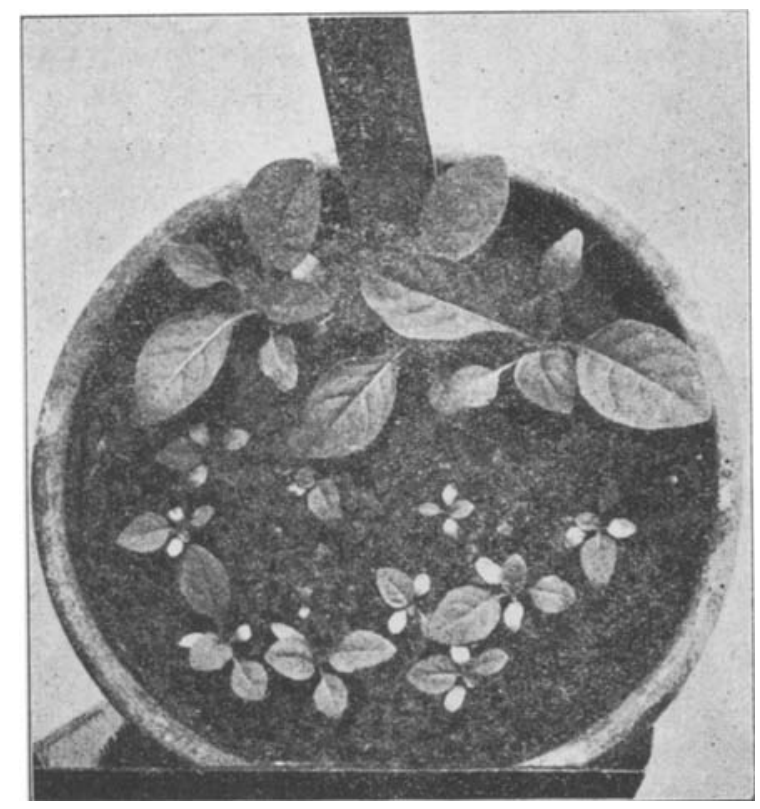

Fig. 11. Mehrere Wochen alte Keimpflanzen der $\mathrm{F}_{1}$ der Kreuzung $O$. biennis $\times$ suaveolens. Oben die kräftige suavis-suaveolens, unten der schwache Zwillingsbruder flava mit gelben Kotyledonen und grünen gezähnelten Primärblättern.

gipfel undeutliche Färbung der Haarbasen auf. Die Blüten beträchtlich größer als bei muricata, der Kelch fast ganz grün, höchstens am Grund der Röhre leicht rötlich angelaufen, die Kronblätter hochgelb, $18 \mathrm{~mm}$ lang, $23 \mathrm{~mm}$ breit. Antheren sehr arm an Pollen. Früchte locker stehend, grün, wegen spärlicher Samenbildung dünn, bucklig, von den dicht gedrängten, dicken Früchten der $O$. muricata weit verschieden (Fig. 10). Samen zu 37-51\% keimhaltig. - Ausführliche Beschreibung bei Davis, 1914. 
Zahlen für biennis I $1 \times$ muricata II, 1914 hergestellt: 1915 keimten 108 Samen, ungekeimt blieben 59, davon waren 20 taub, 39 enthielten einen Embryo. Von 88 ausgepflanzten Keimlingen blieben 20 aus, 54 gaben gesunde grüne Pflanzen, 4 gingen gleich nach der Entfaltung der gelblichweißen Kotyledonen zugrunde. Von den nicht über der Erde erschienenen Keimlingen dürfte die Mehrzahl in dieselbe Gruppe gehören wie die 4 letzten weißen.

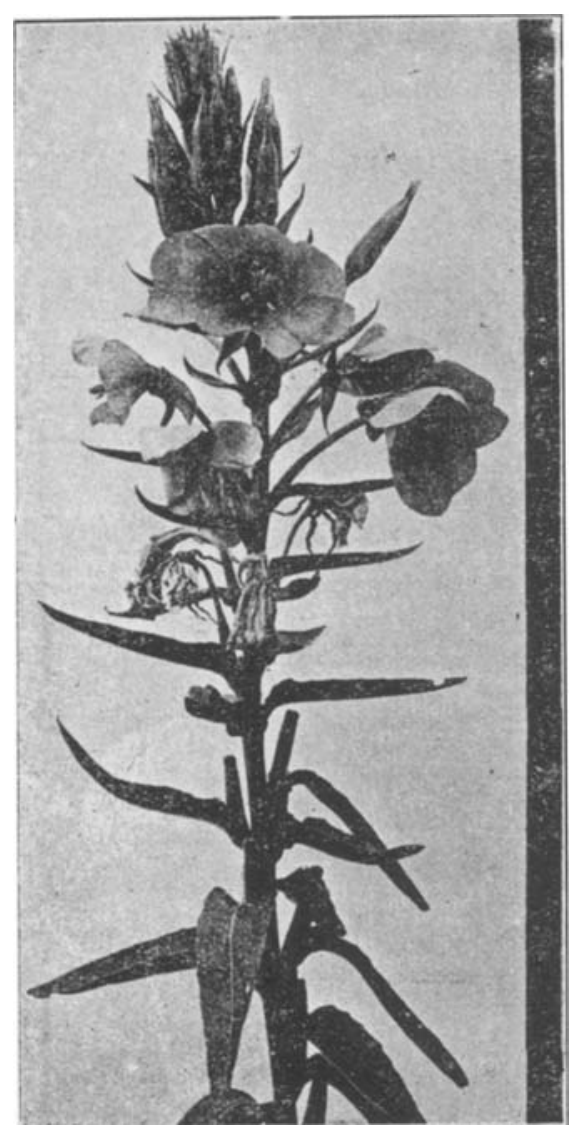

Fig. 12. O. (biennis $\times$ suaveolens) suavis $F_{1}$, einjährig, auf der Höhe der Blüte, 6.8.16.

1915 wurden nur 12 Individuen ausgepflanzt, die alle vollkommen gleichförmig waren. Von den in den Keimschalen überwinterten Keimpflanzen wurden 1916 wieder 23 Stück, ebenfalls ganz gleichförmig, in den Garten gebracht. Auch unter den kleinen Rosetten in den Keimschalen waren keine Unterschiede zu bemerken. Soweit sich nach der Erinnerung und nach Herbarmaterial urteilen läbt, stimmten die drei aus de Vriesschen Samen erzogenen $F_{4}$ und $F_{5}$-Individuen (vergl. oben S. 123) mit der von mir hergestellten Kreuzung ganz überein.

O. muricata $\times$ biennis. Ist bei meinen Materialien nur durch taube Samen dargestellt, wie schon im Sommer 1912 (vergl. Renner 1914, S. 124) und wieder 1914 ermittelt wurde. Der von de Vries erhaltene Bastard, allerdings $\mathrm{F}_{4}$ und $F_{5}$, aber mit $F_{1}$ wohl identisch, ist von muricata wie von biennis weit verschieden, viel schwächer patroklin als die reziproke Kreuzung. Stengel aufrecht, wie die Fruchtknoten rot punktiert. Blätter ziemlich schmal, rotnervig, rein und dunkel grün, Rosette sehr stark. Blüten kleiner als bei $O$. biennis, Krone blaßgelb. Früchte wegen mangelhafter Ausbildung der Samen

klein, dünn, bucklig. Samen zu $30-31 \%$ keimhaltig. - Ausführliche Beschreibung bei Davis, 1914. Zahlen siehe oben S. 123.

O. biennis $\times$ suaveolens (Fig. 6. 8, 11-15). Samen zu 74-83\% keimhaltig. Die Kreuzung ist gleich bei der Samenkeimung als zweiförmig 
zu erkennen (Fig. 11). Die Keimlinge haben teils grüne Kotyledonen und wachsen dann rasch zu Pflänzchen vom suaveolens-Typus heran, teils sind sie gelb, bleiben hinter den grünen weit zurück und bilden erst spät grüne, gezähnelte Primärblätter, wenn ·sie nicht schon vorher absterben. Der grüne Zwilling, der als suavis bezeichnet werden soll

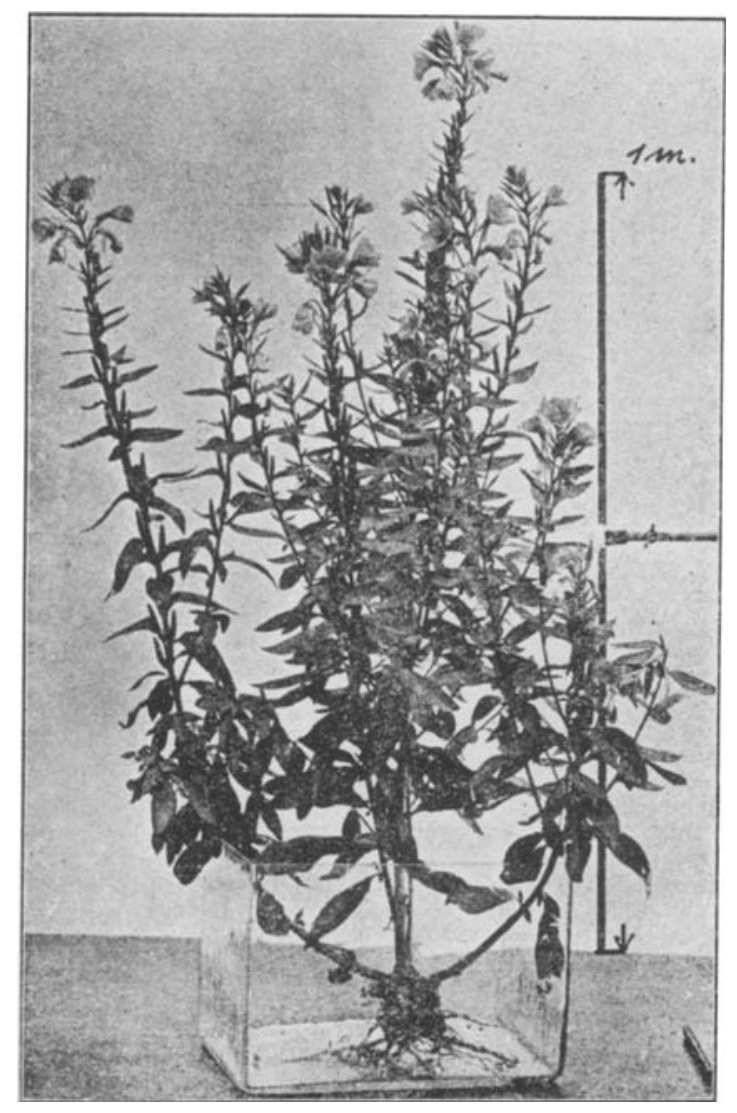

Fig. 13. O. (biennis $\times$ suaveolens) suavis $\mathrm{F}_{1}$, einjährig, gegen Ende der Blüte, September 1915.

(Fig. 6, 8, 12, 13), ist in der Mehrzahl der Individuen in keinem Zustand von $O$. suaveolens zu unterscheiden, wie an gleich alten Kulturen durch Monate hindurch geprüft wurde, also ausgesprochen einjährig, fast ohne Rosette, von buschigem Wuchs, am Stengel unten rot überlaufen, bis $145 \mathrm{~cm}$ hoch, breitblättrig, weißnervig, fein behaart, die Kronblätter 
sind schwefelgelb, 35-38 mm lang, die Früchte lang und schlank (Fig. 8), die Samen zu 33-36\% keimhaltig, dickschalig. Der schwache gelbe Zwilling, flava genannt (Fig. 14, 15), wächst sehr langsam, ist klein, niedrig, bis $65 \mathrm{~cm}$ hoch, ganz ohne Rosette, dauernd gelblich grün, am Stengel mit abstehenden steifen Haaren bestreut; sonst sehr schwach

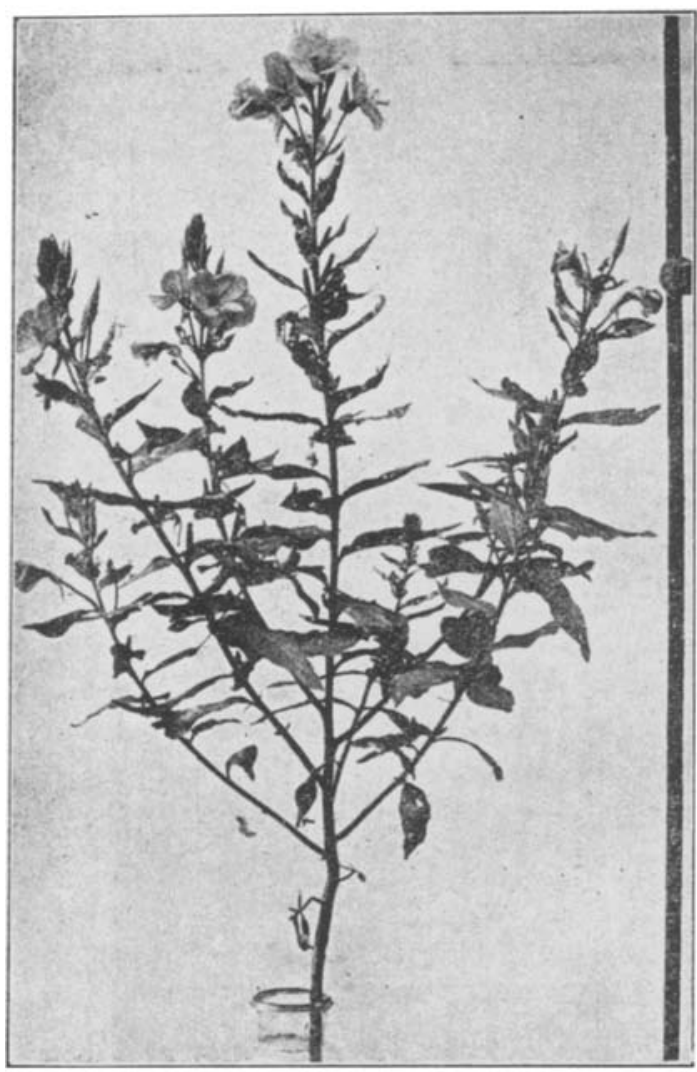

Fig. 14. O.(biennis $\times$ suaveolens) flava $\mathrm{F}_{1}$, einjährig, verhältnismäbig kräftiges Individuum, 16. 8. 16.

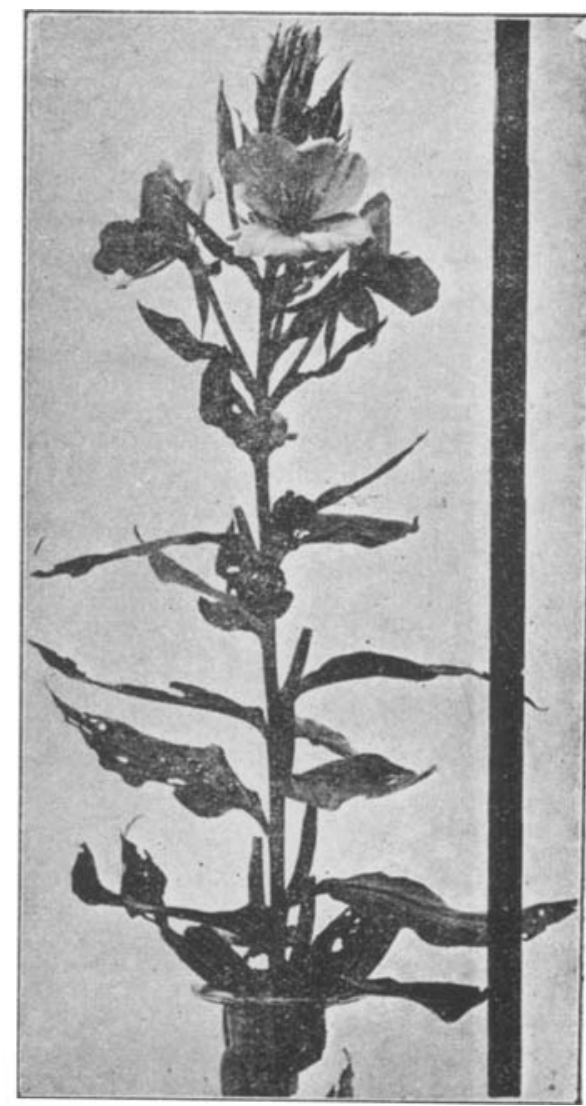

Fig. 10. O. (biennis $\times$ suaveolens) fava $\mathrm{F}_{1}$, einjährig, 13.8.16.

und fein behaart, hat dünne, breite, glatte, fast ganzrandige, schwach aber doch deutlich rotnervige Blätter, sehr schlanke Blütenknospen mit sehr fein ausgezogenen Kelchzipfeln, kaum größere Blüten als O.biennis, blaßgelbe, $28 \mathrm{~mm}$ lange Kronblätter; der Griffel ist kurz wie bei beiden Eltern, die Antheren sind reich an Pollen, die Früchte dünn und lang, 
glänzend grün, sehr schwach und fein behaart, die Samen zu $61 \%$ keimhaltig, dünnschalig. Von der Nervenfarbe abgesehen ist der Zwilling flava von der Mutante lutescens aus O. suaveolens (vergl. oben S. 162) kanm zu unterschф̣iden; über den Wuchs, den die lutescens im Freiland annimmt, bin ich allerdings nicht unterrichtet, weil ich die beiden Exemplare der Mutante im Topf erzogen habe.

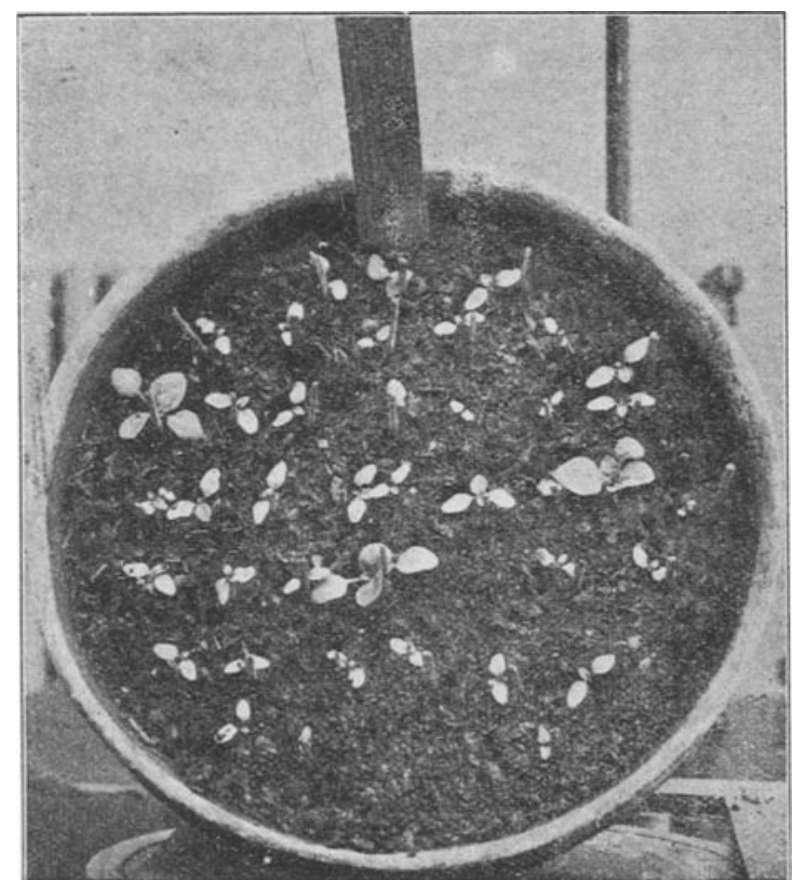

Fig. 16. O. (suaveolens $\times$ biennis) $\mathrm{F}_{1}$, junge Keimptlanzen. Die Schale enthält die spät gekeimten Individuen, unter dènen der Zwilling flava überwiegt. Es sind 3 kräftige grüne redempla (= biennis) und 37 schwache gelbe flava. Vergl Fig. 1.

Zahlen für biennis I $1 \times$ suaveolens I 5: 1915 wurden 197 Samen zum Keimen ausgelegt, von denen 171 keimten, 26 taub waren; 166 wurden in Schalen gepflanzt, davon blieben 13 aus, 120 Keimlinge waren grün, 33 gelb. Von den grünen wurden 108 Individuen zur Blüte erzogen, von denen 106 suavis und 2 Mutanten waren. Die Mutante a unverzweigt, schmalblättrig, kleinblütig, langfrüchtig; die Mutante b fast unverzweigt, mit ziemlich breiten, dicklichen Blättern, Blüten fast von der Größe der suavis, locker stehenden, kleinen, dünnen Früchten. Von den gelben Keimlingen wurden 12 Individuen zur Blüte erzogen; davon waren 11 flava, das zuletzt gekeimte Individuum wich ab durch schwach verzweigten, umfallenden Stengel, schmalere Blätter und ge- 
streckte Infloreszenz; eine flava überwinterte als Rosette und wurde 1916 zu Bestänbungen verwendet, weil sie früher zur Blüte kam als die einjährigen Individuen: fava Nr. 13. 1916 wurden wieder 100 Samen ausgelegt, 78 gekeimt, 22 nicht gekeimt, taub. Von den gekeimten blieben 2 aus, 59 waren grün, 17 gelb. Von den grünen wurden 51 zur Blüte erzogen; alle waren suavis, bis auf ein Individuum, das zwischen suaveolens und biennis die Mitte hielt, mit breiten, derben, blab rotnervigen Blättern, rauher Behaarung, kleinen, wie die Kelchzipfel rot gespitzten Brakteen, kurzen Früchten. Von den gelben Keimlingen kamen 12 als flava zur Blüte.

Im ganzen kommen also auf 179 grüne Keimlinge, die zur Hauptsache suavis sind, 50 gelbe $(22 \%)$, die fast alle, soweit sie genügend weit erwachsen, flava geben. Dazu sind die 48 tauben und die 15 ausgebliebenen Samen zu berücksichtigen, über deren genotypische Beschaffenheit wir nichts wissen.

O. suaveolens $\times$ biennis. Samen zu $73-88 \%$ gesund. Bei der Keimung als zweiförmig zu erkennen (Fig. 1, 16) wie die reziproke Kreuzung. Die grünen Keimlinge geben den Zwilling redempta ${ }^{1}$ ), der in keinem Zustand von der O. biennis zu unterscheiden ist (Fig. 3, 8), mächtige Blattrosetten bildet, einjährig $110 \mathrm{~cm}$, zweijährig $150 \mathrm{~cm}$ hoch wird, und rotnervige Blätter, rauh behaarte Früchte (Fig. 8) und zu $70 \%$ keimhaltige Samen hat. Der andere Zwilling ist mit der flava aus der reziproken Kreuzung identisch, höchstens etwas kräftiger, niedrig, bis $65 \mathrm{~cm}$ hoch, gelblich, schwach rotnervig.

Zahlen für $O$. suaveolens I $4 \times$ biennis I 1 , hergestellt 1914, gekeimt 1915: 134 Samen gekeimt, 30 taub. Ausgepflanzt 130, davon 26 grïn, 100 gelb, 4 ausgeblieben. Die grünen Sämlinge keimten zur Hauptsache vor den gelben, vergl. S. 129. Von der redempla kamen im Sommer 191517 Individuen zur Blüte, 8 blieben Rosetten, die im folgenden Jahr blühten. Von der flava wurden 54 zur Blüte erzogen. - 1916 wurden wieder 6 redempta und 7 flava aufgezogen; die Keimlinge sind nicht ausgezählt worden.

Bemerkenswert ist, daß bei der Kreuzung $O$. suaveolens $\times$ biennis die gelben flava-Keimlinge gegenüber der grünen redempta bedeutend in der Überzahl sind, während bei der reziproken Kreuzung das Zahlenverhältnis zwischen gelb und grün umgekehrt ist.

O. Lamarckiana $\times$ muricata (Fig. 17, 18). Samen zu $91-98 \%$ keimfähig, nur im oberen Teil der kleinen Früchte (vergl. oben S. 146). Die Keimpflanzen sind teils gesund und grün, teils gehen sie mit winzigen rein weißen Kotyledonen rasch zugrunde. Auch die grünen Pflanzen sind schwach, ausgeprägt patroklin. Stengel niedrig, bis $80 \mathrm{~cm}$ hoch, verzweigt, schon lange vor der Blüte nickend, tief rosenrot überlaufen, fein behaart, oben wie die Fruchtknoten spärlich und fein rot getupft. Blätter sehr lang und schmal, bläulichgrün, zart rotnervig, fein behaart.

1) Über die Wahl des Namens vergl. unten S. 236 . 
Blüten von der Form der muricata, doch beträchtlich größer. Kelch tiefrosenrot mit 8 schmalen grünen Streifen und dünnen grünen Zipfelspitzen. Kronblätter satt gelb, $20 \mathrm{~mm}$ lang. Narben an den späteren Blüten über den Antheren. Antheren ziemlich reich an Pollen. Fruchtähren locker, Früchte klein und dünn, zuerst rot überlaufen, später

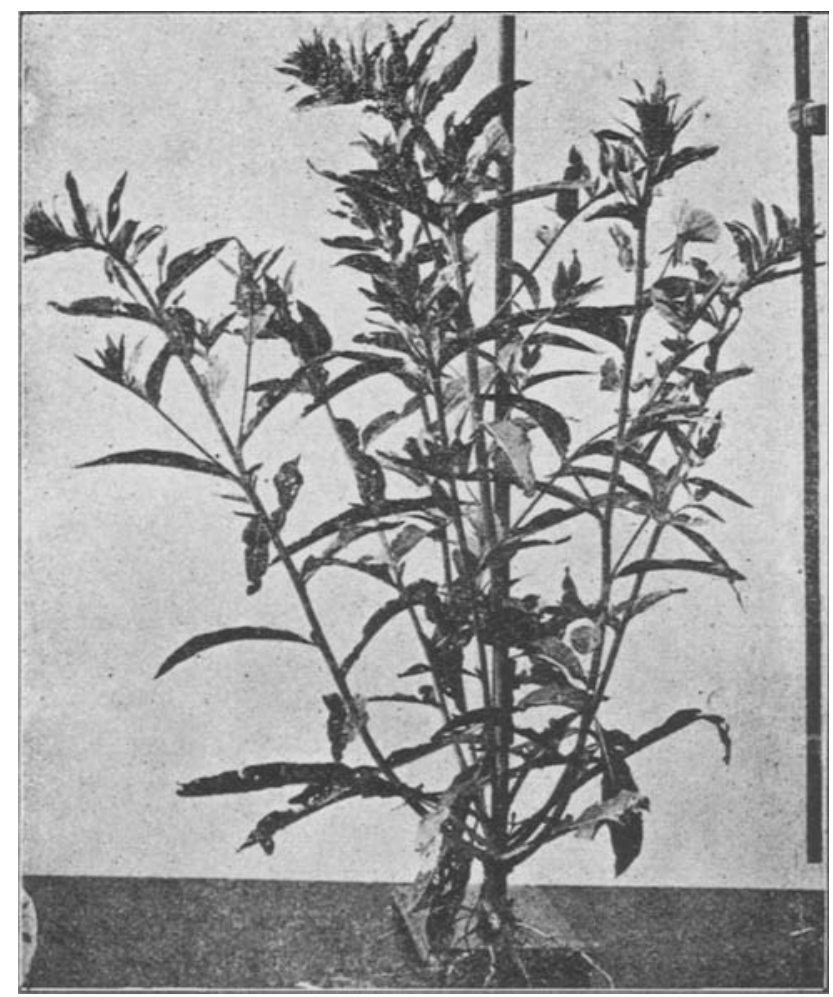

Fig. 17. O. (Lamarckiana $\times$ muricata) gracilis, einjährig, im Beginn der Blüte, 13. 8. 16.

auffallend weißlich gestreift. Samen bei Selbstbestäubung alle taub, wie bei de Vries.

Zablen für $O$. Lamarckiana H.-N. weiBnervig A I $3 \times$ muricata II, hergestellt 1914, gekeimt 1915, blühend 1916 nach Überwinterung im Topf: 51 Samen gekeimt, 5 nicht gekeimt, davon 3 tanb, 2 mit Embryo. Die Zahl der weiben Keimlinge ist nicht aufgezeichnet worden. - $O$. Lamarckiana A I $31 \times$ muricata III, hergestellt 1915, ansgelegt 1916: 25 Samen gekeimt, 52 nicht gekeimt, doch die meisten mit Embryo; die Keimung erfolgte sehr langsam, bei einem andern Material war überhaupt keine 
Keimung zu erzielen. Von den gekeimten 4 ausgeblieben, 8 weiß, 13 grün. Wenn die ausgebliebenen zu den weißen gehören, sind weibe und grüne Keimlinge in gleicher Zahl vorhanden. - 12 zur Blüte erzogene Pflanzen von der ersten und 13 von der zweiten Kreuzung waren gleichförmig.

O. muricata $\times$ Lamarckiana. Samen zu (48-) $80 \%$ keimhaltig. Spaltet wie bei de Vries in die Zwillinge laeta und velutina (Fig. 19).

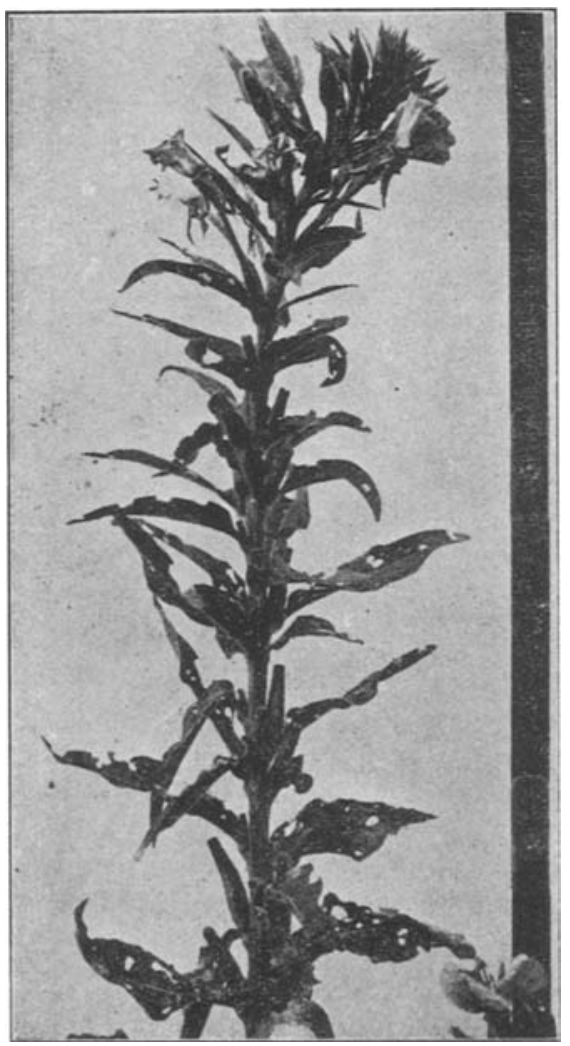

Fig. 18. O. (Lamarckiana $\times$ muricala) gracilis, einjälrig, September 1916.

Beide Zwillinge haben steif aufrechte Stengel, schmale rotnervige Blätter, am Stengel und an den Fruchtknoten steife Haare auf starken roten Polstern (also kräftige rote Tupfen), $28 \mathrm{~mm}$ lange, oben ausgerandete, an der entfalteten Blüte mit den Rändern sich nicht deckende, sehr blaß gelbe Kronblätter. Unterschiede zwischen den Zwillingen: Die laeta wächst sehr hoch, bis $170 \mathrm{~cm}$; die Brakteen sind dauernd aufgerichtet, die Blütenknospen schlank; die Blütenkelche sind erst gegen Ende der Blütezeit am Grund schwach rötlich angelaufen, sonst grün, die Früchte sind kurze Zeit schwach rot gestreift, die Narben liegen über den Antheren, die Antheren sind sehr arm an Pollen; mit dem eigenen Pollen werden keine Samen angesetzt. Die velutina bleibt niedriger, bis $110 \mathrm{~cm}$ hoch, und schwächer, ihre Blätter sind schmäler, die Brakteen nach dem Verblühen zurïckgebogen, die Blätenknospen dick; der

Kelch ist fast ganz rot, nur am Mittelnerv und an dẹ Rändern der Zipfel grïn, die Früchte sind kräftig rotstreifig, am Grund dick, kegelförmig verjüngt, die Narben liegen zwischen den pollenreichen Antheren; mit dem eigenen Pollen werden Samen ảngesetzt, die zu $43 \%$ keimhaltig sind. - Die Keimlinge der $Z$ willinge sind, wenn sie einige Blätter gebildet haben, merklich doch nicht auffallend verschieden; die der velutina haben größere, deutlich zweizähnige Kotyledonen und gelb- 
lichgrüne, zur Gelbstreifigkeit neigende, ziemlich lang gestielte, kaum gezähnelte Primärblätter, die der laeta haben kleinere, dunkler grüne, deutlicher gezähnte, rosettenartig gedrängte Primärblätter.

Zahlen für O. muricata III $1 \times$ Lamarckiana H.N. weifnervig A I 31, hergestellt 1915, gesät 1916: von 86 großen Samen keimten 77, die 9 übrigen waren taub;

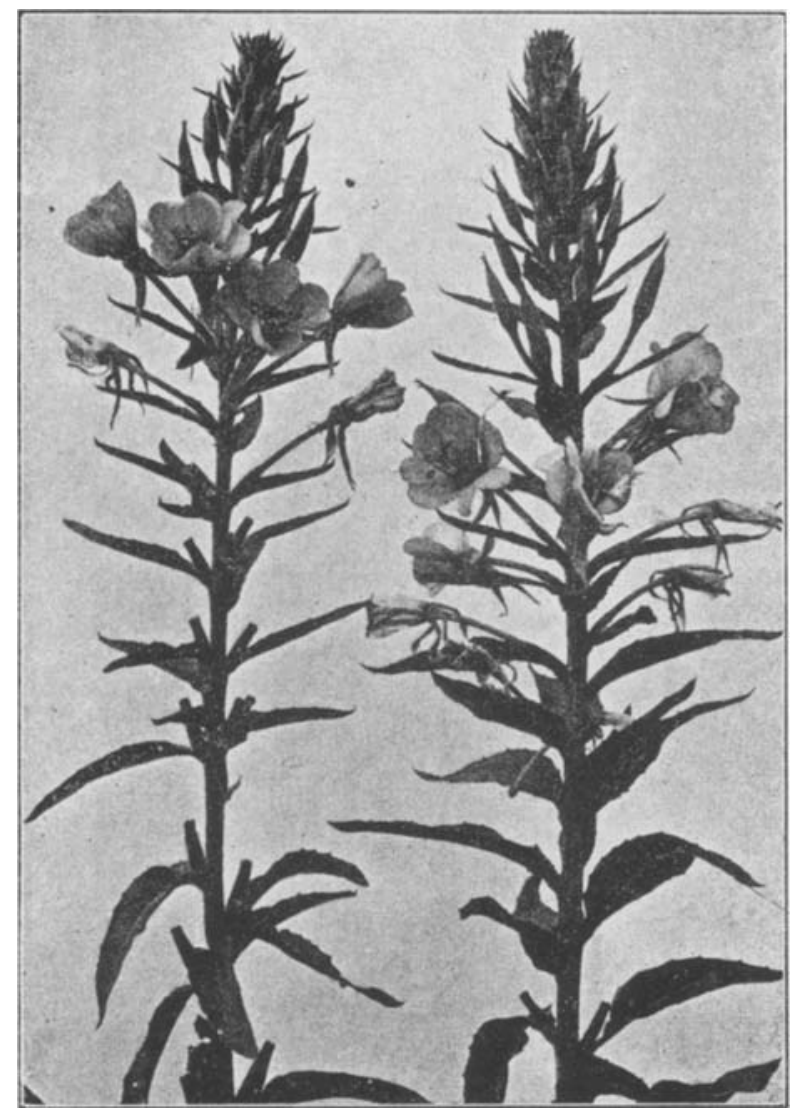

Fig. 19. O. (muricata $\times$ Lamarckiana) $\mathrm{F}_{1}$, einjährig, auf der Höhe der Blüte, 6. 8. 16. Rechts laeta, links velutina.

von 66 zur Blüte gebrachten Individuen waren 17 laeta, 49 velutina; von 4 langsam wachsenden, im Topf Rosetten bleibenden Pflanzen waren 2 laeta und 2 velutina; also zusammen 19 laeta und 51 velutina.

O. Lamarckiana $\times$ biennis (Fig. 20; vergl. auch Fig. 21, 22, 23, 38,45 ). Samen zu 46-55\% gesund bei der schwedischen, zu $79 \%$ bei der de Vriesschen Rasse. Die Kreuzung soll nach de Vries der 
biennis zum Verwechseln ähnlich sein ${ }^{1}$, auch Heribert-Nilsson ${ }^{2}$ ) findet sie stark patroklin, mir erscheint der Bastard ziemlich intermediär zwischen den Eltern, in wichtigen Charakteren eher der $\hat{O}$. Lamarckiana ähnelnd. Er ist bei mir immer einförmig wie bei den beiden genannten Autoren, nicht mehrförmig wie bei $\mathrm{MacDougal}^{3}$ ). Ich will die Bastardform zum Unterschied von anderen fallax nennen, weil sie de Vries und für längere Zeit auch mich auf Irrwege geführt hat; zugleich soll der Name die nahe Beziehung zu der von de Vries laxa genannten Form andenten (vergl. unten S. 229). Auf O. Lamarckiana weisen folgende Merkmale: Die Keimpflanzen und jungen Rosetten sind von denen der Mutter nicht zu unterscheiden; der Stengel hat starke niederliegendaufsteigende Grundäste, die leicht abbrechen (vergl. Fig. 38, 45), die Blätter sind bucklig ${ }^{4}$ ), die Brakteen etwas rinnig ${ }^{5}$ ), Stengel und Fruchtknoten reichlich rot getupft, Kelche und Früchte breit und dunkel rotstreifig, noch stärker gefärbt als die der O. Lamarekiana; die Staubblätter sind reich an Pollen. Auf O. biennis weisende Merkmale: Stengel niedrig, bis $110 \mathrm{~cm}$ hoch, Blätter immer rotnervig, auch wenn die verwendete $O$. Lamarckiana weißnervig war, Stengel und Früchte rauh behaart, Brakteen ziemlich klein, Narben zwischen den Antheren. Intermediäre Merkmale: Früchte kurz und dick, etwas länger als bei $O$. Lamarckiana, kürzer als bei 0 . biennis; Kronblätter $30-35 \mathrm{~mm}$ lang, also in der Größe viel näher denen des Vaters als denen der Mutter; Spitzen der Kelchzipfel oft leicht rötlich, doch manchmal fast rein grün. Besondere Eigentümlichkeiten, die sich bei keinem der Eltern finden: Der Mittelstamm der Infloreszenz bleibt kurz, darunter gehen starke spreizende Äste ab (vergl. Fig. 23); die Fruchtähren sind sehr dicht (vergl. Fig. 21 links); die Kronblätter dunkler gelb als selbst bei $O$. biennis. Samen zu $20-38 \%$ keimhaltig.

Zahlen für $O$. Lamarckiana Vries I 1 (weißnervig) $\times$ biennis I 1 , hergestellt 1914, gesät 1916: Von 113 Samen keimten 88 ; 25 blieben ungekeimt, alle waren taub. Von 80 blühenden Pflanzen waren 79 gleichförmig fallax, eine war eine lata-Mutante, rotnervig wie alle anderen. - O. Lamarckiana Heribert-Nilsson A I 1 (weißnervig) $\times$ biennis I 1: 67 Samen gekeimt, 43 nicht gekeimt, davon 42 taub, 1 mit Embryo; 61 Pfanzen blühend, gleichförmig, fallax, dem Bastard aus der de Vriesschen Sippe ganz gleich. - O. Lamarckiana Heribert-Nilsson A I 31 (weißnervig, zweijährig)

5) de Vries, Gruppenw. Artb., S. 158.

3) Heribert-Nilsson, 1912, S. 185.

3) MacDougal (1915, S. 17) hat sicher eine ganz andere "biennis" verwendet.

4) Vergl. die Fig. 72, de Vries, a. a. O., S. 1.58.

5) Fig. 70 und 71 , de Vries, S. 157. 
$\times$ biennis I 12, hergestellt 1915, gesät 1916: 76 Samen gekeimt, 47 nicht gekeimt, alle obne Embryo; 72 Pflanzen blühend, gleichförmig, fallax.

0 . biennis $\times$ Lamarckiana-weißnervig. Samen bei Verwendung der schwedischen Rasse zu $63 \%$ gesund. Während de Vries aus der Kreuzung immer die Zwillinge laeta und velutina erhielt wie aus der Kreuzung $O$. muricata $\times$ Lamarckiana und auch ich aus $O$. biennis $\times$

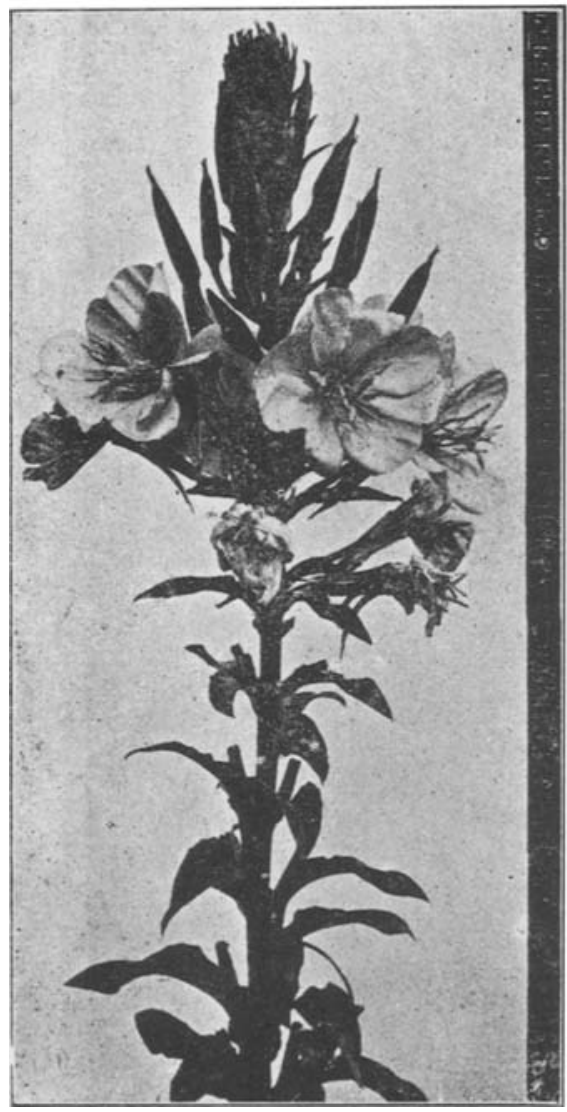

Fig. 20. O. (Lamarckiana Her.-Nilsson weißnervig $\times$ biennis) fallax $\mathrm{F}_{1}$, einjährig, 27. 7. 16.

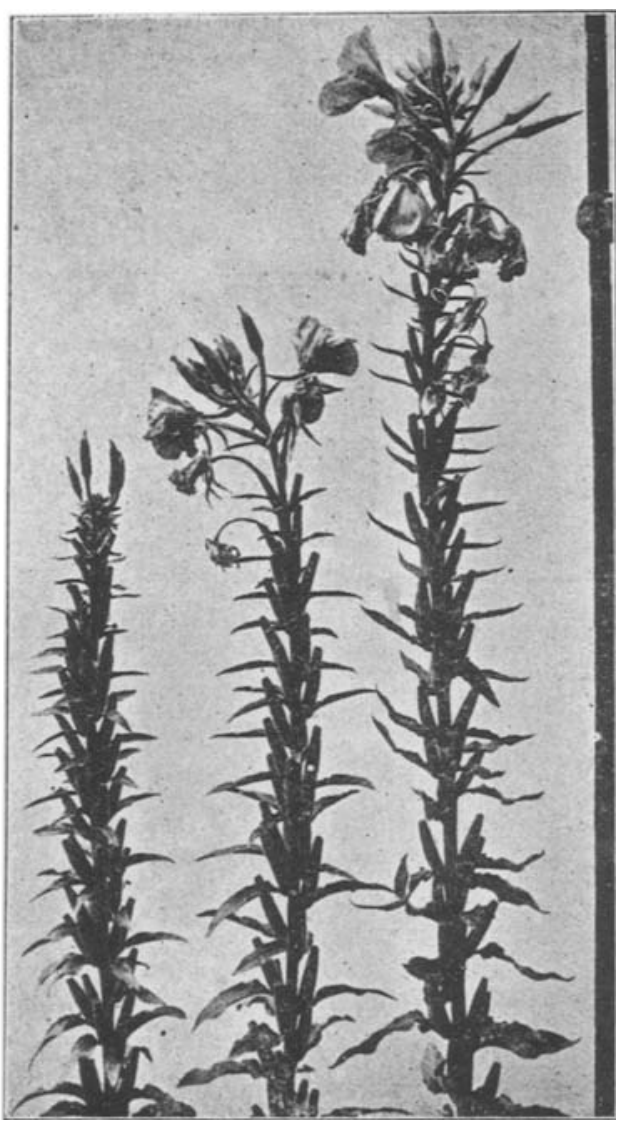

Fig. 21. O. (biennis $\times$ Lamarchiana de Vries) $\boldsymbol{F}_{1}$, einjährig, 13. 8. 16. Die Drillinge gegen Ende der Blütezeit, ungefähr im natürlichen Verhältnis ihrer Höhe aufgenommen. Rechts die hohe laeta noch mit zahlreichen Blütenknospen, links die niedrige fallax mit schon gehemmter Infloreszenzspitze und dichter Fruchtähre, in der Mitte velutina. 
Lamarckiana X (vergl. S. 1) nur die Zwillinge erzog, liefert mir die Rasse von biennis, die ich seit 1914 verwende, immer Drillinge (Fig. 21), nämlich außer laeta und velutina noch eine Form, die mit dem reziproken Bastard O. (Lamarckiana $\times$ biennis) identisch, also eine fallax ist. Die drei Formen sind schon in den Keimschalen mit Sicherheit zu

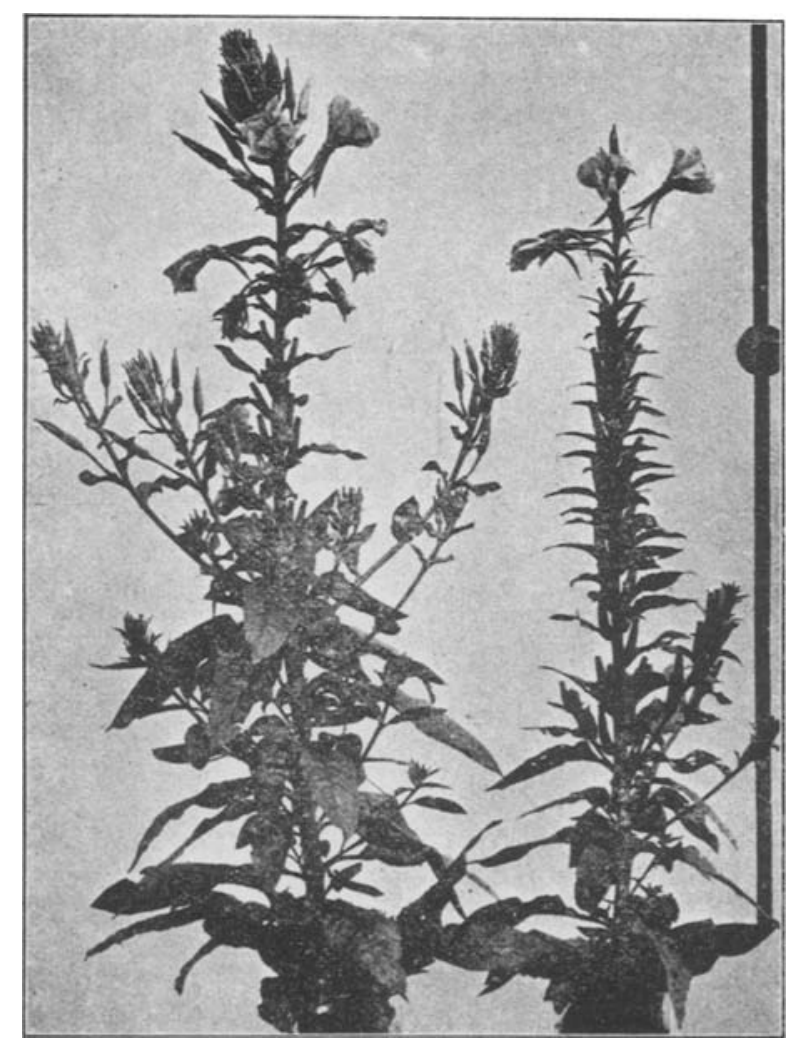

Fig. 22. O. (biennis $\times$ Lamarckiana Her.-Nilss. rotnervig) $\mathbf{F}_{1}$ fallax einjährig, 4. 9. 15. Die Buckligkeit der Stengelblätter ist deutlich.

erkennen, wenn die Pflänzchen einige Primärblätter gebildet haben. Die fallax keimt wie Lamarckiana, die laeta ist von gleich alter biennis nicht zu unterscheiden, die velutina hat ihren besonderen Typus und ist an den Primärblättern häufig gelb gestreift; vergl. die Beschreibung der Keimlingstypen S.158. Im Rosettenzustand hat die fallax breite, bucklige, rotnervige Blätter, die laeta breite, glatte, weilnervige, und 
die velutina schmälere, glatte, weißnervige, stärker behaarte Blätter. Mit dem Treiben der Stengel werden die Unterschiede immer augenfälliger; nur die unteren Stengelblätter der velutina zeigen häufig schwach rosenrote Färbung der Mittelnerven, ohne je dem tiefen blaustichigen Rot der fallax-Nerven nahezukommen. Die fallax (Fig. 21, 22, 23, 38, 39) braucht nicht noch einmal beschrieben zu werden; Stengelhöhe wieder bis $110 \mathrm{~cm}$ bezw. bei zweijähriger Kultur bis $150 \mathrm{~cm}$; Samen zu 26-27\% keimhaltig. Die laeta (Fig. 24) hat von der Mutter biennis: die Art der Verzweigung, die glatten Blätter, die etwas rauhe Behaarung, das Fehlen der roten Tupfen am Stengel und an den Fruchtknoten, die grünen Kelche und Früchte, die gerade abgestutzten Infloreszenzspitzen; vom Vater Lamarckiana: die weißen Blattnerven, die langen Griffel, die die Narben wenigstens an den späteren Blüten fast gánz über die Antheren emporheben; die Blütenknospen sind schlanker als bei biennis, aber nicht ganz so schlank wie bei $L a-$ marckiana; die Blüten sind ziemlich groß, die Kronblätter $35 \mathrm{~mm}$ lang, hellgelb; die Antheren sind groB, aber noch ärmer an Pollen als die der biennis; die Brakteen sind

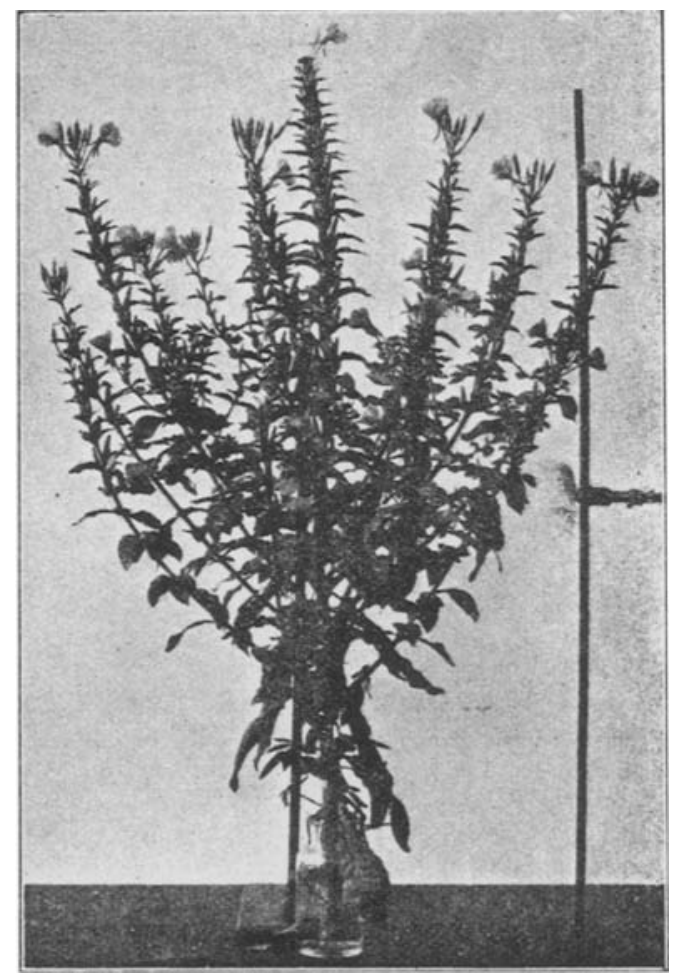

Fig. 23. O. (biennis $\times$ Lamarckiana Her. - Nilss. rotnervig) fallax $\mathrm{F}_{2}$, einjährig, 16.8.16, ohne die starken Grundäste erzogen (vergl. Fig. 38, 45). Der Hauptsproß ist nicht viel höher als die Seitenäste, kaum über $1 \mathrm{~m}$ hoch, der Fruchtstand ist besonders am Hauptsproß sehr dicht. aufrecht, in der Form ähnlich denen der biemis, aber wellig und verdreht, die Spitzen der Brakteen an den jungen Blütenknospen ebenso wie die Spitzen der Kelchzipfel grün, nicht rot wie bei biennis; der Wuchs ist noch höher als bei der Lamarckiana (einjährig bis 155, zweijährig bis $190 \mathrm{~cm}$ ), die stärkeren Achsen rinnig-kantig; dië Frucht- 
ähren, besonders am Hauptstamm, sind sehr lang und schlank; die Früchte sind vielleicht etwas länger und schlanker noch als bei $O$. biennis, wie bei dieser grob behaart; die Samen zu 39-56\% keimhaltig. Alles in allem erscheint die laeta wie eine vergrößerte biennis mit weißen Blattnerven, grünen Kelchzipfel- und Brakteenspitzen, mittellangen Griffeln, schlankeren Fruchtähren, zahlreichen tauben Samen.

Die velutina (Fig. 24) ist von beiden Eltern weit verschieden; von der biennis hat sie die ganz zwischen den Antheren liegenden Narben, von der Lamarckiana die roten Tupfen am Stengel und an den Fruchtknoten, die braunroten, allerdings nicht sehr kräftigen Streifen am Kelch und an den Früchten, die weißen Blattnerven, die pollenreichen Antheren; die Knospen sind dick und plump, ganz anders gestaltet als bei beiden Eltern, die Kronblätter sind $35 \mathrm{~mm}$ lang, dunkler gelb als selbst bei biennis; die Brakteen sind zurückgeschlagen, oft rinnig; die Früchte sind lang und groß, vom dicken Grund schlank kegelförmig verjüngt, fein behaart; die Samen sind zu 16-37\% keimhaltig; Stengel und Blätter sind mit weichen Haaren dicht bedeckt; die Blätter sind beträchtlich schmäler als bei beiden Eltern; der Wuchs ist höher als bei biennis, aber meist etwas niedriger als bei Lamarckiana, beträchtlich niedriger als bei laeta (einjährig bis 130, zweijährig bis $170 \mathrm{~cm}$ hoch), die Achsen zylindrisch, nicht kantig, an den Infloreszenzspitzen zwischen den Blütenknospen purpurn. - Die aus den Beschreibungen zu entnehmenden Unterschiede zwischen laeta und velutina hat de Vries ausführlich geschildert. Wir legen besonderen Wert darauf, daß die beiden Bastardgeschwister außer in den von de Vries hervorgehobenen Merkmalen auch in der Anthokyanbildung sich unterscheiden. die laeta ohne Anthokyan in den Haarpolstern, am Kelch und an den Früchten, die velutina rot getnpft, mit roten Streifen an Kelchen und Früchten ${ }^{1}$ ). Die dritte Schwesterform, die fallax, hat dieselbe Pigmentierung wie die velutina, nur noch bedeutend kräftiger, und zudem die tiefroten Blattnerven, die der velutina abgehen.

1) Honing (S. 266) meint allerdings, daß die rote Färbung des Kelchs „für die laeta- und velutina-Frage von keiner Bedeutung" ist, "da nicht alle velutina - z. B jene von der biennis nicht - einen roten Kelch haben". Sein abweichender Befund dürfte einmal davon herrühren, daß das von ihm verwendete Lamarckiana-Material sehr schwache Anthokyanbildung am Kelch besaß; die Kelche waren hier ,gelbgrün, nur selten mit rötlicher Färbung“ (S. 266); andrerseits wahrscheinlich auch davon, dab er die spät gebildeten Blüten, an denen die Kelchfärbung oft erst deutlich wird, nicht untersucht hat. 
Zahlen für O. biennis II $1 \times$ Lamarckiana Vries II 1 , 1915 hergestellt, 1916 gesät: 47 Samen gekeimt, 11 nicht gekeimt, taub. Die velutina in den Keimschalen teilweise mit gelbstreifigen Blättern. Blühend 42 Individuen, davon 21 weißnervige laeta, 19 weiBnervige velutina, 2 rotnervige fallax. - O biennis II $5 \times$ Lamarckiana Vries II 2 , 1915 hergestellt, 1916 gesät: 70 Samen gekeimt, 27 nicht gekeimt, davon 1 mit

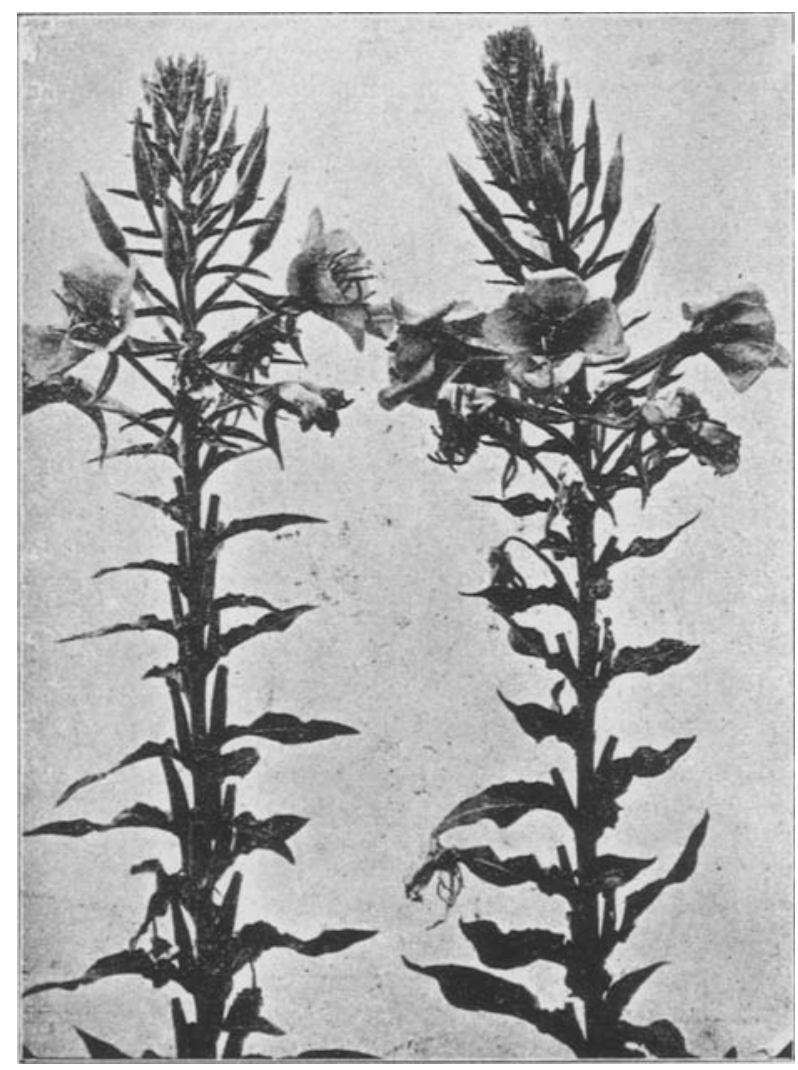

Fig. 24. O. (biennis $\times$ Lamarckiana) $\mathrm{F}_{1}$, einjährig, 29. 7. 16 . Rechts laeta, links velutina.

Embryo, 26 taub. Die velutina in den Keimschalen etwa zur Hälfte gelbstreifig. Blühend 63 Pflanzen, davon 27 weißnervige laeta, 32 weißnervige velutina, 4 rotnervige fallax.

O. biennis I $1 \times$ Lamarckiana Heribert-Nilsson A I 1, 1914 hergestellt, 1915 gesät: 132 Samen gekeimt, 60 nicht gekeimt, davon 55 taub, 5 mit Embryo. Blühend 1915 einjährig 63 Pflanzen, davon 9 weißnervige laeta, 37 weißnervige velutina, 17 rotnervige fallax. 1916 blühen zweijährig 31 Pflanzen, davon 8 weißnervige laeta, 7 weibnervige velutina, 16 rotnervige fallax; zusammen 17 laeta, 44 velutina, 33 fallax. 
O. biennis II $1 \Varangle$ Lamarchiana Heribert-Nilsson A I 31, 1915 hergestellt, 1916 gesät: 59 Samen gekeimt, 22 nicht gekeimt, davon 21 taub, 1 mit Embryo; von den gekeimten 9 ausgeblieben. Die velutina teilweise gelbstreifig. Blühend 46 Pflanzen, davon 7 weißnervige laela, 27 weißnervige velutina, 12 rotnervige fallax.

O. biennis II $2 \times$ Lamarckiana Heribert-Nilsson C II weiBnervig 1,1915 hergestellt, 1916 gesät: 75 Samen gekeimt, 30 nicht gekeimt, taub. Blühend 71 Pflanzen, davon 51 weiBnervige laeta, 19 weiBnervige velutina, die teilweise noch auf den Beeten an den unteren Blättern gelbe Ränder zeigen, 1 rotnervige fallax. Unter den velutina sind zwei Individuen mit breiteren, bellgrünen Blättern und kleineren, blasseren Blumenkronen, sie stimmen mit dem Bastard subvelutina aus biennis $\times$ rubrinervis überein (vergl. S. 194) und sind wohl aus Pollenzellen hervorgegangen, die nach rubrinervis mutiert hatten.

Von den Drillingen fängt die velutina zuerst zu blühen an, die laeta zuletzt. 1916 begann die velutina am 1. Juli mit der Blüte, die fallax am 6. Juli, die laeta am 8. Juli. In der Entfaltung der Blütenknospen am Abend ist die fallax (gleichgültig aus welcher Kombination gewonnen, bei sämtlichen später als fallax aufgeführten Formen) allen übrigen Formen voran, dafür welken die Knospen am Morgen auch am frühesten; von den Drillingen folgt die velutina, die laeta macht den SchluB. An manchen Juli-Abenden waren alle fallax-Beete und vereinzelten fallax-Individuen eine halbe bis eine ganze Stunde lang mit ihren geöffneten Blïten unter den übrigen noch nicht aufgeblühten Formen weithin sichtbar.

O. biennis $\times$ Lamarckiana-rotnervig. Die Kreuzung liefert fünf verschiedene Formen, nämlich laeta weiß- und rotnervig; velutina weißund rotnervig, fallax rotnervig. Das Ergebnis hat nichts Überraschendes, weil Heribert-Nilss on gezeigt hat, daß die rotnervigen LamarckianaIndividuen im Nervenfarbenfaktor immer heterozygotisch sind. Die rote Farbe der Blattnerven hat bei laeta und velutina einen schwachen Stich ins Gelbliche, in Gegensatz zu dem purpurnen, blanstichigen Rot der fallax-Nerven. Die Nervenfarbe ist schon an den Blattrosetten deutlich zu erkennen, gegen Ende der Blüte blaßt das Rot wie überall aus. Die Rotfärbung der Blütenkelche ist bei der rotnervigen velutina intensiver als bei der weißnervigen; die Blätter scheinen bei der rotnervigen laeta etwas breiter zll sein als bei der weißnervigen. Kelche und Früchte der laeta sind auch dann grün, wenn die Nerven rot gefärbt sind.

Zahlen für biennis I $1 \times$ Lamarckiana Heribert-Nilsson B I rotnervig 1 , hergestellt 1914, gesät 1915: 142 Samen gekeimt, 78 nicht gekeimt, davon 67 taub, 11 mit Embryo. Blühend 1915 einjährig 128 Pflanzen, davon 19 laeta, und zwar 6 rotnervige, 9 weißnervige, 4 fragliche (die Auszählung ist zu spät im Jahr vorgenommen worden), 91 velutina, und zwar 33 rotnervige, 47 weißnervige, 11 fragliche, endlich 18 rotnervige fallax. Unter den velutina waren (wie auch auf einigen anderen Beeten) einige schwache 
Individuen mit dünnem, längs aufplatzendem, umfallendem Stengel und sehr schmalen Blättern, vielleicht nur kranke Pflanzen. 1916 blühten zweijährig noch 9 Pflanzen, davon 1 rotnervige lata, 1 rotnervige fallax, 2 rotnervige velutiná, 4 weißnervige velutina, 1 weißnervige velutina-Mutante, niedrig, reich verzweigt, mit kleinen schmalen Blättern und kleinen Bläten. Zusammen traten auf: 20 laeta, 98 velutina, 19 fallax.

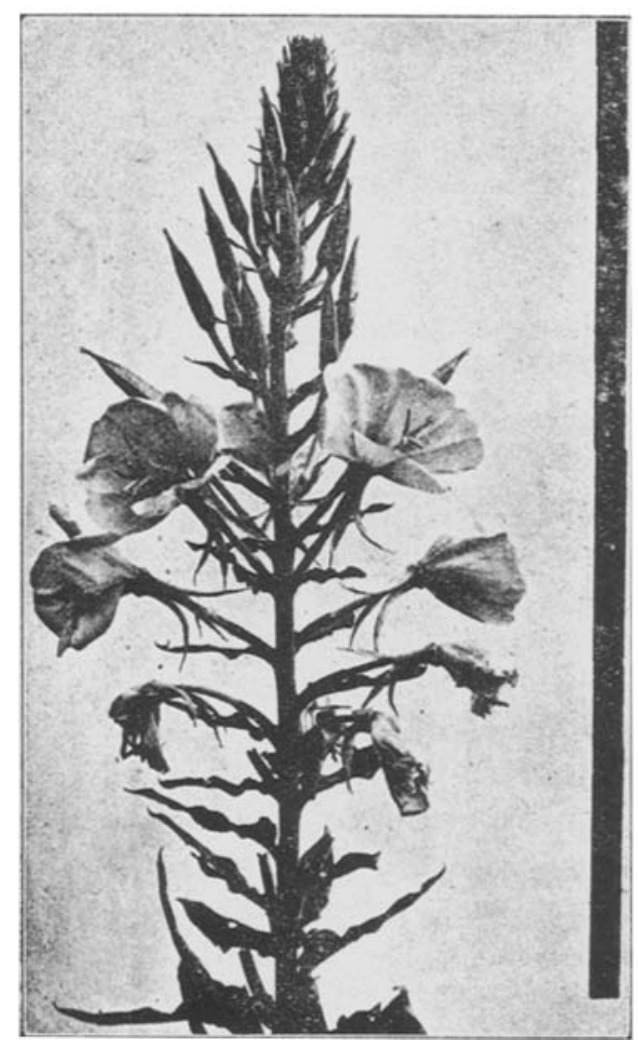

Fig. 25. O. (Lamarckiana $\times$ suaveolens) $\mathrm{F}_{1}$ suavi-laeta, zweijährig, auf der Höhe der Blüte, 26. 7. 16.

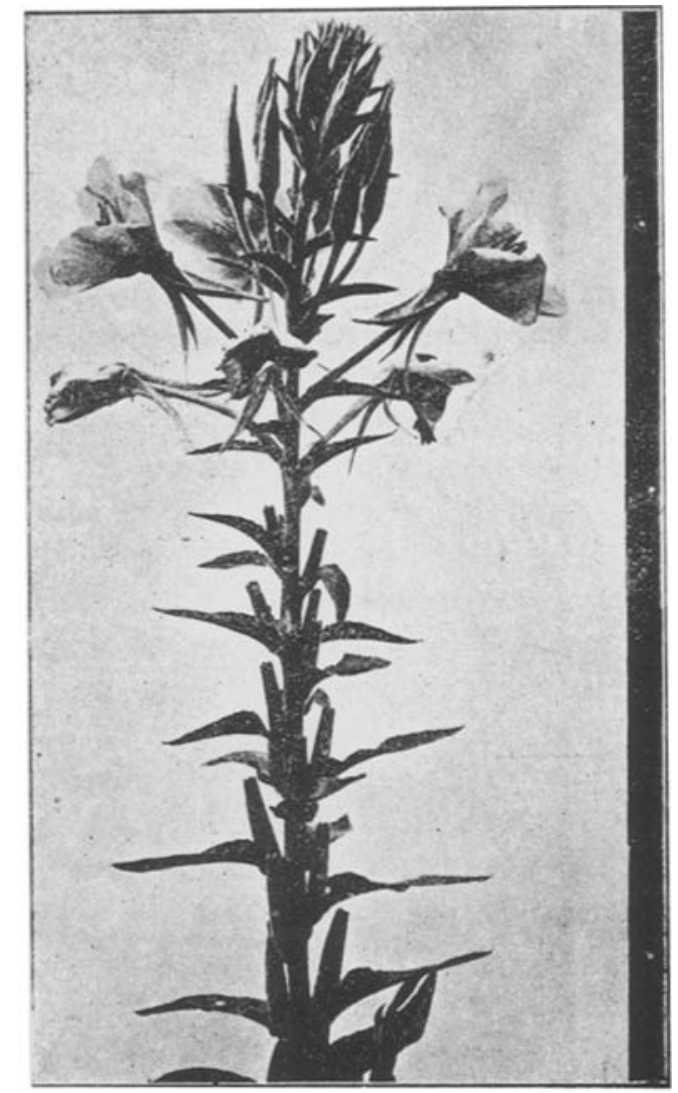

Fig. 26. $\quad 0$. (Lamarckiana $\times$ suaveolens) $\mathrm{F}_{1}$ suavi-velutina, zweijährig, auf der Höhe der Blüte, 24. 7. 16.

O. Lamarckiana (weißnervig) $\times$ suaveolens. Samen zu $92-95 \%$ gesund, Früchte reich an Samen, sehr groß und dick. Es treten Zwillinge auf, die mit laeta und velutina identifiziert werden können, beide deutlich an die flava aus suaveolens $\times$ biennis und reziprok erinnern, aber sehr kräftige, hohe, reich verzweigte Pflanzen werden. Die Rosettenblätter (die Pflanzen wurden im Herbst ausgesetzt, zweijährig erzogen) 
sind bei beiden Zwillingen stark bucklig, mehr oder weniger gelbgrün, die der laeta breiter, auffallend rot gefleckt, die der velutina schmäler, wenig gefleckt. Erwachsene laeta (Fig. 25): Blätter breit, dunkelgrün, weißnervig, bucklig, Stengel hoch, einjährig 140, zweijährig $200 \mathrm{~cm}$ lang, oben kantig, unten rot überlaufen, fein behaart, wie die Fruchtknoten ohne rote Tupfen. Blüten- und Fruchtstände lang und schlank. Brakteen aufgerichtet. Knospen schlank mit fein ausgezogenen Kelchzipfeln, wie bei flava. Kelch grün. Krone sattgelb, flach glockenförmig (wie bei $O$. Lamarckiana), früh am Abend sich öfnend und lange am Tag offen bleibend, Kronblätter $38 \mathrm{~mm}$ lang. Narben zuerst fast ganz zwischen den Antheren, an den späteren Blüten noch zur Hälfte von den Antheren gedeckt. Antheren ziemlich reich an Pollen. Früchte glänzend grün, nicht rotstreifig, fein behaart.

Erwachsene velutina (Fig. 26): Stengel etwas niedriger, einjährig 130 , zweijährig $150 \mathrm{~cm}$ hoch, weit hinauf rot überlaufen, rund, fein behaart, wie die Fruchtknoten reichlich rot getupft, mit starken, niederliegend-aufsteigenden, leicht abbrechenden Grundästen. Blätter sehr breit, sehr dunkel grün, weißnervig. Die Blüte beginnt früher als bei der laeta. Brakteen groß, aus breitem Grund zugespitzt, ähnlich geformt wie bei O. suaveolens, zurückgebogen, oft rinnig, Knospen etwas dicker als bei der laeta, aber noch immer recht schlank, die Kelchzipfel ebenfalls ziemlich fein zugespitzt. Kelch breit rotstreifig. Krone dunkelgelb, radförmig, Kronblätter $38 \mathrm{~mm}$ lang. Narben zwischen den Antheren. Antheren reich an Pollen. Früchte mit starken roten Streifen, sonst glänzend grün, am Grund ziemlich dick, fein behaart. Fruchtähren ziemlich dicht, kürzer als bei der laeta. - In Wuchs, Behaarung, Gestalt und Farbe der Blütenknospen erinnert diese velutina mehr an die fallax als an die velutina aus O. biennis.

Als Abweicher traten unter den zuletzt gekeimten Individuen auf: ein schwaches, fast kahles, graulichgrïnes, nicht zur Blüte gelangendes; zwei einander vollkommen gleiche, velutina-artige, an die blanda aus $O$. rubrinervis $\times$ Lamarckiana (vergl. unten S. 195) erinnernde Individuen, die wahrscheinlich aus nach rubrinervis mutierten Eizellen der $O$. Lamarckiana hervorgegangen waren; Stengel rot angelaufen, mit niederliegenden starken Grundästen, wie die Fruchtknoten stark getupft, Blätter mittelbreit, gar nicht bucklig, weich behaart, die unteren mit rötlichem Mittelnerv, Blütenknospen groß und dick, breit rotstreifig, Kelchzipfel lang zugespitzt, ziemlich dicht und lang abstehend behaart, Kronen groß, tiefgelb, Narben zwischen den Antheren, Früchte groß, 
dick, breit rotstreifig, alle Organe ziemlich brüchig, doch nicht so wie bei blanda.

Zahlen für O. Lamarckiana H.-N. A I $2 \times$ suaveolens I 5, hergestellt 1914, gesät Juli 1915: 317 Samen gekeimt, 6 nicht gekeimt, davon 2 mit Embryo, 4 leer. Die Keimpflanzen wurden größtenteils im Herbst in den Garten gebracht und dort überwintert, wobei viele zugrunde gingen; ein kleiner Teil wurde erst im Frühjahr 1916 ansgepflanzt,

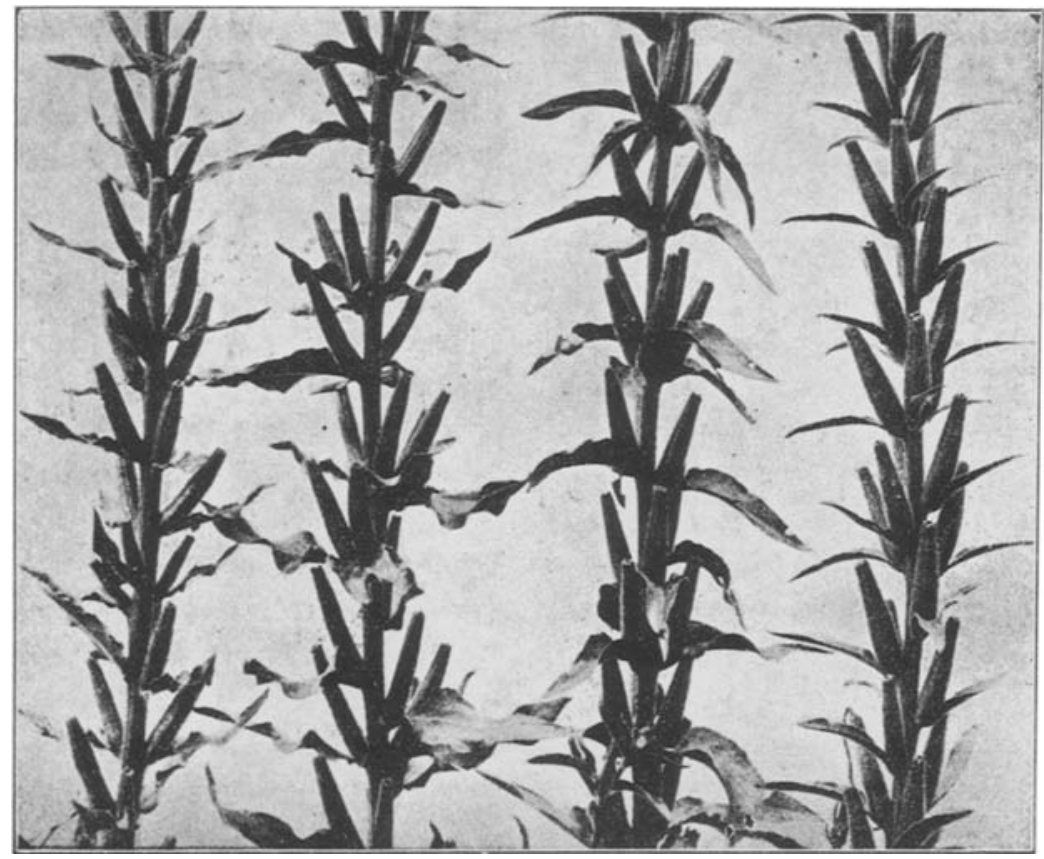

Fig. 27. O. (suaveolens $\times$ Lamarckiana) $\mathrm{F}_{1}$, zweijährig, 13. 8. 16. Untere Früchte der Vierlinge. Von links nach rechts: bienni-laeta, suavi-laeta, suavivelutina, bienni-velutina. Die Brakteen sind bei den suavi-Formen viel größer als bei den bienni-Formen, bei beiden laetae stark wellig und gedreht. Die Friichte sind bei den velutinae schlank kegelförmig, bei den laetae mehr zylindrisch; bei den bienni-Formen, besonders der velutina, sind sie kräftig behaart.

und die betreffenden Individuen sind oben als "einjährig" bezeichnet, weil sich derart behandelte Pflanzen nach meinen sonstigen Erfahrungen wie einjährige, im Frühjahr angekeimte verhalten. Zur B]äte kamen 139 Individuen; eine Auszählung wurde nicht vorgenommen, wegen der möglichen Selektion, die durch das teilweise Auswintern eingetreten sein konnte.

O. suaveolens $\times$ Lamarckiana. Samen zu 91-93\% gesund. Die erste Bastardgeneration ist. vierförmig (Fig. 27, 28, 29). Außer den eben beschriebenen Zwillingen der reziproken Kreuzung treten noch 
eine laeta und eine velutina auf, die mit den aus $O$. biennis gewonnenen identisch sind; diese sollen als bienni-lceta und bienni-velutina bezeichnet werden, während das andere Paar suavi-laeta und suavi-velutina heißen soll. Alle vier Formen sind weißnervig. Die bienni-Zwillinge haben

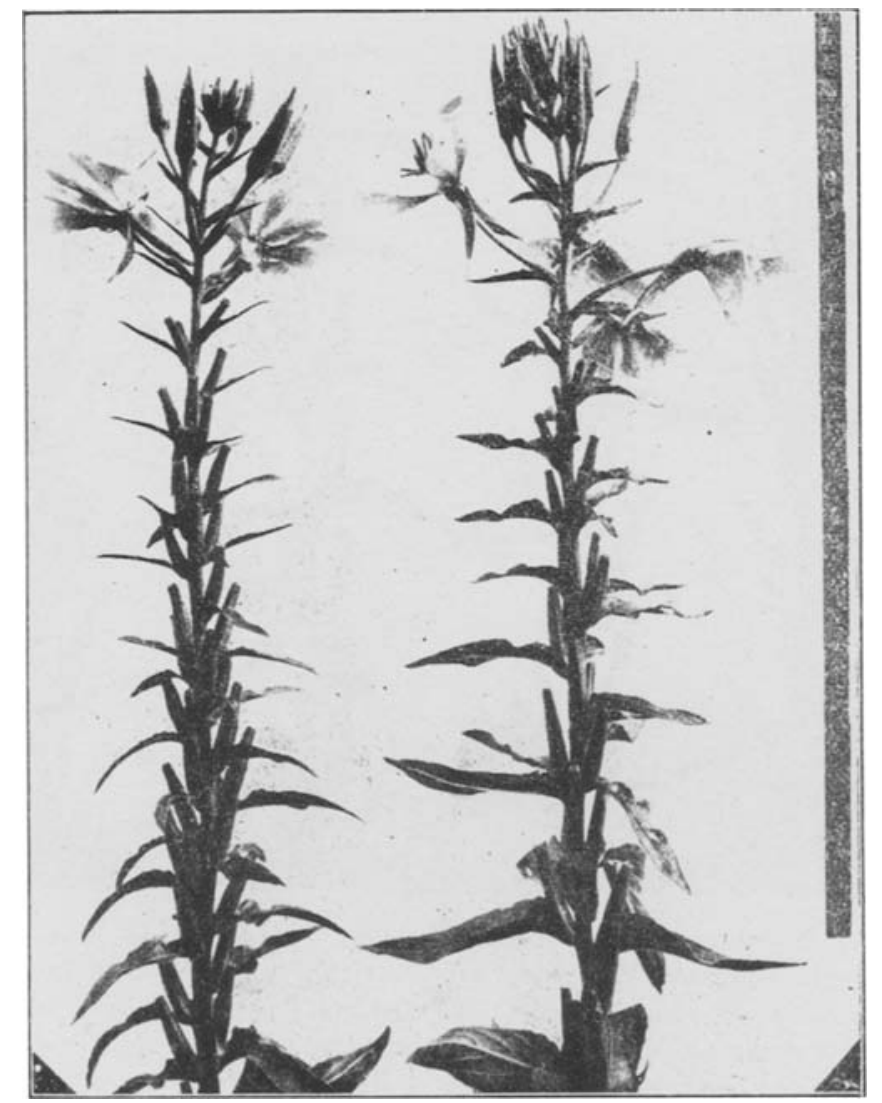

Fig. 28. $\quad$ o. (suaveolens $\times$ Lamarckiana) $\mathrm{F}_{1}$, zweijührig, 26. 7. 16 .

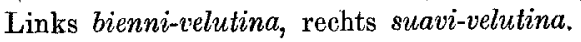

schmälere Blätter und etwas kleinere Blüten (Kronblätter $35 \mathrm{~mm}$ lang) als die suavi-Zwillinge. Zuerst blüht die bienni-velutina (25. Juni 1916), dann die suavi-velutina (1. Juli 1916), darauf die bienni-laeta (7. Juli 1916), endlich die suavi-laeta. Am niedrigsten sind die Stengel der bienni-velutina (einjährig 120, zweijährig $140 \mathrm{~cm}$ hoch), etwas höher die der suavi-velutina (einjährig 130, zweijährig $150 \mathrm{~cm}$ hoch), beträchtlich 
höher und kräftiger die der beiden laetae (zweijährig bis $200 \mathrm{~cm}$ hoch). Die beiden velutinae sind weit voneinander verschieden; vor allem fällt der Unterschied zwischen den großen breiten Brakteen der suavi-velutina und den kleinen schmalen Brakteen der bienni-velutina auf (Fig. 28), weiter die viel stärkere Rotfärbung des Kelchs der suavi-velutina. Die

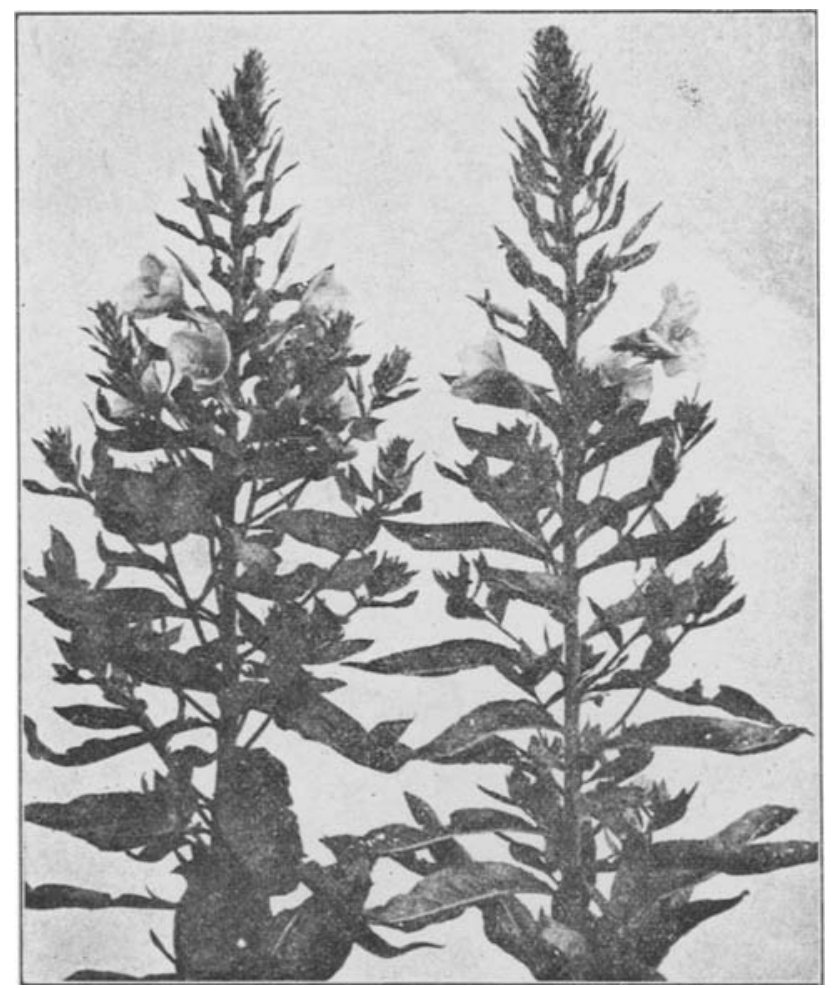

Fig. 29. O. (suaveolens $\times$ Lamarckiana) $\mathrm{F}_{1}$, zweijährig, Anfang Juli 1916, im Beginn der Blüte, sehr kräftig. Links suavi-laeta mit breiten buckligen Blättern und spitz auslaufender Infloreszenz, rechts bienni-laeta mit etwas schmäleren glatten Blättern und breit abgestutzter Infloreszenzspitze; vergl. die laeta in Fig. 24 rechts.

bienni-laeta ist vor allem durch die gerade abgestutzten Infloreszenzspitzen $^{1}$ ), die grob behaarten Stengel und Früchte von der suavi-laeta zu unterscheiden, welche spitzauslaufende Infloreszenzen und feine Haare an Stengeln und Früchten hat (Fig. 29). Der Prozentsatz der gesunden

1) Ganz wie O. (biennis $\times$ Lamarckiana) laeta und wie biennis. 
Samen ist bei den bienni-Formen so niedrig wie bei den Zwillingen aus der biennis, bei den suavi-Formen ist er höher (vergl. S. 142). - Als Mutante trat ein zierliches, nur $50 \mathrm{~cm}$ hohes, sehr schmalblättriges, im übrigen an suavi-laeta erinnerndes Individuam auf ${ }^{\mathbf{1}}$ ).

Zahlen für $O$. suaveolens I $5 \times$ Lamarckiana H.-N. A I 2: Samen wie bei der reziproken Kreuzung behandelt; gekeimt 290, nicht gekeimt 31, davon 3 mit Embryo,

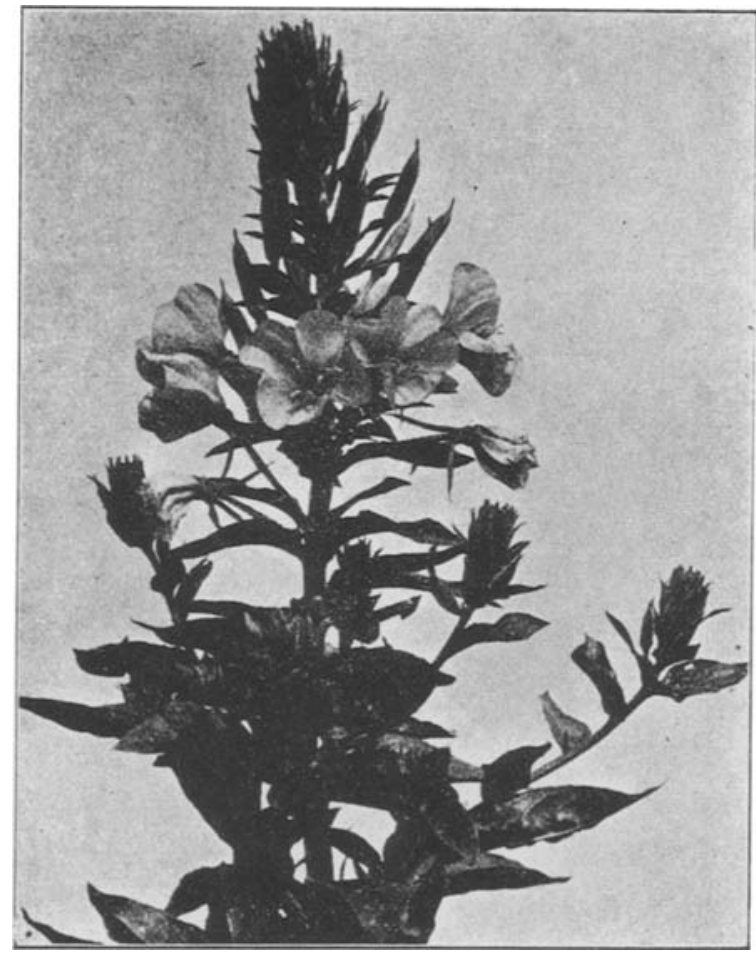

Fig. 30. O. (rubrinervis $\times$ biennis) $\mathrm{F}_{1}$ fallax, zweijährig, 1. 7.16 .

28 leer. Zur Blüte kamen 206 Individuen, die, nicht ausgezählt wurden. Wenn der Winter nicht Selektion getrieben hat, sind die suavi-Formen häufiger als die bienniFormen.

O. rubrinervis $\times$ biennis. Samen zu $94-95 \%$ keimhaltig. Die Kreuzung ist nach de Vries (1913, S. 194) einförmig und führt den

1) Der suaveolens:Anteil bezw. flavens-Komplex dieser Mutante ist vielleicht im selben Sinn abgeändert wie bei der von de Vries (1916a, S. 7) beschriebenen Mutation jaculatrix aus selbstbefruchteter $O$. suaveolens. 
Typus 0 . (Lamarckiana $\times$ biennis). Die Keimpflanzen und Rosetten gehören tatsächlich alle dem fallax-Typus an, die Blätter der Rosetten sind bucklig und haben tiefrote Nerven. Wenn die Stengel treiben, differenzieren sich aber bei mir zwei Formen, wie nach der Beschaffenheit der Samen zu erwarten war, nämlich eine typische fallax (Fig. 30, 32, 33)

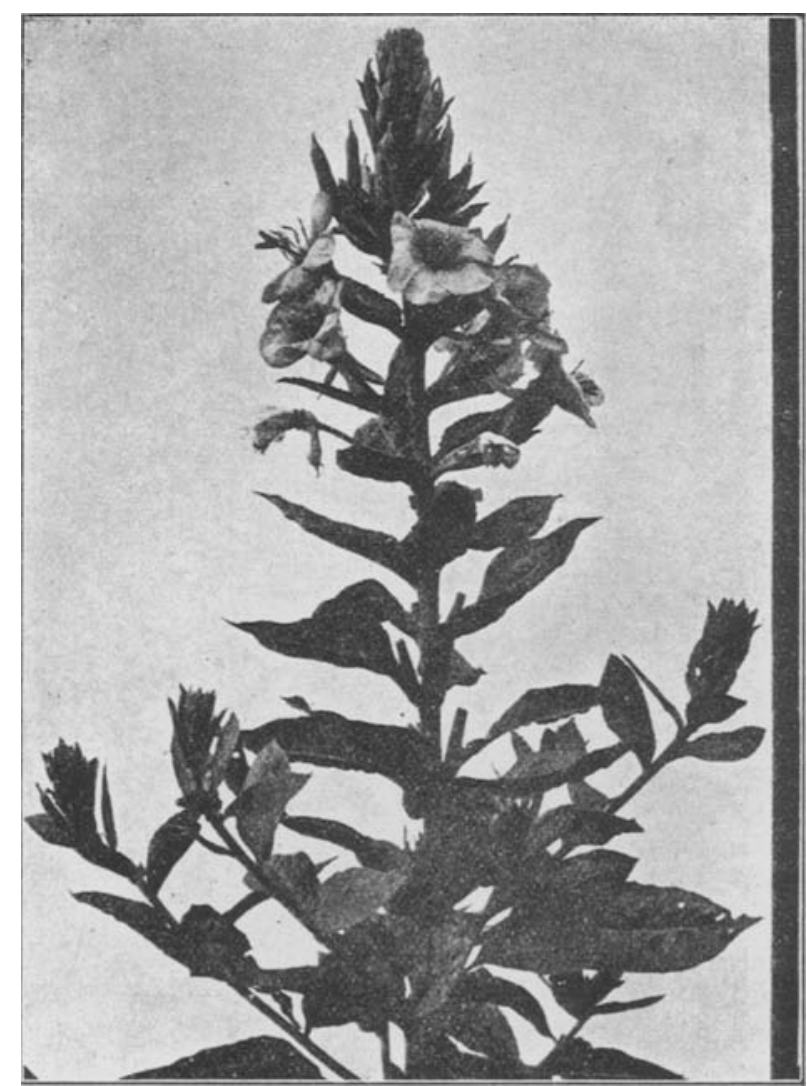

Fig. 31. O. (rubrinervis $\times$ biennis) $\mathrm{F}_{1}$ subfallax, einjährig, 6. 8. 16. Der lange Griffel und die Zurückbiegung der Kronblätter sind zu erkennen.

und eine Form mit etwas schmäleren, zungenförmig verlängerten, weniger buckligen, heller grünen, tiefer gezähnelten Blättern und manchmal schwächer verzweigtem Stengel, die als subfallax bezeichnet werden soll (Fig. 31, 32, 33). Bei der Blüte werden die Unterschiede auffallend. Die eigentliche fallax ist von dem betreffenden Bastard der O. Lamarckiana nicht zu unterscheiden; die Stengel werden zweijährig bis 
$170 \mathrm{~cm}$ hoch, die Kelche sind breit und dunkel rotstreifig, die Kronblätter tief gelb, bis $35 \mathrm{~mm}$ lang, die entfalteten Kronen rad-glockenförmig, die Narben liegen zwischen den Antheren; die Samen sind zu $20-27 \%$ keimhaltig. Bei der subfallax sind die Kelche im unteren

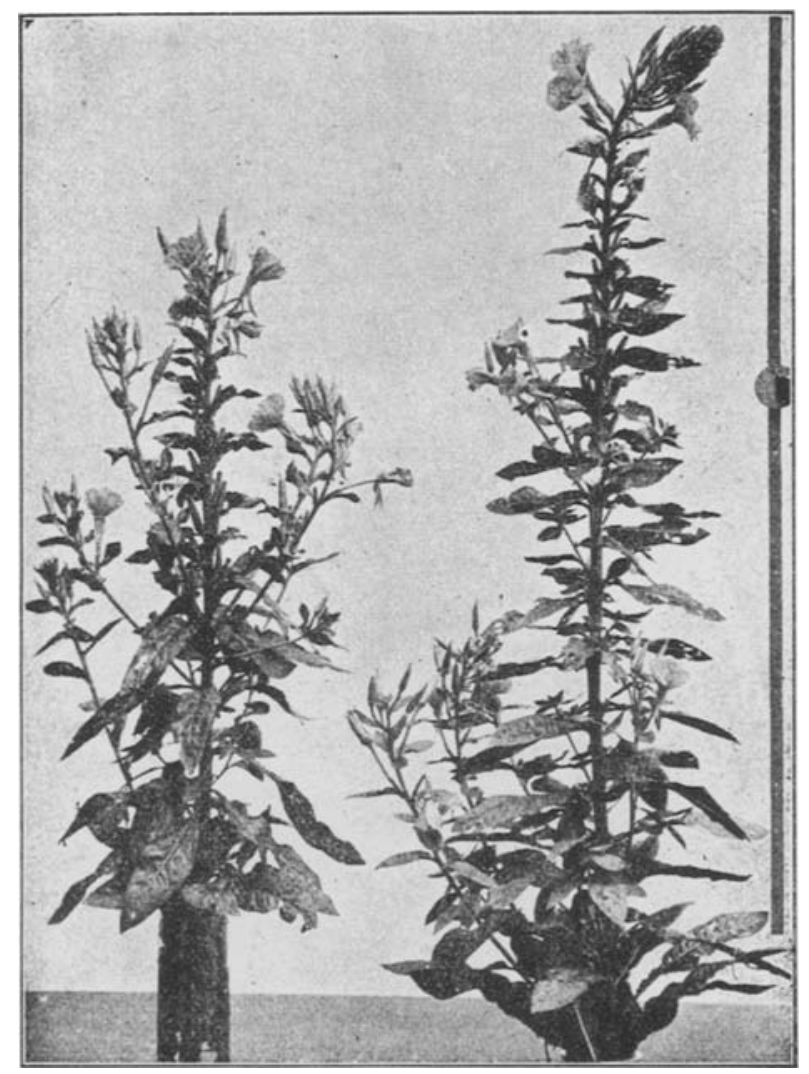

Fig. 32. O.(rubrinervis $\times$ biennis) $\mathrm{F}_{1}$, einjährig, 6.9.15. Links fallax, mit starken Seitenzweigen unter der kurz bleibenden Hauptinfloreszenz, wie die fallax aus 0 . Lamarckiana (vergl. Fig. 22). Rechts die höher aufwachsende subfallax mit lange fortwachsender Hauptinfloreszenz. Beide haben bucklige Stengelblätter, die der subfallax sind länger.

Teil der Infloreszenz rein grün, oben schwach rotstreifig, die Kronblätter hellgelb, bis $32 \mathrm{~mm}$ lang, die entfalteten Kronen fast trichterförmig, ihre Blätter unten zusammenneigend, oben nach außen geschlagen (Fig. 31); die Narben der oberen Blüten liegen meist ganz über den 
Antheren (Fig. 31, 33) was im Verein mit der hellen Kronenfarbe an laeta erinnert. Der Stengel wächst oft etwas höher und schlanker auf als bei der gedrungenen fallax, mit stärkerem Dominieren des Haupt-

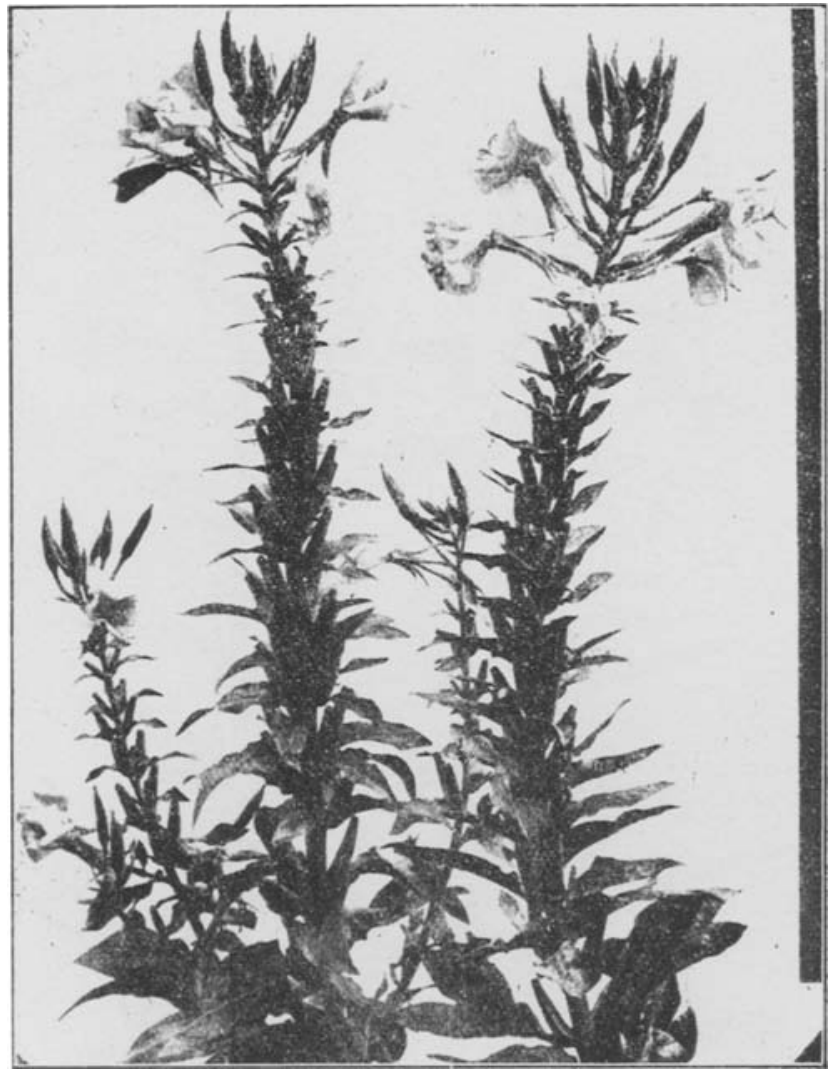

Fig. 33. O.(rubrinervis $\times$ biennis) $\mathrm{F}_{1}$, zweijährig, 26. 7. 16. Links fallax wieder mit Seitenästen nahe dem Hauptgipfel, rechts subfallax, in derselben -Höhe unverzweigt, mit weit vorragenden Narben. - Der auffallende Unterschied in der Dichte der Fruchtstände, der zwischen den in Fig. 32 und den in Fig. 33 wiedergegebenen Pflanzen besteht, ist charakteristisch für den Unterschied zwischen ein- und zweijährig erzogenen Pflanzen. Die zweijährigen haben dichter gedrängte Früchte.

sprosses gegeniiber den oberen Seitensprossen (Fig. 32). Die Samen sind zu $61-62 \%$ keimhaltig. Im übrigen hat die subfallax die purpurne Nervenfarbe, die rote Punktierung der Stengel und Fruchtknoten, die 
Rotstreifigkeit der jungen Früchte, die dichten kurzen Fruchtstände (Fig. 33) ganz wie fallax.

Zahlen für 0 . rubrinervis I $2 \times$ biennis I 1, 1914 hergestellt, 1915 gesät: 208 Samen gekeimt, 10 nicht gekeimt, ohne Embryo. Blühend 1915 einjährig 40 Pflanzen (es waren viel mehr ausgepflanzt worden, aber so dicht, daß die Rosetten sich im Wachs-

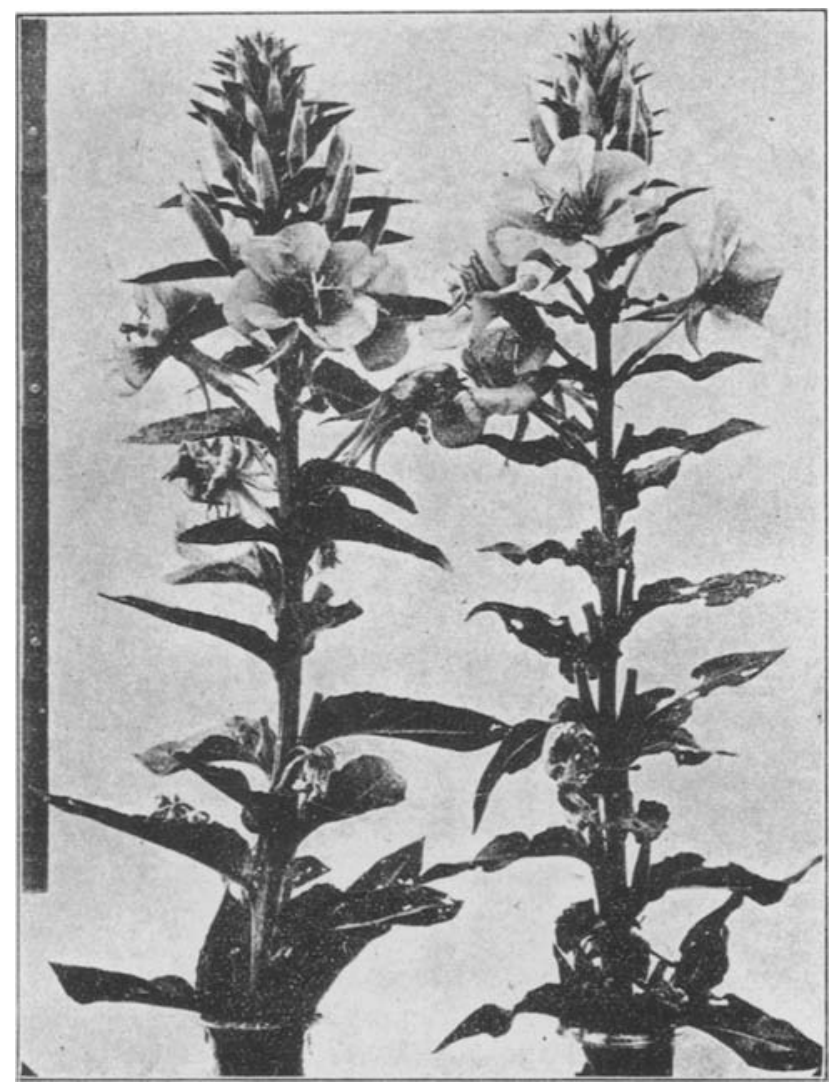

Fig. 34. O. (biennis $\times$ rubrinervis) $\mathrm{F}_{1}$, einjährig, 29. 7. 16. Rechts velutina, links subvelutina mit größeren breiteren Brakteen und etwas kleineren Kronen.

tum behinderten), davon 20 fallax und 20 subfallax. 1916 kamen 22 Individuen zweijährig zur Blüte, davon 13 fallax und 9 subfallax. Von im Topf überwinterten Pflanzen blühten 1916 noch 6 fallax nnd 17 subfallax. Zusammen waren es also 39 fallax und 46 subfallax.

O. biennis $\times$ rubrinervis (weißnervig). Samen zu $62 \%$ keimhaltig. Die Kreuzung liefert nach de Vries (1913, S. 201) die Zwillinge laeta 
und velutina; diesen Befund bestätigt Honing (1911, z. B. S. 275/6), der aber hervorhebt, daß „bei $O$. rubrinervis als Vater die laeta und velutina beide rubrinervis-Kinder" sind; das soll soviel heißen, daß die "laeta" der velutina viel ähnlicher ist als in der Kreuzung biennis $\times$

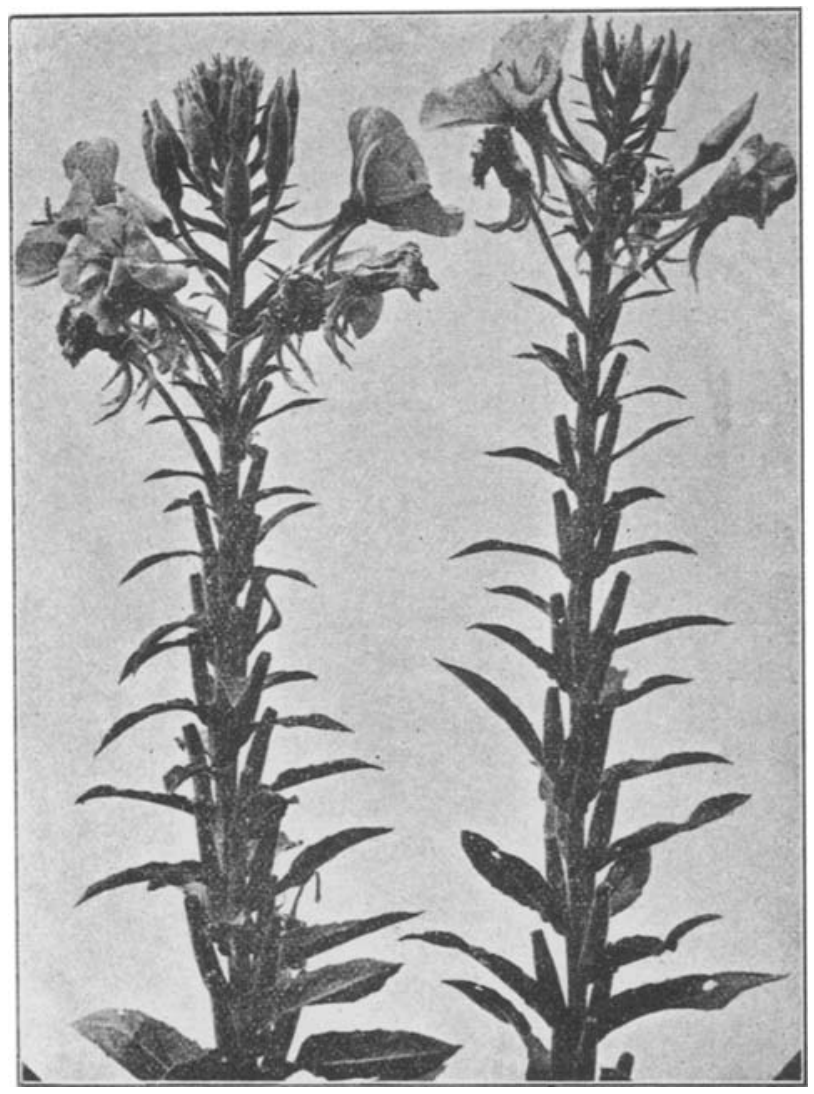

Fig. 35. O. (biennis $\times$ rubrinervis) $\mathrm{F}_{1}$, einjährig, 13.8. 16 . Rechts velutina, links subvelutina mit längerem Griffel. In diesem Zustand sind die beiden Formen, von der Färbung abgesehen, einander sehr ähnlich.

Lamarckiana. Was ich bei meinen Materialien finde, sind zwei ausgesprochene (weißnervige) velutina-Formen (Fig. 34, 35). Die eine velutina ist von der velutina aus der $O$. Lamarckiana kaum zu unterscheiden, sie ist wie diese schmalblättrig und dunkelgrün, wird einjährig $130 \mathrm{~cm}$ hoch, und hat anch deutlich rotstreifige Kelche und 
rotangelaufene Früchte. Die andere Form steht zur ersten ungefähr im selben Verhältnis wie die subfallax der reziproken Kreuzung zur fallax, sie soll entsprechend subvelutina heißen. Thre Blätter sind breiter, hellgrün, die Kronen trichterförmig, die Kronblätter etwas kleiner (28 mm lang), hellgelb, die Kelche zuerst ganz grün, erst bei den späteren Blüten sehr schwach rotgestreift; die Narben liegen bei den letzten Blüten mitunter ganz über den Antheren; der Stengel wächst höher auf, bis $155 \mathrm{~cm}$, was an laeta erinnert. Dagegen hat die subvelutina dicke Knospen, schlank kegelförmige feinhaarige Früchte, zurückgebogene etwas rinnige Brakteen (dasselbe findet Honing S. 263 bei seiner "laeta", während de Vries, 1913, S. 201 die Brakteen der "laeta" flach nennt), dichte, weiche Behaarung, rote Tupfen auf Stengel und Fruchtknoten, alles wie die velutina. Auch die Keimpflanzen der subvelutina sind denen der velutina viel ähnlicher als denen der laeta, doch stellen sie sich durch geringere GröBe der Blätter zwischen velutina und laeta. Es ist also nicht zu leugnen, daß die subvelutina verschiedene Anklänge an laeta zeigt, doch scheint mir die Ähnlichkeit mit velutina zu überwiegen. Das soll aber nur für mein Material gesagt sein; de Vries muß anderes Material verwendet haben, denn seine laeta hat nach seiner Fig. 86, S. 201, viel schlankere Knospen als meine subvelutina. Einzelne Individuen waren nicht mit Sicherheit bei velutina unterzubringen; vielleicht sind bei größerem Umfang der Kulturen drei oder noch mehr Formen unterscheidbar.

Außer den beiden velutinae treten noch die beiden rotnervigen fallax-Formen auf, die wir aus der reziproken Kreuzung schon kennen, fallax (einjährig $110 \mathrm{~cm}$ hoch) und subfallax; im ganzen ist die erste Bastardgeneration also mindestens vierförmig.

Zahlen für O. biennis $I I 4 \times$ rubrinervis II 1, hergestellt 1915, gesät 1916: 41 Samen gekeimt, 22 grobe nicht gekeimt, davon 18 tanb, 4 mit Embryo; die velutinaKeimlinge teilweise gelbstreifig. Blühend 36 Pflanzen, davon 19 velutina, 9 subvelutina, 2 fragliche velutina-Formen, 5 fallax, 1 subfallax.

O. rubrinervis $\times$ Lamarckiana-weißnervig. Samen zu $55-59 \%$ keimhaltig. Nach de Vries besteht die $F_{1}$-Generation zu gleichen Teilen aus Lamarckiana und "subrobusta", einer rubrinervis-ähnlichen Form, die de Vries ursprünglich, z. B.in der "Mutationstheorie", von rubrinervis nicht ausdrücklich unterschieden hat (vergl. 1913, S. 191), bis Honing (1910, S. 239) auf die Differenzen zwischen rubrinervis und dem Bastard und zugleich auf die Übereinstimmung des Bastardes mit der von Schouten beschriebenen Mutante O. Lamarckiana-blanda aufmerksam 
machte. Ich werde im folgenden die Bezeichnung blanda anwenden, weil das Wort für etwa nötig werdende Zusammensetzungen bequemer ist als subrobusta. Ich habe in einer kleinen Kultur, wohl zufällig, nur blanda erhalten, in weißnervigen gleichförmigen, deutlich zwischen den beiden Eltern stehenden Individuen. Honing hat die Form ausführlich beschrieben und mit den Eltern verglichen. Ich möchte vor allem hervorheben, daß schon die Keimpflanzen eine zwischen den Elterntypen stehende Form darstellen, die Stengel und Fruchtknoten reichlich rot getupft, die dicken Kelche und Früchte stark rot gefärbt und alle Organe, ähnlich wie bei rubrinervis, sehr spröde und brüchig sind. Der Stengel hat starke niederliegend-aufsteigende Grundäste und ist rot überlaufen, die Kelchblätter sind abstehend behaart, die Kronblätter dunkelgelb, $42 \mathrm{~mm}$ lang, die Griffel sehr lang, die Narben dick, die Antheren sehr pollenreich.

Zahlen für 0 . rubrinervis $5 \times$ Lamarckiana $\mathrm{H}$. $\mathrm{N}$. weifnervig A I 2. Hergestellt 1914, gesät 1916, und zwar ziemlich spät und gleich in Erde, so dab die nicht keimenden Samen nicht kontrolliert werden konnten. Es blühten 20 gleichförmige blandalndividuen.

O. rubrinervis $\times$ Lamarckiana - rotnervig. Außer blanda fand ich hier wenige Individuen von Lamarckiana, und beide Bastardformen zum Teil weiß- zum Teil rotnervig. Die weißnervige Lamarckiana blieb Rosette, die rotnervige schien mit den rotnervigen Lamarckiana-Stämmen von Heribert-Nilss on nicht ganz identisch zu sein.

Zahlen für 0 . rubrinervis I $5 \times$ Lamarckiana H.-N. rotnervig B I 2. Behandlung der Samen wie vorher. Blühend 14 blanda, davon 9 weißnervig, 5 rotnervig, und 1 rotnervige Lamarckiana. Rosette 1 weißnervige Lamarckiana.

\section{Das Verhalten der Bastarde in den späteren Generationen.}

O. (biennis $\times$ muricata). $\quad \mathrm{F}_{4}$ von de Vries (in 1 Exemplar) und $F_{5}$ (in 2 Exemplaren) waren untereinander identisch und, soweit ich nach der Erinnerung urteilen kann, der von mir aus anderem Material hergestellten $F_{1}$ in allen wesentlichen Punkten gleich. In der $F_{2}$ tritt nach Baur ${ }^{1}$ ) Spaltung. nach der Blütengröße ein. Im übrigen dürfte der Bastard aber, was die sich entwickelnden Individuen betrifft, konstant sein.

$O$. (muricata $\times$ biennis). $\quad F_{4}$ und $F_{5}$ von de Vries (in 15 bezw. 27 Individuen) waren gleichförmig und identisch.

O. (suaveolens $\times$ biennis) flava $\mathrm{F}_{2}$. Die auf der $\mathrm{F}_{1}$. geernteten Samen gaben teils gelbe, teils fast weiße, teils rein weiß̧e Keimpflanzen,

1) E. Baur, „Einführung", 1. Aufl. S. 219. 
von denen nur der größere Teil der gelben am Leben blieb, während die übrigen zugrunde gingen, ohne Primärblätter zu bilden. Die zur Blüte erzogenen Individuen glichen der rotnervigen Mutterpflanze, von

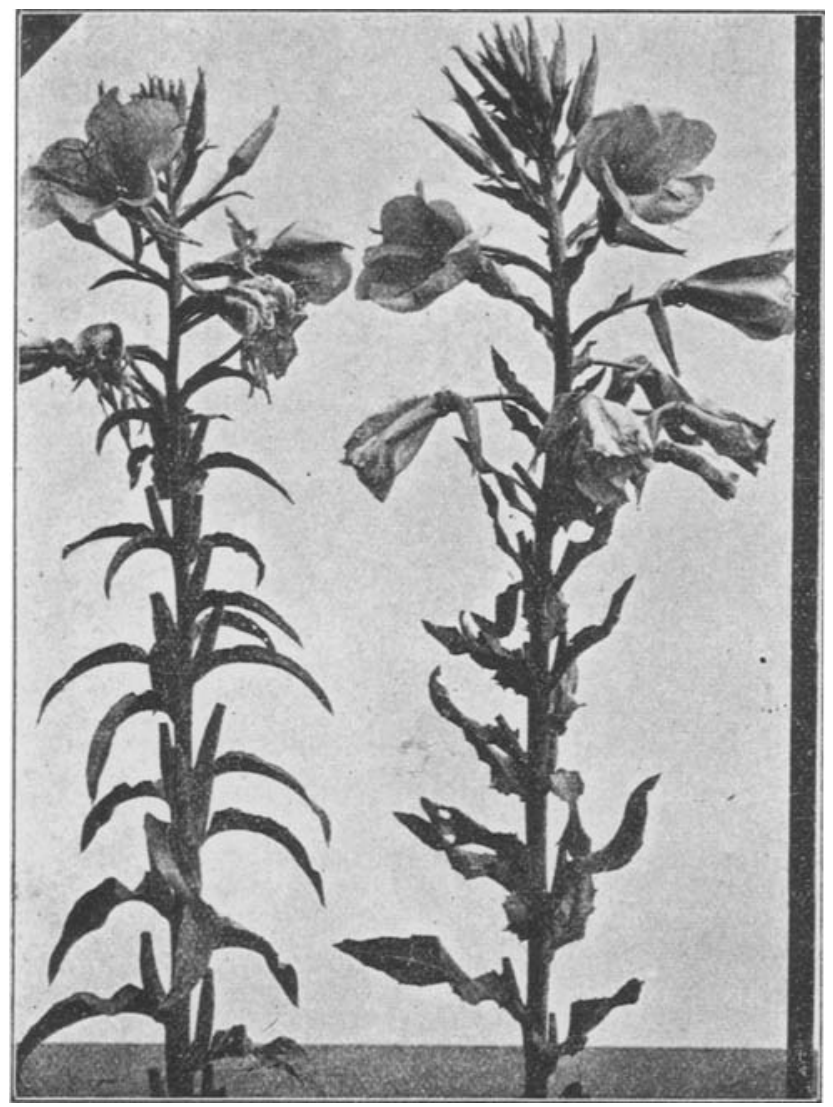

Fig. 36. O. (biennis $\times$ Lamarckiana X) $\mathrm{F}_{2}$, einjährig, 3. 9. 15. Rechts laeta rotnervig, grobblütig, langgriffelig, mit aufgerichteten sehr welligen Brakteen, links velutina weifnervig, grobblütig, mit stark abwärts gebogenen rinnigen Brakteen. Der Unterschied zwischen der velutina $\mathrm{F}_{2}$ and der velutina $\mathrm{F}_{1}$ (Fig. 24) rührt vielleicht von der Verwendung verschiedener P-Pflanzen her.

stärkerer Verzweigung abgesehen, durchaus, nur waren sie zum gröBten Teil weißnervig. Kronblätter $30-32 \mathrm{~mm}$ lang.

Gekeimt 93 Samen, 1915 gewonnen, 1916 gesät. Blühend 26 Stück, davon nur eines schwach rotnervig wie $\mathrm{F}_{1}$. 
O. (biennis $\times$ Lamarckiana) laeta-rotnervig. Die $\mathbf{F}_{2}$ (Fig. 36) war durchweg typische laeta, zweijährig bis $190 \mathrm{~cm}$ hoch, rotnervig, nur in der Blütengröße verschieden. Die größten Blüten, mit langen Griffeln, beträchtlich größer als bei der $\mathrm{F}_{1}$, die Kronblätter $45 \mathrm{~mm}$ lang. Weißnerven traten nicht auf. - Die $\mathrm{F}_{3}$ (Fig. 37), von einem klein-

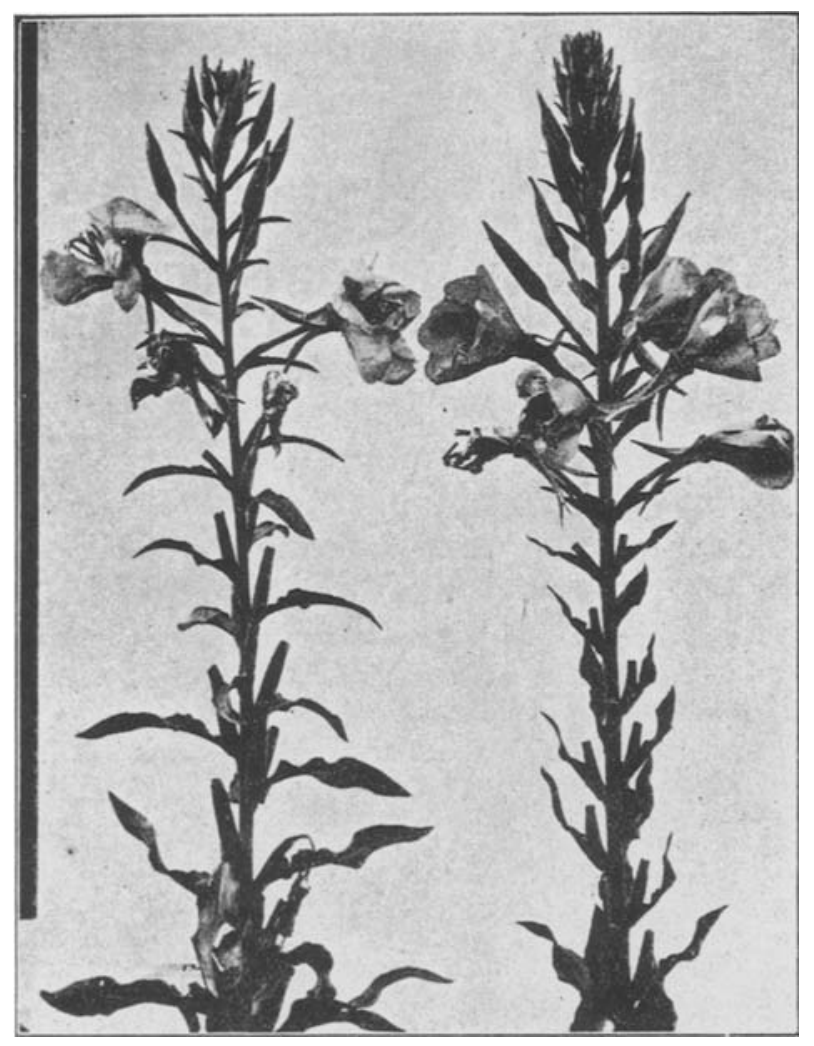

Fig. 37. O. (biennis $\times$ Lamarckiana $\mathrm{X}$ ) $\mathrm{F}_{3}$, einjährig, 29. 7. 16. Rechts laeta rotnervig, links velutina weißnervig, beide kleinblütig, von kleinblütigen $\mathrm{F}_{2}$-Pflanzen.

blütigen $\mathrm{F}_{2}$-Individuum, war wieder ganz einförmige, rotnervige, kleinblütige (Kronblätter $32 \mathrm{~mm}$ lang), der O. biennis sehr ähnliche, auch nur $140 \mathrm{~cm}$ hohe laeta, mit nicht sehr langen Griffeln; die Spitzen der Kelchblätter erst grün, an den späteren Blüten schwach rot; die Narben an den späteren Blüten meist über den Antheren; die Brakteen klein, schwach wellig, die Fruchtstände wesentlich schlanker als bei O. biennis. - 
Von der Blütengröße abgesehen, die aber von der $\mathbf{F}_{2}$ an wenigstens teilweise konstant sein dürfte, kann die laeta als vollkommen konstant bezeichnet werden.

Zahlen für $\mathrm{F}_{2}$ aus $O$. (biennis $\times$ Lamarckiana $\mathrm{X}$ ) laeta rotnervig 3: Samen 1914 gewonnen, 1915 gesät. Gekeimt 291 Samen, nicht gekeimt 84, davon 83 tanb, 1 mit Embryo. 1915 blïhten einjährig 208 Individnen, 1916 zweijährig 3 großblütige Stöcke; Abweicher fehlten. $-\mathrm{F}_{3}$, Samen 1915 gewonnen, 1916 gesät. Gekeimt 54 Samen, nicht gekeimt 80 größere, sämtlich taube Samen. Blühend 48 Stück, ohne Abweicher.

O. (biennis $\times$ Lamarckiana) velutina-weißnervig. Die $\mathrm{F}_{2}$ (Fig. 36) war durchweg typische velutina, weißnervig, nur in der Blütengröße auffallend verschieden. Es waren mindestens zwei Typen, die kleineren Blüten mit ziemlich hellgelber Krone, ihre Kelche schwach gestreift, die größeren Blüten mit dunkler gelber Krone, mit breit rotstreifigen Kelchblättern. Das zuletzt, in weitem zeitlichem Abstand von den übrigen Samen gekeimte Individuum war ein sehr langsam wachsender Zwerg mit kleinen, rundlichen, dicken Blättern, schwach getupftem Stengel und kleinen Blüten, im übrigen von unzweideutiger velutinaPrägung. - Die $\mathrm{F}_{3}$ (Fig. 37), von einem kleinblütigen $\mathrm{F}_{2}$-Individuum gewonnen, war typische, einförmige, kleinblütige velutina; die unteren Blätter waren blaß rotnervig; Stengel nur $1 \mathrm{~m}$ hoch.

Zahlen für $\mathrm{F}_{2}$ aus $O$. (biennis $\times$ Lamarckiana $\mathrm{X}$ ) velutina weifnervig 3 (Samen 1914 gewonnen, 1915 gesät): Gekeimt 72 Samen, nicht gekeimt 171, davon 169 taub, 2 mit Embryo; 1915 blühten 64 typische Individuen und der $Z_{\text {werg. }}-\mathrm{F}_{\mathrm{s}}$ (Samen 1915 gewonnen, 1916 gesät): Gekeimt 24 Samen, nicht gekeimt 113, davon 109 taub, 4 mit Embryo. Blühend 16 Stück, ohne Abweicher. - Die Samen keimen sehr langsam, was vielleicht mit der ungewöhnlichen Härte der Testa zusammenhängt.

Die Unterschiede zwischen den Zwillingen bleiben in $\mathrm{F}_{2}$ und $\mathrm{F}_{3}$, wie die Figuren 36 und 37 zeigen, genan so scharf wie in $F_{1}$.

O. (biennis $\times$ Lamarckiana-rotnervig) fallax. Die $\mathrm{F}_{2}$ besteht zur Hauptsache aus rotnervigen Individuen, die in Wuchs (Fig. 38), Blattform, Anthokyanbildung, Dichte der Fruchtähren ausgesprochenen fallax-Charakter haben. Nach den Blüten sind aber vier Typen zu unterscheiden: a) Blüten sehr groB (Fig. 39), Kronblätter tief gelb, bis $50 \mathrm{~mm}$ lang, Kelch bis auf schmale grüne Streifen tief kupferfarbig, Griffel lang, Narben über den Antheren; also die Blüten ganz Lamarckiana-ähnlich, nur der Kelch viel stärker pigmentiert als bei der weißnervigen Lamarckiana. b) Kronblätter $40 \mathrm{~mm}$ lang, tief gelb, Griffel kurz, Kelch breit dunkelrotstreifig etwa wie bei fallax $\mathbf{F}_{1}$. c) Kronblätter $30 \mathrm{~mm}$ lang, sonst wie b. d) Kronblätter $30 \mathrm{~mm}$ lang, blasser gelb, Griffel kurz, Kelch schwach rotstreifig. Außerdem fanden 
sich: ein Weißnerv mit etwas kürzeren breiteren Blättern, sehr schwach rotstreffigen Kelchen, blaßgelben, $30 \mathrm{~mm}$ langen Kronblättern, kurzen Griffeln, ziemlich langer und lockerer, Lamarckiana-ähnlicher Fruchtähre; ein verkrüppelter spät blühender Weißnerv, der vielleicht demselben Typus wie das andere Individuum angehörte; ein sehr schwacher, nicht zur Blüte gelangender Weißnerv, mit schmalen rubrinervis-ähnlichen Blättern, aber zähen, nicht spröden Organen; endlich zwei Individuen einer Form, die mit der de Vriesschen "Mutante" oblonga und

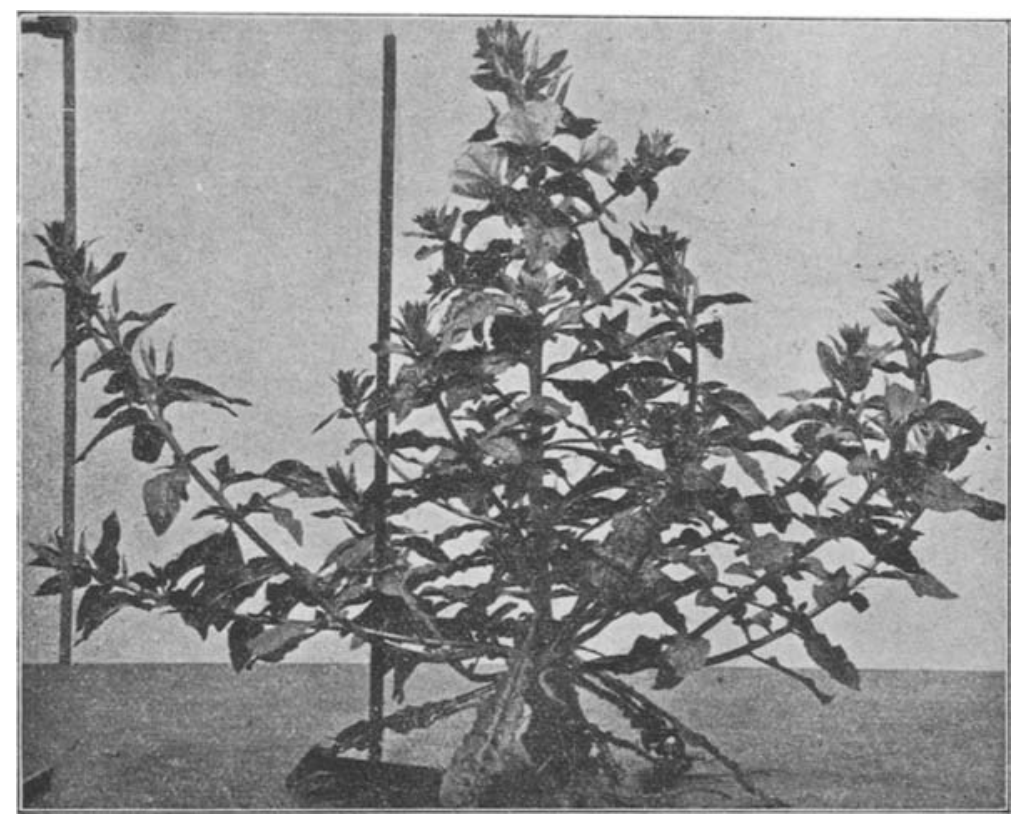

Fig. 38. O. (biennis $\times$ Lamarckiana Her.-Nilss. rotnervig) fallax $\mathrm{F}_{2}$, einjährig, rotnervig, großblütig, beim Beginn der Blüte, 7. 7.16. Niederliegendaufsteigende Grundäste sehr stark.

mit der Heribert-Nilssonschen "Kombinante" dependens (1915, S. 67) verwandt zu sein scheint: Stengel mit großen schlanken bogig aufsteigenden Grundästen, Blätter rotnervig, die unteren sehr bucklig, unten hohl, die Blätter in der Blütengegend sehr breit, kurz, teilweise herzeiförmig, Kronblätter blaßgelb, $26 \mathrm{~mm}$ lang, Griffel kurz, Kelch erst ganz grün, an den späteren Blüten mit kurzen roten Streifen, Spitzen der Kelchzipfel wie der Brakteen kräftig rot, Früchte sehr kurz, in lockerer langer Ähre, schwach rotstreifig. 
Auch die vom Haupttypus abweichenden Formen haben sämtlich rot getupfte Stengel und Fruchtknoten und mehr oder weniger rotstreifige Kelche und Früchte.

$\mathrm{F}_{2}$ aus 0 . (biennis $\mathrm{I} 1 \times$ Lamarckiana Heribert-Nilsson $\mathrm{B}$ I rotnervig 1 ) fallax 1, Samen 1915 gewonnen, 1916 gesät: Gekeimt 49 Samen, nicht gekeimt 106, davon 104 taub, 2 mit Embryo. Von den gekeimten Samen blieben 2 aus, 3 gaben dickblätterige krüppelhafte, die übrigen 43 gleichmäßige fallax-Keimpflanzen. Es blühten 30 fallax von den Formen a-d, dazu kamen die 5 beschriebenen Abweicher.

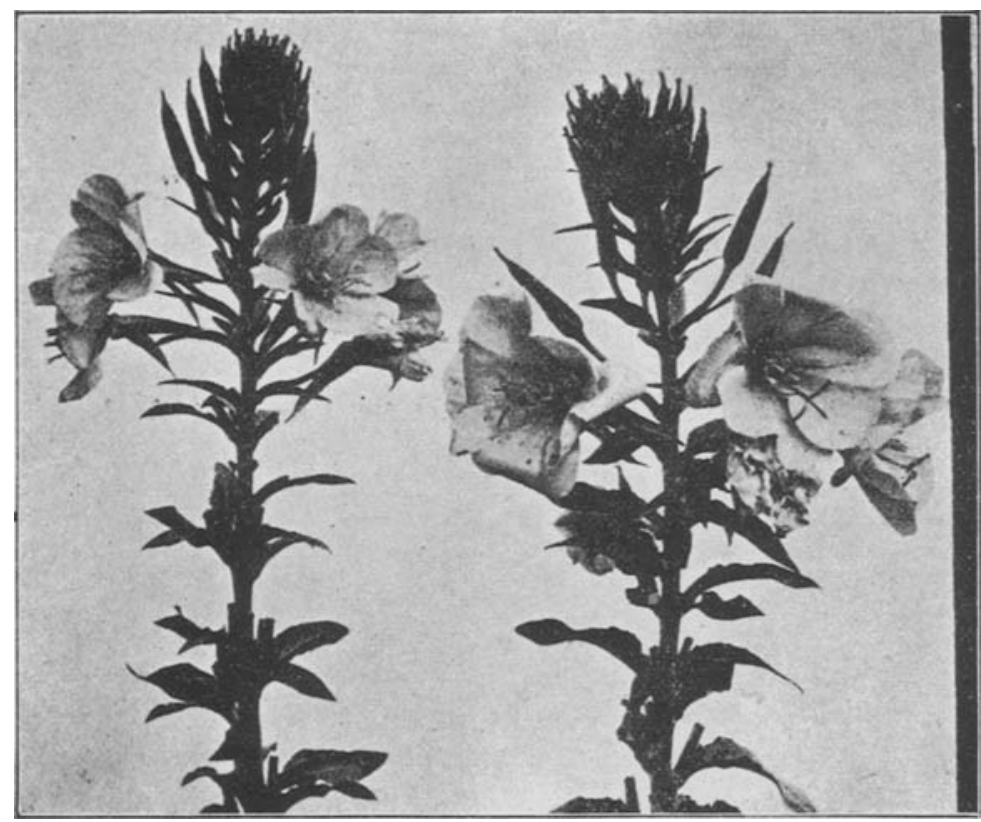

Fig. 39. O.(biennis $\times$ Lamarckiana) fallax, einjährig, 27. 7. 16. Links $\mathrm{F}_{1}$, rechts ein rotnerviges, großblütiges, langgriffeliges Individuum der $\mathrm{F}_{2}$.

O. (Lamarckiana $\times$ biennis) fallax $\mathrm{F}_{3}$ und $\mathrm{F}_{4}$ von HeribertNilsson. Alles typische fallax, rot getupft, mit mittelgroßen Blüten, rot gestreiften Kelchen und Früchten, kurzen Griffeln, dichten Fruchtähren, fast durchweg rotnervig.

Zahlen für $\mathrm{F}_{\mathrm{s}}$ ans einer kleinblütigen $\mathrm{F}_{\mathbf{2}}$-Pflanze 56/8: Gekeimt 22 Samen, nicht gekeimt 91, davon 85 taub, 6 mit Embryo. 1914 blühten 14 Rotnerven mit ziemlich verschieden starker Rotfärbung des Kelchs and 1 Weißnerv mit schwach gestreiftem Kelch; 1915 kamen noch 3 rotnervige Pflanzen zweijährig zur Blüte.

$\mathrm{F}_{4}$ aus einer kleinblütigen $\mathrm{F}_{3}$-Pflanze 50/25: Gekeimt 15 Samen, nicht gekeimt 210, davon 208 taub, 2 mit Embryo. 1914 blühten 15 rotnervige Pflanzen. 
In der $\mathrm{F}_{2}$-Generation tritt nach Heribert-Nilsson (1912, S. 186) Spaltung nach der Blütengröße ein, wie wir sie bei der auf reziprokem Weg gewonnenen fallax gefunden haben. In späteren Generationen findet derselbe Autor Abspaltung von Weißnerven (1915, S. 36).

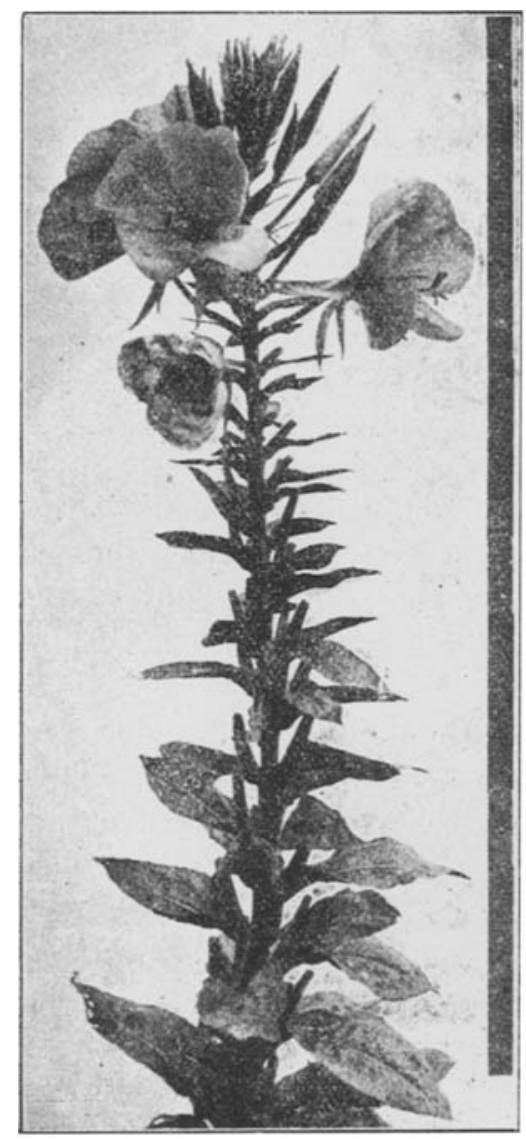

Fig. 40. O. (rubrinervis $\times$ biennis) subfallax $\mathrm{F}_{2}$, einjährig, 15. 8. 16 . Großblütiges, langgriffliges, rotnerviges subfallax-Individuum.

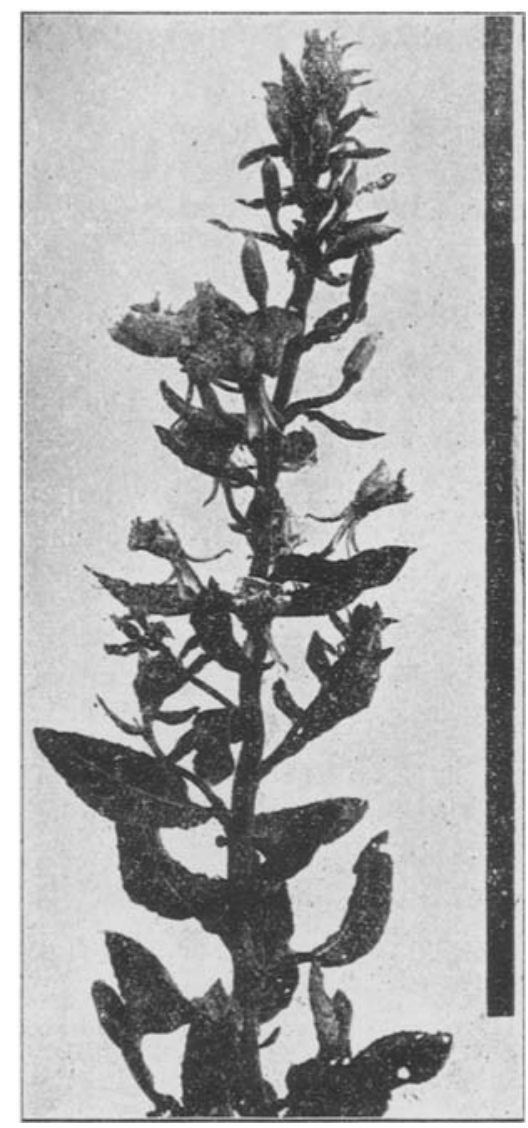

Fig. 41. O. (rubrinervis $\times$ biennis) subfallax $\mathrm{F}_{2}$, einjührig, 15.8 .16 . Kleinblïtiges, weibnerviges rubrinervisIndividuum. Infloreszenzachse geschlängelt, Blïtenknospen plump, aufgekrümmt.

O. (rubrinervis $\times$ biennis) fallax $\mathrm{F}_{2}$. Sämtliche Individuen stellen den fallax-Typus dar, es sind aber sicher 2 , vielleicht 3 Blütengrößen Induktive Abstammungs- und Vererbungslehre. XVIII. 
zu unterscheiden, die sich zudem auf Rot- und Weißnerven verteilen. Die gröBten Blüten haben $48 \mathrm{~mm}$ lange Kronblätter und lange Griffel, die kleineren Blüten sind kurzgrifflig, die kleinsten Blüten beträchtlich kleiner. Der Kelch ist bei den Rotnerven stärker gefärbt als bei den Weißnerven, in beiden Gruppen bei den großen Blüten wieder stärker als bei den kleinen; fast ganz roten Kelch haben die großblütigen Rotnerven. Die Fruchtähren der Rotnerven sind sehr dicht, die der Weißnerven etwas schlanker.

Zahlen für die $\mathrm{F}_{2}$ aus $O$. (rubrinervis I $2 \times$ biennis I 1) fallax 1; Samen 1915 gewonnen, 1916 gesät: Gekeimt 35 Samen, nicht gekeimt 116, davon 1 mit Embryo, 115 taub. Von den gekeimten Samen blieben 2 aus, 6 gaben Krüppel, 27 normale fallax. Es blühten 18 gesunde Pflanzen, davon waren 12 rotnervig und 6 weißnervig; von den Rotnerven waren 7 groß- und 5 kleinblütig, von den Weißnerven 2 groß- und 4 kleinblütig.

0 . (rubrinervis $\times$ biennis) subfallax $\mathrm{F}_{2}$. Die zweite Bastardgeneration spaltet in subfallax und rubrinervis, und jeder Typus spaltet wieder nach der Nervenfarbe und nach der Blütengröße. Bei der subfallax (Fig. 40) scheinen 3 BlütengröBen vorzukommen, mit 45, 35 und $28 \mathrm{~mm}$ langen Kronblättern; die größten Blüten haben sehr lange Griffel, sind ganz Lamarckiana-ähnlich, die kleinen sind kurzgrifflig, ihre entfaltete Krone ist trichterförmig wie in der $F_{1}$. Die großblütigen Individuen haben breitere Blätter als die kleinblütigen und als die $F_{1}$, die Blätter der Weißnerven sind breiter und stärker bucklig als die der Rotnerven. Nach der sehr schwachen Färbung des Kelchs, der Farbe der Blätter und Kronen sind alle diese Formen zweifellos subfallax, keine erinnert an fallax. - Die abgespaltene rubrinervis (Fig. 41) ist in der Sprödigkeit, der Blattgestalt, der Behaarung, der Schlängelung der Infloreszenzachse, der Gestalt und Lage der Blütenknospen, der Zerknitterung der Kronblätter in der Knospe, der Dicke der Narben ganz identisch mit der Muttèrart. Aber die Pflanzen sind beträchtlich schwächer, wenig verzweigt, die Blüten viel kleiner, die Kelche viel schwächer rot gefärbt. Die Länge der Kronblätter ist $33 \mathrm{~mm}$ bei einem, und $27 \mathrm{~mm}$ bei einem zweiten Typus. Die Blätter sind teils rot-, teils weißnervig; die Rotnerven haben dunkelgelbe Krone und kräftig rotstreifige Kelche, die Kronen der Weißnerven sind viel blasser, ihre Kelche zuerst rein grün, an den späteren Blüten mit schmalen und kurzen roten Streifen versehen. - Ein rotnerviges subfallax-Individuum wich von den übrigen auffallend ab. Die Blätter dunkelgrün, viel schmaler als selbst bei der $\mathrm{F}_{1}$, die Blüten klein, die Kronblätter nur $28 \mathrm{~mm}$ lang, hellgelb, die entfaltete Krone ganz vom subfallax-Typus, die Griffel sehr lang, die Narben kurz, dicklich, die 
Fruchtähren sehr dicht. - Die Früchte sind bei allen Formen rotstreifig, die Stengel und Fruchtknoten rot punktiert.

Zahlen der $F_{2}$ aus 0 . (rubrinervis I $2 \times$ biennis I 1 ) subfallax 1, Samen 1915 gewonnen, 1916 gesät: Gekeimt 71 Samen, nicht gekeimt 32 größere Samen, davon 1 mit Embryo, 31 taub. Die Keimpflanzen waren teilweise sehr schwach, manche krüppelhaft (wahrscheinlich waren die Samen besonders schlecht ausgereift). Es blühten 36 Individuen, davon 14 subfallax, 22 rubrinervis. Von der subfallax 11 rotnervig, 3 weißnervig, von der rubrinervis 13 rot- und 9 weißnervig. Im ganzen 24 Rotnerven, 12 Weißnerven.

\section{Kreuzungen der Bastarde mit den Elternarten.}

a) Sesquireziproke Kreuzungen.

O. (biennis $\times$ muricata) $\times$ biennis (Samen zu 81-82\% keimhaltig) gibt nach de Vries reine biennis, unter vollständiger Ausschaltung der muricata-Merkmale ${ }^{1}$ ). Ich habe die Kreuzung mit dem von de Vries erhaltenen Bastard und meiner biennis gemacht und finde seine Angaben vollkommen bestätigt. Die Nachkommenschaft weist deutliche Unterschiede in der Blütengröße auf (Fig. 42), insofern als die Blüten teils die Größe der von biennis haben, teils merklich kleiner sind, im übrigen ist sie aber gleichförmig und von meiner biennis-Rasse in nichts $\mathrm{zu}$ unterscheiden: Stengel aufrecht, $110 \mathrm{~cm}$ hoch, ohne rote Tupfen, Blätter rotnervig, Spitzen der Kelchzipfel und der Brakteen rot, Samen zu $64-74 \%$ keimhaltig.

Auch in Kreuzungen verhält sich die so gewonnene biennis normal. Bei Bestäubung mit dem Pollen von $O$. muricata entsteht ein Bastard, der mit O. (biennis $\times$ muricata) identisch ist. Bei Bestäubung mit dem Pollen von $O$. Lamarckiana-weißnervig entstehen die Drillinge laeta, velutina und fallax, alle vom reinen biennis-Typus, ohne jeden Anklang an die Bastarde der O. muricata, mit der gewöhnlichen Blütengröße und Wuchshöhe.

Zahlen für O. (biennis $\times$ muricata) de Vries $\mathrm{F}_{5} \times$ biennis I 1, Samen 1914 gewonnen, 1915 und 1916 gesät: Gekeimt 69 Samen, nicht gekeimt 9, davon 7 taub, 2 mit Embryo. Es blühten 1915 einjährig 56 normale Individuen und 1 Mutante, schmalblättrig, unverzweigt; $1916 \mathrm{kam}$ ein als Rosette überwintertes Exemplar zweijährig zur Blüte. Bei der zweiten Anssaat 1916 keimten 29 Samen, kein Same blieb ungekeimt, es blühten 28 Stück.

O. [(biennis $\times$ muricata $) \times$ biennis $] 1 \times$ muricata II, Samen 1915 gewonnen, 1916 gesät: Gekeimt 24 Samen, nicht gekeimt 23 Samen, alle taub. Die Kotyledonen

1) Über die "Ausschaltung der Eigenschaften des zentralen Großelters" vergl. de Vries, Doppeltreziproke Bastarde, 1911; und 1913, S. $89 \mathrm{ff}$. 
sind anfangs fast immer gelb, der untere Teil wird dann meistens grün; ganz gelb bleibende Keimlinge, 7 Stück, gingen bald ein. Es blühten 16 Individuen.

O. [(biennis $\times$ muricata) $\times$ biennis] $1 \times$ Lamarckiana Vries II 1, Samen 1915 gewonnen, 1916 gesät: Gekeimt 38 Samen. Es blühten 32 Individuen, davon 20 laeta weißnervig, 6 velutina weißnervig, 6 fallax rotnervig.

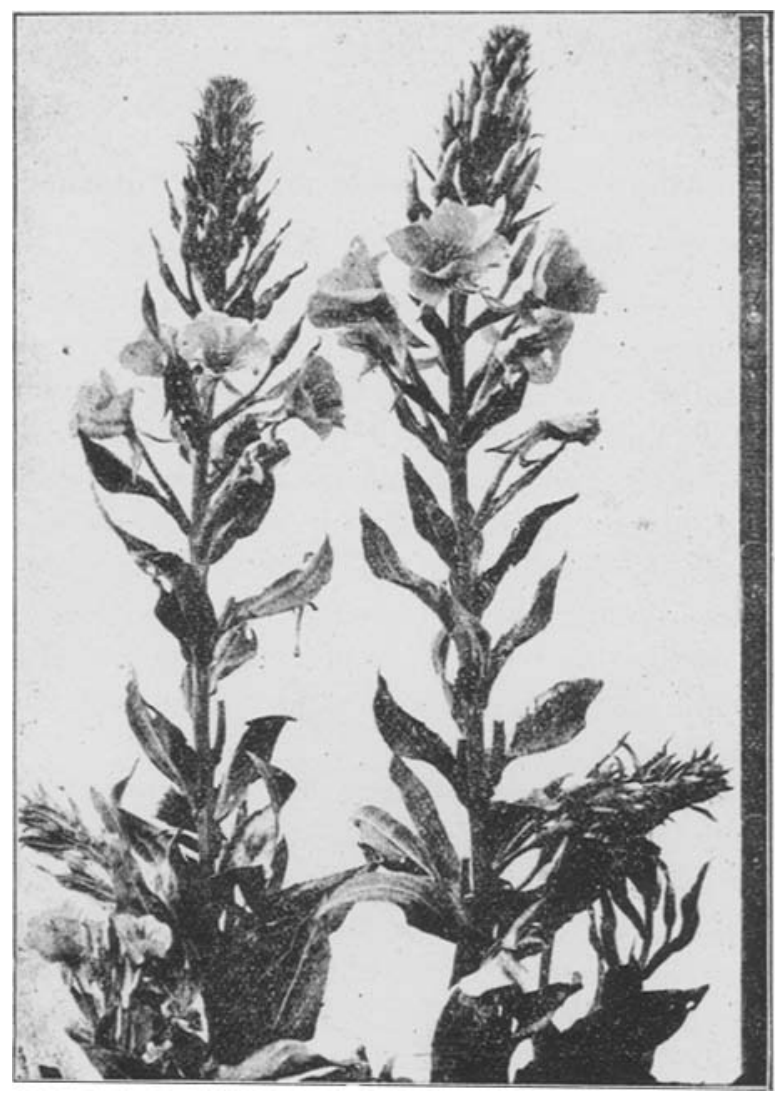

Fig. 42. O. (biennis $\times$ muricata $) \times$ biennis, einjährig, 31. 7.16. Rechts großblütig, von 0. biennis nicht zu unterscheiden, links kleinblütig.

O. (biennis $\times$ Lamarckiana) laeta $\times$ biennis. Samen (bei weißnerviger laeta) zu 46\% keimhaltig. Es entsteht einförmige biennis, vollkommen typisch, in allen Teilen und in allen Stadien, die Merkmale der $O$. Lamarckiana werden ausgeschaltet. Vor allem die geringe Höhe der Pflanzen $(100-110 \mathrm{~cm})$ unterscheidet sie weithin von der laeta; dazu kommt die Rotnervigkeit, die Rotfärbung der Kelch- und Brakteen- 
spitzen, die Kürze der Griffel, die Kleinheit der Blüten. - De Vries berichtet über diese Kreuzung nichts, ebensowenig über die folgende.

Zahlen für 0 . (biennis $\times$ Lamarckiana $\mathrm{X}$ ) laeta weißnervig $6 \times$ biennis I 1, Samen gewonnen 1914, gesät 1916: Gekeimt 44 Samen, nicht gekeimt 52, davon 1 mit Embryo, 51 taub. Es blühten 41 Individuen, teilweise etwas verkrüppelt, sonst gleichförmig biennis.

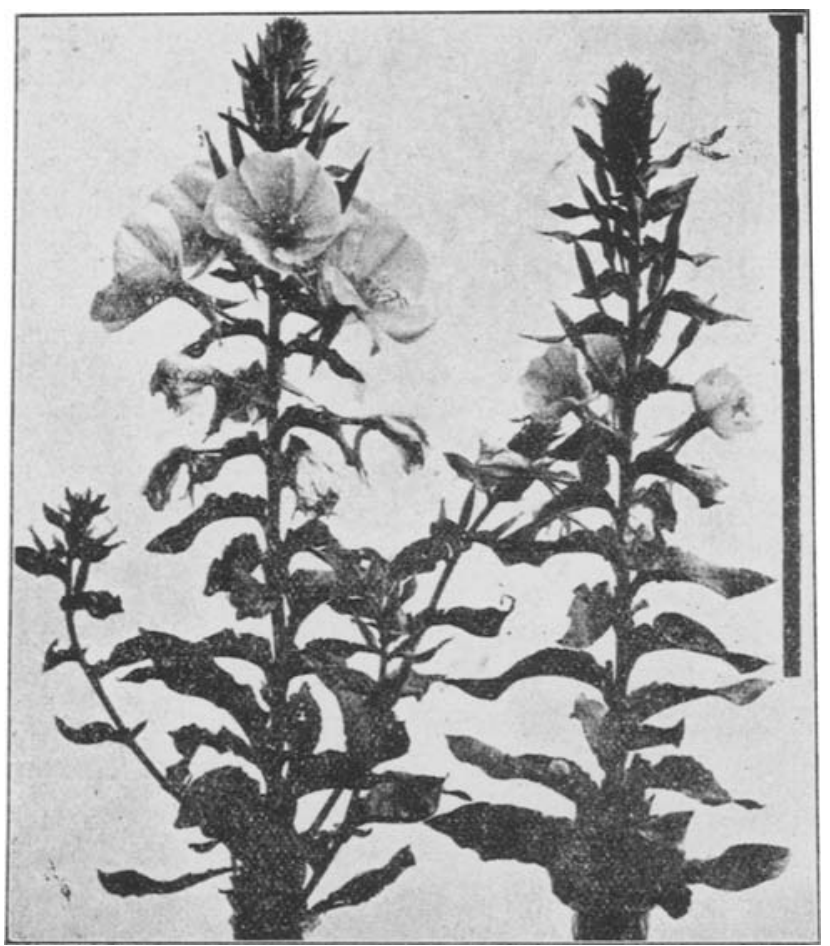

Fig. 43. O. Lamarchiana aus der Kreuzung O. Lamarckiana Her.-Nilss. weißnervig $\times($ biennis $\times$ Lamarckiana $\mathrm{X}$ ) laeta weißnervig, einjährig, bald nach dem Beginn der Blüte, 24. 7. 16. Links grob-, rechts kleinblütig. Brakteen zurückgeschlagen, rinnig, etwas wellig.

O. (biennis $\times$ Lamarckiana) velutina $\times$ biennis. Samen (bei rotnerviger velutina) zu $14 \%$ keimhaltig. Schon in den Keimschalen fehlt jede Ähnlichkeit mit velutina, die Keimpflanzen haben ganz den biennisbezw. laeta-Typus. Die erwachsenen Pflanzen sind wieder typische biennis, höchstens $130 \mathrm{~cm}$ hoch.

Zahlen für $O$. (biennis $\times$ Lamarckiana $X$ ) velutina rotnervig $1 \times$ biennis $I 1$, Samen gewonnen 1914, gesät 1916: Gekeimt 29 Samen, nicht gekeimt 40 größere Samen, alle tarb. Es blühten 29 Exemplare, teilweise etwas verkrüppelt. 
O. (biennis $\times$ Lamarckiana) fallax $\times$ biennis. Samen zu $45-68 \%$ keimhaltig. Es entsteht nicht biennis, sondern fallax, der zentrale Großelter wird hier also nicht ausgestoBen. Vergleiche auch die iterative Kreuzung $O$. (Lamarckiana $\times$ biennis) $\times$ biennis, S. 212. Die Kronenlänge war annähernd $35 \mathrm{~mm}$, geringe Unterschiede in der Blütengröße schienen vorhanden, doch ließen sich ohne genaue Messungen keine Gruppen bilden. Der Kelch war immer kräftig rot gestreift, doch nicht überall gleich; die Spitzen der Kelchzipfel waren teilweise kräftig rot, was sonst bei fallax nicht in diesem Maß vorkommt. In der Art der Verzweigung, der roten Punktierung der Stengel und Fruchtknoten usw. war keine Abweichung von fallax zu beobachten. Höhe $1 \mathrm{~m}$.

Zahlen für O. (biennis I $1 \times$ Lamarckiana H.-N. B I rotn. 1) fallax $\times$ biennis II 5, Samen 1915 gewonnen, 1916 gesät: Gekeimt 65 Samen. Von den gekeimten 2 schon in den Keimschalen ausgeblieben. Es blühten 61 Pflanzen, sämtlich rotnervig, größtenteils typische gesunde fallax. 2 Individuen waren krüppelhaft, 1 war ein $Z$ werg mit rundlichen Blättern, 2 spät schießende und blühende Exemplare hatten etwas schmälere Blätter, 2 Individuen blieben Rosetten.

O. Lamarckiana $\times$ (biennis $\times$ Lamarckiana) laeta. Samen $\mathrm{zu}$ $53 \%$ keimhaltig bei der schwedischen, zu $73 \%$ bei der de Vriesschen Rasse. Wie de Vries (1913, S. 162) mitteilt, entsteht unter Ausschaltung der biennis nur Lamarckiana. Ich nnterscheide aber nach der Blütengröße mindestens 2 Typen (vergl. Fig. 43), bei denen in der Mitte der Blütezeit (15. August) die Kronblätter 45 und $32 \mathrm{~mm}$ lang waren; zu Beginn der Blüte war die Länge der größten Kronen bis $55 \mathrm{~mm}$. Die großblütigen Individuen sind typische Lamarckiana, haben lange Griffel und breite braunrote Streifen auf den schlanken Kelchen, die kleinblütigen haben kurzen Griffel und schwache Streifen auf den plumperen Kelchen. Im Wuchs, in der Farbe, in der Punktierung der Stengel und Fruchtknoten, in der Streifung der Früchte, in der Gestalt der Fruchtähren kommen auch die kleinblütigen Individuen der $O$. Lamarckiana näher als irgend einer anderen Form. Stengelhöhe bis $150 \mathrm{~cm}$. Außer den Haupttypen fanden sich: 1 typische lata und 2 Individuen, die wohl als Mutante oblonga anzusprechen sind, mit schlanken Ästen, kurzen Blättern, kleinen Blüten, schmalen hellroten Streifen am Kelch, kurzen grïnen Früchten.

Zahlen für 0 . Lamarckiana V ries I $2 \times$ (biennis $\times$ Lamarckiana X) laeta weiBnervig 6, Samen gewonnen 1914, gesät 1916: Gekeimt 91 Samen, davon einige mit kranker Wurzel, nicht gekeimt 35, davon 1 mit Embryo, 34 taub. Es blühten $81 \mathrm{La}$ marckiana, davon 40 großblütig, 41 kleinblütig, und die 3 Mutanten, alle weibnervig. 
O. Lamarckiana $\times$ (biennis $\times$ Lamarckiana) velutina. Samen $\mathrm{zu}$ $3 \tilde{5}-\overline{4} 1 \%$ keimhaltig (bei der schwedischen Rasse als Mutter). Auch hier kann ich die Angabe von de Vries bestätigen, daß die biennis ausgeschaltet wird. Die entstehende Lamarekiana ist mindestens zweiförmig wie bei der vorhergehenden Kreuzung, die Blütengrößen sind dieselben. Stengelhöhe bis $160 \mathrm{~cm}$.

Zahlen für O. Lamarckiana $\mathrm{H}$. -N. weiBnervig A I $2 \times($ biennis $\times$ Lamarckiana $\mathrm{X}$ ) velutina weißnervig 2, Samen 1914 gewonnen, 1916 gesät: Gekeimt 48 Samen, nicht gekeimt 92, davon 91 tanb, 1 mit Embryo. Es blühten 46 Individuen, davon 24 grobblütig, 22 kleinblütig, alle weißnervig, 2 abweichende Keimpflanzen kamen nicht zur Entwicklung.

O. biennis $\times$ (Lamarckiana $\times$ biennis $)$ fallax. Samen $\mathrm{zu} 41 \%$ keimhaltig. Hier wird der zentrale Großelter Lamarckiana nicht ausgeschaltet, vielmehr entstehen neben typischer rotnerviger, $110 \mathrm{~cm}$ hoher biennis folgende Formen: am zahlreichsten velutina, und zwar weißnervig und rotnervig, $130-145 \mathrm{~cm}$ hoch, wobei die auch durch stärker rotstreifigen Kelch ansgezeichneten Rotnerven in zwei Typen, einen kräftig und einen schwach gefärbten, zu zerfallen scheinen; weiter rotnervige fallax, $110 \mathrm{~cm}$ hoch; dann eine ungetupfte, grünkelchige Form, die sich von der biennis nur durch weiße Blattnerven unterscheidet; am seltensten eine Form, die in den meisten Charakteren vollkommen einer laeta entspricht, hoch und schlank aufwächst, fast ganz über den Antheren liegende lange Narben und pollenarme Antheren besitzt, kräftig rot gefärbte Kelchspitzen hat wie biennis, bald weißnervig bald blaß rotnervig ist, aber wie velutina rote Tupfen am Stengel und an den Fruchtknoten trägt, an den späteren Blätenkelchen auch leicht rot gestreift ist, und punctilaeta heißen soll. - Als "Mutanten" wurden beobachtet: oblonga, rotnervig, mit kleinen Blüten, ziemlich breit rotstreifigem Kelch, kurzen Früchten, ziemlich dichter Fruchtähre, im übrigen der fallax recht ähnlich; eine Zwergform von velutina, mit sehr kurzen Internodien, breiten Blättern, kleinen hellgelben Blüten. - De Vries berichtet über diese Kreuzung nichts.

Zahlen für $O$. biennis I $1 \times$ (Lamarckiana $\times$ biennis) fallax $\mathrm{F}_{\mathrm{3}} 1$ von HeribertNilss on, Samen gewonnen 1914, gesät 1915: Gekeimt 142 Samen, nicht gekeimt 63, davon 61 taub, 2 mit Embryo; 1915 einjährig blühend: 84 velutina, teils weiß- teils rotnervig (die Auszählung wurde nicht früh genug vorgenommen, um die Rotnerven sicher zu unterscheiden), 17 fallax rotnervig, 9 biennis rotnervig, 1 punctilaeta blabrotnervig; Rosetten blieben 6 velutina, 4 fallax, 9 biennis, die zum gröBten Teil im Sommer 1916 zur Blüte kamen; darunter 5 rotnervige und 2 weißnervige biennis. Von denselben Samen wurde 1916 wieder eine Probe gesät, davon keimten 46, ungekeimt blieben 18 größere Samen, alle taub. Es blühten einjährig: velutina weißnervig 12 
darunter ein $Z$ werg, velutina rotnervig 12, fallax rotnervig 14, darunter eine "oblonga", biennis rotnervig 5, punctilaeta weißnervig 1; Rosette mit schwachen nicht blühenden Seitentrieben blieb 1 weißnerviges Individuum vom biennis-Typus. Zusammen wurden also erzogen 114 velutina, 35 fallax, 24 biennis, 2 punctilaeta. - O. biennis II $1 \times$ (Lamarckiana $\times$ biennis) H.-N. $\mathrm{F}_{3}$ zweijährig 16, Samen 1915 gewonnen, 1916 gesät: Gekeimt 68 Samen, nicht gekeimt 12 größere Samen, davon 2 mit Embryo, 10 taub. Es blühten 55 Pflanzen, davon velutina weißnervig 27 , velutina rotnervig 19 , fallax rotnervig 9; als Mutante trat ein velutina-ähnliches sehr spät schießendes Individuum auf mit sehr schmalen, fein gezähnten, glänzend dunkelgrünen, erst schwach rotnervigen, dann weißnervigen Blättern, mit fein getupftem, dicht abstehend behaartem Stengel; biennis und punctilaeta fehlten.

O. biennis $\times$ (rubrinervis $\times$ biennis) fallax. Es entstehen zur Hauptsache dieselben Formen wie bei Verwendung der fallax aus Lamarckiana, nämlich rot- und weißnervige velutina, und zwar von der dunkelgrünen schmalblättrigen Form, rotnervige biennis $(110 \mathrm{~cm}$ hoch), rotnervige fallax; punctilaeta ist noch nicht beobachtet worden.

Zahlen für O. biennis II $3 \times$ (rubrinervis I $2 \times$ biennis I 1) fallax 1, Samen 1915 gewonnen, 1916 gesät: Gekeimt 43 Samen, nicht gekeimt 27, alle taub. Die Keimlinge teilweise schwächlich und krüppelhaft, wohl weil die Samen nicht genügend ausgereift. waren. Es blühten 27 Pflanzen, davon 15 biennis rotnervig, 6 velutina rotnervig, 5 velutina weißnervig, 1 fallax rotnervig.

0 . biennis $\times$ (rubrinervis $\times$ biennis) subfallax. Die schmalblättrige velutina der vorhergehenden Kreuzung ist durch die breitblättrige, fast grünkelchige subvelutina ersetzt, die fallax durch subfallax, biennis tritt ebenso auf wie dort, außerdem ist ein laeta-artiges Individuum gefunden worden, mit hoch aufwachsendem, ungetupftem Stengel, grünem Kelch, roten Kelchspitzen, weißnervigen Blättern, ziemlich kurzen Griffeln, Blüten etwa von der Größe der biennis.

Zahlen für $O$. biennis II $3 \times$ (rubrinervis I $2 \times$ biennis I 1) subfallax 2, Samen 1915 gewonnen, 1916 gesät: Gekeimt 32 Samen, nicht gekeimt 23, alle taub. Es blühten 27 Pflanzen, davon 3 biennis rotnervig, 6 subvelutina rotnervig, 12 subvelutina weißnervig, 5 subfallax rotnervig, 1 "laeta" weißnervig.

0. (Lamarckiana $\times$ biennis) fallax $\times$ Lamarckiana. Samen zu $31 \%$ keimhaltig. Wie de Vries angibt (1913, S. 162), werden die Merkmale der biennis zur Hauptsache ausgeschaltet und es entsteht Lamarckiana, doch teilweise mit kleinen Blüten und kurzen Griffeln. Ich stellte die Kreuzung her, um den Rotnervenfaktor der biennis auf weißnervige Lamarckiana zu übertragen und erbielt tatsächlich unter anderen Formen großblütige rotnervige Lamarckiana. Es traten Rot- und Weißnerven auf, von denen die Rotnerven weniger buckliges Laub hatten, wie es auch Heribert-Nilsson von seinen Rotnerven beschreibt; Stengelhöhe bis $145 \mathrm{~cm}$. Nach der Blütengröße waren 
mindestens zwei Typen zu unterscheiden, der eine mit (am 16. August) $45 \mathrm{~mm}$ langen Kronblättern, langen Griffeln, stark gefärbtem schlankem Kelch, der andere mit $35 \mathrm{~mm}$ langer Krone, kürzerem Griffel, schwächer gefärbtem, ziemlich plumpem Kelch. Die Rotfärbung des Kelchs war bei den Rotnerven stärker als bei den Weißnerven, fast ganz kupferfarben war der Kelch bei den großblütigen Rotnerven. Nach der Höhe der Fruchtähren zeigten auch die kleinblütigen Individuen den Typus der Lamarckiana, nur ein kleinblütiger Rotnerv hatte kürzere dichtere Fruchtähren und war recht fallax-ähnlich, auch nur $1 \mathrm{~m}$ hoch. In einem einzigen Individuum trat eine ganz laeta-artige Form auf, ohne Tupfen am Stengel und an den Fruchtknoten, hoch und schlank, rotrervig, mit langen Griffeln, grünen Kelchen und Früchten, doch pollenreichen Antheren. Als Mutanten fanden sich zwei verkrüppelte, reich verzweigte Individuen mit kleinen, dicklichen rotnervigen Blättern, kleinen Blüten, rot getupftem Stengel.

Zahlen für 0 . (Lamarckiana-weißnervig $\times$ biennis) $\mathrm{H}$.-N. fallax $\mathrm{F}_{\mathrm{g}} 1 \times \mathrm{La}$ marckiana H.-N. weiBnervig A I I: Gekeimt 47 Samen, nicht gekeimt 69, alle taub. Es blühten 45 Individuen, davon Lamarckiana weißnervig 26, rotnervig 16, laeta rotnervig 1 , rotnervige $Z_{\text {werge }} 2$; zusammen 26 Weiß- und 19 Rotnerven.

Wenn die schwedische rotnervige $O$. Lamarckiana, wie ich glaube, einer Kreuzung von Lamarckiana und biennis ihre Entstehung verdankt, so sind gewisse Eigentümlichkeiten, die nach Heribert-Nilsson die rotnervigen von den weißnervigen Typen unterscheiden ${ }^{1}$ ), leicht verständlich. Die größere Fruchtlänge der Rotnerven wird ein Erbstück der O. biennis sein, denn die Früchte der 0 . biennis sind schlanker als die der $O$. Lamarckiana, und die Früchte der fallax stehen zwischen denen der beiden Eltern. Die rein grüne Farbe des Laubes der Rotnerven gegenüber dem graulichen Grün der Weißnerven ist ebenfalls bei $O$. biennis und bei dem Bastard fallax vorzufinden.

\section{b) Iterative Kreuzungen.}

O. biennis $\times$ (biennis $\times$ Lamarckiana) laeta. Samen zu $61-63 \%$ keimhaltig (bei weißnerviger laeta). Nach de Vries entsteht laeta (1913, S. 138). Bei Verwendung einer weißnervigen laeta erhielt ich eine durchaus einförmige weißnervige Nachkommenschaft, die ganz und gar den laeta-Typus trug (Fig. 44) und fast noch höher wuchs (zweijährig bis $220 \mathrm{~cm}$ ) als die ursprüngliche laeta.

1) Heribert-Nilsson 1912, S. $103 ; 1915$, S. 37. 
Zahlen für O. biennis I $1 \times$ (biennis $\times$ Lamarckiana $\mathrm{X}$ ) laeta weißnervig 6 , Samen 1914 gewonnen, 1915 gesät: Gekeimt 134 Samen, nicht gekeimt 84, alle ohne Embryo. Es blühten 1915 einjährig 84 Stück, 1916 zweijührig 35 Stück, zusammen 119.

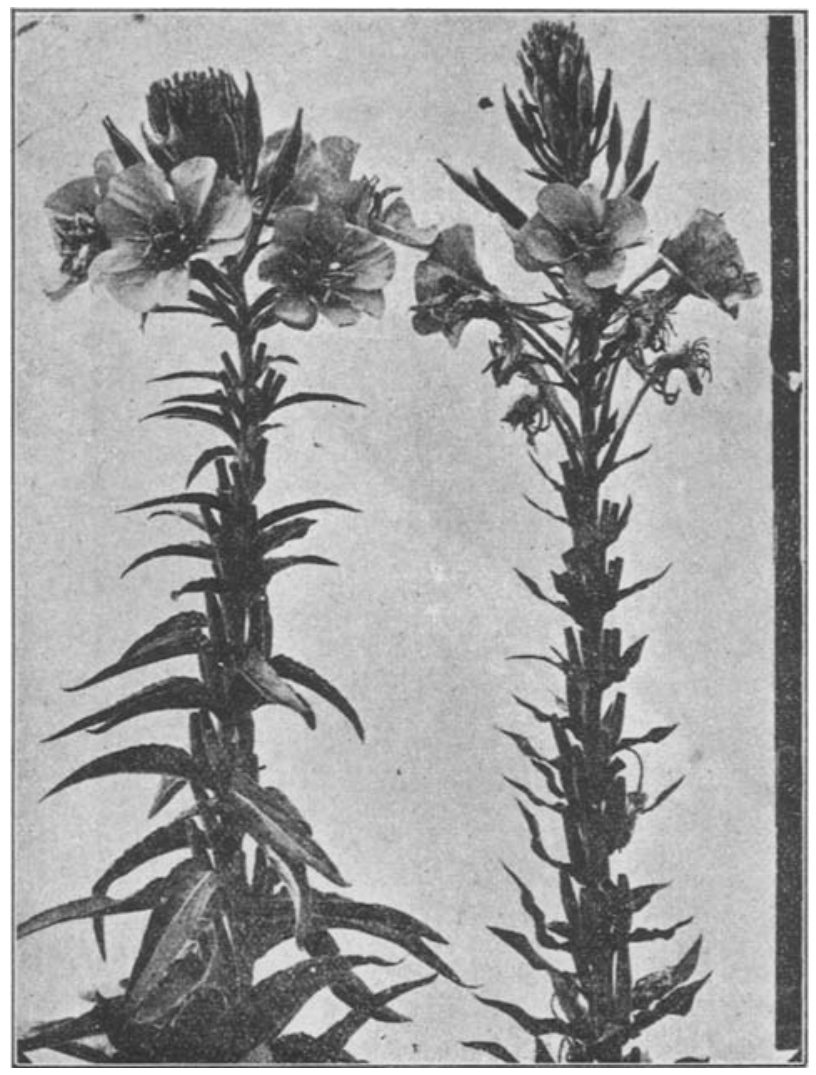

Fig. 44. Rechts weißnervige laeta aus $O$. biennis $\times$ (biennis $\times$ Lamarckiana $X)$ laeta-weißnervig, links rotnervige großblütige velutina aus 0 . biennis $\times$ (biennis $\times$ Lamarckiana $\mathrm{X}$ ) velutina-rotnervig. -Beide zweijährig; 30. 7. 16. An der velutina fallen die großen Brakteen auf, im übrigen sind die beiden Formen durch dieselben Charaktere unterschieden wie die Zwillinge in der $F_{1}$ der ursprünglichen Kreuzung. Die Dichte der Fruchtstände ist nicht charakteristisch für die iterativen Kreuzungen, sondern rührt davon her, daß die Individuen zweijährig gewachsen waren.

O. biennis $\times$ (biennis $\times$ Lamarckiana) velutina. Samen $\mathrm{zu} 43 \%$ keimhaltig (bei rotnerviger velutina). Nach de Vries entsteht velutina bei Verwendung von (muricata $\times$ Lamarckiana) velutina (1913, S. 138). 
Ich erhielt mit dem Pollen einer rotnervigen velutina lauter ausgesprochene velutina (Fig. 44), und zwar rot- und weißnervig mit unscharfer Grenze zwischen den schwächer rotnervigen und den weißnervigen Individuen. Der Wuchs war meist etwas niedriger als bei der ursprünglichen velutina (zweijährig bis $130 \mathrm{~cm}$ hoch), der Habitus etwas verschieden, vor allem die Verzweigung stärker, die roten Haarpolster mitunter recht spärlich. Die Rotnerven hatten größere tiefgelbe Kronen

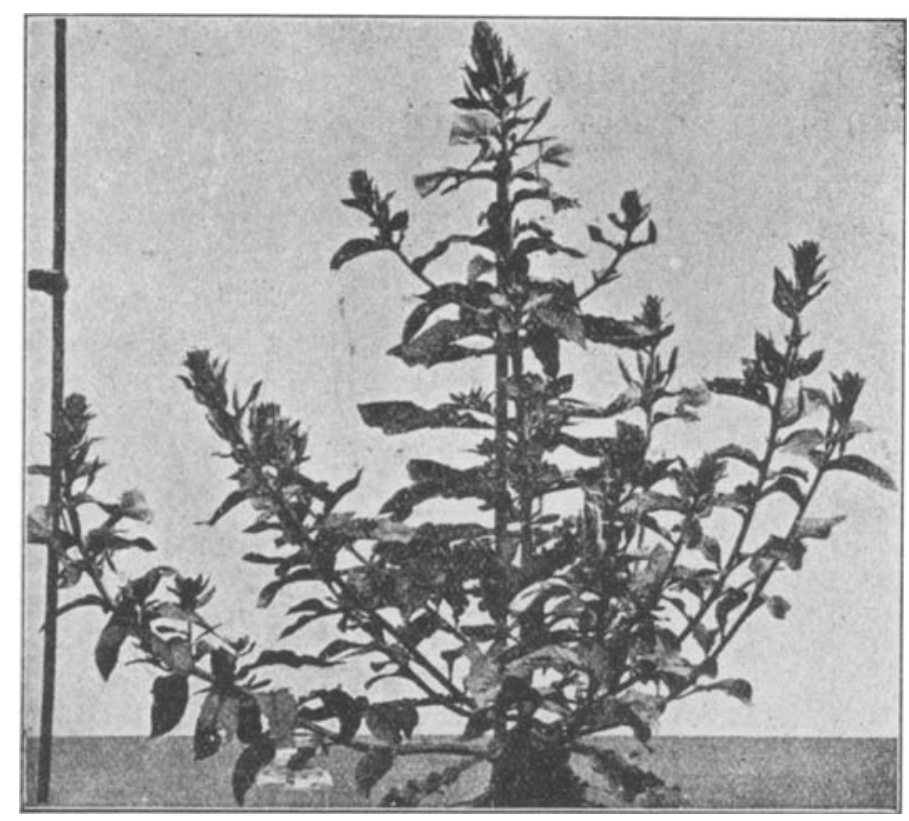

Fig. 45. O. (Lamarckiana $\times$ biennis) fallax $\mathrm{F}_{\mathrm{B}}$ rotnervig von Her.-Nilss. $X$ biennis, einjährig, beim Beginn der Blüte, 11. 7. 16. Typische fallax. Blüten so grob wie bei der $\mathrm{F}_{1}$ von fallax.

und breit rotstreifige Kelche, die Weißnerven waren schwächer verzweigt und hatten kleinere hellgelbe Kronen und schwach gefärbte Kelche.

Zahlen für O. biennis $\mathrm{I} 1 \times$ (biennis $\times$ Lamarckiana $\mathrm{X}$ ) velutina rotnervig 1 , Samen 1914 gewonnen, 1915 gesät: Gekeimt 119 Samen, nicht gekejmt 42, davon 41 taub, 1 mit Embryo. Es blühten 1915 einjährig 61 Rotnerven und 20 Weißnerven, 1916 zweijährig 6 Rotnerven und 1 Weißnerv, zusammen 88 Pflanzen.

O. biennis $\times$ (biennis $\times$ Lamarckiana) fallax. Samen zu $62-69 \%$ keimhaltig. Es entstehen dieselben Formen wie bei Verwendung der auf dem reziproken Weg gewonnenen fallax: rotnervige biennis, rot- 
und weißnervige velutina, rotnervige fallax, weißnervige punctilaeta, die in allen Stücken der oben beschriebenen Eorm gleicht; weißnervige biennis ist noch nicht gefunden worden.

Zahlen für O. biennis II $5 \times$ (biennis $11 \times$ tamarckiana $\mathrm{H} . \mathrm{N}$. B I rotnervig 1 ) fallax 1, Samen gewonnen 1915, gesät 1916: Gekeimt 37 Samen, nicht gekeimt 32, alle taub; Keimlinge großenteils schwach, weil die Samen schlecht ansgereift. Es blühten 27 Pflanzen, davon 16 biennis rotnervig, 3 velutina weißnervig, 3 velutina rotnervig, 4 fallax rotnervig, 1 punctilaeta weißnervig.

O. (Lamarckiana $\times$ biennis) fallax $\times$ biennis. Samen $\mathrm{zu} 47-59 \%$ keimhaltig. Es entsteht nur fallax (Fig. 45), ebenso wie bei Verwendung der auf dem reziproken Weg gewonnenen fallax. Der Stengel wird $1 \mathrm{~m}$ hoch, die Blätter sind tief rotnervig, die Fruchtähren kurz und dicht. Nach den Blüten scheinen zwei transgredierende Typen vorzukommen, der eine mit etwas größerer Krone und stärker rotstreifigem Kelch als der andere. - Bis auf ein schmalblättriges weit abweichendes Individuum war die Saat recht gleichförmig.

Zahlen für O. (Lamarckiana $\times$ biennis) $\mathrm{H} . \mathrm{-N}$. fallax $\mathrm{F}_{3} 1 \times$ biennis $\mathrm{I} 1$, Samen gewonnen 1914, gesät 1916: Gekeimt 88 Samen, nicht gekeimt 114, alle taub, 25 sehr klein. Es blühten 80 Pflanzen, davon 79 typische fallax, 1 eine schmalblättrige Mutante.

O. (biennis $\times$ Lamarckiana) laeta $\times$ Lamarckiana. Samen zu $58 \%$ keimhaltig. Nach de Vries entstehen laeta und velutina; "unter den laeta kommen jedoch mehrfach abweichende Exemplare vor, welche sich der Lamarckiana mehr nähern" (1913, S. 134). Mein Befund ist derselbe, doch handelt es sich zweifellos um das Auftreten typischer Lamarckiana neben laeta und velutina. Die Lamarckiana-Individuen sind durch die roten Tupfen am Stengel und an den Fruchtknoten und durch die roten Streifen an den Kelchen und Früchten von der anthokyanfreien laeta weit verschieden; ihre Höhe beträgt bis $135 \mathrm{~cm}$. Alle drei Formen kommen in zwei Typen vor, mit großen und kleinen Blüten; die großen Blüten entsprechen in den Maßen denen der Lamarckiana (Länge der Kronblätter etwa $45 \mathrm{~mm}$ ) und sind langgrifflig, die kleineren haben dieselben Maße wie die der primären Zwillinge (etwa $35 \mathrm{~mm}$ ) und besitzen ziemlich kurze Griffel. Die kleinblütigen Individuen von laeta und velutinna haben steil aufsteigende, die großblütigen weit ausladende Grundäste. Besonders auffallend ist die großblütige velutina (Fig. 46), die dunkelgelbe Kronen, lange Lamarckiana-artige Griffel und kräftig rotstreifige Kelche besitzt und höher wird $(150 \mathrm{~cm})$ als die kleinblütige velutina $(130 \mathrm{~cm})$. Die großblütige laeta hat sehr lange Griffel und wächst sehr hoch auf, bis $165 \mathrm{~cm}$. 
Zahlen für 0 . (biennis $\times$ Lamarckiana $\mathrm{X}$ ) laeta weiBnervig $6 \times$ Lamarckiana Vries I 2, Samen gewonnen 1914, gesät 1916: Gekeimt 96 Samen, nicht gekeimt 58, davon 57 taub, 10 sehr klein, 1 mit Embryo. Schon in den Keimschalen fällt auf, daß die velutina teilweise nicht typisch ist, kleinere Blätter hat als sonst. Es blühten

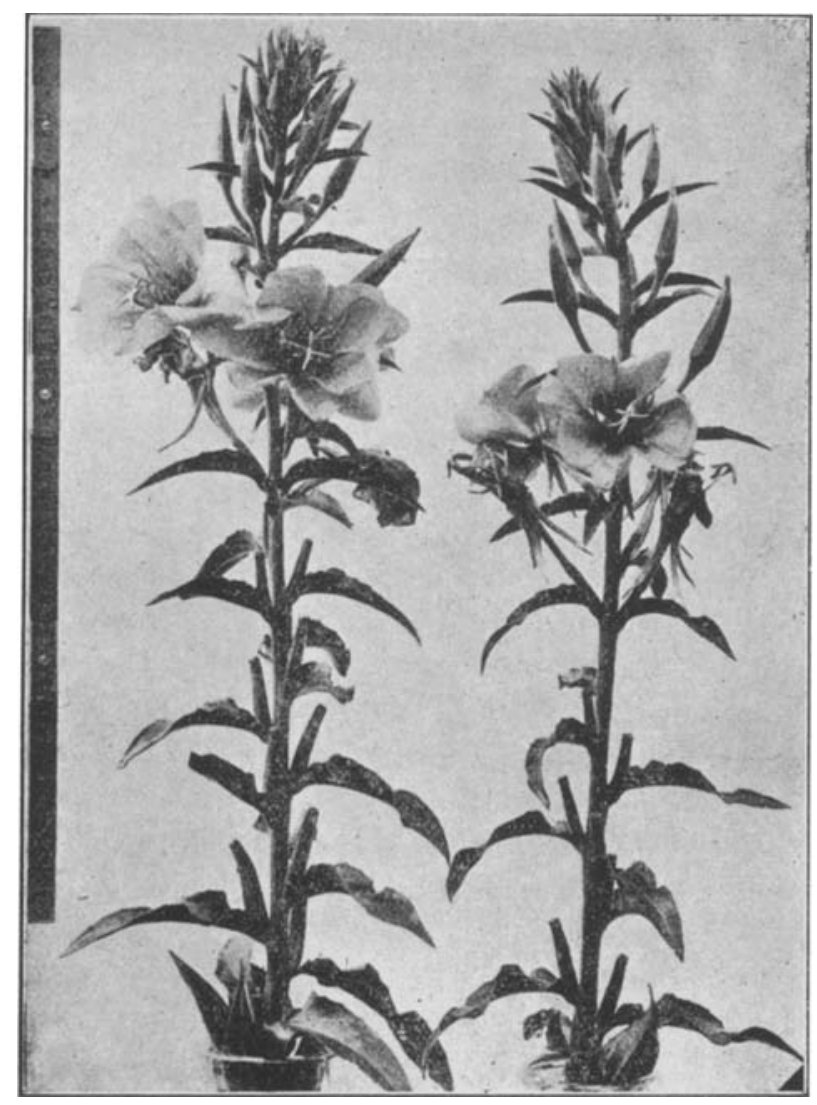

Fig. 46. Links großblütige langgrifflige, rechts kleinblütige kurzgrifflige velutina aus 0 . (biennis $\times$ Lamarckiana $\mathrm{X}$ ) laeta-weißnervig $\times$ Lamarckiana de Vries. Beide einjährig. 29. 7. 16.

91 Pflanzen, davon 41 laeta, und zwar 19 großblütig, 22 kleinblütig, 23 velutina, und zwar 11 großblütig, 12 kleinblütig, 27 Lamarckiana, und zwar 15 großblütig, 12 kleinblütig; im ganzen 45 groß- and 46 kleinblütig, alle weißnervig.

\section{Kreuzungen von Zwillingsbastarden miteinander.}

O. (biennis $\times$ Lamarckiana) laeta $\times$ (biennis $\times$ Lamarckiana) velutina. Samen zu 68-75\% keimhaltig. Nach de Vries (1913, S. 142) 
entstehen laeta und velutina, und zwar ist "die Velutina stets einförmig, die Laeta oft zum Teil mehr der Lamarckiana selbst ähnlich". Bei mir trat keine laeta auf, sondern zur Hauptsache Lamarckiana und daneben velutina. Die velutina war in der Blütengröße mindestens zweiförmig wie in der vorstehenden Kreuzung, die kleinblütige Form 110, die großblütige $140 \mathrm{~cm}$ hoch; die Lamarckiana dreiförmig, am 15. August mit 42, 34 und $24 \mathrm{~mm}$ langen Kronblättern, in der Anthokyanbildung am

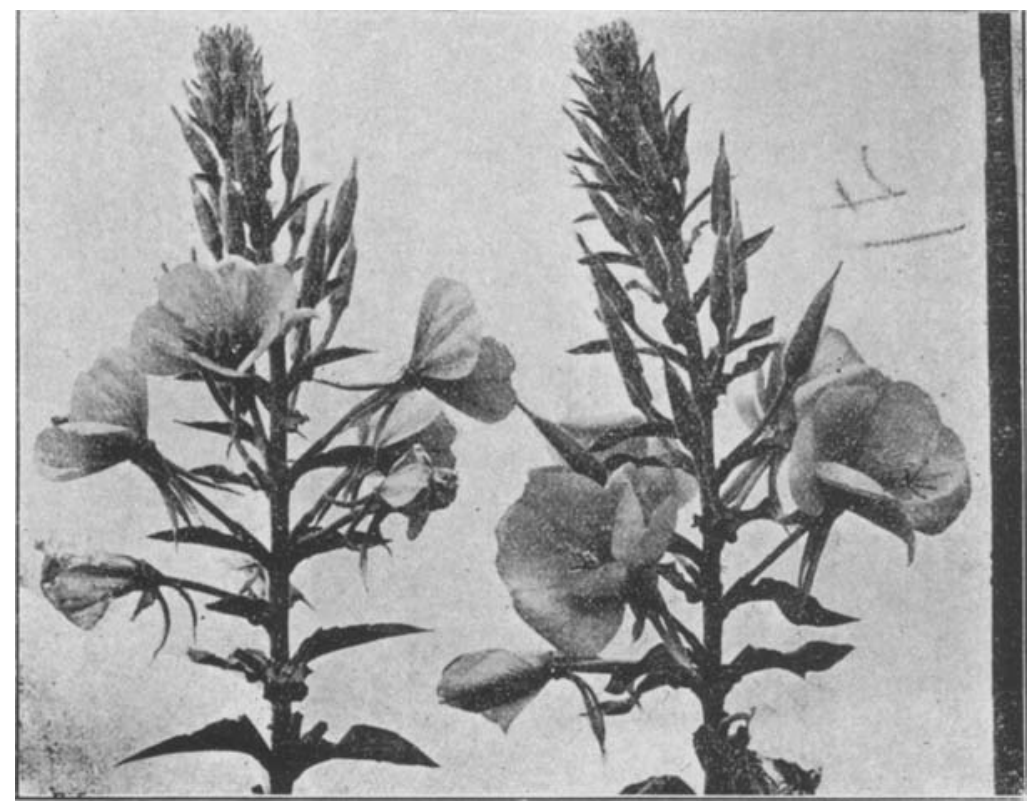

Fig. 47. Links kleinblütige, kurzgrifflige, rechts großblütige langgrifflige Lamarckiana aus 0 . (biennis $\times$ Lamarckiana $\mathrm{X}$ ) velutina $\times$ (biennis $\times$ Lamarckiana X) laeta. Beide einjährig. 31.7.16.

Kelch verschieden, aber immer zweifellos Lamarckiana und nicht laeta, bis $160 \mathrm{~cm}$ hoch.

Zahlen für O. (biennis $\times$ Lamarckiana $\mathrm{X}$ ) laeta weißnervig $1 \times($ bien. $\times$ Lam. $\mathrm{X}$ ) velutina weißnervig 2, Samen 1914 gewonnen, 1916 gesät: Gekeimt 68 Samen, nicht gekeimt 20, davon 3 mit Embryo, 17 taub. Die velutina schon in den Keimschalen als teilweise nicht typisch zu erkennen. Es blühten 58 Pflanzen, davon 46 Lamarckiana, 12 velutina, alle weißnervig.

0 . (biennis $\times$ Lamarckiana) velutina $\times($ bien. $\times$ Lam.) laeta. Samen zu 88-91\% keimhaltig. Nach de Vries entsteht laeta, doch ist sie "teils reine laeta, teils mehr der Lamarckiana ähnlich" (1913, S. 143). 
Ich finde zur Hauptsache unzweifelhafte Lamarckiana (Fig. 47) und daneben laeta (Fig. 48), beide in drei besonders nach der Blütengröße verschiedenen Formen, wobei die großen Blüten längere Griffel und bei Lamarckiana auch stärkere Rotstreifung des Kelches besitzen. Bei der

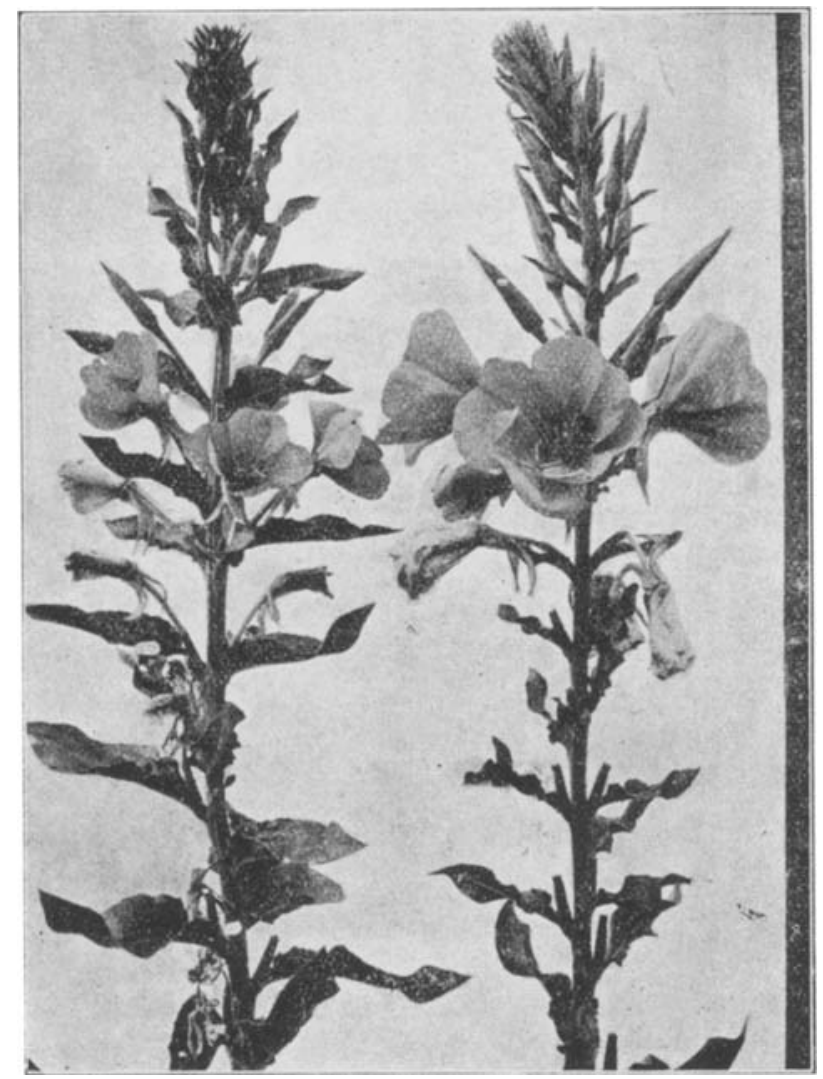

Fig. 48. Links kleinblïtige kurzgrifflige, rechts großblütige langgrifflige laeta aus $O$. (biennis $\times$ Lamarckiana $\mathrm{X}$ ) velutina $\times 0$. (biennis $\times$ Lamarckiana X) laeta. Beide einjährig. Als laeta sind die Individuen in der Photographie vor allem zu erkenmen an den welligen gedrehten Brakteen und an den lockeren Infloreszenzen. Anfang August 1916.

Lamarckiana sind die Extreme der Kronenlänge zu Beginn der Blüte 50 und $30 \mathrm{~mm}$, am 15. August 40 und $24 \mathrm{~mm}$; die Knospen der großen Blüten sind schlank wie bei der Mutterart Lamarckiana, die der kleinen viel plumper; die Stengel sind bis $140 \mathrm{~cm}$ hoch. Bei der. laeta wurden 
45 und $28 \mathrm{~mm}$ lange Kronen gemessen, am 15. August drei Größen, nämlich 45, 35 und $27 \mathrm{~mm}$, die Stengel bis $150 \mathrm{~cm}$ hoch. - Als Abweicher wurden beobachtet: ein Individuum vom Lamarckiana-Typus, mit sehr kleinen Blüten, kurzen und dicken, abstehend behaarten Blütenknospen, sehr schwach rotgestreiftem Kelch, kurzem Griffel, krausen Deckblättern, kurzen dicken Früchten; ein schlankes, sehr hoch aufwachsendes (über $170 \mathrm{~cm}$ erreichendes) wenig verzweigtes Individuum, mit schmalen glänzenden Blättern, wenig behaart, am Stengel nur spärlich rot getupft, mit sehr langer schlanker lockerer Fruchtähre, grünen Früchten, zwischen den Blütenknospen tief rot gefärbter Achse (velutina-Merkmal!).

Zahlen für O. (biennis $\times$ Lamarcliana $\mathrm{X}$ ) velutina weißnervig $1 \times$ (biennis $\times$ Lamarckiana X) laeta weißnervig 2, Samen 1914 gewonnen, 1916 gesät: Gekeimt 71 Samen, viele mit schlechter Wurzel, nicht gekeimt 6, davon 1 mit Embryo, 5 taub. Es blühten 48 Lamarckiana, meist kleinblütig, 10 laeta, davon 6 klein- und 4 großblütig, und die zwei Abweicher; alle weißnervig.

Mein Befund für die Kreuzungen zwischen den beiden Zwillingen ist also: Wenn laeta und velutina gekreuzt werden, besteht die Nachkommenschaft zur Hauptsache aus Lamarckiana. Daneben tritt in geringerer Zahl die Zwillingsform auf, die als Vater verwendet wurde.

\section{Allgemeine Erfahrungen über die Vererbungs- erscheinungen.}

\section{Die Zahlenverhältnisse.}

Fürs erste muß das wenig erfreuliche Bekenntnis ausgesprochen werden, daß die Zahlenverhältnisse, die bei den als Mendelspaltung aufgefaßten Erscheinungen der Zwillingsbildung auftreten, durchaus inkonstant sind. Die einzige Kreuzung, die ich mehrmals ausgeführt habe, ist die zwischen $O$. biennis 9 und $O$. Lamarekiana $\sigma^{7}$. Schon de Vries teilt mit, daß die hier entstehenden Zwillinge laeta und velutina in ziemlich wechselndem Zahlenverhältnis erscheinen; die laeta-Individuen machten in seinen Versuchen 27-66\% der Nachkommenschaft aus (vergl. z. B. die Übersicht 1913, S. 288). Weil de Vries nicht kontrolliert hat, ob sämtliche voll entwickelten Samen auch wirklich zur Keimung kamen, sind seine Zahlen nicht recht verwertbar, aber in meinen eigenen Kulturen, in denen diese Kontrolle durchgeführt wurde, ist der Prozentgehalt an laeta ebenso variabel. Allerdings sind nicht alle gekeimten 
Samen bis zur Blüte gekommen, wie in den allermeisten Fällen, so daß die Zahlen noch weit davon entfernt sind wirklich zuverlässig $\mathrm{zu}$ sein. Die oben (S. 181/2) mitgeteilten Zahlen sind in der folgenden Tabelle unter a-f zusammengestellt, zunächst unter Übergehung der fallax; $\mathrm{g}$ bezieht sich auf muricata $\times$ Lamarckiana.

\begin{tabular}{|c|c|c|c|c|c|c|c|c|}
\hline Kreuzung & & a & $\mathrm{b}$ & c & $d$ & e & $\mathrm{f}$ & $\mathbf{g}$ \\
\hline Zahl der laeta-Individuen & . & 21 & 27 & 17 & 7 & 51 & 20 & 19 \\
\hline Zahl der velutina-Individuen & . & 19 & 32 & 44 & 27 & 19 & 98 & 51 \\
\hline laeta in $\%$. . . . . & . & 52 & 46 & 28 & 21 & 73 & 17 & 27 \\
\hline
\end{tabular}

Es dürfte schwer sein, für die laeta-velutina-Spaltung eine andere theoretische Deutung zu geben als eine solche, bei der die Zwillinge zunächst in gleicher Zahl zu erwarten wären. Tatsächlich schlägt der Prozentsatz an laeta nach beiden Seiten weit über $50 \%$ hinaus, ebenso wie bei de Vries. Zahlreiche andere Kreuzungen, die de Vries ausgeführt hat, haben zu demselben Ergebnis einer großen Variabilität der Zahlenverhältnisse geführt (vergl. z. B. die schon zitierte Übersicht 1913, S. 288); besonders überraschend sind seine Erfahrungen bei der Kreuzung o. Lamarckiana $\times$ nanella, bei der der. Prozentsatz der neben den hochwüchsigen Lamarckiana-Individuen auftretenden Zwerge sich zwischen 1 und $94 \%$ bewegt. Bei den älteren, in der Mutationstheorie mitgeteilten Versuchen war der höchste Gehalt an nanella $48 \%$. Vor kurzem hat de Vries ${ }^{1}$ ) aber berichtet, daß der Gehalt an Zwergen weit über $50 \%$, bis auf $94 \%$, gesteigert werden kann, wenn man sehr kräftige, zweijährige Individuen beider Arten zu den Bestäubungen verwendet. Streng genommen ist das Resultat wegen der Unterlassung der Kontrolle der Samenkeimung eigentlich nicht diskutabel, aber zufällig steht mir ein ungefähr vergleichbarer Versuch zur Verfügung, gegen den dieser Einwand nicht erhoben werden kann. Im Sommer 1915 habe ich ein einjähriges Individuum von $O$. biennis (e der obigen Tabelle) mit dem Pollen einer einjährigen $O$. Lamarckiana, und eine zweite einjährige $O$. biennis (d der Tabelle) mit dem Pollen einer zweijährigen $O$. $L a$ marckiana bestäubt. Im ersten Fall bekam ich 51 laeta, 19 velutina und 1 fallax, im zweiten 7 laeta, 27 velutina und 12 fallax. Ob diese

1) „Über amphikline Bastarde," 1915, S. 465. 
Unterschiede im züchterischen Verhalten mit dem ein- bezw. zweijährigen Zustand etwas zu tun haben, ist aber vorläufig unklar, solange nicht ein und dasselbe Individuum im ein- und im zweijährigen Zustand verwendet wird; eine solche Prüfung ist wenigstens für $O$. biennis leicht möglich, weil hier häufig basale Seitensprosse als Rosetten über den Winter am Leben bleiben. Es könnte ja ganz wohl sein, daß die beobachteten Verschiedenheiten individueller Art sind, daß z. B. das Verhältnis zwischen laeta und velutina für ein und dasselbe pollenliefernde Lamarckiana-Individuum zwischen gewissen Grenzen fest und von Individunm zu Individuum verschieden ist. Dafür scheint zu sprechen, $\mathrm{daß}$ in den Versuchen $\mathrm{d}$ und $\mathrm{g}$, zu denen derselbe Vater O. Lamarckiana H.-N. A I 31 verwendet wurde, der Prozentgehalt an laeta ziemlich ähnlich ist $(21 \%$ bei biennis als Mutter, 27 bei muricata). Für wahrscheinlicher freilich halte ich es, daß schon bei getrennter Aussaat der Samen einzelner gleich behandelter Früchte derselben Pflanze das Zahlenverhältnis zwischen den Zwillingen ähnlich variabel gefunden wird wie das zwischen gesunden und tauben Samen ${ }^{1}$ ). Vielleicht kommt der physialogischen Ungleichartigkeit verschiedener Pollentypen dabei eine wesentliche Bedentung zu; das läBt sich natürlich leicht prüfen durch Vergleichung solcher Kreuzungen, in denen gleichartige Eizellen mit ungleichartigem Pollen verbunden werden, mit anderen Verbindungen, in denen die Eizellen verschiedenen Typen angehören und der Pollen einen einzigen Typus darstellt. Vorläufig müssen wir uns mit der einfachen Feststellung begnügen, daß die Zahlenverhältnisse zwischen den sichtbar werdenden Biotypen sehr variabel sind, sogar noch variabler als das Verhältnis zwischen gesunden und tauben Samen, und wir haben daraus den Schluß zu ziehen, daß wir bei geringer Anzahl der Einzelversuche bei einer und derselben Kreuzung - meistens ist die Verbindung zweier Sippen überhaupt nur ein einziges Mal hergestellt worden - auf die Zahlenverhältnisse gar keinen Wert legen dürfen. Von den Zahlen wird deshalb bei der Besprechung der Züchtungsergebnisse im allgemeinen nicht die Rede sein. Auch die eingehenden Diskussionen, die Heribert-Nilsson an die in seinen Kulturen beobachteten Zahlenverhältnisse knüpft, dürften bedauer-

1) Für die Kreuzung O. Lamardiana $\times$ nanella hat de Vries (1915, S. 465) den Versuch schon gemacht, wobei der Gehalt an Zwergen sich bei Früchten desselben Lamarckiana-Individuum als stark schwankend erwies. Leider war er gezwungen den Pollen von mehreren nanella-Exemplaren zu verwenden. 
licherweise durch unsere Erfahrungen an Wert beträchtlich verlieren, um so mehr als die Keimung der Samen nicht kontrolliert ist.

Über einfache Mendelsche Zahlenverhältnisse bei der Spaltung nach der Blütengröße und nach der Blattnervenfarbe vergleiche die nächsten Abschnitte.

\section{Die Vererbung der Blütengröße.}

Werden zwei Oenothera-Arten von verschiedener Blütengröße gekreuzt, so ist dieser Charakter in der ersten Bastardgeneration intermediär. Die Blïtengröße ist für die ganze $\mathrm{F}_{1}$ gleichförmig, falls diese einen einzigen Typus darstellt, wie z. B. 0 . (biennis $\times$ muricata) oder $O$. (Lamarckiana $\times$ biennis) fallax. Sind mehrere Typen vorhanden, so kann die Blütengröße innerhalb der $F_{1}$ verschieden sein; so hat aus der Kreuzung O.biennis $\times$ suaveolens der Zwilling suavis größere Blüten als der Zwilling flava. Innerhalb jedes Typus ist die Blütengröße wieder konstant. Gleich groß sind die Blüten der Drillinge laeta, velutina und fallax aus $O$. biennis $\times$ Lamarekiana. - Wenn de Vries $(1913$, S. 119, 127) die Größe der Blumenkronen bei laeta und bei velutina in $\mathrm{F}_{1}$ sehr wechselnd fand, so rührte das wahrscheinlich von der verwendeten $O$. Lamarckiana her, die vielleicht aus irgendwelchen Kreuzungen herausgespalten war und auch bei Selbstbestäubung verschiedene Blütengrößen hervorgebracht hätte.

In der $\mathrm{F}_{2}$-Generation tritt allgemein Spaltung nach der Blütengröße ein. In den etwas genauer untersuchten Fällen ließen sich meist drei Typen unterscheiden, wobei der mittlere Typus die Blütengröße der $F_{1}$ wiederholt, die beiden anderen ungefähr zu den Eltern zurückkehren; so bei den fallax-Formen. Es ist aber doch fraglich, ob zwischen $O$. Lamarckiana und biennis und zwischen biennis und muricata jeweils ein einziger mendelnder Unterschied inbezug auf die Blütengröße tätig ist.

Wenn zwei nah verwandte Bastarde, wie die Zwillinge laeta und velutina aus 0 . biennis $\times$ Lamarckiana, miteinander gekreuzt werden, so sind die Verhältnisse der Faktoren für die Blütengröße wohl nicht anders als bei der Selbstbefruchtung jedes Bastards. Es ist also zu verstehen, da $B$ auch hier drei Blütengrößen sichtbar werden: die der biennis, die der Lamarckiana, und die intermediäre der primären Bastarde.

Wird die $\mathrm{F}_{1}$ eines Bastardes mit einem der Eltern rückgekreuzt, so ist die BlütengröBe in der Nachkommenschaft ebenfalls meist wechselnd. Geringe Unterschiede in der Blütengröße waren vorhanden bei der velutina aus $O$. biennis $\times($ biennis $\times$ Lamarckiana) velutina, bei der fallax 
aus fallax $\times$ biennis, bei der biennis aus 0 . (biennis $\times$ muricata) $\times$ biennis; hier tritt immer die Blütengröße der biennis neben der des primären Bastardes auf. Beträchtliche Differenzen wurden sichtbar bei der Kreuzung der Zwillinge aus $O$. biennis $\times$ Lamarckiana mit $O$. Lamarckiana; zwischen der Blütengröße der Lamarckiana und der der primären Zwillinge ist eben noch ein bedeutender Unterschied. Ganz einförmig schien auffallenderweise die biennis aus 0 . (biennis $\times$ Lamarckiana) laeta $\times$ biennis und aus velutina $\times$ biennis.

Wo in den Kreuzungen der O. Lamarckiana mit ihren Bastarden aus 0. biennis ㅇ die Exemplare nach der Blütengröße ausgezählt wurden, ergab sich das glatte Mendelsche Verhältnis 1:1. Es waren bei $L a-$ marckiana $\times$ laeta 40 groß- und 41 kleinblütige, bei Lamarckiana $\times$ velutina 24 groß- und 22 kleinblïtige, bei laeta $\times$ Lamarckiana 45 großund 46 kleinblütige Individuen.

Die dritte Bastardgeneration habe ich bis jetzt nur von $O$. (biennis $\times$ Lamarckiana) laeta und velutina erzogen, und zwar in beiden Fällen aus einem kleinblütigen Individuum. Die $\mathrm{F}_{3}$ erwies sich dabei vollkommen gleichförmig; das Ergebnis ist am leichtesten verständlich unter der Annahme, daß die betr: $\mathrm{F}_{2}$-Individuen im Blütengrößenfaktor schon homozygotisch geworden waren. Auch de Vries teilt mit, daß die kleinund großblütigen Typen seiner Bastarde in späteren Generationen rein weiterzüchten $(1913$, S. 119, 127). Ob Typen von mittlerer Blütengröße dort, wo sie in der $\mathrm{F}_{2}$ vorkommen, danernd weiterspalten, bleibt zu prüfen. - Über die Konstanz der Blütentypen von Bastarden von der zweiten Generation an ist vor allem Lehmann zu vergleichen.

\section{Die Vererbung der Griffellänge.}

Bei Kreuzung zweier kurzgriffeliger Arten ist die $F_{1}$ kurzgriffelig. Wird die langgriffelige 0 . Lamarckiana mit einer der kurzgriffeligen Arten gekreuzt, so sind die Griffel der Bastarde kurz bis ziemlich lang. Kurz bei $O$. (biennis $\times$ Lamarckiana) velutina und fallax, bei (suaveolens $\times$ Lamarckiana) suavi-velutina, etwas länger bei (biennis $\times$ Lamarckiana) laeta, (suaveolens $\times$ Lamarckiana) suavi-laeta, mittellang bei (muricata $\times$ Lamarckiana) velutina und laeta, (rubrinervis $\times$ biennis) subfallax, ziemlich lang bei (Lamarckiana $\times$ muricata) gracilis.

In der $F_{2}$ traten lange Griffel immer in Verbindung mit auffallender Blütengröße auf, bei $O$. (biennis $\times$ Lamarckiana) laeta und bei den fallax-Formen sicher, wahrscheinlich auch bei $O$. (biennis $\times L a$ - 
marckiana) velutina. Die kleinblütigen $\mathrm{F}_{2}$-Typen haben immer kurze Griffel.

Spaltung nach der Griffellänge wird auch sichtbar, wenn laeta, velutina oder fallax mit Lamarckiana und wenn laeta und velutina miteinander verbunden werden. Wieder sind es die größten Blüten, die die längsten Griffel haben. Es besteht also feste Korrelation zwischen den beiden Charakteren, wie sie East (1913) bei Nicotiana-Bastarden gefunden hat.

In der $\mathrm{F}_{3}$ der laeta und der velutina war die Griffellänge konstant.

\section{Die Vererbung der Anthokyanbildnng.}

a) Die Farbe der Blattnerven.

Heribert-Nilsson hat darauf hingewiesen, daß O. Lamarckiana in weißnervigen und rotnervigen Formen vorkommt, von denen die rotnervigen dauernd weißnervige Individuen abspalten, also in der Nervenfarbe immer heterozygotisch sind. Die Mutante rubrinervis hat ihren Namen wohl davon bekommen, daß die zuerst gefundenen Exemplare rote Nerven besaßen; doch sagt de Vries schon in der Mutationstheorie Bd. I, S. 161 "mit meist roten Blattnerven", es waren also schon damals Weißnerven abgespalten worden. Das rubrinervis-Material, das ich von ihm erhielt, war, von der zart rötlichen Färbung der Mittelnerven an den unteren Stengelblättern abgesehen, durchaus weißnervig, wie die von ihm jetzt gezüchtete Rasse der Stammform, desgleichen die Mutanten gigas und nanella. Noch Honing hat 1911 rotnervige $O$. rubrinervis and rot- und weißnervige $O$. Lamarckiana ans dem Amsterdamer Garten erhalten (1911, Tab. XVI, S. 261). - Weißnervig ist weiter $O$. suaveolens. Immer rotnervig sind $O$. biennis und muricataVenedig; Abspaltung von Weißnerven ist nicht beobachtet.

Werden zwei weißnervige Arten gekreuzt, also O. Lamarckiana und suaveolens, Lamarckiana und rubrinervis, so ist die Nachkommenschaft in allen Typen weißnervig. Wird weißnervige O. Lamarekiana mit der rotnervigen $O$. muricata gekreuzt, so sind die Zwillinge $O$. (muricata $\times$ Lamarckiana) laeta und velutina intensiv rotnervig, $O$. (Lamarckiana $\times$ muricata) gracilis dagegen hat nur schwach rosenrote Nerven. Von den Bastarden zwischen O. Lamarckiana-weißnervig und der rotnervigen $O$. biennis sind $O$. (biennis $\times$ Lamarekiana) laeta und velutina weißnervig (die velutina hat nur an den unteren Stengelblättern blaßrote Nerven), die fallax ist immer tiefrotnervig, einer- 
lei ob O. biennis Vater oder Mutter ist. Ebenso verhalten sich die Bastarde zwischen O. rubrinervis und O. biennis; die velutina und die subvelutina sind weißnervig, die fallax und die subfallax sind tief rotnervig. O. (suaveolens $\times$ biennis) redempta und flava sind rotnervig, $O$. (biennis $\times$ suaveolens) suavis ist weißnervig, die zugehörige flava ist rotnervig wie die auf dem reziproken Weg gewonnene fava. O. muricata $\times$ biennis ist rotnervig, O. biennis $\times$ muricata dagegen weißnervig, trotzdem beide Eltern rote Nerven besitzen. Bastarde von 0 . muricata 우 sind also immer rotnervig, von muricata $\sigma^{7}$ sind weißnervig oder höchstens blaß rotnervig, von biennis $\sigma^{7}$ immer rotnervig, von biennis $q$ weißoder rotnervig.

Wird rotnervige $O$. Lamarckiana zu Kreuzungen verwendet, so sind die sonst weißnervigen Bastardtypen teils weiß- teils rotnervig. Das gilt für $O$. (biennis $\times$ Lamarckiana) laeta und velutina, für $O$. (rubrinervis $\times$ Lamarckiana) Lamarckiana und blanda. Die Heterozygotie der rotnervigen $O$. Lamarekiana in bezug auf die Nervenfarbe kommt also auch hier zum Vorschein. Die fallax aus 0 . biennis $\times$ Lamarckiana-rotnervig ist natürlich rotnervig.

Die $\mathrm{F}_{2}$ weißnerviger Bastarde ist wieder weißnervig. Die rotnervigen Bastarde der biennis mit Lamarckiana und rubrinervis spalten in der $\mathrm{F}_{2}$ meistens nach der Nervenfarbe. Das gilt für fallax aus $O$. biennis $\times$ Lamarekiana und reziprok, für fallax und subfallax aus $O$. rubrinervis $\times$ biennis. Der Erfolg der Kreuzung biennis $\times$ velutina läßt erwarten, daß auch die $\mathrm{F}_{2}$ der rotnervigen velutina aus 0 . biennis $\times$ Lamarckiana-rotnervig aus Rot- und Weißnerven besteht. Dagegen ist die $\mathrm{F}_{2}$ und $\mathrm{F}_{3}$ der rotnervigen laeta aus 0 . biennis $\times$ Lamarckiana durchaus rotnervig. Dasselbe ist zu erwarten von der redempta (soviel wie biennis) aus der Kreuzung O. suaveolens $\times$ biennis; der zugehörige Zwillinge Hava spaltet wieder nach der Nervenfarbe. O. muricata $\times$ biennis ist in späteren Generationen $\left(\mathrm{F}_{4}\right.$ and $\mathrm{F}_{5}$ ) durchaus rotnervig gefunden worden; es ist wohl wahrscheinlich, daß auch in der $\mathrm{F}_{2}$ Spaltung nach der Nervenfarbe fehlt. Das Verhältnis Rotnerven:Weißnerven war in der $\mathrm{F}_{2}$ von $O$. (rubrinervis $\times$ biennis) fallax und subfallax genau 2:1; vergl. dazu oben S. 202/3. Augenseheinlich ist der Rotfaktor in allen fallax-Formen homozygotisch nicht realisierbar.

$O$. biennis $\times$ (biennis $\times$ Lamarckiana) laeta-weißnervig ist eine weißnervige laeta, 0 . biennis $\times$ (biennis $\times$ Lamarckiana) velutina-rotnervig ist eine teils rot- teils weißnervige velutina (67 rot-, 21 weißnervig). Auch die Kreuzung $O$. biennis $\times$ (biennis $\times$ Lamarckiana) fallax 
liefert teils rot- teils weißnervige Formen, desgleichen 0 . biennis $\times(L a-$ marckiana $\times$ biennis) fallax. Ebenso verhalten sich die entsprechenden Kreuzungen der fallax und subfallax aus 0 . rubrinervis $\times$ biennis. $O$. (biennis $\times$ Lamarckiana) fallax $\times$ biennis und $O$. (Lamarckiana $\times$ biennis) fallax $\times$ biennis sind rotnervige fallax. Kreuzungen zwischen weißnerviger $O$. Lamarekiana and den weißnervigen $Z$ willingen laeta und velutina aus der biennis liefern nur weißnervige Typen. In der Kreuzung O. (Lamarckiana $\times$ biennis) fallax $\times$ Lamarckiana-weißnervig treten Rot- und Weißnerven in ziemlich gleichen Zahlen (26 und 19) auf.

b) Die Färbung der Blütenkelche.

Rein grünen oder etwas ins Gelbliche spielenden Kelch haben O. biennis und suaveolens. Schwach rötlich ist der ganze Kelch, Röhre wie freie Zipfel, bei $O$. muricata. Breite rotbraune Streifen auf den Zipfeln hat der Kelch von $O$. Lamarckiana, und bis auf feine grüne Streifen am Mittelnerv und an den äußersten Rändern der Zipfel tief braunrot ist der Kelch von O. rubrinervis.

Grün ist der Kelch bei allen Bastarden zwischen O. biennis und suaveolens, ebenso bei $O$. (biennis $\times$ muricata), dagegen leicht rot angelaufen bei $O$. (muricata $\times$ biennis). Von den Bastarden der O. Lamarckiana haben rein grünen Kelch: $O$. (biennis $\times$ Lamarckiana) laeta, $O$. (suaveolens $\times$ Lamarckiana) bienni-laeta und suavi-laeta; an den späteren Blüten ist der Kelch am Grunde schwach rötlich bei $O$. (muricata $\times$ Lamarckiana) laeta; deutlich, doch nicht sehr stark rotstreifig sind die Kelchzipfel von $O$. (biennis $\times$ Lamarckiana) velutina und von $O$. (suaveolens $\times$ Lamarckiana) bienni-velutina; sehr breit und dunkel, stärker ausgeprägt als bei $O$. Lamarckiana selbst, sind die Kelchstreifen bei $O$. (Lamarckiana $\times$ biennis) fallax und reziprok, bei $O$. (suaveolens $\times$ Lamarckiana) suavi-velutina und reziprok; fast wie bei O. rubrinervis ist das Grün zum größten Teil verdeckt an den Kelchen von $O$. (muricata $\times$ Lamarckiana) velutina, doch ist die Farbe ein reines, ziemlich dunkles Rot; ganz rosenrot, mit Ausnahme sehr dünner grüner Streifen, ist der Kelch, anch die Röhre, bei $O$. (Lamarckiana $\times$ muricata) gracilis. Aus der Kreuzung $O$. biennis $\times$ rubrinervis ist die velutina am Kelch etwa so pigmentiert wie die velutina aus Lamarckiana, die subvelutina hat erst an den späteren Blüten ganz leichte Färbung; die fallax entspricht ganz der aus Lamarckiana, die subfallax hat wieder viel weniger Anthokyan im Kelch, das erst gegen Ende der Blütezeit deutliche rot $\epsilon$ Streifen bildet. 
Die Rotstreifigkeit des Kelchs ist an Rotfärbung der Blattnerven nicht gebunden, wie auch rein grüner Kelch mit Rotnervigkeit der Blätter kombiniert sein kann ( $O$. biennis, O. [biennis $\times$ Lamarckiana] laeta-rotnervig). Tritt aber Anthokyan in den Blattnerven auf, so erscheint die Pigmentierung des Kelchs, wenn sie überhaupt vorhanden ist, gegenüber den weißnervigen Typen gesteigert. Das gilt für die Rot- und Weißnerven von $O$. Lamarckiana ${ }^{1}$ ), von $O$. (biennis $\times L a$ marckiana) velutina. Entsprechend ist die fallax am Kelch stärker pigmentiert als die 0 . Lamarckiana; dagegen haben fallax und subfallax aus rubrinervis, trotzdem sie rotnervig sind, schwächer gefärbten Kelch als die weißnervige $O$. rubrinervis. $\mathrm{W}_{0}$ in der $\mathrm{F}_{2}$ eines rotnervigen, gestreiftkelchigen Bastardes Spaltung nach der Nervenfarbe eintritt, erhalten die weißnervigen Individuen schwächere Kelchfärbung als die $F_{1}$, die rotnervigen dagegen zum Teil noch stärkere als die $F_{1}$; sehr schwach ist die Pigmentierung des Kelchs bei der rubrinervis in der $\mathrm{F}_{2}$ von $O$. (rubrinervis $\times$ biennis) subfallax, soweit sie weißnervig ist. Weiter ist die Kelchfärbung, wenn Spaltung nach der Blütengröße erfolgt, stärker bei den großen Blüten als bei den kleinen; so in der $\mathrm{F}_{2}$ von $O$. (biennis $\times$ Lamarckiana) velutina. In der zweiten Generation der fallax-Formen, aus Lamarckiana wie aus rubrinervis, haben deshalb die am stärksten rotgefärbten Kelche die großblütigen rotnervigen Individuen, am schwächsten gefärbt ist der Kelch der kleinblütigen Weißnerven. So sind tief kupferrot gefärbte Kelche, fast ohne Grün, gefunden worden bei großblütigen Rotnerven von $O$. (biennis $\times$ Lamarckiana) fallax $\mathrm{F}_{2}$ und bei entsprechenden Individuen der Kreuzung 0 . (Lamarckiana $\times$ biennis) fallax $\times$ Lamarckiana.

Herausspalten ganz grünkelchiger Typen aus gefärbtkelchigen Bastarden ist nicht gefunden worden. Nur bei der Kreuzung eines solchen Bastardes mit der ebenfalls gestreiftkelchigen $O$. Lamarckiana, nämlich bei $O$. (Lamarckiana $\times$ biennis) fallax $\times$ Lamarekiana ist ein Individuum eines grünkelchigen, laeta-ähnlichen Typus aufgetreten.

c) Die Färbung der jungen Früchte.

Die roten Streifen auf den Früchten mittleren Alters finden sich nur kombiniert mit Färbung des Kelchs. Sie sind sehr ausgeprägt bei O. Lamarckiana und rubrinervis, schwächer bei 0 . muricata; sie fehlen bei $O$. biennis und suaveolens und bei deren Verbindungen. Von den

1) Heribert-Nilsson 1915, S. 39, macht dieselbe Beobachtung. 
Bastarden haben leichte Streifen auf den Früchten: O. (biennis $\times$ Lamarckiana) velutina, $O$. (suaveolens $\times$ Lamarckiana) bienni-velutina, $O$. (biennis $\times$ rubrinervis) velutina und subvelutina, O. (muricata $\times$ Lamarckiana) laeta, O. (Lamarckiana $\times$ muricata) gracilis (bei der letztgenannten Form ist die Rotfärbung der Früchte besonders vergänglich, dafür färben sich die sonst grün werdenden Streifen auffallend weißlich). Stark rotgestreift sind die Früchte bei den fallax- und subfallax-Formen aus $O$. Lamarckiana und rubrinervis, bei $O$. (muricata $\times$ Lamarckiana) velutina, bei $O$. (suaveolens $\times$ Lamarckiana) suavi-velutina und reziprok. Die Färbung fehlt ganz bei O. (biennis $\times$ muricata), O. (biennis $\times \mathrm{La}$ marckiana) laeta, $O$. (suaveolens $\times$ Lamarckiana) bienni-laeta und suavi-laeta.

Durch Rotnervigkeit wird die Fruchtfärbung gesteigert. Die aus fallax $\mathrm{F}_{2}$ abgespaltenen Weißnerven haben schwächere Streifen an den Früchten als die $\mathrm{F}_{1}$ und als die Rotnerven der $\mathrm{F}_{2}$. Ganz grünfrüchtige Formen spalten aus gestreiftfrüchtigen Bastarden nicht heraus.

d) Die rote Punktierung der Stengel und Fruchtknoten.

Rote Färbung der haartragenden Höckerchen an Stengeln und Fruchtknoten ist nicht unabhängig von sonstiger Anthokyanbildung; sie findet sich nämlich nur da, wo die Kelche rotes Pigment, wenn auch nur in Spuren, besitzen. $O$. (muricata $\times$ Lamarckiana) laeta z. B. ist sehr kräftig rot punktiert, während der Kelch nur leicht rot angelaufen ist. Die Blattnerven können bei roter Punktierung des Stengels ebensogut weiß wie rot sein (O. Lamarckiana und ihre Mutanten). Die roten Tupfen fehlen bei $O$. biennis und suaveolens und ihren Verbindungen, sie sind vorhanden bei $O$. muricata, Lamarckiana, mubrinervis, gigas, nanella. In den Kreuzungen fehlen sie bei $O$. (biennis $\times$ muricata), o. (biennis $\times$ Lamarckiana) laeta, o. (suaveolens $\times$ Lamarckiana) biennilaeta und suavi-laeta; sie sind vorhanden bei $O$. (muricata $\times$ biennis), bei $O$. (muricata $\times$ Lamarckiana) laeta und velutina, bei $O$. (Lamarckiana $\times$ muricata) gracilis, bei allen velutina-, subvelutina-, fallax- und subfallax-Formen der Kreuzungen von O. biennis und suaveolens mit Lamarckiana und rubrinervis. Eine Abspaltung von ungetupften Typen ist in der $\mathrm{F}_{2}$ von getupften Bastarden nicht beobachtet worden ${ }^{1}$ ). Da-

1) Vielleicht nur wegen der kleinen Zahlen. Davis vermißt ungetupfte Individuen in der $\mathrm{F}_{2}$ der Kreuzung 0 . biennis $\times$ Franciscana (1916a, S. 225), dagegen findet er eine kleine Gruppe von solchen in der $\mathrm{F}_{2}$ der reziproken Kreuzung (S. 220). 
gegen ist in der Kreuzung $O$. (Lamarckiana $\times$ biennis) fallax $\times$ Lamarckiana ein Exemplar einer ungetupften laeta-Form aufgetreten. Eine getupfte laeta-artige Form "punctilaeta" kommt in den Kreuzungen biennis $\times$ (Lamarckiana $\times$ biennis) fallax and biennis $\times$ (biennis $\times$ Lamarckiana) fallax als seltener Typus vor, der in den unteren Teilen der Infloreszenz ganz grüne, weiter oben sehr schwach rotstreifige Kelche besitzt.

e) Die Färbung der Blumenkronen.

Ohne farbige Darstellung oder Bezugnahme auf eine bestimmte Farbenskala läßt sich über die Schattierungen des Gelb in den OenotheraBlüten nicht viel reden. Am reinsten schwefelgelb sind die Kronen der O. suaveolens, etwas rötlicher die von $O$. Lamarckiana und biennis, auch die im übrigen recht blassen Kronen der 0 . muricata, besonders tief gelb mit deutlichem Stich ins Rötliche die Blüten der O. rubrinervis. Unter den Bastarden hat die blassesten Blüten $O$. (biennis $\times$ suaveolens) flava und reziprok. Eine deutliche Beziehung besteht zwischen der Färbung des Kelchs und der der Krone, insofern als die Krone tiefer gelb gefärbt ist, wenn der Kelch rote Streifen besitzt; für $O$. rubrinervis weist schon de Vries (1913, S. 191) darauf hin, daß die tiefe Kronenfärbung auf einem Gehalt an dem in den Kelchblättern so reichlich vorhandenen Anthokyan beruhen dürfte. Von den Drillingen aus $O$. biennis $\times$ Lamarckiana hat die grünkelchige laeta die blasseste, rein gelbe Krone, die velutina mit ihrem leicht gestreiften Kelch dunklere, und noch tiefer gefärbte die auch sonst an Anthokyan sehr reiche fallax; die bienni-laeta und bienni-velutina aus suaveolens $\times$ Lamarckiana verhalten sich wie die Zwillinge aus $O$. biennis, auch die suavi-laeta aus derselben Kreuzung ist blasser als die suavi-velutina. Ebenso hat die fast grünkelchige subfallax aus 0 . rubrinervis $\times$ biennis und reziprok viel blassere Krone als die fallax, die subvelutina aus $O$. biennis $\times$ rubrinervis ist blasser als die am Kelch stärker pigmentierte velutina.

Wo eine Spaltung nach der Quantität des Kelchpigments eintritt, spaltet die Kronenfarbe im selben Sinn. Die großblütige, am Kelch kräftig gefärbte velutina in der $\mathbf{F}_{2}$ von $O$. (biennis $\times$ Lamarckiana) velutina und in den Kreuzungen laeta $\times$ velutina und laeta $\times$ Lamarckiana hat tiefgelbe, die kleinblütige, an Kelchpigment arme velutina blassere Kronen. Ebenso ist die Krone der aus O. (rubrinervis 
$\times$ biennis) subfallax $\mathrm{F}_{2}$ herausspaltenden rubrinervis bei den weißnervigen, am Kelch schwach gefärbten Individuen blasser als bei den mit reichlichem Kelchpigment versehenen Rotnerven.

\section{Die Vererbung des Verhältnisses zwischen gesunden und tauben Samen.}

Es ist an dieser Stelle nur davon zu reden, ob bei den künstlich hergestellten konstanten Bastarden der Prozentsatz der keimhaltigen Samen in den späteren Generationen derselbe bleibt wie in $F_{1}$. Meine eigenen Erfahrungen sind noch sehr spärlich. Nur von den Drillingen aus $O$. biennis $\times$ Lamarckiana, von fallax, laeta und velutina, habe ich die Samen der $\mathrm{F}_{2}$ untersucht and das fragliche Verhältnis ebenso gefunden wie bei $\mathrm{F}_{1}$ (vergl. oben S. 143). Reicheres Material hat de Vries (1916 b, S. 271, 272, 278) mitgeteilt; sein Befund ist derselbe wie der meine. Wo Spaltung nach der Nervenfarbe eintritt, dürften die abgespaltenen Weißnerven mitunter einen anderen Prozentsatz an gesunden Samen aufweisen als die Rotnerven, wie es bei $O$. Lamarckiana der Fall ist. Sonst ist bei den konstanten Bastardtypen angenscheinlich auch das Verhältnis zwischen gesunden und tauben Samen zwischen denselben Grenzen konstant wie bei den Arten. Kommt dagegen auffälligere Spaltung nach den Habituscharakteren vor wie in der $\mathrm{F}_{2}$ von $O$. (rubrinervis $\times$ biennis) subfallax, so werden die verschiedenen $\mathbf{F}_{2}$ Typen wohl verschiedene Samenverhältnisse aufweisen.

\section{Die Vererbung der Hahituscharaktere; die artunterscheidenden Merkmalskomplexe bezw. Faktorenkomplexe.}

Während bei einigen der bis jetzt besprochenen untergeordneten Merkmale, nämlich in bezug auf Blätengröße samt Griffellänge und auf Rotfärbung der Blattnerven, unzweifelhafte Mendelsche Vererbung mit Spaltung in der zweiten Generation rorliegt, folgt die Vererbung der komplexen Habituscharaktere, der eigentlichen Artmerkmale, augenscheinlich anderen Gesetzen, zum mindesten was die wirklich sichtbar werdenden Phänotypen anlangt. Wir finden ja, daß die Artbastarde bei Selbstbefruchtung fast sämtlich in den wesentlichen Charakteren konstant sind; die einzige von den beschriebenen Kreuzungen, die in $\mathrm{F}_{2}$ die eine Elterform abspaltet, ist die subfallax aus o. rubrinervis $\times$ biennis. Sogar die Vererbung der Anthokyanführung schließt sich in der Hauptsache an das Verhalten der Habituscharaktere an; denn eine 
Spaltung nach der Punktierung des Stengels und der Fruchtknoten fehlt ganz, und die Rotstreifung der Kelchblätter und der Früchte kann in der zweiten Bastardgeneration wohl bei einem Teil der Nachkommenschaft abgeschwächt werden, ohne jedoch vollständige Auslöschung zu erfahren. Es ist allerdings im höchsten Grad wahrscheinlich, daß in den tauben Samen der Bastarde gewisse zygotische Kombinationen mit derselben Regelmäßigkeit wiederkehren wie die uns bekannten Phänotypen, und daß uns zahlreiche existierende haploide Genotypen überhaupt nicht in diploider Verbindung, auch nicht in Form tauber Samen, bekannt werden. Wir müssen also notwendig mit der Möglichkeit rechnen, daß überall in einem gewissen $M a ß$ auch nach den Habituscharakteren Spaltung eintritt, aber über die Natur der sich nicht entwickelnden Kombinationen können wir nur in verschwindend wenigen, besonders günstig liegenden Fällen Vermutungen aufstellen.

Was uns hier zu betrachten bleibt, sind also nicht Spaltungen in den späteren Bastardgenerationen, sondern die zunächst so sonderbar erscheinenden Spaltungen, die in der ersten Generation der Artkreuzungen ähnlich wie bei Rückkreuzung der Bastarde mit den Eltern auftreten, und weiter die auffällige Verschiedenheit des Ergebnisses reziprokerKreuzungen. Am genauesten sind wir bis jetzt über die Bildung der Zwillingsbastarde bei der Kreuzung der O. Lamarckiana mit anderen Arten unterrichtet, über die Spaltung der ersten Bastardgeneration in die Typen laeta und velutina. Aúf die Theorie der labilen, mutabeln Pangene, die de Vries zur Erklärung der fraglichen Erscheinungen ausgearbeitet hat (1913), möchte ich nicht wieder eingehen. Ich habe früher (1914) die Beobachtungen und Überlegungen mitgeteilt, die mich dazu zwangen eine andere $\mathrm{Hy}-$ pothese auf mendelistischer Grundlage aufzustellen, und diese Hypothese hat sich bei den Züchtungsexperimenten, die ich nach den embryologischen Untersuchungen begann, durchaus bewährt. Sie ist bei der Auswahl unter den endlosen Möglichkeiten der Krenzungen ein nützlicher Weiser und bei der Deutung der Erscheinungen ein überall brauchbarer Schlïssel gewesen.

a) Komplexanalyse von O. Lamarekiana, muricata und biennis.

O. Lamarckiana ist nach der früher begründeten Auffassung ein Doppelwesen, das dauernd zwei verschiedene Typen von Keimzellen bildet. Bei Bastardierung erzeugt der eine Typus die laeta-, der andere die velutina-Formen. Die Annahme, daß laeta und velutina aus einer Kreuzung sich in einem einzigen Gen unterscheiden - S. $151 \mathrm{u}$. ff. ist 
diese Annahme der Einfachheit wegen noch beibehalten worden -, hat sich nicht aufrecht erhalten lassen, als ich die Formen aus eigner Anschauung kennen lernte. Phänotypisch sind die Zwillinge jedenfalls in einer ganzen Anzahl von Merkmalen verschieden, und wenn diese Unterschiede auf gewissen, in günstigen Fällen vielleicht noch zu isolierenden Einzelfaktoren beruhen, so müssen diese unterscheidenden Gene in der O. Lamarckiana zu zwei in sich fest zusammenhängenden Komplexen verkoppelt sein, so daß die Art sich bei der Keimzellenbildung doch wie eine Monohybride verhält. Ein ähnlicher Vererbungsmodus liegt auch bei den anderen Arten vor, und das Studium der Anlagenkomplexe möchte ich, im Gegensatz zu Faktorenanalyse, als Komplexanalyse bezeichnen; es ist dasselbe, was de Vries, mit Beschränkung auf die heterogamen Arten, Gamolyse nennt $(1913$, S. 61). Für vorteilhaft halte ich es, vor allem die haploiden Genotypen, die in den Keimzellen auftretenden Komplexe von Erbanlagen, von denen sich mit der Zeit wohl allerhand gut zu definierende, d. h. mendelnde Faktoren werden abschälen lassen, mit Namen zu belegen. Diese Namen sollen als participium praesentis activi, also mit der Endung ans oder ens, gebildet sein. Diploide Biotypen, die einander phänotypisch ähneln, unter Gruppennamen zusammenzufassen, wie de Vries tut, steht dann noch immer frei.

Ich nenne die beiden haploiden Anlagenkomplexe der O. Lamarckiana jetzt gaudens und velans ${ }^{1}$ ). Beide Komplexe treten sowohl in den Eizellen wie im Pollen anf; O. Lamarekiana ist "isogam" (de Vries). Bei Selbstbestäubung entstehen $50 \%$ Heterozygoten, die Hälfte als gaudens$\uparrow \cdot$ velans $\sigma^{\nabla}$, die andere Hälfte als velans - gaudens $\sigma^{\top}$, alle lebensfähig als $O$. Lamarckiana, und 50\% Homozygoten als bald absterbende Embryonen in den taub werdenden Samen, davon die eine Hälfte vom Typus gaudens $\cdot$ gaudens und die andere Hälfte vom Typus velans $\cdot$ velans. In Wirklichkeit machen die gesunden Samen oft viel weniger als $50 \%$ aus.

Wird O. muricata mit dem Pollen der O. Lamarckiana belegt, so entsteht der Bastard laeta dann, wenn eine muricata-Eizelle von

1) Der gaudens-Komplex liefert die laeta- und die densa-Formen (vergl. unten); mit laeta ist gaudens dem Sinn nach identisch, an densa erinnert das Wort im Klang. Der Komplex velans liefert die velutina-Formen, die sich durch dichte, weiche Behaarung auszeichnen; velare heiBt nicht blob einhüllen, sondern auch verbergen, und damit spielt das Wort auf fallax an (S. 176). Fallax weist andrerseits in Klang auf die laxaFormen (s. unten). 
einem Pollenkorn vom Typus gaudens befruchtet wird, und velutina, wenn das befruchtende Pollenkorn den Typus velans repräsentiert. Beide Bastardformen sind steif aufrechte und hoch wachsende Formen. Bei der reziproken Kreuzung $O$. Lamarckiana $\times$ muricata entsteht eine lebensunfähige Form, die es nur bis zur Entfaltung der blassen Kotyledonen bringt, und ein schwacher Bastardtypus mit nickenden Sproßgipfeln, der von de Vries als gracilis bezeichnet wird und weder mit laeta noch mit velutina Ähnlichkeit hat. Von seiten der $O$. Lamarckiana ist an der Bildung der gracilis wahrscheinlich der velans-Komplex beteiligt. Die $O$. muricata steuert aber sicher etwas ganz anderes bei als zur Bildung der velutina. Nun hat schon de Vries nachgewiesen, daß die Vererbungserscheinungen bei $O$, muricata und biennis nur verständlich werden, wenn wir annehmen, $\mathrm{da} ß$ bei diesen Arten die Eizellen einen anderen Genotypus repräsentieren als die Pollenzellen; er nennt solche Arten heterogam. Wir nennen den im Pollen der 0 . muricata aktiven Typus curvans, weil er die nickenden Sproßgipfel der $O$. muricata auf geradstengelige Formen überträgt (z. B. anch in der Kreuzung biennis $\times$ muricala), den in den Eizellen auftretenden Komplex rigens ${ }^{1}$ ), weil er normalen, geraden Stengelwuchs vererbt. Die laeta ist also rigens $\cdot$ gaudens, die velutina ist rigens $\cdot$ velans, die gracilis ist velans $\cdot$ curvans, die vierte Bastardverbindung gaudens $\cdot$ curvans geht früh zugrunde.

In den Früchten der $O$. Lamarckiana sind nach Bestäubung mit mit dem Pollen der 0 . muricata keine tauben Samen zu erwarten, weil sowohl die velans - wie die gaudens-Eizellen keimfähige Embryonen liefern; gefunden wurden 91-98\% Samen mit voll entwickelten Embryonen. Bei O. muricata ist natürlich keine Veranlassung zur Veränderung des Gehaltes an tauben Samen gegeben, wenn statt des eigenen Pollens der der $O$. Lamarckiana die Befruchtung ausführt; auch hier ist die Erwartung gewöhnlich bestätigt (vergl. Tabelle II, S.140). Die gesunden Samen sollten zu gleichen Teilen laeta und velutina darstellen. In der einzigen von mir ausgeführten Kultur ist aber die laeta mit nur $27 \%$ vertreten; de Vries hat 38-66\% laeta gefunden (1913, S. 288).

Der Unterschied zwischen der gametischen Konstitution der „isogamen" (de Vries) O. Lamarckiana und der der "heterogamen" $O$.

1) De Vries hat 1911 die vom "Eizellenbild" der O. muricata hergeleiteten Formen als "frigida-Typus" bezeichnet; 1913 kommt er auf den Namen nicht zurück, dagegen nennt er eine Gruppe von Formen, zu denen auch Bastarde der muricata gehören, rigida-Typus (1913, S. 80, 82). 
muricata ist also nicht ganz so groß, wie de Vries ihn auffaßt. Beide Arten sind dauernd heterozygotisch, sie bilden Keimzellen von zwei verschiedenen Typen. Bei der isogamen Lamarckiana sind beide haploide Komplexe in den Eizellen wie im Pollen aktiv, Eizellen wie Pollen sind dityp; bei der heterogamen muricata tritt noch eine Erscheinung der Geschlechtsbegrenzung hinzu: der rigensKomplex tritt nur in den Eizellen aktiv auf, soweit bis jetzt bekannt, der curvans-Komplex nur im Pollen; Eizellen wie Pollen sind monotyp. Die Annahme liegt nahe, daß curvans-Megasporen und rigens-Mikrosporen wohl gebildet werden, aber nicht in Funktion treten, vielleicht frühzeitig zugrunde gehen (de Vries 1911). Nach Geerts (1909, S. 183) hat $O$. muricata etwa $55 \%$ sterilen Pollen, aber nur etwa $25 \%$ sterile Samenanlagen (vergl, oben S. 149).

Betrachten wir nun zunächst $O$. biennis in ihrem Verhältnis zu O. muricata. An der Kreuzung $O$. (biennis $\times$ muricata) ist das Auffälligste, daß der Bastard weißnervig ist, während beide Eltern rote Blattnerven haben. Der Eizellenkomplex der O. biennis vererbt also hier, und wie wir sehen werden auch in anderen Kreuzungen, nichtrote oder "weiße" Blattnerven und soll deshalb albicans heißen. Die reziproke Kreuzung $O$. (muricata $\times$ biennis) ist in dem von de Vries erhaltenen Material rotnervig; der Pollenkomplex der O. biennis soll, weil er hier Rotnervigkeit zum mindesten zuläßt und anderswo sicher selber überträgt, als rubens bezeichnet werden. Die Kreuzung $O$. (biennis $\times$ muricala) ist also genau genommen eine Verbindung albicans $9 \cdot$ curvans $\sigma^{\prime \prime}$, die reziproke Kreuzung $O$. (muricata $\times$ biennis) ist rigens $9 \cdot$ rubens $\sigma^{7}$.

Bei Bestäubung der O. biennis mit dem Pollen der O. Lamarckiana entstehen vorzugsweise (jei de Vries ausschlieBlich) die Zwillinge laeta und velutina. Die laeta ist jetzt genauer zu definieren als albicans • gaudens, die velutina als albicans • velans; beide sind weißnervig, wenn die Lamarckiana weißnervig ist, sie sind teilweise rotnervig, wenn (heterozygotisch-) rotnervige Lamarckiana verwendet wird. Die Weißnervigkeit des albicans-Komplexes ist also rezessiv gegenüber der Rotnervigkeit der Lamarckiana wie gegenüber der des Komplexes rubens, der normal mit albicans zu der rotnervigen biennis verbunden ist. Weiter ist zu erkennen, daß der Rotnervenfaktor, der wie wir wissen (S. 152) in der O. Lamarekiana homozygotisch nicht verwirklicht werden kann, bei der Keimzellenbildung ebensogut an den gaudens- wie an den velansKomplex sich angliedern kann. Weil die $O$. biennis selber keine roten Tupfen am Stengel und an den Fruchtknoten and ebensowenig rote Streifen 
an den Kelchen und Früchten besitzt, läßt sich erkennen, welchem der beiden in der Lamarckiana enthaltenen Komplexe diese Charaktere zukommen: es ist der velans-Komplex, weil nur die velutina diese Merkmale aufweist, während die laeta ebenso wie die Mutter biennis ungetupfte Stengel und grüne Kelche und Früchte besitzt. Weiter vererbt velans niedrigeren Wuchs, schmälere Blätter, stärkere weichere Behaarung, dickere Knospen und Früchte, dunklere Kronenfarbe, pollenreichere Antheren als gaudens. Die langen Griffel der O. Lamarckiana gehören wohl beiden Komplexen $\mathrm{zu}$, denn in der $\mathrm{F}_{2}$ der laeta wie der velutina kommen wieder lange Griffel in den großblütigen Individuen zum Vorschein. - Die laeta und velutina aus der O. muricata-Venedig sind bei Verwendung des Pollens einer weißnervigen Lamarckiana beide rotnervig. Der rigens-Komplex besitzt bei meiner Rasse also den Rotnervenfaktor, was sich aus der Rotnervigkeit des von de Vries erhaltenen Bastardes $O$. (muricata $\times$ biennis) nicht erschließen läßt, weil hier die biennis in ihrem rubens-Pollen selber Rotnervigkeit beigestenert hat. Ob curvans ebenfalls einen Rotnervenfaktor besitzt, ist fraglich; O. ( $\mathrm{La}$ marckiana $\times$ muricata) gracilis ist wohl schwach rotnervig, aber $O$. (biennis $\times$ muricata) ist rein weißnervig. Die roten Tupfen der 0 . muricata gehören einmal sicher dem rigens-Komplex an; das zeigt die Punktierung des Bastardes $O$. (muricata $\times$ biennis), und seit wir wissen, daß die roten Tupfen dem gaudens-Komplex der Lamarckiana abgehen, auch das Vorkommen der Tupfen bei der laeta aus der 0 . muricata. Die zugehörige velutina bekommt die Tupfen von beiden Eltern, in rigens und in velans, der Tupfenfaktor kann also homozygotisch verwirklicht werden ${ }^{1}$ ). Daß die Punktierung der $O$. (muricata $\times$ Lamarckiana) velutina stärker ist als die der 0 . muricata, hat aber mit der Homozygotie der velutina in Bezug auf diesen Faktor nichts zu tun, denn die laeta aus muricata. ist eben so kräftig getupft. Der Tupfencharakter des rigens-Komplexes kommt also in der Verbindung mit gaudens zu stärkerer Ausprägung als in der Verbindung mit curvans. Ob dem curvans-Pollen der Tupfenfaktor ebenfalls zugehört, ist wieder fraglich. $O$. (biennis $\times$ muricata) hat Spuren von Rotpunktierung, und $O$. (Lamarckiana $\times$ muricata) gracilis ist deutlich rot getupft; die Lamarckiana ist aber vielleicht als velans an der gracilis beteiligt, und dann könnten die Tupfen von der Lamarckiana stammen.

1) Dasselbe ist der Fall bei der von Davis (1916) studierten O. Franciscana, die bei Kreuzung mit $O$. biennis $\sigma$ und $q$ getupfte Bastarde gibt, also in den Eizellen wie im Pollen die roten Tupfen vererbt. 
$\nabla$ on der Kreuzung $O$. Lamarckiana $\times$ biennis ist nur die fallax lebensfähig, die andere Hälfte der Zygoten stirbt früh (Renner 1914), noch früher als bei der entsprechenden Kreuzung der O. muricata. Von seiten der biennis ist der rubens-Komplex beteiligt, das zeigen die roten Blattnerven. Die mit rubens-Pollen entwicklungsfähigen Eizellen der O. Lamarckiana gehören zweifellos dem velans-Typus an. Denn die fallasc hat mit der velutina aus der reziproken Kreuzung die roten Tupfen und die rotgestreiften Kelche und Früchte, auch die pollenreichen Antheren gemein. Die Anthokyanbildung ist allerdings beträchtlich stärker als bei der.velutina, was auf Rechnung des ebenfalls Anthokyanbildung übertragenden rubens-Komplexes zu setzen ist; die Rotfärbung des Kelches ist sogar intensiver als bei der weißnervigen Lamarckiana, entspricht aber ungefähr der der rotnervigen Lamarckiana. Die fallax ist also velans . rubens, der zugehörige Zwilling gaudens - rubens ist nur in Form von tauben Samen vorhanden. - Die Blattnerven der $O$. biennis sind meist blasser rot als die der fallax. Nun überträgt der velans-Komplex, anders als gaudens, in die Verbindung mit albicans eine schwache Rotfärbung der Nerven. Denn die unteren Stengelblätter der O. (biennis $\times$ Lamarckiana) velutina haben fast immer schwach rötliche Mittelnerven. Daß die Kombination velans - rubens stärkere Nervenfärbung zeigt als albicans • rubens, ist deshalb nicht verwunderlich, wenn wir annehmen, daß das betreffende Gen des velans-Komplexes mit dem nur heterozygotisch möglichen eigentlichen Rotnervenfaktor nicht identisch ist.

Nun tritt die fallax in vollkommen identischer Form auch bei der reziproken Kreuzung $O$. biennis $\times$ Lamarckiana neben den "Zwillingen" laeta und velutina auf, also als Drilling. Das ist kaum anders zu verstehen als unter der Annahme, daß die O. biennis in geringer Zahl auch funktionsfähige Embryosäcke vom rubens-Typus erzeugt. Die fallax ist hier als rubens - velans gebildet, die Kombination rubens $\cdot$ gaudens, die wahrscheinlich auch entsteht, ist ebensowenig lebẹnsfähig wie die reziprok gebildete Kombination gaudens - rubens und wird wie diese nur in Form von tauben Samen vorkommen. Die O. biennis ist also halb heterogam, sie erzeugt aktiven Pollen nur vom rubens-Typus, dagegen aktive Embryosäcke, die teils den albicans-, teils den rubens-Komplex darstellen. Wollen wir die de Vriesschen Termini auf die Komplexe statt auf die Art anwenden, so müssen wir sagen, daß der rubens-Komplex sich isogam verhält, der albicans-Komplex heterogam ist. Fassen wir die Geschlechter ins Auge, so ergibt sich, daB das weibliche dityp, das männliche monotyp ist. - Das Verhalten erinnert an das von Miss 
Saunders bei den viel besprochenen Levkojen gefundene, die mehrere Typen von Eizellen, aber nur einen (aktiven?) Typus von Pollenkörnern besitzen; die Pollenkörner sollen alle ähnlich und gesund aussehen (1913, S. 306). Auch Tanaka wäre hier zu vergleichen.

Die velutina und die fallax aus 0 . biennis $\times$ Lamarckiana bekommen von der Lamarckiana denselben Anteil, velans. Wenn nun aus irgend einem Grund die gaudens-Verbindung, d. h. der Bastard laeta, gegenüber den velans-Verbindungen begünstigt ist, so wird nicht nur die velutina in geringerer Zahl erscheinen als die laeta, sondern auch die fallax wird selten sein. Umgekehrt wird bei reichlichem Auftreten der velutina auch die fallax verhältnismäBig häufig zur Entstehung kommen. Die in der folgenden Tabelle zusammengestellten Beobachtungen bestätigen diese Erwartung.

\begin{tabular}{c|c|c|c|c|c|c}
\hline \multirow{2}{*}{ Krenzung } & \multicolumn{3}{|c|}{ Absolute Zahlen } & \multicolumn{3}{c}{ Prozentzahlen } \\
\cline { 2 - 7 } & laeta & velutina & fallax & laeta & velutina & fallax \\
\hline & & & & & & \\
a & 21 & 19 & 2 & 50 & 45 & 5 \\
b & 27 & 32 & 4 & 43 & 51 & 6 \\
c & 17 & 44 & 33 & 18 & 47 & 35 \\
d & 7 & 27 & 12 & 15 & 59 & 26 \\
e & 51 & 19 & 1 & 72 & 27 & 1 \\
f & 20 & 98 & 19 & 15 & 71 & 14
\end{tabular}

Aus rubens-Samenanlagen dürften auch die bleichen, sehr früh absterbenden Keimlinge der Kreuzung 0 . biennis $\times$ muricata hervorgehen (S. 166); sie stellen die lebensunfähige Kombination rubens • curvans dar. Bei Selbstbestäubung müssen die rubens-Eizellen der O. biennis taube Samen vom Typus rubens - rubens geben. Für einen Teil der bei $O$. biennis immer anzutreffenden tauben Samen ist also eine wahrscheinliche Deutung gefunden. Nebenbei bemerkt, weisen die kleinsten dieser tauben Samen genau dieselben Störungen in der Entwicklung der wenigzelligen Embryonen und des wenigkernigen Endosperms auf, wie sie für die Kreuzung O. Lamarckiana $\times$ biennis, nach unserer jetzigen Bezeichnungsweise genauer für gaudens.rubens, beschrieben worden sind (Renner 1914). Hätten alle tauben Samen der selbstbestäubten $O$. biennis denselben Charakter, so müßten bei Bestäubung mit dem Pollen der O. muricata die tauben Samen ganz fehlen. Das ist aber nicht der Fall. Eine Erhöhung des Prozentsatzes der Samen mit großen Embryonen scheint durch die Verwendung von muricata-Pollen allerdings herbei- 
geführt zu werden; bei Selbstbefruchtung machen die gesunden Samen 55-70 (selten bis 77) \% aus, bei Bestäubung mit dem Pollen von $O$. muricata $71-84 \%$. Geringer muß die Vermehrung der gesunden Samen durch Belegung mit dem Pollen der 0 . Lamarckiana sein, weil nur rubens - velans, aber nicht rubens -gaudens große Embryonen liefert. Tatsächlich sind hier nur $63 \%$ gesunde Samen gefunden worden, also nicht mehr als gewöhnlich bei selbstbestäubter O. biennis; doch kann der Befund natürlich zufällig sein. Jedenfalls besteht kein Anhalt dafür, daß sämtliche bei $O$. biennis nach Selbstbestäubung anzutreffenden tauben Samen aus rubens-Samenanlagen hervorgehen. Was es aber mit dieser zweiten Kategorie von tauben Samen für eine Bewandtnis hat, ist noch unklar.

Das Auftreten der fallax neben laeta und velutina fällt unter den Begriff der metaklinen Bastarde von de Vries (1913, S. 308). Die Kreuzung $O$. biennis-Chicago $\times$ Lamarckiana gibt ausnahmsweise unter densa und laxa einige velutina- und laeta-Exemplare, die mit der velutina bezw. der laeta aus $O$. Lamarekiana $\times$ biennis-Chicago ganz übereinstimmen; umgekehrt fand de Vries einmal eine laxa unter den Zwillingen velutina und laeta (S. 310). Ebenso erzeugt 0 . cruciata mit dem Pollen der O. Lamarckiana zur Hauptsache die Zwillinge densa und laxa, aber darunter auch gelegentlich gracilis, die sonst als Produkt der reziproken Kreuzung bekannt ist. De Vries sieht als Ursache der Erscheinung, wie wir es getan haben, den "Übergang einer Sexualzelle in den dem entgegengesetzten Geschlecht eigenen Sexnaltypus" an; natürlich ist das Phänomen nur bei heterogamen Arten möglich. Bemerkenswert ist, daß bis jetzt nur solche Fälle bekannt geworden sind, in denen ein Teil der Eizellen den sonst im Pollen aktiven Faktorenkomplex enthält, während Pollenzellen vom Typus der normalen Embryosäcke nicht aktiv aufgetreten sind.

b) Komplexanalyse der O. suaveolens.

o. suaveolens $\mathrm{mu} B$ in ihren Eizellen denselben albicans-Komplex besitzen wie die biennis, statt des rubens-Komplexes aber, und zwar wieder im Pollen wie in einem Teil der Eizellen, einen neuen Komplex flavens. Die Art ist halb heterogam wie $O$. biennis. Das ist zu erschließen ans folgenden Tatsachen: biennis $\times$ suaveolens gibt außer der sehr charakteristischen Bastardform flava einen Typus suavis, der von suaveolens schlechterdings nicht zu unterscheiden ist, die reziproke Kreuzung ebenfalls flava und den Typus redempia, der mit biennis 
identisch zu sein scheint ${ }^{1}$ ). Die flava ist rotnervig und entsteht im ersten Fall aus rubens-Eizellen und flavens-Pollen, im zweiten Fall ans flavens-Eizellen und rubens-Pollen. Die suaveolens entsteht als albicans $\left({ }^{\circ}\right) \cdot$ flavens $\left(\sigma^{7}\right)$, die biennis als albicans $\left({ }^{\circ}\right) \cdot$ rubens $\left(\sigma^{7}\right)$. Die flavensEizellen der $O$. suaveolens scheinen zahlreicher zu sein als die albicans-Eizellen; denn bei Selbstbestäubung treten meist viel mehr $(85-54 \%)$ taube Samen (= flavens $\cdot$ flavens $)$ auf als gesunde $(15-46 \%)$, and entsprechend gibt die Kreuzung suaveolens $\times$ biennis, bei der die iuberwiegende Zahl der Samen gesund ausfällt $(73-88 \%)$, viel mehr $(79 \%)$ flava (= flavens $\cdot$ rubens) als redempta (= albicans $\cdot$ rubens). Alles in allem sind die flavens-Keimzellen der O. suaveolens augenscheinlich den albicans-Keimzellen gegenüber bedeutend in der Überzahl. Daß die O. biennis bei Bestäubung mit dem Pollen der suaveolens mehr gesunde Samen gibt als bei Selbstbestäubung, scheint deutlich; es sind $74-83 \%$ statt $55-77 \%$. Das rührt von der Entwicklung der rubensEizellen mit dem flavens-Pollen her. Auch daß die flava in der Kreuzung biennis $X$ suaveolens in größerer Zahl $(22 \%)$ aufzutreten scheint als die fallax in der Kreuzung biennis $\times$ Lamarckiana $(1-35 \%$, im Mittel 15\%), entspricht der Theorie; alle vom suaveolens-, genauer flavens-Pollen befruchteten rubens-Samenanlagen müssen sich ja entwickeln, während bei Verwendung von Lamarckiana-Pollen nur die Kombination rubens • velans, nicht rubens • gaudens gesund ausfällt. - Der Bastard suavis gleicht dem Vater $O$. suaveolens auch in seinem Gehalt an gesunden Samen, die $33-36 \%$ ausmachen, der Bastard redempta gleicht im selben Sinn seinem Vater $O$. biennis, mit $70 \%$ keimhaltiger Samen; wird die suavis mit dem Pollen der redempta belegt, so ist die Beschaffenheit der Samen dieselbe wie bei der Kreuzung der $O$. suaveolens mit O. biennis $\sigma^{7}$, insofern als $80 \%$ der Samen gesund sind.

Die Kreuzungen zwischen $O$. suaveolens und O. Lamarckiana liefern vollkommen entsprechende Ergebnisse. Beide Arten erzengen, mit dem Pollen der anderen Art befruchtet, fast lauter gesunde Samen, wie schon de Vries ${ }^{2}$ ) mitgeteilt hat. O. Lamarekiana $\times$ suaveolens (Samen $\mathrm{zu}$ 92-99\% gesund) gibt Zwillinge, weil der Pollen der $O$. suaveolens ebenso wie der von $O$. biennis und O. muricata von einerlei Art ist;

1) Der Name redempta soll besagen, daß der albicans-Komplex aus der Verbindung mit flavens frei gemacht ist und die uns geläufigere Verbindung mit rubens eingegangen hat.

2) de Vries 1915, S. 173, 1916 b. 
suavi-laeta entsteht als gaudens - flavens, suavi-velutina als velins - flavens. Hier ist also die gaudens-Verbindung aus O. Lamarckiana , , die wir aus der Kreuzung mit $O$. muricata $\sigma^{\top}$ in Form von nicht ergrünenden Keimlingen, aus der Kreuzung mit biennis $\sigma^{\top}$ gar nur in Form von tauben Samen kennen, endlich einmal voll lebensfähig. O. suaveolens $\times$ Lamarckiana (Samen zu 91-93\% keimhaltig) liefert Vierlinge, weil zwei Pollentypen mit zwei Eizelltypen zusammentreffen und sämtliche Verbindungen lebensfähig sind. Aus den albicans-Eizellen entstehen bienni-laeta und bienni-velutina; das Paar entspricht der biennis (redempta) aus $O$. suaveolens $\times$ biennis. Aus den flavens-Samenanlagen gehen suavilaeta als flavens - gaudens und suavi-velutina als flavens - velans hervor; dieses Paar entspricht der flava aus 0 . suaveolens $\times$ biennis. Wieder scheinen die suavi-Typen häufiger aufzutreten als die bienni-Typen.

Nach den bisherigen Erfahrungen sind die binären Konstitutionsformeln für die vier behandelten Arten: O. Lamarckiana = velans $\$ \sigma^{\top}$. gaudens $^{\top}$, O.biennis $=$ albicans 우 rubens 우 $\sigma^{\top}$, O. suaveolens $=$ albi-

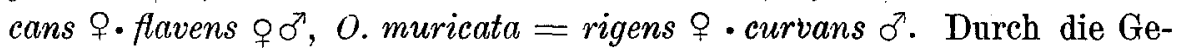
schlechtszeichen ist angedeutet, ob ein Komplex nur in einem Geschlecht oder in beiderlei Keimzellen als aktiv bekannt geworden ist; neue Kreuzungen können freilich noch andere Möglichkeiten und Fähigkeiten ans Licht bringen, vielleicht einen bisher als heterogam erscheinenden Komplex als isogam erkennen lassen. O. Lamarckiana ist so als isogam, biennis und suaveolens als halb heterogam, muricata als heterogam gekennzeichnet.

Über das gegenseitige genotypische Verhältnis der hypothetischen Komplexe läßt sich noch nicht viel sagen. Am ähnlichsten dürften sich gaudens und rubens sein, von dem Rotnervenfaktor in rubens, der aber auch auf gaudens übergehen kann, und der verschiedenen Blütengröße und Griffellänge abgesehen. Denn die laeta aus der O. biennis, also albicans. gaudens, kommt der $O$. biennis, also albicans • rubens, so nahe, daß die kleinblütige rotnervige $\mathrm{F}_{3}$ der laeta von biennis kaum mehr zu unterscheiden ist. Auch die Ähnlichkeit zwischen $O$. (muricata $\times$ biennis) $=$ rigens $\cdot$ rubens und $O$. (muricata $\times$ Lamarckiana $)$ laeta $=$ rigens $\cdot$ gaudens ist, besonders im Blütenstand, unverkennbar. Die ausgesprochene Ähnlichkeit, die mir, im Gegensatz zu anderen Beobachtern, zwischen $O$. Lamarckiana $=$ velans $\cdot$ gaudens und $O$. (Lamarckiana $\times$ biennis) fallax = velans : rubens zu bestehen scheint - es ist hier vor allem an die Gleichheit der Keimpflanzen, an die nur bei Lamarckiana und bei fallax so stark ausgeprägte Buckligkeit der unteren Blätter und an die 
Tabelle

\begin{tabular}{|c|c|c|c|c|}
\hline Komplex & Art & SproB & Blätter & Behaarung \\
\hline $\begin{array}{l}\text { gaudens } \\
\text { rubens } \\
\text { flavens } \\
\text { albicans } \\
\text { rigens } \\
\text { velans } \\
\text { curvans }\end{array}$ & $\begin{array}{c}\text { Lamarekiana } \\
\text { biennis } \\
\text { suaveolens } \\
\text { biennis u. suaveolens } \\
\text { muricata } \\
\text { Lamarckiana } \\
\text { muricata }\end{array}$ & $\begin{array}{c}\text { aufrecht } \\
" \\
" \\
" \\
" \\
\text { nickend }\end{array}$ & $\begin{array}{c}\text { breit } \\
\text { breit } \\
\text { breit } \\
? \\
\text { schmal } \\
\text { schmal } \\
\text { sehr schmal }\end{array}$ & $\begin{array}{c}\text { grob } \\
\text { grob } \\
\text { sehr schwach } \\
\text { schwach, fein } \\
\text { ? } \\
\text { stark, weich } \\
\text { weich }\end{array}$ \\
\hline
\end{tabular}

weit ausladenden Grundäste zu erinnern -, ist eine weitere Bestätigung. Auf der nahen Verwandtschaft $\mathrm{z}$ wischen gaudens und rubens könnte ihre Unverträglichkeit beruhen; ganz homozygotische Kombinationen sind ja bei unseren Önotheren immer lebensunfähig. - Verhältnismäßig nahe können sich sonst noch albicans und rigens stehen. Die auffallende Ähnlichkeit zwischen 0 . muricata $=$ rigens $\cdot$ curvans und $O$. (biennis $\times$ muricata) = albicans - curvans dürfte allerdings durch Dominanz der curvansCharaktere verursacht sein. Denn größer sind die Unterschiede schon zwischen der laeta aus der O. biennis und der aus der 0 . muricata, und ebenso zwischen den beiden velutinae. Vor allem besitzt der rigens-Komplex, anders als albicans, den Tupfenfaktor, wie die Bastarde $O$. (muricata $\times$ Lamarckiana) laeta und $O$. (muricata $\times$ biennis) zeigen. Der Tupfenfaktor findet sich sonst nur noch bei dem velans-Komplex der $O$. Lamarckiana. Der curvans-Komplex der O. muricata ist scharf gekennzeichnet durch die immer dominierenden nickenden Sproßgipfel. Der flavens-Komplex bedingt oft mangelhafte Clorophyllbildung, doch nicht in der ursprünglichen Kombination albicans - flavens $=O$. suaveolens. Schmalblättrigkeit haben die Komplexe velans, rigens und curvans miteinander gemein.

In der Tabelle IV ist der Versuch gemacht, die hauptsächlichen unterscheidenden Merkmale der angenommenen haploiden Faktorenkomplexe anzugeben, soweit über sie eine Vermutung geäußert werden kann. Von den aufgeführten Charakteren dominieren: nickender Sproß über aufrechten, Vorhandensein von Anthokyan in Haarbasen, Nerven, Kelch und Frucht über Fehlen des Anthokyans, mitunter kurzer Griffel über langen Griffel; mehr oder weniger intermediär ist die Vererbung bei der Gestalt von Kelch und Frucht, bei der Blattbreite und der 
IV.

\begin{tabular}{c|c|c|c|c|c|c|c}
\hline \hline \multicolumn{3}{c|}{ Anthokyan } & Kelch & Krone & Griffel & Frucht \\
\hline Tupfen & Nerven & Kelch & Frucht & & & & \\
\hline & & & & & & & \\
- & - & - & - & schlank & sehr groB & lang & schlank \\
- & + & - & - & mittel & mittel & kurz & mittel \\
- & - & - & - & sehr schlank & groB & kurz & sehr schlank \\
- & - & - & - & mittel & mittel & kurz & mittel \\
+ & + & + & + & dick & klein & kurz & dick \\
+ & - & + & + & dick & sehr groB & lang & dick \\
$?$ & $?$ & $?$ & - & dick & klein & kurz & $?$
\end{tabular}

Kronengröße, meist auch bei der Griffellänge. Die Begründung der Daten ist in den Einzelbeschreibungen enthalten, im übrigen soll die Tabelle mehr ein Programm für den künftigen Versuch von Faktorenanalyse sein als eine Tafel der gesicherten Einsichten.

c) Komplexanalyse einiger Bastarde.

Wenn die Artbastarde der Önotheren bei Selbstbefruchtung sich konstant reproduzieren, von den oben behandelten untergeordneten Merkmalen abgesehen, so können die Nachkommen, die den elterlichen $\mathbf{F}_{1-}$ Typus wiederholen, auf zweierlei Weise entstehen. Entweder kombinieren sich die Charaktere der Elternarten in den aktiven Keimzellen des Bastards derart, daß homozygotische Verbindungen dieser Keimzellen wieder denselben Phänotypus hervorrufen wie ihn die $\mathrm{F}_{1}$ darstellt $^{1}$ ). Oder es bleiben, was a priori und nach den Angaben von de Vries als unbedingt zu-

1) Literatur und Diskussion bei Federley, 1913, S. 69, 77. - Im mendelistischen Sinne möglich scheint mir dieser Modus, falls auch keine inaktiven Keimzellen abgespalten werden sollen, nur dann, wenn die Unterschiede zwischen den in der Heterozygote vereinigten Komplexen sämtlich auf dem einseitigen Vorhandensein von je zwei gleich sinnigen, ja vollkommen identischen Faktoren beruhen und wenn zwischen den Gliedern eines Paares solcher Gene in der Heterozygote vollkommene AbstoBung besteht. Auf der einen Seite sei $\mathbf{A A _ { 1 }}$, auf der anderen $a a_{1}$ verwirklicht, so wären die Keimzellen des Bastardes $\mathrm{Aa}_{\mathbf{1}}$ und $\mathbf{A}_{1} \mathrm{a}$ identisch, einfach so viel wie $\mathbf{A} ; \mathbf{A A}_{\mathbf{1}}$ und aa dürften wegen der Abstobung zwischen $A$ und $A_{1}$ sich nicht bilden. Die Zygoten, ans denen die $F_{2}$ hervorginge, dürften wir dann unbedenklich $A A$ schreiben statt $A a A_{1} a_{1}$. Denken wir uns die Gene unter dem Bild von Radikalen, so können zwei gleichsinnige Faktoren keine homologen Radikale sein, weil sie nicht beide an der gleichen Stelle des Moleküls stehen können (vergl. dazu Johannsen S. 608, Anmerkung 2). Wenn aber beim Austausch das Radikal $A_{1}$ genan an die Stelle treten würde, die im antagonistischen Keimplasma das Radikal A einnimmt, so wären die Gene A und $A_{1}$ auch homolog geworden. 
treffend erscheint, die elterlichen Faktorenkomplexe im Bastard annähernd unverändert und wohl auch meistens in den ursprünglichen Verhältnissen der Geschlechtsverteilung erhalten. Der Bastárd $O$. (biennis $\times$ muricata) z. B. erhält sich dadurch konstant, daß von seinen Samenanlagen immer nur solche vom albicans-Typus zur vollen Embryoentwicklung kommen, und zwar nur dann, wenn sie durch Pollenschläuche vom curvans-Typus befruchtet werden. Über die tauben Samen und über die sterilen Pollenkörner und Samenanlagen wird später zu sprechen sein. Daß die Vererbung auf diesem Weg erfolgt, geht eindeutig aus den Rückkreuzungen der Bastarde mit den Eltern und aus den Kreuzungen der Bastarde untereinander und mit anderen Arten hervor. Das von de Vries geschaffene Material ist hier außerordentlich reich, doch will ich mich auf die Erörterung der wenigen Fälle beschränken, die ich aus eigener Anschauung kenne.

O. (biennis $\times$ muricata) $\times$ biennis (genauer [albicans $\cdot$ curvans] $\times$ rubens) gibt reine biennis, nur in der Blütengrößè sind Unterschiede unter der Nachkommenschaft aus der sesquireziproken Kreuzung vorhanden. Wir haben es aber nicht mit diesen wenig wichtigen, sondern mit den Habituscharakteren zu tun, und hierin wird der biennis-Typus vollkommen wieder hergestellt. Der Bastard bildet eben nur aktive Embryosäcke von derselben Konstitution wie die Eizelle war, aus der er selber hervorgegangen ist, also. vom albicans-Typus. In der bezeichneten sesquireziproken Kreuzung werden also albicans-Eizellen mit rubens-Pollen verbunden, somit reine biennis hergestellt und der "zentrale Großelter" muricata "ausgeschaltet" (de Vries). Wichtig ist nun, daß der erfahrungsgemäß isogame rubens-Komplex in der rekombinierten biennis sofort wieder in den Eizellen (neben albicans) aktiv wird, nicht nur im Pollen. Das geht daraus hervor, daß die fragliche biennis mit Pollen von $O$. Lamarckiana nicht nur laeta und velutina, sondern auch fallax liefert (s. S. 204). Aus dem Bastard $O$. (biennis $\times$ muricata) sind natürlich bei Kreuzung mit Lamarckiana $\sigma^{7}$ nur laeta und velutina zu erwarten, weil hier der rubens-Komplex notwendig fehlen muß. - Die ausgebildeten Samen in den Früchten des Bastardes $O$. (biennis $\times$ muricata) sind nach Bestäubung mit biennis-Pollen so gut wie alle gesund und keimfähig, während bei Selbstbestäubung zahlreiche Samen taub werden. Das deutet darauf hin, daß vielleicht doch von dem Bastard auch Pollenkörner gebildet werden, die einen andern als den curvans-Typus darstellen und auch $\mathrm{zu}$ befruchtungstüchtigen Pollenschläuchen auswachsen, daß aber die gebildeten Zygoten nicht lebensfähig sind. - 
In der rekombinierten 0 . biennis ist bei Selbstbestäubung das Verhältnis zwischen gesunden und tauben Samen wieder dasselbe wie in der ursprünglichen Form.

Von dem Bastard $O$. (biennis $\times$ Lamarckiana) laeta (= albicans. gaudens) ist zunäcbst nach den oben mitgeteilten Erfahrungen zu vermuten, daß er Pollenzellen vom Typus gaudens und Eizellen von den Typen albicans und gaudens erzeugt; der gaudens-Komplex ist ja isogam. Die Konstanz bei Selbstbestäubung widerspricht dieser Vermutung nicht, ohne sie zu bestätigen. Desgleichen das Auftreten einförmiger biennis in der Kreuzung $O$. (biennis $\times$ Lamarckiana) laeta $\times$ biennis; denn albicans.rubens ist biennis, und gaudens.rubens schlägt immer fehl. Der Gehalt an tauben Samen ist bei Kreuzung mit $O$. biennis $\sigma^{7}$ ungefähr ebenso groß wie bei Selbstbestänbung (etwa 50\%), denn rubens- und gaudens-Pollen verhalten sich den albicans- und den gaudens-Eizellen gegenüber gleich. Wichtiger ist die Kreuzang $O$. (biennis $\times$ Lamarckiana) laeta $\times$ Lamarckiana; es entstehen laeta $=$ albicans $\cdot$ gaudens, velutina $=$ albicans $\cdot$ velans und Lamarckiana $=$ gaudens $\cdot$ velans; gaudens $\cdot$ gaudens muß natürlich fehlschlagen. Hier ist die Annahme also gut bestätigt. Durch die Bestäubung mit Lamarckiana-Pollen wird der Gehalt an gesunden Samen vielleicht etwas erhöht ( $58 \%$ statt 39-51\%), weil jetzt auch gaudens-Eizellen zur Entwicklung kommen. O. Lamarckiana $\times$ (biennis $\times$ Lamarckiana) laeta liefert, wie zu erwarten, nur Lamarekiana $=$ velans $\cdot$ gaudens; gaudens $\cdot$ gaudens schlägt fehl. Die Zahl der gesunden Samen ist dabei in den Lamarckiana-Früchten, wie ebenfalls zu erwarten, so groß wie bei Bestäubung mit biennis-Pollen, also bei der de Vriesschen Rasse zwischen 70 und 80\%, bei der schwedischen Rasse $53 \%$. O. biennis $\times($ biennis $\times$ Lamarckiana) laeta gibt albicans $\cdot$ gaudens $=$ laeta, ganz nach Vorschrift, ohne Veränderung des Gehaltes an gesunden Samen.

Der zugehörige Zwilling $O$. (biennis $\times$ Lamarckiana) velutina dürfte entsprechend im Pollen den velans-Komplex und in den Eizellen die Komplexe albicans und velans besitzen. Bei Bestäubung mit dem Pollen von biennis sollte hier nicht nur albicans $\cdot$ rubens $=$ biennis auftreten, sondern anch velans $\cdot$ rubens $=$ fallax. Die fallax fehlte aber. Doch ist hier hervorzuheben, daß ich aus den zuerst verwendeten Materialien von biennis und Lamarckiana $\mathrm{X}$ eine fallax überhaupt nicht gesehen habe, es ist also abzuwarten, ob bei Verwendung der aus den gut bekannten Materialien gewonnenen velutina nicht doch fallax ans Licht kommt. Eine Komplikation liegt auch darin, daß die benutzte 
velutina rotnervig war und die "rotnervigen“ Eizellen vielleicht mit rubens-Pollen keine lebensfähigen Zygoten geben. - Das Ergebnis der übrigen Kreuzungen ist wieder das erwartete. O. velutina $\times$ Lamarckiana ist noch nicht aufgezogen. O. Lamarekiana $\times($ biennis $\times$ Lamarckiana) velutina gibt nur gaudens $\cdot$ velans $=$ Lamarckiana; das Verhältnis zwischen gesunden und tauben Samen ist dasselbe wie bei Selbstbestäubung $(41 \%$ gesunder Samen). O. biennis $\times($ biennis $\times$ Lamarckiana $)$ velutina lieferte nur velutina = albicans $\bullet$ velans, wieder keine fallax. Als Ergänzung kann hier der Befund von de Vries angeführt werden, daß $O$. (muricata $\times$ nanella) velutina $\times$ biennis lauter Pflanzen „vom Typus Lamarckiana $\times$ biennis", also fallax gibt (1913, S. 241). Warum hier die Bastardform $O$. (muricata $\times$ biennis $)=$ rigens $\cdot$ rubens fehlt, ist ebenso unklar wie in meinen Kreuzungen 0 . (biennis $\times$ Lamarckiana) velutina $\times$ biennis und reziprok das Fehlen der fallax.

Besonders wichtig sind natürlich die Kreuzungen zwischen den Zwillingen. Wie oben mitgeteilt, entsteht aus $O$. (biennis $\times$ Lamarckiana) velutina $\times$ O. (biennis $\times$ Lamarckiana) laeta zur Hauptsache Lamarckiana, die aus den velans-Eizellen der velutina und dem gaudens-Pollen der laeta gebildet sein muß; daneben tritt laeta auf, die den albicans-Eizellen der velutina die Entstehung verdanken muß. Aus der reziproken Kreuzung laeta $\times$ velutina geht wieder Lamarckiana hervor, diesmal aus den gaudens-Eizellen der laeta und dem velans-Pollen der velutina gebildet, und velutina, die als albicans - velans entsteht. Die Zahl der gesunden Samen wird durch die Kreuzung gegenüber der bei Selbstbestäubung erzeugten beträchtlich erhöht, bei der laeta von $39-56 \%$ auf $68-75 \%$, bei der velutina von $16-37 \%$ auf $88-91 \%$. - Die beiden Kreuzungen sind wohl der wichtigste Prüfstein für meine Auffassung der laeta-velutina-Spaltung, denn sie zeigen, daß durch $\mathrm{Zu}$ sammenfügung der beiden in der Zwillingspaltung getrennten Elemente die zusammengesetzte Form Lamarckiana wiederhergestellt wird. Von hohem Interesse scheinen nach den Mitteilungen von de Vries die Kreuzungen zu sein, in denen die aus $O$. muricata gewonnenen Zwillinge, also $O$. (muricata $\times$ Lamarckiana) laeta und velutina, mit dem Pollen der Elternart muricata bestäubt werden. Es treten dabei (de Vries 1913, S. 169 ff.) eine muricata-ähnliche Form auf, die er als coerulea bezeichnet, und ein gracilis-Typus, der mit $O$. (Lamarckiana $\times$ muricata) identisch sein soll. Hier ist also das Verhalten verwirklicht, das ich bei der Kreuzung 0 . (biennis $\times$ Lamarckiana) velutina $\times$ biennis erwartet, aber bis jetzt nicht beobachtet habe. Die coerulea dürfte 
wirklich einer muricata entsprechen und als rigens - curvans entstehen. Die gracilis soll in gleicher Weise aus $O$. (muricata $\times$ Lamarckiana) laeta und velutina hervorgehen, muß also das eine Mal gaudens $\cdot$ curvans, das andere Mal velans $\cdot$ curvans sein. Daß die beiden gracilis-Typen identisch sind, ist ausgeschlossen; de Vries beschreibt sie nicht eingehend. Ich habe aus der Kreuzung $O$. (Lamarekiana $\times$ muricata) nur ein en lebensfähigen Bastard erhalten, wohl velans - curvans, es ist also auffallend, daß aus laeta der Bastard gaudens - curvans in lebensfähigem Zustande gewonnen werden kann. Doch wäre einerseits das de Vriessche Material daraufhin zu prüfen, ob auch hier die Kreuzung $O$. Lamarckiana $\times$ muricata zur Hälfte gesunde und zur Hälfte früh absterbende Keimlinge liefert, und andererseits ist abzuwarten, ob bei meiner muricata die Rückkreuzung der Zwillinge mit der Mutterart dasselbe Ergebnis liefert wie in den Versuchen von de Vries. Warum diese Kreuzungen von großer Bedeutung sein können, wird unten zu erörtern sein.

De Vries gibt auch kurz an $(1913$, S. 172), daß er aus den Kreuzungen 0 . (biennis $\times$ Lamarckiana) laeta $\times$ muricata und (biennis $\times$ Lamarckiana) velutina $\times$ muricata "nebst gelben Keimen nur eine Form, und zwar die gracilis", erhielt. Ob diese gracilis eine albicansoder aber eine gaudens- bezw. velans-Kombination ist, bleibt zu prüfen.

Der Bastard fallax entsteht sowohl als 0 . (Lamarckiana $\times$ biennis), und zwar hier ohne lebenden Bruder, wie als $O$. (biennis $\times$ Lamarckiana), hier mit den "Zwillingen" laeta und velutina zusammen. Das rührt davon her, daß der rubens-Komplex der biennis, der die fallax erzeugt, sich isogam verhält. Der Komplex velans ist erwiesenermaßen ebenfalls isogam, es ist also zu erwarten, daß sowohl in den Eizellen wie in den Pollenzellen die beiden Komplexe aktiv auftreten. Wird nun fallax, einerlei auf welchem Wege gewonnen, mit dem Pollen von biennis, also rubens-Pollen bestäubt, so muß velans $\cdot$ rubens $=$ fallax entstehen, und zwar als einzige lebensfähige Form, weil die homozygotische Kombination rubens $\cdot$ rubens fehlschlagen muß. Das ist tatsächlich festgestellt worden (S. 206, 212). Wird O. biennis mit dem Pollen der fallax belegt, so sind zu erwarten: albicans $\cdot$ rubens $=$ biennis, albicans $\cdot$ velans $=$ velutina, rubens $\cdot$ velans $=$ fallax; rubens $\cdot$ rubens schlägt fehl. Alle drei Formen sind in Wirklichkeit beobachtet worden, und dazu noch weißnervige biennis und die Form punctilaeta, von denen wir später zu reden haben. Nach der Menge der auftretenden velutina gegenüber der biennis zu urteilen, besteht der Pollen zum größeren Teil aus velans, zum kleineren aus rubens; oder wächst der velans-Pollen rascher? 
Wenn auch in den Samenanlagen der velans-Komplex vorherrscht, ist die geringe Zahl der gesunden Samen bei Selbstbestäubung verständlich; es müssen dann ja viele untüchtige Homozygoten velans. velans gebildet werden. Der Gehalt an gesunden Samen wird bei Bestäubung mit dem Pollen von O. biennis gesteigert - von 26-27\% auf $45-68 \%$ bei $O$. (biennis $\times$ Lamarckiana) fallax $\mathrm{F}_{1}$, von $26-38 \%$ auf $47-49 \%$ bei $O$. (Lamarckiana $\times$ biennis) fallax $F_{1}$, von $4-9 \%$ auf $59 \%$ bei $O$. (Lamarekiana $\times$ biennis) fallax $\mathrm{F}_{3}$ von HeribertNilsson -, weil die Heterozygoten velans rubens jetzt hăufiger zustande kommen. Wird $O$. (biennis $\times$ Lamarcliana) fallax $\mathrm{F}_{1}$ mit $O$. (Lamarekiana $\times$ biennis) fallax $\mathbf{F}_{1} \sigma^{7}$ gekrenzt, so bleibt der Prozentsatz der gesunden Samen gering, $19 \%$, weil die Kreuzung einer Selbstbestäubung gleichkommt. Bei der reziproken Verbindung sind $40 \%$ gesunder Samen gefunden worden, also etwas mehr als bei Selbstbestäubung der O. (Lamarckiana $\times$ biennis) fallax $\mathrm{F}_{1}(26-38 \%$ ), doch kann das ein Zufall sein. Auch der Unterschied, der zwischen den beiden reziproken fallax-Formen in dem Prozentsatz der gesunden Samen bei Selbstbestäubung gefunden warde $(26-27 \%$ gegen $26-38 \%)$, braucht nicht konstant zu sein. Hat doch de V ries bei $O$. (Lamarckiana $\times$ biennis) fallax Schwankung zwischen 20 und $64 \%$ beobachtet $(1916 \mathrm{~b}$, S. 273).

Werden $O$. (Lamarckiana $\times$ biennis) fallax \& und 0. Lamarckiana $\sigma^{\circ}$ verbunden, so sind $\mathrm{zu}$ erwarten: velans gaudens = Lamarckiana, rubens $\cdot$ velans $=$ fallax. Doch ist $\mathrm{zu}$ bedenken, daß fallax nur dann erscheinen kann, wenn die verwendete biennis im rubens-Komplex isogam ist. Die als Mutter benutzte fallax war eine $\mathrm{F}_{3}$-Pflanze von Heribert-Nilsson, und über die Beschaffenheit seiner biennis weiß ich nichts, als daß sie rotnervig ist. Gefunden wurde Lamarckiana, ob anch fallax vorkommt, muß durch größere Kulturen entschieden werden. Der Prozentsatz der gesunden Samen ist bei der Kreuzung bedeutend höher als bei Selbstbestäubung, $31 \%$ statt $4-9 \%$.

\section{Das Verhalten des Rotnervenfaktors gegenüber den artunterscheidendeu Faktorenkomplexen.}

In der immer rotnervigen $O$. biennis wird der Rotnervenfaktor, den wir mit $\mathrm{R}$ bezeichnen wollen, von dem Komplex rubens augenscheinlich streng festgehalten, er geht nicht auf den albicans-Komplex über. Die Veränderung von albicans in die mit dem Rotfaktor ausgestattete Form, also von r-albicans in R-albicans, wäre natürtich nur möglich auf Kosten des Übergangs von R-rubens in r-rubens. Das Fehlen von weißnervigen 
Individuen in der Nachkommenschaft selbstbefruchteter O. biennis ist noch kein Beweis für das Fehlen eines solchen Austauschs, denn die negativen Homozygoten könnten ja untauglich sein. Aber daß die Verbindungen des albicans-Komplexes mit anderen den Rotfaktor nicht besitzenden Komplexen immer weißnervig sind, und daß die Verbindungen des rubens-Komplexes immer rotnervig sind, ist schon eher ein Beweis dafür. Wir haben weißnervig gefunden $O$. biennis $\times$ muricata $=$ albicans $\cdot$ curvans, O. (biennis $\times$ suaveolens) suavis $=$ albicans $\cdot$ flavens, O. (biennis $\times$ La marckiana-weißnervig) laeta und velutina $=$ albicans $\cdot$ gaudens bezw. albicans $\cdot$ velans, ebenso 0 . (biennis $\times$ rubrinervis) subvelutina und velutina, die wir erst später analysieren können (s. unten). Rotnervig haben wir gefunden $O$. (muricata $\times$ biennis) $=$ rigens $\cdot$ rubens, $O$. (suaveolens $\times$ biennis) flava $=$ flavens $\cdot$ rubens und reziprok, $O$. (Lamarckiana $\times$ biennis) fallax $=$ velans $\cdot$ rubens und reziprok, $O .($ rubrinervis $\times$ biennis $)$ fallax und subfallax und reziprok.

Hat der rubens-Komplex mit flavens oder velans eine Verbinduñg eingegangen, so kann er seinen Rotfaktor abgeben. Die $\mathrm{F}_{2}$ von $O$. (biennis $\times$ Lamarckiana) fallax spaltet ja Weißnerven ab, die als velans $\cdot \mathrm{r}-$ rubens entstehen müssen, ebenso ist die $\mathrm{F}_{2}$ der rotnervigen o. (suaveolens $\times$ biennis) flava sogar zum größten Teil weißnervig. Daß in der fallax der Komplex $\mathrm{r}$-rubens nur entstehen kann auf Kosten einer Umwandlung von velans in R-velans, ist klar, und $\mathrm{daB}$ die fallax tatsächlich zahlreiche mit dem Rotfaktor ausgestattete velansKeimzellen erzeugt, geht aus dem Auftreten von rotnerviger velutina in der Kreuzung biennis $\times$ fallax hervor; diese velutina muß ja als albicans $\cdot$ R-nelans gebildet sein. Die Befruchtung der biennis-Eizellen durch Pollenzellen, die r-rubens sind, scheint auffallend selten zu sein, denn der weißnervige biennis-Typus ist in ganz wenigen Individuen der Nachkommenschaft von biennis $\times$ fallax gefunden worden; vielleicht vertragen sich die albicans-Eizellen mit diesem Pollentypus schlecht, vielleicht wächst auch schon der Pollen schlecht. Die Beobachtung, daß die Färbung der Blattnerven bei der velutina aus biennis $\times$ fallax sehr verschieden kräftig ist, macht aber noch auf die Möglichkeit aufmerksam, daß die Rotnervigkeit der $O$. biennis durch mehr als einen Faktor bedingt ist, und daneben sind die Ausführungen von HeribertNilsson (1912, S. 101; 1915, S. 31) über die Polymerie der Rotnervig. keit von $O$. Lamarckiana zu stellen.

Nach den mitgeteilten Erfahrungen ist es sicher, daf der Rotnervenfaktor des rubens-Komplexes sich gegenüber albicans anders ver- 
hält als gegenüber velans und flavens. Die Komplexe velans und flavens vermögen den Rotfaktor von rubens abzureißen, weil sie etwa gleich starke "Affinität" zu dem Faktor haben wie rubens, albicans dagegen stößt den Rotfaktor ab oder zieht ihn wenigstens schwach an.

Die Übertragbarkeit des Rotnervenfaktors auf den velans-Komplex der $O$. Lamarckiana macht es möglich rotnervige $O$. Lamarckiana herzustellen. Einer der Wege zu diesem Ziel ist die Kreuzung fallax $\times$ Lamarckiana-weißnervig, bei der rotnervige Lamarckiana-Typen neben weißnervigen auftreten (S. 208). Diese Rotnerven müssen als R-velans • gaudens gebildet sein. Mit den so gewonnenen Pflanzen habe ich noch keine Kreuzungen ausgeführt, aber die von Heribert-Nilsson so sorgfältig studierten rotnervigen Lamarckiana-Stämme haben wohl eine ähnliche Genese ${ }^{1}$ ), und das Verhalten eines solchen Stammes kennen wir: Die Kreuzung mit $O$. biennis 9 liefert beide Zwillinge, laeta wie velutina, als Rot- und als Weißnerven (S. 182). Die rotnervige laeta $\mathrm{muß}$ als albicans $\cdot \mathrm{R}$-gaudens entstehen, und der R-gaudens-Komplex durch Austausch des Rotfaktors zwischen R-velans und gaudens. Auf dem Umweg über den velans-Komplex kann der Rotnervenfaktor also auch auf den gaudens-Komplex übertragen werden. Die direkte Angliederung des Rotfaktors der biennis an gaudens ist deswegen nicht möglich, weil die Verbindung gaudens • rubens fehlschlägt. - Von dem rigens-Komplex der $O$. muricata-Venedig läßt sich der hier vorhandene Rotnervenfaktor auf gaudens unmittelbar übertragen, denn $O$. (muricata $\times$ Lamarckiana) laeta ist ebenso wie die zugehörige velutina rotnervig. Ob der Rotfaktor der muricata mit dem der biennis identisch ist, wissen wir noch nicht.

Die zweite Generation der rotnervigen $O$. (biennis $\times$ Lamarckiana) laeta kenne ich nur aus der ersten, von ungenügend bekannten Eltern stammenden Kreuzung. Diese $\mathrm{F}_{2}$-laeta, die in der Gestalt und Farbe der Blätter von dem aus der rotnervigen Heribert-Nilssonschen $O$. Lamarckiana gewonnenen Bastard deutlich sich unterscheidet, hat sich in einer ansehnlichen Individuenzahl (221 Stïck) als durchweg rotnervig erwiesen. Der Befund hat nichts Auffallendes, wenn wir uns an die Ähnlichkeit zwischen den Komplexen rubens und gaudens erinnern. Diese Ähnlichkeit wird durch Übertragung des Rotfaktors auf den gaudens-Komplex noch erhöht, und wenn $\mathrm{R}$-gaudens-Pollenzellen der

$\left.{ }^{1}\right)$ de Vries (1916 b, S. 284) denkt an eine Entstehung durch Mutation aus der weiknervigen Form. 
rotnervigen $O$. Lamarckiana mit den albicans-Eizellen der O. biennis zusammentreten, so kann der Rotnervenfaktor in der rotnervigen laeta sich ganz wohl ebenso verhalten wie in der 0 . biennis: er sitzt fest am gaudens-Komplex und bleibt dem albicans-Komplex fern. In diesem Fall erhält die laeta sich auf demselben Weg in der Nervenfarbe konstant wie die biennis es tut. Natürlich muß die aus Heribert-Nilssonschem Material gewonnene rotnervige laeta auf diesen Punkt hin noch geprüft werden.

Die rotnervige velutina, ebenfalls aus der Lamarckiana $\mathrm{X}$ hergestellt, verhält sich anders als die zugehörige laeta. Die $\mathrm{F}_{2}$ habe ich noch nicht aufgezogen, aber die aus der Kreuzung $O$. biennis $\times$ velutinarotnervig gewonnene velutina ist teils rot- und teils weißnervig (S. 210). Spaltung nach der. Nervenfarbe ist deshalb in der $F_{2}$ mit Sicherheit zu erwarten. Hier muß der R-velans-Komplex seinen Rotfaktor gelegentlich an albicans abgeben. Der albicans-Komplex stößt den Rotfaktor also nicht unter allen Umständen ab, sondern er übt nur geringe Anziehung auf ihn aus, so daß er ihn zwar von R-velans, aber nicht von rubens und von $\mathrm{R}$-gaudens abzureißen vermag. Diese Erscheinungen, die auffallend an chemische Reaktionen ${ }^{1}$ ) erinnern, verdienen jedenfalls genaue Prüfung.

In der genannten Kreuzung überträgt der velans-Pollen der velutina teils rote, teils weiße Nerven, es muß also auch bei der Pollenbildung der Übergang des Rotnervenfaktors von $\mathrm{R}$-velans auf albicans vorkommen. Das Vorhandensein des nicht aktiv werdenden albicansKomplexes macht sich also in der Wirkung, die er bei der Reduktionsteilung auf den aktiven velans-Komplex ausübt, deutlich bemerkbar; nur die Anwesenheit des stillen Partners albicans gibt dem R-velans-Komplex die Möglichkeit den Faktor R abzustoßen.

Die Erfahrung mit dem Rotnervenfaktor ist wichtig, weil sie zeigt, daß zwischen den beiden artverschiedenen Komplexen, die durch Kreuzung zweier Arten miteinander verbunden werden, doch Faktoren ausgetauscht werden können, wenn auch inbezug auf die wichtigsten Charaktere die Komplexe in den Keimzellen des Bastards ziemlich rein wieder in die Erscheinung treten. Mit der Blütengröße und mit der Griffellänge steht es augenscheinlich ähnlich wie mit der Färbung der Nerven, doch

1) Eine ausfürliche Erörterung der Analogien von Vererbungserscheinungen mit chemischen Vorgängen hat Lehmann gegeben (1914, S. $161 \mathrm{ff}$.). Seine Bedenken gegen den Vergleich der Gene mit chemischen Radikalen kann ich nicht teilen. 
sollen diese Merkmale jetzt nicht eingehender betrachtet werden, weil sie uns etwas grundsätzlich Neues kaum lehren können und zudem in den Kulturen nicht sorgfältig genug studiert worden sind. Das Auftreten kleinblütiger, kurzgriffeliger Lamarckiana-Formen in verschiedenen Kreuzungen weist jedenfalls darauf hin, daß die Faktoren für die betreffenden Charaktere in den Komplexen der Lamarckiana verändert werden können.

Die weitgehende Konstanz der Komplexe in den Arten und in den künstlich erzeugten Bastarden können wir uns durch die Annahme zurechtlegen, daß die einem Komplex zugehörigen Chromosomen aufeinander stärkere Anziehung ansüben als auf die Chromosomen des antagonistischen Komplexes, so daa bei der heterołypischen Mitose die beiden haploiden Chromosomensätze so voneinander getrennt werden, wie sie in die Zygote eingegangen sind, ohne Austausch ganzer Chromosomen. Die schwache Anziehung zwischen Chromosomen, die verschiedenen Komplexen angehören, kommt vielleicht in dem Ausbleiben der Konjugation in der Diakinese zum Ansdruck, wie es von Davis (1910a, 1911a) bei O. Lamarckiana und biennis beobachtet worden ist; für Artbastarde in der Gattung Digitalis wird dasselbe Verhalten von Haase-Bessell (S. 304), für Sehmetterlingsartbastarde von Federley (S. 36) beschrieben. Gelegentlich kommt aber nach Davis bei den Önotheren Paarung einzelner Chromosomen vor, und damit wäre die Möglichkeit des "crossing over", des Austauschs von Chromosomenteilen gegeben, der zu Spaltung nach der Nervenfarbe, Blütengröße usw. führen kann. Bastarde, die in $F_{2}$ nach mehreren Charakteren spalten, wären auf diese zytologischen Vorgänge hin mit den stabilsten Formen, wie O. biennis, muricata, zu vergleichen.

\section{Die artunterscheidenden Faktorenkomplexe und die Mutationen.}

Von besonderer Wichtigkeit sind die seltenen Bastardformen, deren Verhältnis zu den gewöhnlich auftretenden einigermaßen genau und sicher definiert werden $\mathrm{kann}^{1}$ ). Hier steht an erster Stelle die punctilaeta, die in drei Exemplaren aus biennis $\times$ fallax erhalten worden ist. Die Form gleicht im großen und ganzen einer laeta, hat aber die rot getupften Stengel und Fruchtknoten der velutina und auch etwas Anthokyan an den späteren Kelchen. Die Eizellen, die die weißnervige punctilaeta (zwei Individuen) geliefert haben, müssen albicans gewesen sein. Der Pollen hatte den Tupfenfaktor $\mathrm{P}$ von dem velans-Komplex, im übrigen muß er gaudens-artig gewesen sein. Nun ist aber gaudens in der fallax, die ja als rubens -velans oder als velans - rubens entsteht, nicht vorhanden. Dagegen haben wir wahrscheinlich gemacht, dab der rubens-Komplex dem gaudens-Komplex recht ähnlich ist, und deswegen steht nichts der Annahme im Weg, daß der fragliche Komplex durch

1) Bei der Mehrzahl der im speziellen Teil aufgeführten Abweicher ist eine solche Bestimmung noch nicht möglich. 
Faktorenaustausch zwischen rubens und velans konstruiert worden ist; rP-velans wäre zu rp-velans geworden, Rp-rubens zu RP-rubens. Im Fall der beiden weißnervigen Individuen hat der neu gebildete Komplex den Rotnervenfaktor nicht erhalten; er war rP-rubens. Das dritte Individuum dagegen war blaß rotnervig; es wird aus einer albicansEizelle und einer RP-rubens-Pollenzelle entstanden sein.

Eine biennis-artige, hohe Form ist in der Kreuzung biennis $X$ suaveolens aufgetreten. Die Rotnervigkeit weist darauf hin, daß der Komplex rubens daran irgendwie beteiligt ist; als Pollen nehmen wir unveränderten flavens-Pollen an, aber rubens - flavens ist flava und von dem fraglichen Typus weit verschieden. Dagegen ist nicht von der Hand zu weisen, daß die biennis eine Eizelle geliefert hat, in der Charaktere des albicans- und des rubens-Komplexes gemischt waren. Wir nehmen damit an, daß in vereinzelten Fällen doch auch in der biennis der Komplex albicans den Rotfaktor von rubens übernimmt, vielleicht sogar zusammen mit anderen rubens-Faktoren.

Schwieriger ist das Auftreten einer ungetupften, grünkelchigen, rotnervigen laeta-Form in der Kreuzung $O$. (Lamarekiana $\times$ biennis) fallax $\mathbf{F}_{3} \times$ Lamarckiana-weißnervig zu verstehen. Ein albicans-Komplex, den wir für einen wesentlichen Bestandteil aller laeta- und biennisartigen Formen halten, steht hier nicht zur Verfügung; gaudens wäre im Lamarckiana-Pollen vorhanden.

Wenn wir unter der durch Selbstbestäubung gewonnenen Nachkommenschaft so weit abweichende Formen finden, wie wir sie eben unter den Produkten von Kreuzungen betrachtet haben, sprechen wir mit de Vries von Mutation bezw. von Mutanten. Die einzige Mutante, die in meinen Kulturen der Arten nach Selbstbefruchtung aufgetreten ist, ist die lutescens aus suaveolens. Sie hat mit der flava aus biennis $\times$ suaveolens und reziprok große Ähnlichkeit, ist aber weißnervig. Sie könnte hervorgegangen sein aus einer favens-Keimzelle und einer Keimzelle, die ein Mittelding zwischen albicans und favens darstellt.

Es soll natürlich nicht behauptet werden, daß alle Mutationen der Önotheren auf dem angedeuteten Weg zustande kommen. Aber das Auftreten der rotnervigen laeta und vor allem der punctilaeta zwingt dazu die Mutanten daraufhin zu prüfen, ob sie aus Keimzellen entstanden sein können, in denen die Faktoren des jeweils vorhandenen Paars von Komplexen gemischt sind. Die Heterozygotie sämtlicher genauer untersuchten Formen ist außer Zweifel, Spaltungserscheinungen sind also eigentlich selbstverständlich, und was merkwürdig erscheint, ist nur die 
Seltenheit der Spaltungen. Doch ist nicht zu vergessen, daß in den tauben Samen allerhand Mutanten stecken können. Wenn O. Lamarckiana immer weniger als $50 \%$ gesunde Samen erzeugt, so stellen die über $50 \%$ hinausgehenden tauben Samen vielleicht teilweise die Produkte mutierter Keimzellen dar.

Heribert-Nilsson hat auf Grund umfangreicher Züchtungen den Versuch gemacht, die Mutationserscheinungen bei 0 . Lamarckiana samt und sonders auf Mendelsche Spaltung und Rekombination zurückzuführen (1915). Er hält die Lamarckiana-Stämme für sehr komplizierte Heterozygoten, in denen zahlreiche Faktoren nur im heterozygotischen oder negativ-homozygotischen, aber nicht im positiv-homozygotischen Zustand verwirklicht werden können. Die negativen Homozygoten machen für ihn die Mehrzahl der Mutanten aus, und die gewöhnlich geringe Häufigkeit der Abweicher erklärt er aus Polymerie, aus der Wirksamkeit mehrerer gleichsinnig wirkender Faktoren für dieselbe Eigenschaft. Er streift auch die Möglichkeit von Koppelungs- und Abstoßungserscheinungen (S. 107), ohne dieser Deutung vor der ersten den Vorzug zu geben ${ }^{1}$ ). Wir möchten uns eher für den zweiten Erklärungsversuch aussprechen, weil wir in den beiden außerordentlich stabilen Komplexen gaudens und velans solche sehr haltbar verketteten Faktorengruppen mit Sicherheit nachgewiesen zu haben glauben ${ }^{2}$ ). Natürlich können Komplexe, die verschiedenen Individuen angehören und sich noch fraglos z. B. als gaudens zu erkennen geben, untereinander sich doch in zahlreichen Faktoren unterscheiden; es genügt an den Rotnervenfaktor zu erinnern. Für gewisse Eigenschaften, wie eben die Rotnervigkeit, können die Konstruktionen von Heribert-Nilsson sehr wohl ihre Berechtigung haben. Die Spaltungserscheinungen kommen eben durch Austausch zwischen den beiden in ihrem wesentlichen. Bestand hänfig unverändert bleibenden Komplexen zustande, und die Abänderungen, die in den meisten Mutanten den Lamarckiana-Typus zur Hauptsache unangetastet lassen, sind fast geringfügiger, als wir zu erwarten geneigt sind. Ein Mittel der Analyse, das Heribert-Nilsson nicht angewendet hat, darf jedenfalls in Zukunft bei den Mutanten der O. Lamarckiana

1) Bei einem allgemeineren Versuch einer "mendelschen Erklärung der Verlustmutanten" (1916) rechnet er mit der Kombination von Polymerie und Koppelung.

${ }^{2}$ ) Für den Versuch, die Koppelungsverhältnisse zahlenmäßig zu fassen, z. B. für das punctilaela-Beispiel den Wert von $\mathrm{n}$ in der Relation $\mathrm{n} P$-velans: $1 \mathrm{p}$-velans: $1 \mathrm{P}$ rubens : n p-rubens zu bestimmen, falls der Wert überhaupt konstant ist, ist der Umfang meiner Kulturen noch viel zu klein. 
nicht unversucht bleiben: die Kreuzung mit Arten wie 0 . biennis, muricata, suaveolens, durch die wir über den Zustand der Komplexe gaudens und velans in günstigen Fällen wichtige Aufschlüsse erhalten können.

Wollen wir wieder die Anknüpfung an zytologische Vorgänge versuchen, so können wir uns vorstellen, daß weit abweichende Keimzelltypen durch Austausch ganzer Chromosomen zwischen den antagonistischen Chromosomensätzen entstehen, geringfügige Abweichungen durch Austausch von Chromosomenteilen zustande kommen.

\section{Die Faktorenkomplexe einiger von de Vries verwendeten Arten.}

Nach den ausführlichen Studien von de Vries ist die von ihm benutzte $O$. biennis ebenso streng heterogam wie $O$. muricata. Die Kreuzung 0 . biennis $\times$ Lamarckiana hat ihm immer die Zwillinge laeta und velutina gebracht, nicht dazu noch den Typus der reziproken Kreuzung, den wir fallax genannt haben. Als heterogam beschreibt er außerdem O. biennis-Chicago. Diese Art bringt, wenn ihr Pollen zar Bestäubung der O. Lamarckiana herangezogen wird, die Zwillinge laeta und velutina hervor, sie besitzt also im Pollen einen Komplex, der dem albicans-Komplex der biennis-Eizellen verwandt ist. Die reziproke Kreuzung $O$. biennis-Chicago $\times$ Lamarckiana ist ebenfalls zweiförmig, und die Bastardzwillinge werden von de Vries als densa und laxa bezeichnet. Die laxa, mit schmäleren Blättern und zurückgebogenen rinnigen Brakteen muß die velans-Kombination sein, also einer velutina bezw. fallax entsprechen; sie hat nach der Fig. 61, S. 146, bei de Vries (1913) viel Ähnlichkeit mit $O$. (Lamarckiana $\times$ suaveolens) suavi-velutina. Sie dürfte unter allen Umständen rote Tupfen am Stengel und an den Fruchtknoten besitzen. Der Name laxa für unseren fallax-Typus konnte deswegen nicht gewählt werden, weil die Fruchtähren der fallax außerordentlich dicht sind. Die densa, mit breiteren Blättern und abstehenden welligen Brakteen (nach der Fig. 62, S. 147, bei de Vries 1913 zu schließen), ist die gaudens-Kombination, entspricht also einer laetaForm. Falls O. biennis-Chicago am Stengel nicht rot getupft ist, muß die densa ebenfalls ungetupft sein. Die beiden Komplexe der Art sind nach dem Befund von de Vries heterogam, doch nicht ganz streng (vergl. oben S. 235 über die metaklinen Bastarde). - Als densa und laxa bezeichnete Zwillingsbastarde beschreibt de Vries auch von der Kreuzung 0 . eruciata $\times$ Lamarckiana. Die reziproke Kreuzung liefert eine nickende gracilis-Form.

Für de Vries beruht die Fähigkeit der O. Lamarckiana das Bastardpaar laeta und velutina einerseits und das Paar densa und laxa andrerseits 
hervorzubringen auf verschiedenen Qualitäten der Spezies, auf dem Vorhandensein verschiedener mutabler, labiler Pangene. Wir sehen in dem Auftreten der beiden Bastardpaare die Äußerung einer und derselben Eigenschaft, nämlich der Zusammensetzung aus den Komplexen gaudens und velans, und die Verschiedenheiten zwischen den jeweils einander entsprechenden Zwillingsformen, zwischen laeta und densa hier und zwischen velutina und laxa bezw. fallax dort, führen wir auf die Verschiedenheit der Komplexe zurück, die mit dem betreffenden Komplex der O. Lamarckiana verbunden werden. Noch größer ist der Unterschied zwischen den von de Vries gracilis genannten Formen und den ihnen von seiten der $O$. Lamarckiana wahrscheinlich entsprechenden velutina- bezw. laxa-Typen. Für uns zerlegen sich die in den verschiedenen Spezies vertretenen Komplexe vorderhand in drei Gruppen: 1. solche, die mit O. Lamarckiana die Zwillinge laeta und velutina geben, also rigens $q$ in muricata, albicans $O$ in biennis und in suaveolens, der Pollenkomplex in biennisChicago; 2. solche, die mit $O$. Lamarckiana die Zwillinge densa und laxa bezw, fallax erzengen, also rubens ${ }^{7} \sigma^{7}$ in biennis, flavens $9 \sigma^{\top}$ in $s u a-$ veolens, der Eizellenkomplex in biennis-Chicago und in cruciata; 3. solche, die nickende graicilis geben, also curvans $\sigma^{\top}$ in muricata, der Pollenkomplex in cruciata. Der gaudens-Komplex der O. Lamarckiana ist zweifellos der rubens-Gruppe nächst verwandt, velans hat wohl am meisten Ähnlichkeit mit rigens.

Die isogamen Arten $O$. Hookeri, Cockerelli und strigosa, mit denen de Vries experimentiert hat, interessieren uns natürlich vorzugsweise in dem Sinn, daß wir zu erfahren wünschen, ob sie wie normale Arten homozygotisch sind. In erster Linie ist deshalb der Zustand der durch Selbstbefruchtung gewonnenen Samen zu prüfen. Bei O. Hookeri (Samen, nicht Früchte, von Herrn Prof. de Vries) habe ich unter 50 Samen keinen einzigen tauben gefunden; de Vries selber (1916 b, S. 244, 245) zählt bei $O$. Hookeri $91-97 \%$, bei $O$. Cockerelli $79-89 \%$ keimhaltiger Samen. Die reziproken Kreuzungen zwischen diesen Arten sollen keine vollkommen identischen Bastardtypen liefern, ebenso die Kreuzungen mit der isogamen O. Lamarckiana. Besonders die Bastarde zwischen O. Lamarckiana und $O$. Hookeri sind beträchtlich verschieden, je nachdem die eine oder die andere Art Mutter ist (de Vries 1913, S. 60, 116). Von reziproken Krenzungen, die nach den beteiligten Komplexen identisch sind, haben wir im vorausgehenden sechs kennen gelernt: die fallax aus $O$. Lamarckiana $\times$ biennis und reziprok, die fallax und subfallax aus $O$. rubrinervis $\times$ biennis und reziprok, die flava aus $O$. 
suaveolens $\times$ biennis und reziprok, die suavilaeta und die suavivelutina aus O. Lamarckiana $\times$ suaveolens und reziprok. In allen diesen Fällen schienen die reziprok entstandenen Formen einander vollkommen gleich, mit Ausnahme der flava, die schwächer ist, wenn sie als biennis $\times$ suaveolens entsteht, etwas stärker und reicher verzweigt, wenn sie als suaveolens $\times$ biennis gebildet wird. Honing (1911, S. 244) findet die blanda aus den reziproken Kreuzungen in den meisten Charakteren identisch, doch die Bruchstärke des Holzes bei $O$. Lamarckiana $\times$ rubrinervis zu $1,27 \mathrm{~kg}$ für $1 \mathrm{qmm}$, bei $O$. rubrinervis $\times$ Lamarckiana zu $0,71 \mathrm{~kg}$. Nach der Schilderung von de Vries sind die Unterschiede zwischen den aus seinen isogamen Arten gewonnenen reziproken Bastarden recht ausgesprochen, und genaue Messungen würden vielleicht auch zwischen den Bastardtypen, die mir vollkommen gleich schienen, leichte Differenzen aufdecken. Absolute Gleichheit zwischen reziproken Hybriden kann ja nur dann bestehen, wenn dem Zytoplasma der Eizelle gar kein Einfluß auf den Phänotypus des Bastardes zukommt. Und das ist nicht einmal wahrscheinlich. Das Eiplasma ist für die teils dem Ei selber, teils dem Pollen entstammenden Kernelemente mindestens Umwelt, Substrat, und wenn dieselbe durch Bastardierung konstruierte Chromosomenkombination $\mathrm{a} \cdot \mathrm{b}$ das eine Mal im Plasma von a, das andere Mal in dem von b lebt, so brauchen die aus den beiderlei Eizellen sich entwickelnden reziproken Bastardtypen einander nicht vollkommen zu gleichen. Es werden ja wohl Wechselwirkungen zwischen Plasma und Chromatin sich einstellen, vielleicht wird vorzugsweise das Plasma vom Kern aus modifiziert, aber. deswegen brauchen die Plasmen $a$ und $b$ einander nicht bis zur völligen Gleichheit angeähnelt zu werden ${ }^{1}$ ).

Von den isogamen Arten hat de Vries die O. Hookeri am genauesten studiert. Sie gibt in der Verbindung O. Hookeri $\times$ biennis, also als Hookeri rubens, einen Bastard rubiennis, der bei Selbstbestäubung in rubiennis und Hookeri spaltet (1913, S. 104). Wir finden hier also einmal die (fast?) reine Abspaltung einer Elterform aus einem Bastard. Bei Kreuzung der O. Hookeri mit Lamarckiana, und zwar nach beiden Richtungen, treten die Zwillinge laeta und velutina in der ersten Generation auf. Die velutina bleibt bei Selbstbestänbung konstant, die laeta dagegen soll dauernd velutina abspalten (S. 131). Die Beob-

1) Auf die Theorie der "Anlagenschwächung" von A. v. Tschermak (1917) können wir hier nicht eingehen. - Ganz unmöglich ist es, die Verschiedenheit der von O. muricata 9 und $\sigma^{\nearrow}$ erzengten Bastarde anf dieselbe Ursache zurückzuführen wie die schwachen Unterschiede zwischen den reziproken Verbindungen is ogamer Komplexe. 
achtung wäre für die Aufklärung des Verhältnisses zwisthen den Komplexen gaudens und velans der O. Lamarckiana von groBer Bedeutung, ich zweifle aber daran, daß de Vries seinen Befund richtig gedeutet hat. Die velutina scheint nämlich der Hookeri recht ähnlich zu sein, und die aus der laeta abgespaltene "velutina" entspricht vielleicht in Wirklichkeit der aus rubiennis abgespaltenen Hookeri. Wir stoßen immer wieder auf die Ähnlichkeit zwischen dem rubens-Komplex des biennis-Pollens und dem gaudens-Komplex der Lamarckiana, und so hat ein ähnliches Verhalten von Hookeri-rubens und Hookeri-gaudens nichts Auffallendes.

Über das vom Standpunkt meiner Hypothese als kaum möglich zu érachtende Auftreten von velutina aus laeta-Formen berichtet de Vries noch an anderer Stelle (1913, S. 139). O. (biennis $\times$ Lamarckiana) laeta $\times$ Hookeri soll $94 \%$ laeta und $6 \%$ velutina geben. Ich vermute, daß diese "velutina" in Wirklichkeit dem schmalblättrigen, velutinaähnlichen (S. 81, Fig. 36), von de Vries wie die velutina zu seinem Conica-Typus gerechneten Bastard $O$. biennis $\times$ Hookeri entspricht. Die Eizellen der laeta aus biennis sind teils gaudens teils albicans, der genannte Bastard kann also sehr wohl als albicans. Hookeri gebildet werden. - O. (muricata $\times$ Lamarckiana) laeta $\times$ Hookeri soll gar $39 \%$ velutina neben $61 \%$ laeta geben. Ich vermute wieder, daß die "velutina" tatsächlich als rigens. Hookeri entsteht und mit dem Bastard O. muricata $\times$ Hookeri identisch sein müßte, der ebenfalls der $O$. Hookeri und den velutina-Formen ähnlich ist (S. 81, Fig. 37).

Um die aus Verbindungen von laeta mit $O$. biennis-Chicago gewonnenen "velutina" (S. 139) ist es jedenfalls ähnlich bestellt. De Vries legt eben bei der Vergleichung von laeta und velutina das Hauptgewicht auf die Blattbreite und nennt deswegen in den fraglichen Kreuzungen alles was breitblättrig ist laeta und alles was schmale Blätter hat velutina.

Im Vorbeigehen mögen noch zwei Arten erwähnt werden, mit denen Atkinson kürzlich experimentiert hat. Er findet in der Kreuzung O. pycnocarpa $\times$ nutans Zwillinge, die er nutella und pyenella nennt, in der reziproken Verbindung $O$. nutans $\times$ pycnocarpa Drillinge, nämlich außer den schon genannten beiden Formen noch eine dritte, tortuosa. Meine Erklärung ist die: $O$. nutans ist halb heterogam und hat die Formel $\mathrm{a}$ 우 $\mathrm{b}$ 우, O. pycnocarpa ist isogam und hat die Formel $\mathrm{c}+\sigma^{7} \cdot \mathrm{d}$ 우 $\sigma^{7}$. O. pycnocarpa $\times$ nutans gibt $\mathrm{c} \cdot \mathrm{b}=$ nutella und $\mathrm{d} \cdot \mathrm{b}=$ pycnella,$O$. nutans $\times$ pycnocarpa gibt $\mathrm{a} \cdot \mathrm{c}=$ tortuosa, $\mathrm{b} \cdot \mathrm{c}=$ nutella, $\mathrm{b} \cdot \mathrm{d}=$ pyc- 
nella, und eine nicht lebensfähige Form a $\cdot d$. Abgesehen von dem Fehlen der vierten Bastardform verhalten sich also O. pycnocarpa und nutans zueinander wie O. Lamarekiana und suaveolens; sie verhalten sich damit genau so wie O. Lamarckiana und meine O. biennis.

\section{Das Verhältnis einiger Mutanten von $O$. Lamarckiana und O. biennis zu den Mutterarten.}

Nachdem in der typischen Lamarckiana zwei dauernd getrennte Komplexe von Charakteren unterschieden werden konnten, muß der Versuch gemacht werden ein Urteil darüber za gewinnen, welche Veränderungen der Komplexe das Wesen der "Mutanten" in ihrem Verhältnis zur Stammform ausmachen. Fürs erste muß entschieden werden, ob die bei der "Mutation" aufgetretenen Änderungen des Genotypus den gaudens- oder den velans-Komplex betroffen haben oder beide. Aus eigener Anschauung kann ich vorerst nur über die rubrinervis reden. Über die nanella läßt sich dem reichen von de Vries mitgeteilen Material fast alles entnehmen, was wir zu wissen brauchen, für die meisten übrigen Mutanten fehlt vorerst jede Möglichkeit einer Analyse. Einen besonderen Typus von Mutanten dürften die Glieder der gigasund der lata-Gruppe insofern darstellen, als die primäre Veränderung, die der "Matation“ zugrunde liegt, nach den neuen Untersuchungen und Überlegungen von Winkler (1916) wohl doch in den bekannten Abweichungen der Chromosomenverteilung von der Regel zu suchen ist, trotz der Kritik, die z. B. von Heribert-Nilsson, von Stomps an dieser Auffassung geübt worden ist.

\section{a) Die Mutanten der lata-Gruppe.}

Die lata-Formen besitzen soweit untersucht sämtlich 15 Chromosomen statt 14. Sie müssen also durch Zusammentreffen einer mutierten achtchromosomigen Keimzelle mit einer normalen siebenchromosomigen entstehen und bilden selber Keimzellen teils mit sieben teils mit acht Chromosomen. Aus der Kreuzung der eigentlichen lata mit Hookeri $\sigma^{7}$ gingen in Versuchen von de Vries (1913, S. 252) sowohl laeta als velutina vom lata-Typus hervor. Das überzählige Chromosom kann also in der einmal gebildeten Mutante sowohl dem gaudens- wie dem velansKomplex zugeteilt werden, und auch die mutierten achtchromosomigen Keimzellen der $O$. Lamarckiana können vielleicht bald dem gaudensbald dem velans-Typus angehören. Daß verschiedene lata-Formen zu 
erwarten sind, leuchtet ein. Denn die überzähligen Chromosomen können von Fall zu Fall verschiedene. Erbqualitäten tragen, schon wenn wir etwa lauter solche Fälle vergleichen, in denen dem velans-Komplex immer ein gaudens-Chromosom angegliedert wird. Hat die mutierte Keimzelle gaudens-Charakter, so muß das ïberzählige Chromosom dem velans-Komplex entstammen. Für die in lata mutierten Zygoten von O. Lamarckiana gilt, daß in ihnen jedes der 14 Chromosomen doppelt, als Nr. 15, vorhanden sein kann; Individualität der Chromosomen angenommen, sind also theoretisch 14 verschiedene lata-Formen möglich allein nach den chromosomalen Verhältnissen, falls sämtliche Chromosomen des gaudensKomplexes von denen des velans-Komplexes verschieden sind. Die betreffenden Keimzellen bezw. Zygoten können aber zudem noch in anderem Sinn mutiert sein, auf dieselbe Weise wie bei Mutanten mit der normalen Chromosomenzahl, d. h. durch crossing over, und so ist zu erwarten, daß alle möglichen Formen in lata-Prägung zur Entstehung kommen. Diese Erwartung scheint durch die Erfahrung bestätigt. De Vries hat ja schon 1909 (S. 415) eigentliche lata und semilata unterschieden, Gates findet die Grenze zwischen beiden Formen unscharf (1914, S. 530), doch ausgesprochene semilata ziemlich in der Mitte zwischen lata und Lamarckiana stehend, und Frl. Lutz (1910) hat unter den 15-chromosomigen Individuen, die sie untersuchte, eine ganze Anzahl distinkter Typen unterscheiden können. - Die Annahme, die Stomps (1916, S. 133) zu widerlegen sich bemüht, daß der 15-Zahl der Chromosomen eine ganz besondere "Statur" entspreche, wird wohl von keinem der Autoren gemacht, die die abweichende Chromosomenzahl für die primäre Ursache der Mutation halten, deswegen, weil die betreffenden Autoren qualitative Verschiedenheit der einzelnen Chromosomen eines haploiden Satzes annehmen. - Die laeta-lata ist in den Versuchen von de Vries viel seltener aufgetreten als die velutina-lata ${ }^{1}$ ). Es besteht also entweder eine

1) Auch de Vries (1917 a, S. 134) legt hierauf Gewicht. Es könnte ja sein, daß die betreffenden lata-Formen aus mit einem gaudens-Chromosom ausgestatteten velansKeimzellen hervorgegangen sind und $\mathrm{daB}$ bei der Reduktionsteilung dieses Chromosom öfter dem velans- als dem gaudens-Komplex zugeteilt wird. Mit diesem größeren Quantum gaudens könnte die gesteigerte Blattbreite der meisten lata-Formen zusammenhängen. $\mathrm{Zu}$ der lata-Gruppe gehört aber nach der Chromosomenzahl auch die von Gates (1915) anfgefundene incurtata mit schmalen Blättern (zitiert nach Winkler 1916, S. 519). Hier könnte das überzählige Chromosom von dem "schmalblättrigen" velans-Komplex stammen. Es wäre wichtig zu erfahren, ob in den Keimzellen dieser Form das 15. Chromosom vorzugsweise an den gaudens-Komplex gebunden erscheint; daranf wäre zu schließen, wenn in Krenzungen die laeta-iata häufiger erschiene als die velutina-lata. 
gewisse Abstoßung zwischen dem gaudens-Komplex und dem überzähligen Chromosom, oder die laeta-lata erleidet leicht Entwicklnngsstörungen. Eine fallax von unzweifelhaftem lata-Charakter, rotnervig, habe ich unter der ersten Generation von $O$. Lamarckiana $\times$ biennis gefunden; sie wird aus einer velans-Keimzelle hervorgegangen sein, die als achtes Chromosom ein gaudens-Element enthielt.

\section{b) Die Mutanten der gigas-Gruppe.}

Die de Vriessche Mutante Lamarckiana-gigas mit 28 Chromosomen hat die roten Tupfen des velans-Komplexes ${ }^{1}$ ), aber sehr breite Blätter, enthält also wohl auch den gaudens-Komplex. Was die Entstehung der Mutante betrifft, so hat für mich am meisten Wahrscheinlichkeit die Annahme, daß die diploiden Keimzellen, durch deren Zusammentreten die tetraploide gigas ins Leben gerufen wird, beiderseits (gaudens + velans) sind, daß die Formel der neuen Bildung also (gaudens + velans) $\cdot$ (gaudens + velans) zu schreiben ist. Es ist ja wahrscheinlicher, daB der Doppelkomplex (gaudens + velans) homozygotisch verwirklicht wird, als daß in den Keimzellen die als Zygoten untanglichen Verbindungen (gaudens + gaudens) und (velans + velans) funktionsfähig sind. Damit ist angenommen, daß die diploiden Keimzellen unter Überspringung der Reduktionsteilung gebildet werden, nicht ihre doppelte Chromosomenzahl durch nachträgliche Verdoppelung der Haploidzahl erhalten, wie Stomps will (1916, S. 157).

Zwei verschiedene echte, $d . h$. tetraploide Riesentypen dürften, wenn meine Vermutung richtig ist, in der Nachkommenschaft eines diploiden Individuum nicht gefunden werden. Nun hat HeribertNilsson drei Riesenformen beschrieben, die er als gigantea, excelsa und stricta unterscheidet (1915, S. 54), und in seinem Stammbaum I (S. 72) erzeugen zwei Lamarekiana-Individuen je excelsa und stricta nebeneinander. Die Chromosomenzahlen der schwedischen Riesenmutanten sind noch nicht bekannt. Wenn excelsa und stricta als tetraploid sich erweisen, ist meine Annahme von der gametischen Struktur der gigas-Formen falsch, oder es ist sogar das ganze Problem der Tetraploidie der Riesentypen im Sinne von Heribert-Nilsson und von Stomps aufzufassen, die in der Chromosomenzahl eine sekundäre Wirkung der veränderten genotypischen Konstitution sehen, statt für die Veränderung des Geno-

1) Der Ansicht von de Vries (1917 a, S. 134), daß der gigas der velutina-Anteil fehlt kann ich mich also nicht ansebließen. 
typus die Verdoppelung der Chromosomenzahl verantwortlich zu machen, wie Gates und Winkler tun. Stricta und excelsa spalten aber Lamarckiana ab, sind also vielleicht triploide semigigas-Formen, und solche sind natürlich von einer und derselben Mutterpflanze als (gaudens + velans) - gaudens und als (gaudens + velans) - velans möglich, wobei außerdem noch die haploiden Keimzellen mutiert sein, Mittelbildungen zwischen gaudens und velans darstellen können. Die dritte Riesenform von Heribert-Nilsson, die gigantea, spaltet keine Lamarckiana ab und ist vielleicht tetraploid.

Die aktiven Keimzellen der O. gigas de Vries dürften zur Hauptsache den Typus (gaudens + velans) wiederholen. Zwillinge, die der zaeta und der velutina entsprechen, können dann in den Kreuzungen mit O. biennis usw. nicht auftreten, und tatsächlich soll die Nachkommenschaft immer einförmig sein (de Vries 1913, S. 180 u. ff.) ${ }^{1}$ ); augenscheinlich entsprechen die betreffenden Bastarde weder den laeta- noch den velutina-Formen, sondern sind eigentliche "Lamarckiana"-Bastarde, nicht Bastarde eines ihrer Komplexe. Der Verlust der „Labilität des laeta-Pangens", der bei der Mutation der O. Lamarckiana in O. gigas eintreten soll (de Vries, Stomps), würde sich so auf einfache Weise erklären. Wie sich der diploide Komplex zu seinen Komponenten verhält, muß einerseits an den Kreuzungen mit $O$. Lamarckiana, andererseits an den Verbindungen mit $O$. (biennis $\times$ Lamarckiana) laeta und velutina geprüft werden. $\mathrm{Da} ß$ hier lehrreiche Aufschlüsse über die Wirkung der quantitativen Faktoren- und Chromosomenverhältnisse zu erwarten sind, liegt auf der Hand, denn unter günstigen Umständen wird es möglich sein, die triploiden semigigas-Kombinationen (gaudens + velans) - gaudens und (gaudens + velans) - velans zu vergleichen.

Wenn in den Keimzellen nur Faktorenkombinationen gebildet würden, die dem ursprïnglichen Doppelkomplex (gaudens + velans) genau entsprechen, dann wäre $O$. gigas eine streng homozygotische Form und müßte die Variabilität der heterozygotischen $O$. Lamarckiana ganz verloren haben. Tatsächlich ist $O$. gigas sogar stärker variabel als die Stammart. Heribert-Nilsson hat diese Variabilität der de Vriesschen Mutante ansführlich geschildert (1912, S. 140 u. ff.) und, wie andere Autoren, besonders das Vorkommen schmalblättriger und selbststeriler Typen hervorgehoben. Auch mir sind in Kulturen von sehr geringem

1) Davis $(1910 \mathrm{~b}$, S. 109) findet muricata $\times$ gigas zweiförmig, seine muricata ist aber mit der holländischen heterogamen Rasse nicht identisch. 
Umfang dieselben Abweichungen vom klassischen gigas-Typus mehrfach zu Gesicht gekommen. De Vries kennt die Erscheinung natürlich auch und verschweigt sie auch nicht, hat ihr aber kein großes Gewicht beigelegt. Mir scheint die auffallende Inkonstanz darauf hinzuweisen, daß die Chromosomen bei der Reduktionsteilung, selbst wenn die Zahl beibehalten bleiben sollte, sehr unregelmäßig verteilt werden, so daß die Keimzellen gelegentlich ein größeres Quantum von velans als von gaudens oder umgekehrt erhalten. Die schmalblättrigen Typen sind vielleicht dadurch gekennzeichnet, daß in ihnen der velans-Komplex gegenüber gaudens stark vorwiegt; wir wissen $\mathrm{ja}$, daß die velutina-Bastarde schmälere Blätter haben als die laeta-Bastarde. Die auch bei gigas nicht fehlenden tauben Samen (Renner 1914, S. 138; de Vries 1916 b, S. 262) sind wohl, wenigstens zum Teil, wie sonst ganz untaugliche zygotische Kombinationen.

Ein Beleg für die vorgetragene Hypothese über die Struktur der gigas ist das Verhalten der unten (S. 266) zu erwähnenden gigas-nanella. Kreuzungsversuche, bei denen das wirkliche oder scheinbare Fehlen einer laeta-velutina-Spaltung sorgfältig zu prüfen ist, müssen über allerhand strittige Punkte in der Auffassung der gigas-Mutation sicheren Aufschluß bringen. - Bei der Analyse der O.biennis-gigas wäre vor allem darauf zu achten, ob reziproke Kreuzungen dieser Riesenform mit isogamen Komplexen untereinander identisch sind, wie es zu erwarten ist, falls die Keimzellen dieses gigas-Typus die Konstitution (albicans + rubens) haben.

Daß die Neigung der Önotheren diploide Keimzellen zu bilden ${ }^{1}$ ) mit ihrer Heterozygotie zusammenhängt, ist nicht von der Hand zu weisen. Federley hat ja bei gewissen Schmetterlingsartbastarden das Ausbleiben der Meiose bei den Reifeteilungen als Norm gefunden.

c) O. Lamarckiana-brevistylis.

Die Mutante brevistylis ist durch sehr kurze Griffel ausgezeichnet, die bei Kreuzung mit der Stammart sich rezessiv verhalten und in der $\mathrm{F}_{2}$ typische Mendelspaltung bedingen. Der brevistylis-Charakter wird also nur sichtbar, wenn er homozygotisch vorhanden ist, $d . h$. wenn die beiden Komplexe gaudens und velans in gleichem Sinn verändert sind.

1) Gigas-Formen sind bis jetzt bekannt bei $O$. Lamarckiana, biennis, atrovirens (= cruciata de Vries), stenomeres, pratincola; vergl. Stomps, 1916, S. 130. Die beiden letztgenannten Arten mutieren nach Bartlett auch sonst, sind also sicher auch heterozygotisch. 
Danach ist $\mathrm{zu}$ erwarten, daß die beiden Zwillinge laeta und velutina mit brevistylis-Ausprägung auftreten können. Das ist nach der Mitteilung von de Vries (1913, S. 189) der Fall. Aus Kreuzungen der Mutante mit O. biennis, muricata, Cockerelli als Müttern gehen normale laeta- und velutina-Pflanzen hervor, und beide Zwillinge spalten in $\mathrm{F}_{2}$ etwa $25 \%$ brevistylis-Formen ab. Aus diesen Erfahrungen ist zu schließen, daß in der Mutante der brevistylis-Faktor beiden Komplexen zukommt, und daß der Faktor auf die von den gekreuzten Arten stammenden Komplexe, also z. B. auf albicans und rigens, übertragen wird.

d) Die Zwergformen.

aa) o. Lamarckiana-nanella.

Worauf der Zwergcharakter der bei $O$. Lamarckiana und biennis beobachteten nanella-Formen beruht, kann noch nicht erörtert werden. Nur über die Beziehungen des Zwergfaktors zu den Elementarkomplexen der O. Lamarckiana können wir aus dem reichen Züchtungsmaterial von de Vries Schlüsse ziehen. Die wichtigsten Daten sind folgende: Werden 0 . Lamarckiana und nanella miteinander gekreuzt, einerlei in welcher Richtung, so besteht die Nachkommenschaft aus Lamarckiana und nanella. Wird $O$. muricata $\$$ mit nanella $\sigma^{\prime}$ gekreuzt, so entstehen in $\mathrm{F}_{1}$ nur hohe Pflanzen, und zwar laeta und velutina; von den Zwillingen bleibt die laeta bei Selbstbestäubung konstant hoch, die velutina spaltet dauernd Zwerge ab, die ihrerseits konstant Zwerge erzeugen. Die einfachste Deutung für diese Erscheinungen ist folgende: Der Zwergcharakter hängt am velans-Komplex, gaudens ist unverändert ${ }^{1}$ ). Die Formel für $O$. nanella ist also gaudens ${ }^{\circ} \sigma^{7} \cdot$ nanovelans ${ }^{\circ} O^{7}$, und der nano-Faktor im velans-Komplex dominiert über das Gen für hohe Statur in gaudens. Aus der Kreuzung Lamarekiana $\times$ nanella gehen hervor gaudens $\cdot$ nanovelans $=$ nanella und velans $\cdot$ gaudens $=$ Lamarckiana . In der Kreuzung nanella $\times$ Lamarckiana entsteht die nanella als nanovelans - gaudens, die Lamarckiana als gaudens - velans. Die Verbindungen velans - nanovelans und reziprok sind nicht lebensfähig. Woher die außerordentlich hohe Variabilität des Zahlenverhältnisses zwischen den hohen und den verzwergten Individuen kommt (vergl. S. 217), ist noch rätselhaft ${ }^{2}$ ). - Weiter: Die muricata liefert in ihren

1) De Vries kommt (1917 a, S. 134) zu demselben Schluß, „daß die Zwergmutationen in den velutina-Gameten von $O$. Lamarckiana stattzufinden pflegen".

s) Die Variabilität kann davon herrühren, daß das Zahlenverhältnis zwischen den zur Befruchtung gelangenden nanovelans- und gaudens-Pollenschläuchen variiert. Wenn 
Eizellen den rigens-Komplex. Die laeta als rigens -gaudens muB natürlich hochwüchsig sein. Die velutina als rigens - nanovelans hat zunächst ebenfalls hohe Statur, der Zwergcharakter ist also rigens gegenüber rezessiv. In $\mathrm{F}_{2}$ entstehen velutina-Zwerge, die im Zwergfaktor homozygotisch sein müssen. Der Zwergfaktor ist also auf den rigens-Komplex übergegangen, die Formel für die "murinella"Zwerge, die wir nanovelutina nennen wollen, ist nanorigens ? nanovelans $+\sigma^{\top}$. Außer den beiden nano-Komplexen müssen in den Keimzellen $\operatorname{der}\left(\right.$ nuricata $\times$ nanella) velutina auch noch rigens $q$ und velans $q \sigma^{\top}$ auftreten; der Komplex nanorigens wird sich ja nur auf Kosten eines nanovelans-Komplexes bilden können, der in velans übergeht. Falls alle diese Komplexe in den Keimzellen der velutina aktiv sind und lebensfähige Zygoten ergeben, müBten wir in der $\mathrm{F}_{2}$ der velutina finden: nanarigens $\cdot$ nanovelans $=$ nanovelutina (murinella), nanorigens $\cdot$ velans $=$ spaltende? velutina, rigens $\cdot$ nanovelans $=$ spaltende velutina, rigens - velans $=$ hohe nicht spaltende velutina. De Vries findet $62 \%$ nanovelutina und $38 \%$ velutina, von der die geprüften Individuen spalteten (S. 220). Daß uns das Fehlen einer erwarteten Form nicht schrecken darf, dafür haben wir schon genug Beispiele. Es soll also versucht werden auf Grund der gemachten Annahmen auch die übrigen Verbindungen durchzusprechen, über die de Vries berichtet, und zwar in der Reihenfolge, wie sie de Vries gewählt hat (1913, S. 221 u. ff.).

O. nanella $\times$ nanovelutina (S. 221) gibr nur breitblättrige Zwerge. Erwartung: gaudens $\cdot$ nanovelans $=$ nanella; nanovelans $\cdot$ nanovelans schlägt natürlich fehl ${ }^{1}$ ).

O. Lamarckiana $\times$ nanovelutina (S. 221) gibt $95 \%$ breitblättrige Zwerge und $5 \%$ hohe Exemplare. Erwartung: gaudens - nanovelans = nanella. Die hohen Exemplare könnten aus mutierten Keimzellen stammen, denen gegenüber der Zwergcharakter rezessiv ist. Die Theorie der labilen Pangene von de Vries verlangt hohe Individuen, aber in gröberer Zahl.

O. nanovelutina $\times$ Lamarckiana (S. 221) gibt $8 \%$ breitblättrige Zwerge, $60 \%$ hohe velutina, $32 \%$ hohe laeta. Erwartung: nanovelans $\cdot$ gaudens = nanella; nanorigens $\cdot$ gaudens $=$ laeta, wohl $\mathrm{z}$ wergig; nanorigens $\cdot$ veluns $=$ hohe velutina (wahrscheinlich spaltend). Daß die laeta hohe Statur hat, ist nicht zu verstehen.

O. muricata $\times$ nanovelutina (S. 221) gibt hohe velutina. Erwartung: rigens - nanorelans $=$ spaltende hohe velutina. In $\mathrm{F}_{2}$ tatsächlich $45 \%$ velutina and $55 \% \mathrm{Zwerge.}$

O. (muricata $\times$ nanella) laeta $\times$ nanella (S. 222) gibt etwa $50 \%$ Zwerge rom laeta-Typus, die hohen Nachkommen sind teils laeta, teils velutina. Erwartung: rigens .

die bei trübem Wetter gebildeten Früchte weniger Zwerge hervorbringen als die bei sonniger Witterung entstandenen (de Vries $1915 \mathrm{c}, \mathrm{S} .465$ ), so heißt das wohl, daß bei trïbem Wetter verhältnismäßig weniger nanovelans-Schläuche die Befruchtung vollziehen.

1) Die ausfallenden Kombinationen werden im folgenden nicht aufgeführt werden. 
gaudens $=$ hohe laeta $;$ rigens $\cdot$ nanovelans $=$ hohe, spaltende velutina; gaudens $\cdot$ nanovelans $=$ nanella. Wir glauben also, da. die Zwerge reine nanella waren, nicht laeta; es ist hier daran zu erinnern, daß de V ries auch bei anderen Kreuzungen die auftretende Lamarckiana als laeta anspricht (vergl. oben S. 212, 214).

0 . (muricata $\times$ nanella) laeta $\times$ nanovelutina (S. 222) gibt etwa $50 \%$ Zwerge vom laeta-Typus und $50 \%$ hohe, spaltende velutina. Erwartung: rigens - nanovelans $=$ hohe, spaltende velutina; gaudens $\cdot$ nanovelans $=$ nanella. Die „laeta"-Zwerge dürften auch hier nanella gewesen sein. Daß „eine Assoziation der Zwergmerkmale mit denen der laeta" vorliegt, "wie solche öfter vorkommt", glaube ich nicht.

O. (muricata $\times$ nanella) laeta $\times$ Lamarckiana (S. 222) gibt $58 \%$ hohe laeta und $42 \%$ hohe velutina. Erwartung: rigens $\cdot$ gaudens $=$ laeta $;$ rigens $\cdot$ velans = velutina $;$ gaudens velans $=$ Lamarckiana. De Vries dürfte die Lamarckiana mit der laeta zusammengefaßt haben, wie bei der entsprechenden Kreuzung 0 . (biennis $\times$ Lamarckiana) laeta $\times$ Lamarckiana (vergl, oben S. 212).

O. (muricata $\times$ nanella) laeta $\times($ muricata $\times$ Lamarckiana) velutina (\$. 222) gibt $57 \%$ hohe laeta und $43 \%$ hohe velutina. Erwartung: rigens - velans = velutina; gaudens $\cdot$ velans $=$ Lamarckiana. Die Lamarckiana hat de Vries wieder als laeta angesprochen.

O. nanovelutina $\times$ O. (muricata $\times$ nanella) laeta (S. 222) gibt $100 \%$ Zwerge. Erwartung: nanovelans $\cdot$ gaudens $=$ nanella; nanorigens $\cdot$ gaudens $=$ zwergige laeta . Nach dem Ergebnis der Krenzung nanovelutina $\times$ Lamarekiana müBte eine hohe laeta auftreten. De Vries selber erwartet nach seiner Theorie der labilen Pangene eine hohe Form, für deren Ausbleiben er keine recht plausible Erklärung hat (S. 222/23).

O. nanella $\times O$. (muricala $\times$ nanella) laeta (S. 222) gibt wieder nur Zwerge. Erwartung: nanovelans $\cdot$ gaudens $=$ nanella. . De Vries erwartet nach seiner Theorie auch hier Spaltung in hohe laeta und Zwerge. Nach unserer Hypothese kann hohe laeta nicht auftreten, weil gaudens $\cdot$ gaudens fehlschlagen muß.

O. nanella $\times$ O. (muricala $\times$ Lamarckiana) laeta (S. 223) gibt wieder nur Zwerge. Die Übereinstimmung mit dem Ergebnis der vorher aufgeführten Kreuzung ist nach unserer Annahme selbstverständlich, weil die laeta aus der nanella mit der aus der Lamarckiana identisch ist.

O. nanella $\times$ O. (biennis $\times$ Lamarekiana) laeta (S. 223) gibt einmal nur Zwerge, ein andresmal $3 \%$ hohe Individuen. De Vries sieht bierin natürlich eine Bestätigung seiner Theorie. Ich möchte die Wirkung von etwas abgeänderten gaudens-Pollenzellen annehmen, wie es in der ähnlichen Kreuzung $O$. Lamarckiana $\times$ nanovelutina Eizellen waren. In beiden Fällen sind die abweichenden Individuen aus der Verbindung von nanovelans mit gaudens hervorgegangen. $\mathrm{DaB}$ die Dominanzverhältnisse des Zwergcharakters, verschiedenen Komplexen gegenüber verschieden sind, wissen wir ja. Und über das Verhalten eines mit gaudens nahe verwandten Komplexes werden wir bei Betrachtung der O. rubrinervis uns unterrichten.

O. nanovelutina $\times 0 .($ muricata $\times$ nanella) velutina (S. 223) gibt lauter Zwerge. Erwartung: nanorigens $\cdot$ nanovelans $=$ nanovelutina $;$ nanorigens $\cdot$ velans $=$ hohe, spaltende? velutina. Von dem Aktivwerden dieser velans-Keimzellen haben wir auch sonst keine Kenntnis.

O. nanella $\times 0$. (muricata $\times$ nanella) velutina (S. 223) gibt nur Zwerge. Erwartung: gaudens $\cdot$ nanovelans $=$ nanella; gaudens $\cdot$ velans $=$ Lamarckiana. Wieder finden wir kein Aktivwerden des abgespaltenen velans-Komplexes. 
O. Lamarckiana $\times O .($ muricata $\times$ nanella) velutina (S. 223) gibt $95 \%$ Zwerge. Erwartung: gaudens $\cdot$ nanovelans $=$ nanella $;$ gaudens $\cdot$ velans $=$ Lamarckiana. Hier könnten die velans-Pollenzellen der velutina einmal aktiv aufgetreten sein. Wahrscheinlicher ist aber, daß die $5 \%$ hoher Individuen aus veränderten gaudens-Eizellen und nanovelans-Pollen entstanden sind, wie in der Kreuzung Lamarckiana $\times$ nanovelutina.

$O$. (muricata $\times$ nanella) laeta $\times O$. (muricata $\times$ nanella) velutina $($ S. 223) gibt $50 \%$ Zwerge. Erwartung im günstigsten Fall: gaudens $\cdot$ nanovelans $=$ nanella $;$ gaudens $\cdot$ velans $=$ Lamarrkiana $;$ rigens $\cdot$ nanovelans $=$ hohe, spaltende velutina $;$ rigens $\cdot$ velans $=$ hohe, konstante velutina.

O. (muricata $\times$ nanella) velutina $\times$ nanovelutina $($ S. 224$)$ gibt $59 \%$ Zwerge. Erwartung: rigens $\cdot$ nanovelans $=$ bohe, spaltende velutina; nanorigens $\cdot$ nanovelans $=$ nanovelutina

$O$. (muricata $\times$ nanella) velutina $\times$ nanella $(\mathrm{S} .224)$ gibt $57 \%$ Zwerge. Erwartung: rigens $\cdot$ nanovelans $=$ hohe, spaltende velutina $;$ nanorigens $\cdot$ nanovelans $=$ nanovelutina $;$ rigens $\cdot$ gaudens $=$ hohe laeta $;$ nanorigens $\cdot$ gaudens $=$ hohe $?$ laeta; nanovelans $\cdot$ gaudens $=$ nanella $;$ velans $\cdot$ gaudens $=$ Lamarcliana. De Vries gibt über den Typus der Zwerge und der hohen Individuen nichts an.

O. (muricata $\times$ nanella) velutina $\times$ Lamarckiana (S. 225) gibt 11 bezw. 51\% "laeta"-Zwerge, 19 bezw. $30 \%$ hohe laeta, 70 bezw. $19 \%$ hohe velutina. Erwartung: nanorigens $\cdot$ gaudens $=$ hohe? laeta $;$ rigens $\cdot$ gaudens $=$ hohe laeta $;$ nanorigens $\cdot v e l a n s$ $=$ hohe velutina (vergl. die Kreuzung O. nanovelutina $\times$ Lamarchiana, oben S. 261); nanovelans $\cdot$ gaudens $=$ nanella $;$ velans $\cdot$ gaudens $=$ Lamarckiana. Die "laeta"-Zwerge dürften in Wirklichkeit wieder nanella gewesen sein; zwergige laeta sollte nach dem Ergebnis der leichter zu übersehenden Kreuzung nanovelutina $\times$ Lamarcliana nicht vorkommen. Das Auftreten von Lamarckiana in größerer Zahl würde das Aktivwerden des abgespaltenen velans-Komplexes in der spaltenden velutina sicher stellen. - Dab keine velutina-Zwerge auftreten, deutet nach de Vries wieder "auf eine Assoziation

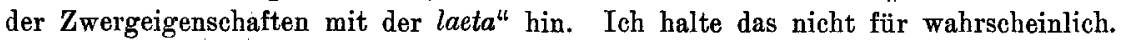

O. (muricata $\times$ nanella) velutina $\times 0 .($ muricata $\times$ nanella $)$ laeta $(\mathrm{S} .225)$ gibt $53 \%$ "laeta ${ }^{\mu}$-Zwerge und $47 \%$ hohe laeta, keine velutina. Erwartung: rigens $\cdot$ gaudens $=$ hohe laeta $;$ nanovelans $\cdot$ gaudens $=$ nanella $;$ velans $\cdot$ gaudens $=$ Lamarckiana ist wie immer fraglich, desgleichen nanorigens $\cdot$ gaudens $=$ hohe? laeta nach den Erfahrungen der Kreuzung nanovelutina $\times($ murieata $\times$ nanella $)$ laeta.

O. (muricata $\times$ nanella) velutina $\times 0$. (muricata $\times$ Lamarckiana) laeta gibt $31 \%$ Zwerge und $69 \%$ hohe laeta. Die Erwartung ist dieselbe wie vorher, weil die laeta aus Lamarckiana mit der aus nanella identisch ist.

De Vries gibt (S. 225) noch eine Zusammenstellung der Tatsachen, aus denen ersichtlich ist, daß die laetae aus Lamarckiana und nanella sich gleich verhalten, während die velutinae verschieden konstituierten Pollen besitzen. Die Deutung, daß die nanella gegenüber der Lamarckiana überhaupt nur im velans-Komplex verändert ist, erklärt die Tatsachen wohl auf die einfachste Weise.

o. Hookeri $\times$ nanella gibt in der ersten Generation hohe laeta und hohe velutina (S. 227). Die laeta spaltet "velutina" ab, worüber die früheren Ausführungen zu vergleichen sind (oben S. 254). Die velutina spaltet in Zwerge vom Hookeri-Typus, in weiter spaltende velutina und in konstante velutina. Am meisten interessiert uns hier die letztgenannte Bastardform, weil wir diesen Typus bisher nur postuliert, aber unter 
den Protokollen von de Vries nicht mit Sicherheit gefunden haben. Die spaltende velutina der ersten und der folgenden Generationen ist Hookeri - nanovelans, wobei der Zwergcharakter zunächst wieder rezessiv ist, die Zwerge sind nano-Hookeri $\cdot$ nanovelans die konstante hohe velutina ist wahrscheinlich Hookeri-velans. Bei der Ähnlichkeit zwischen Hookeri und velutina ist allerdings Vorsicht in der Deutung geboten, doch erwähnt de Vries nirgends etwas von Abspaltung der Hookeri aus velutina. - Die reziproke Kreuzung $O$. nanella $\times$ Hookeri liefert natürlich das gleiche Ergebnis, weil beide Arten isogam sind. Mit den komplizierteren Kreuzungen wollen wir uns hier nicht abgeben, weil sie im groben wohl ebenso leicht zu deuten sind wie die Kreuzungen der O. muricata.

$O$. biennis $\bigcirc$ verhält sich in den Kreuzungen mit $O$. nanella zur Hauptsache ebenso wie $O$. muricata O. Die Zwillinge laeta und velutina aus $O$. biennis $\times$ nanclla sind beide hoch, die laeta bleibt so, die velutina spaltet dauernd zwergige velutina, also nanovelutina ab. Der $Z$ wergcharakter von nanovelans ist also dem Komplex albicans gegenüber wieder rezessiv, die $Z$ werge müssen nanoalbicans nanovelans sein. - Die reziproke Kreuzung $O$. nanella $\times$ biennis gibt fast lauter Zwerge in der ersten Generation, nur bei großer Individuenzahl sind wenige hohe Exemplare zu finden (S. 241). Sämtliche Pflanzen, die zwergigen wie die hohen, haben den 'Typus von fallax. Die Zwerge sind also nanovelans $\cdot$ rubens $=$ nanofallax und zeigen in dem Dominieren des Zwergmerkmals wiederum die Ähnlichkeit zwischen dem rubens- und dem gaudens-Komplex. Die hohen fallax-Pflanzen dürften aus veränderten rubens-Keimzellen hervorgegangen sein. Warum die Zwerge ans $O$. nanella $\times$ biennis mitunter zwei Typen darstellen, einen gesunden semialta und einen krïppelhaften debilis (S. 242), weiB ich nicht zu erklären.

O. (muricala $\times$ nanella) velutina $\times$ biennis (S. 241) gibt $75 \%$ Zwerge und $25 \%$ hohe Pflanzen, alle vom fallax-Typus. Hier haben wir endlich einmal eine Bestätigung für das Auftreten des velans-Komplexes aus der Verbindung rigens • nanovelans, wenn die hohe "fallax" wirklich velans $•$ rubens und nicht rigens $\cdot$ rubens ist. Erwartet werden ja: rigens $\cdot$ rubens $=O$. (muricata $\times$ biennis $)$, nanorigens $\cdot$ rubens $(\mathrm{zwergig})$, velans $\cdot$ rubens $=$ fallax, nanovelans $\cdot$ rubens $=$ nanofallax.$-O$. nanofallax $\times$ biennis gibt natürlich nur Zwerge und zwar nanofallax (S. 244). Desgleichen nanofallax $\times$ nanella, doch müssen die Zwerge hier nunella sein, nicht nanofallax, weil sie als nanovelans -gaudens entstehen; der rubens-Komplex ist bei der die Vriesschen $O$. biennis streng männlich, er kann in den Eizellen der nanofallax nicht auftreten. De Vries berichtet anch, daß die Merkmale der biennis hier ausgeschaltet werden.

o. biennis-Chicago $\times$ nanella gibt hohe konstante densa und hohe laxa, die Zwerge abspaltet (S. 235). Die laxa gibt sich durch ihre Verbindung mit dem Zwergmerkmal wieder als velans-Kombination zu erkennen. Ebenso verhalten sich densa und laxa aus O. cruciata $\times$ nanella (S. 236).

Für eine Bastardform, nämlich die $O$. (muricata $\times$ nanella) velutina, nimmt de Vries selber an, „daß die Erbschaften der beiden elterlichen Arten (hohe Statur der muricala und Zwergstatur der nanella) in dem Bastarde nebeneinander liegen, etwa so, wie es bei den Mendelschen Hybriden der Fall ist"; er glaubt nicht, daß „die Spaltungsfähigkeit des weiblichen Sexualtypus der velutina auf dem labilen Zustande der Pangene beruht". Man sieht aber, daß die Kreuzungsergebnisse sich auch sonst zum großen Teil nach Mendelschem 
Schema voraussagen lassen, wenn auch gewisse Einzelheiten, so besonders der Charakter der Verbindung nanorigens - gaudens und das Auftreten des velans-Komplexes in den Keimzellen von $O$. (muricata $\times$ nanella) velutina $\mathrm{F}_{1}$ - vor allem wäre das Vorkommen von velans im Pollen interessant, weil es wieder einen Faktorenaustansch zwischen dem aktiven (nanovelans) und dem inaktiven (rigens) Komplex bestätigen würde, vergl. oben S. 247 -, noch recht unklar sind. Für eine genauere Charakterisierung der in den Kreuzungen auftretenden "Zwerge", der "hohen" und der "laeta"-Formen ist jedenfalls ein Schlïssel gegeben, dessen Handhabung Erfolg verspricht. Die Angabe z. B. von de Vries, daB das Zwergmerkmal, trotzdem es im allgemeinen nur den velutinaFormen zukommt, in vereinzelten Fällen umgekehrt an den laeta-Typus geknüpft sei, läßt sich mit der überwiëgenden Mehrzahl der Erscheinungen nicht vereinbaren, und die Erfahrung, daß de Vries anderswo zweifellos das Auftreten von laeta zu Unrecht annimmt, läßt es erlaubt erscheinen, die von ihm mitgeteilten Ausnahmen auf eine Irrung in der Deutung der Formen zurückzuführen.

De Vries hat für das Auftreten der Mutante nanella die zunächst plausible Annahme gemacht, daß sie im Zwergcharakter homozygotisch sei - oder, wie er es ausdrückt, daß sie im Staturfaktor inaktiv sei - , und Heribert-Nilsson z. B. schließt sich dieser Deutung an. Wir können die beobachteten Erscheinungen auch in diesem Sinn erklären, auf Grund der Annahme, daß gaudens den Zwergfaktor immer besitze, und daß niedere Statur gegen hohe Statur immer rezessiv sei, auffällig wäre dann freilich, daß gerade die laeta-Formen immer so hochwüchsig sind. Dann entsteht die Mutation in nanella, sobald eine ebenfalls mit dem Zwergfaktor ausgestattete velans-Keimzelle mit gaudens zusammentrifft. Diese Zurechtlegung hätte den Vorzug, daß sie das Auftreten der nanella-Mutanten einigermaßen verständlich machen würde. Der nano-Faktor, vielleicht das Fehlen eines Staturfaktors, wäre verhältnismäßig fest an gaudens gekoppelt, ginge aber doch gelegentlich auf velans über. Nach den im Austausch veränderten gaudensKeimzellen müßte dann gesucht werden; sie müBten mit nanovelansKeimzellen hohe Individuen geben, wie solche z. B. in den Kreuzungen Lamarckiana $\times$ nanovelutina und nanella $\times$ (biennis $\times$ Lamarckiana) laeta wirklich gefunden worden sind. Wäre nanella im Staturfaktor heterozygotisch, wie es oben angenommen worden ist, dann sollte sie eigentlich mitunter hochwüchsige Mutanten abspalten, und davon ist bis jetzt nichts bekannt. 


\section{bb) O. biennis -nanella.}

Neuerdings hat de Vries (1915 a, S. 185 ff.) auch über Kreuzungen der aus $O$. biennis hervorgegangenen nanella-Mutante mit der normalen biennis und mit Lamarckiana eine kurze Mitteilung gemacht. Wenn wir dem biennis-Zwerg die denkbar größte Ähnlichkeit mit dem Lamarckiana-Zwerg versuchsweise zusprechen wollen, so muß er die Struktur nano-albicans - rubens haben. Die Komplexe rubens und gaudens sind ja nahe verwandt, und wir können uns einmal vorstellen, daß der Zwergcharakter bei biennis mit dem bei Lamarckiana identisch sei und nicht auf den rubens-Komplex überzugehen vermöge, so wenig wie auf gaudens. Im Pollen muß die biennis-nanella sich dann so verhalten wie die normale biennis, der Zwergcharakter ihrer Eizellen dagegen muß dominieren über die im Pollen übermittelte hohe Statur der Stammform. Tatsächlich gibt die Kreuzung biennis-nanella $\times$ biennis lauter Zwerge (S. 185), die Kreuzungen biennis $\times$ biennis-nanella und Lamarckiana $\times$ biennis-nanella lauter hohe Pflanzen, im ersten Fall typische biennis, im zweiten fallax (S. 186).

Wie in gaudens, so können wir auch in rubens einen rezessiven, fest gebundenen, selten auf albicans überspringenden Zwergfaktor annehmen. Die Verbindung gaudens - rubens müßte die sichere Entscheidung bringen, denn sie müßte Zwerge liefern. Leider ist die Kombination nicht lebensfähig.

\section{c) O. Lamarckiana-gigas-nanella.}

Die bisher behandelten Zwergformen sind zum Teil vielleicht heterozygotisch im Zwergfaktor mit Dominanz des Zwergmerkmals (Lamarckianananella $=$ nanovelans $\cdot$ gaudens, biennis-nanella $=$ nano-albicans $\cdot$ rubens, [nanella $\times$ biennis] nanofallax $=$ nanovelans $\cdot$ rubens), teils sind sie sicher homozygotisch im Zwergfaktor mit Rezessivität des Zwergmerkmals gegenüber hoher Statur (alle nanovelutinae, die aus biennis = nanoalbicans $\cdot$ nanovelans, die aus muricata $=$ nanorigens $\cdot$ nanovelans, die aus Hookeri $=$ nano-Hookeri $\cdot$ nanovelans, desgleichen die Zwerge aus der laxa von biennis-Chicago und von cruciata). An diesen zweiten, sicheren Typus schließen sich nun die Zwerge an, die aus der Mutante gigas hervorgegangen sind und die de Vries als gigas-nanella beschreibt. (1915 d). Wird die hohe Form der gigas mit dem Zwerg gekreuzt, so entstehen zur Hauptsache hohe Individuen, die bei Selbstbefruchtung in $1 / 4$ hohe Zwerge, $1 / 4$ hohe konstante Individuen und $1 / 2$ hohe spaltende 
Individuen spalten. Das Mendelsche Verhalten dieses Zwergfaktors liegt klar zutage, was de Vries auch nicht in Zweifel zieht. Hohe Statur dominiert hier über Zwergwuchs, der Zwergwuchs tritt nur in die Erscheinung bei homozygotischer Verwirklichung des Zwergfaktors. Diese ist nach unserer früheren Annahme (S. 257) möglich, weil zwei velans-Komplexe zur Verfügung stehen. Der Zwerg dürfte die Formel (gaudens + nanovelans) $\cdot$ (gaudens + nanovelans) haben, die anch als $\mathrm{Mu}-$ tante auftretende spaltende Form die Formel (gaudens + velans) - (gaudens + nanovelans).

\section{e) O. Lamarckiana-rubrinervis.}

Die Krenzung $O$. biennis $\times$ rubrinervis liefert aus dem albicansKomplex der biennis nicht laeta und velutina, sondern zwei velutinaTypen, die eigentliche velutina und die subvelutina. Die rubrinervis unterscheidet sich also von der Lamarckiana dadurch, daß der gaudensKomplex durch einen velans-ähnlichen Komplex subvelans ersetzt ist. Aus der Kreuzung 0 . (rubrinervis $\times$ biennis) gehen ebenfalls zwei sehr ähnliche Zwillingstypen hervor, die fallax als velans - rubens, die subfallax als subvelans $\cdot$ rubens. Während also die aus $O$. Lamarckiana $\times$ biennis zu gewinnende Verbindung gaudens $\cdot$ rubens nicht lebensfähig ist, liefert der für gaudens eintretende subvelans-Komplex mit rubens eine gesunde kräftige Bastardform. Dem entspricht die Erfahrung, daß die Kreuzung O. rubrinervis $\times$ biennis fast lauter gesunde Samen ergibt, nämlich 94-95\%, während O. rubrinervis bei Selbstbestäubung $65-73 \%$ gesunder Samen erzeugt. Warum hier die keimhaltigen Samen immer beträchtlich mehr als $50 \%$ ausmachen, ist ebenso unklar ${ }^{1}$ ), wie das regelmäßige Vorkommen von weniger als $50 \%$ gesunder Samen bei O. Lamarckiana. Die fallax und die subfallax entstehen natürlich auch in der Kreuzung O. biennis $\times$ rubrinervis aus den rubens-Eizellen der biennis, neben dem anderen Paar velutina und subvelutina. Der subvelans-Komplex ist von velans weit genug verschieden, daß die zygotische Kombination beider Komplexe lebensfähig ist. $\mathrm{Er}$ ist aber auch weit genug von gaudens verschieden, um mit dem gaudens-verwandten rubens-Komplex sich in der Zygote zu vertragen. Die Vermutung liegt

1) De V ries hat neulich (1917) eine rubrinervis-Form studiert, die eine "Vollmutante“, d. h. homozygotische Form deserens abspaltet; hier ist der hohe Keimgehalt verständlich. Bei meinem Material sind mir abweichende Individuen nicht aufgefallen. Jedenfalls sind unter dem Namen rubrinervis bis jetzt allerhand durch Sprödigkeit ausgezeichnete Biotypen zusammengefaßt worden. 
also nahe, daß subvelans einem Faktorenaustausch zwischen velans und gaudens die Entstehung verdankt.

Wird rubrinervis क mit Lamarckiana of gekreuzt (nach de Vries ist das Resultat der reziproken Kreuzung das gleiche), so entsteht Lamarckiana neben der blanda (Honing 1911, S. 240) oder subrobusta (de Vries), die eine Mittelform zwischen rubrinervis und Lamarckiana darstellt. Die Lamarckiana kann hier nur als velans ? $\cdot$ gaudens $\sigma^{7}$ entstehen. Die blanda dürfte die Kombination subvelans $\cdot$ velans, nicht subvelans gaudens darstellen, denn sie ähnelt der rubrinervis beträchtlich mehr als der Lamarckiana und auch als der subfallax, die als subvelans rubens Ähnlichkeit mit subvelans gaudens haben müßte. Der subvelans-Komplex verträgt sich also nicht mit gaudens, vielleicht weil er dem gaudens-Komplex noch zu ähnlich ist. Wie oben ausgesprochen (S. 193), finde ich allerdings im Habitus der subvelutina mehr Annäherung an velutina als an laeta. Wenn die Entstehung der blanda richtig gedeutet ist, müssen wir an der Formel für rubrinervis noch eine Korrektur anbringen, wir müssen annehmen, daß anch der zunächst velans genannte Komplex leicht verändert ist; er wäre etwa paenevelans zu nennen. Die Formel der rubrinervis wäre also paenevelans 웅 subvelans $9 \sigma^{7}$, und die Bastarde zwischen Lamarckiana und rubrinervis wären subvelans $\cdot$ velans $=$ blanda and paenevelans $\cdot$ gaudens = „Lamarckiana“. Diese letztere Form dürfte mit der ursprünglichen Lamarckiana nicht identisch sein und müßte bei Kreuzung mit rubrinervis gleich mbrinervis geben statt blanda; nach de Vries (1913, S. 194) spaltet die blanda erst bei Selbstbestäubung rubrinervis ab. Auch die velutina aus biennis $\times$ rubrinervis dürfte dann mit der aus biennis $\times$ Lamarckiana nicht ganz identisch sein, sie müßte eine paenevelutina sein, desgleichen die fallax eine paenefallax. Die Aufklärung des jetzt noch fraglichen Punktes ist jedenfalls durch ein paar geeignete Kreuzıngen leicht zu gewinnen.

Bei Honing habe ich aber nachträglich schon eine Bestätigung für die aufgestellte Forderung gefunden. .Die aus der Kreuzung $L a-$ marckiana $\times$ rubrinervis gewonnene Lamarckiana hat vielleicht ein anderes Verhältnis zwischen Blattlänge und -breite als die ursprüngliche Lamarckiana; der Punkt müßte allerdings wegen der verschiedenen für Lamarckiana gewonnenen Werte (Tabelle XIII, S. 254) noch genauer geprüft werden. Klarer scheint die Sache bei der velutina zu liegen. Die Bruchstärke des Holzes von Seitenzweigen der velutina aus biennis $\times$ Lamarckiana ist im Mittel $1,67 \mathrm{~kg}$ für $1 \mathrm{~mm}^{2}$, bei der velutina aus 
biennis $\times$ rubrinervis dagegen $1,34 \mathrm{~kg}$ (Tabelle VIII, S. 245); für rubrinervis selber, bei der ja die außerordentliche Brüchigkeit aller Organe zu den auffälligsten Eigentümlichkeiten zählt, ist der Wert zu $0,25 \mathrm{~kg}$ gefunden worden.

Die fallax ans rubrinervis und biennis verhält sich bei Selbstbestäubung und bei Kreuzung mit biennis $O$ wie die fallax aus $L a-$ marckiana. Ganz entsprechend ist auch das Verhalten der subfallax in der Verbindung mit biennis + ; es entsteht biennis = albicans $\cdot$ rubens, subvelutina $=$ albicans $\cdot$ subvelans, subfallax $=$ rubens $\cdot$ subvelans $;$ dazu noch eine ungetupfte laeta-artige Form, vielleicht weißnervige biennis = albicans - r-rubens (vergl. S. 245). Bei Selbstbestäubung spaltet die subfallax aber rubrinervis ab, als die einzige unter den von mir in $\mathbf{F}_{2}$ beobachteten Bastardformen, die auffällige Spaltung nach den wesentlichsten Artcharakteren aufweist, und zwar ziemlich rein den einen Eltertypus wiederherstellt. Dementsprechend ist der Prozentsatz der keimhaltigen Samen bei der subfallax auch recht hoch, $61-69 \%$, gegenüber $20-27 \%$ bei der fallax. Auch de Vries berichtet von verschiedenen "laeta"-Formen aus der rubrinervis, also zweifellosen subvelansKombinationen, daß sie rubrinervis abspalten (1913, S. 195 ff.), während die zugehörige velutina jeweils konstant bleibt, wie in meiner Kultur die fallax; Honing findet Spaltung bei 0 . (biennis $\times$ rubrinervis) "laeta" (S. 234, 235), die ungefähr das gleiche ist, wie unsere subvelutina. Ganz identisch mit der ursprünglichen rubrinervis ist der abgespaltene Typus äußerlich nicht, auch in den Versuchen von de Vries nicht; er hat bei mir viel weniger verzweigte Stengel, kleinere Blüten und schwach pigmentierte Kelche. Eine identische Wiederherstellung der rubrinervis etwa aus subfallax kann auch von vornherein nicht erwartet werden, weil dem Bastard der paenevelans-Komplex fehlt. Vielmehr muß das Wiederauftreten der "rubrinervis" darauf beruhen, daß durch Faktorenaustausch zwischen dem rubens- und dem subvelans-Komplex ein paenevelans-ähnlicher Komplex gebildet wird, der mit subvelans (oder mit einem ebenfalls neu kombinierten Komplex; oder gar in homozygotischer Kombination?) einen der Mutterart rubrinervis ähnlichen Phänotypus konstruiert.

Befremdend ist nach den eben erörterten Erfahrungen der Befund von de Vries, daß die beiden aus der Kreuzung O. biennis-Chicago $\times$ rubrinervis gewonnenen Bastarde densa (soviel wie laeta bezw. subfallax) und laxa (soviel wie velutina bezw. fallax) spröde rubrinervis abspalten (1913, S. 202 ff.). Mit den bisher beschriebenen Erscheinungen dürfte nur die Spaltung der densa vergleichbar sein, die der laxa da- 
gegen hat wohl mehr zu tun mit der hier sonst beobachteten Abspaltung von atra (1913 S. 151). Über alle diese Spaltungsvorgänge werden eingehendere Vorstellungen erst dann entwickelt werden können, wenn das züchterische Verhalten der miteinander kaum identischen abgespaltenen "rubrinervis"-Formen bekannt ist; vorläufig wissen wir durch de Vries nur, daß sie bei Selbstbefruchtung konstant sind. Es wird sich empfehlen, diese spröden Formen, oder vielleicht sogar die ganze rubrinervis-Gruppe, die ja in den jetzt gezüchteten Biotypen zum kleinsten Teil rotnervig ist, mit einem neuen Namen, etwa fragilis, zu belegen.

Schon Honing („Doppelnatur", z.B.S.227, S.275) hat ausgesprochen, daß zwischen der Mutante rubrinervis und den velutina-Bastarden der Eamarckiana unverkennbare Ähnlichkeit besteht. Tatsächlich erscheint die rubrinervis wie eine potenzierte, in den eigentlichen velutina-Charakteren: geringe Breite der Blätter, Lage und Rinnenform der Brakteen, Größe und Dicke der Früchte, Rotfärbung der Kelche und Früchte, Tiefe der Kronenfarbe, Brüchigkeit der Stengel, sozusagen homozygotisch gewordene velutina. Dieser aus dem Habitus gewonnene Eindruck hat durch die Bastardanalyse volle Bestätigung gefunden. Auch ein Punkt, der für Honing noch unverständlich war, ist jetzt aufgeklärt. Fr berichtet (S. 294), daß nach seinen Bestimmungen der Bruchstärke der Stengel "die laeta aus biennis $\times$ Lamarckiana stärker ist als die zugehörige velutina" - ich möchte dazu bemerken, daß die größere Zähigkeit der laeta beim Säubern der zu stark verzweigten Pflanzen gegenüber der Brüchigkeit der velutina ohne weiteres auffällt —, daß aber "die laeta aus biennis $\times$ rubrinervis schwächer ist als die velutina". Nun haben wir gefunden, daß diese "laeta" aus der rubrinervis, unsere subvelutina, gerade den für rubrinervis besonders charakteristischen Komplex subvelans enthält und infolgedessen mitunter (bei Honing, S. 239, nicht bei de Vries 1913, S. 201) wie die subfallax befähigt ist, vollkommen spröde rubrinervis abzuspalten. Es hat also nichts Erstaunliches mehr, daß sie spröder ist als die zugehörige eigentliche velutina oder paenevelutina.

Von den Kreuzungen zwischen O. rubrinervis und nanella soll nur hervorgehoben werden, daß die erste Bastardgeneration - die Verbindung gibt nach beiden Richtungen dasselbe Resultat - aus Lamarckiana und hoher blanda ("subrobusta") besteht, von denen die Lamarckiana konstant bleibt, die blanda in konstante rubrinervis, konstante rubrinervisZwerge und weiter spaltende blanda spaltet (de Vries 1913, S. 215). Das Abspalten der Zwerge aus der blanda beweist, daß die blanda tat- 
sächlich, wie wir oben (S. 268) angenommen haben, die Verbindung des subvelans-Komplexes der rubrinervis mit velans, nicht mit gaudens ist; im jetzt vorliegenden Fall ist die blanda = subvelans $\cdot$ nanovelans. Was uns besonders interessiert, ist die Rezessivität des Zwergmerkmals gegenüber dem subvelans-Komplex. Dieser stimmt also in seinem Verhalten gegenüber dem Zwergfaktor nicht mehr mit dem gaudens-Komplex überein, sondern schließt sich an rigens (aus muricata) und albicans (aus biennis) an, auch insofern, als er selber oder ein von ihm erzeugter Komplex den Zwergfaktor aufzunehmen vermag. Die Zwerge müssen ja im Zwergfaktor homozygotisch sein, können also etwa als nanovelans nanosubvelans entstehen. Die Diskussion der Spaltungserscheinungen in ihrer Gesamtheit ist nicht möglich, solange die Abspaltung von rubrinervis aus einfacher zu übersehenden Kreuzungen, z. B. aus $O$. (rubrinervis $\times$ biennis) subfallax und aus O. (rubrinervis $\times$ Lamarckiana) blanda, nicht vollkommen aufgeklärt ist.

\section{f) O. Lamarckiana-oblonga.}

Aus der Mutante oblonga ist durch Kreuzungen mit den geeigneten Arten nur velutina zu erhalten, laeta bleibt immer aus. In den Kreuzungen von O. biennis, muricata, Cockerelli, Hookeri mit oblonga $\sigma^{7}$ ist die velutina die einzige Bastardform; wird oblonga 9 mit biennis-Chicago, Cockerelli, Hookeri gekreuzt, so findet sich neben der velutina auch „oblonga" selbst; die letztgenannte Form kann natürlich mit dem Eltertypus nicht identisch sein. $O$. oblonga $\times$ biennis liefert nur fallax, O. biennis-Chicago $\times$ ablonga nur laxa. Nach diesen von de Vries (1913, S. 266, 267) mitgeteilten Befunden ist in den Keimzellen von oblonga fast nur der velans-Komplex aktiv; gaudens muB zum mindesten tief verändert sein, wenn überhaupt vorhanden. Dazu stimmt auch das Verhalten der Kreuzungen mit nanella, in denen nie Zwerge auftreten (abgesehen von dem S. 266, Anm. 3 erwähnten Fall), also der nanovelansKomple ${ }^{-}$der nanella entweder 'gar keinen tauglichen Partner findet, oder zum mindesten nicht gaudens.

\section{Die Zahlenverhältnisse zwischen den Keimzelltypen.}

Es gehört zum Wesen der dauernd „komplex-heterozygotischen“ Formen, wie ich unsere Önotheren nennen möchte ${ }^{1}$ ), daß die Zahl der

1) In der vorläufigen Mitteilung (Berichte 1916) habe ich von Heterogametie gesprochen. Ich möchte aber doch aus verschiedenen Gründen davon absehen, den bisher für die Erscheinungen der Geschlechtsvererbung vorbehaltenen Terminus auf unseren Fall anzuwenden. 
Haupttypen von Keimzellen nicht größer ist als zwei, daß die betreffenden Formen sich also wie Mendelsche Monohybriden verhalten. Innerhalb der Komplex-Heterozygotie kann dann noch typische Mendelsche FaktorenHeterozygotie vorkommen, wie bei der rotnervigen 0 . Lamarckiana, bei Bastarden zwischen groß- und kleinblütigen Arten. Eine vollkommen strenge Komplexheterozygotie gibt es vielleicht überhaupt nicht, denn die bei den meisten Arten beobachteten "Mutationen" weisen darauf hin, daß die Koppelung der in den Komplexen vereinigten Faktoren nicht absolut ist. Von den seltenen, "mutierten " Keimzellen soll aber abgesehen werden, weil wir über ihre Häufigkeit noch zu wenig Erfahrungen haben.

Nach Analogie mit Mendelschen Verhältnissen möchten wir die beiden Keimzelltypen, die die beiden verschiedenen Komplexe repräsentieren, im selben Geschlecht in gleichen Zahlen erwarten. Die weißnervige $O$. Lamarckiana von Heribert-Nilsson scheint auch wirklich die gaudens- und die velans-Samenanlagen zu gleichen Teilen auszubilden; denn bei Bestäubung mit dem rubens-Pollen von O. biennis und mit dem gaudens-Pollen von $O$. (biennis $\times$ Lamarekiana) laeta sind gesunde und taube Samen gleich häufig. In anderen Fällen dagegen ist mit Sicherheit entschieden, daß die beiden in einem Geschlecht auftretenden Keimzelltypen in verschiedener Zahl vorhanden sind. Bei der de Vriesschen Rasse von O. Lamarckiana sind die gaudens-Eizellen spärlicher als die velans-Eizellen. Denn bei Bestäubung mit dem Pollen von $O$. Hookeri tritt die laeta in $11-41 \%$, die velutina in $59-89 \%$ anf (de Vries 1913, S. 118); bei Kre uzung mit O. Cockerelli $\sigma^{\top}$ sind die Zahlen $7-15 \%$ bezw. $85-93 \%$ (S. 118), bei Kreuzung mit $O$. biennisChicago o $3-29 \%$ bezw. $71-97 \%$ (S. 124). Ganz entsprechend machen bei Bestäubung mit biennis-Pollen die gesunden, fallax liefernden, also aus velans-Eizellen entstehenden Samen $79 \%$, die tauben, aus gaudens gebildeten $21 \%$ aus (bei de Vries $1916 \mathrm{~b}, \mathrm{~S} .266,69-92 \%$ gesunde), und ebenso gibt die Kreuzung mit 0 . (biennis $\times$ Lamarckiana) laeta $\sigma^{7}$, also die Belegung mit gaudens-Pollen, $73 \%$ gesunde Samen. - Bei $O$. suaveolens sind die albicans-Eizellen seltener als die favens-Eizellen, denn in der Kreuzung $O$. suaveolens $\times$ biennis sind die gelben Keimlinge zu etwa $3 / 4$, die grünen $z \mathfrak{u}$ etwa $1 / 4$ vertreten. Bei meiner Rasse der O. biennis sind die rubens-Eizellen viel seltener als die albicans-Eizellen, denn in der Kreuzung mit O. Lamarekiana o steht die fallax hinter der velutina an Zahl meistens weit zurück. Noch seltener findet sich bei $O$. biennis-Chicago und O. cruciata der Pollenkomplex in den Embryo- 
säcken in aktivem Zustand (vergl. S. 235). Der letzte Schritt ist dann in der strengen Heterogamie verwirklicht, bei der in den Samenanlagen überhaupt nur der eine der beiden Komplexe aktiv wird. Auf welchem Wege die Veränderung des in der Ontogenie wahrscheinlich im Anfang doch vorhandenen Verhältnisses $1: 1$ zustande kommt, muß noch untersucht werden.

Beim Pollen ist die Bestimmung des Zahlenverhältnisses für die Pollenkörner streng genommen gegenwärtig gar nicht möglich, nur das Verhältnis der wirklich zur Befruchtung gelangenden Pollenschläuche läßt sich ermitteln. Daß dieses bei $O$. Lamarckiana recht variabel ist, haben wir oben erörtert (S. 218). Den Fall, in dem im Pollen nur der eine Komplex aktiv wird, kennen wir wieder von den streng heterogamen Formen wie O. muricata, und bei den halb heterogamen wie O. biennis und suaveolens.

Das Verhältnis zwischen gesunden und tauben Samen muß bei heterozygotischen Formen nach Selbstbestäubung 1:1 sein, wenn auch nur in einem Geschlecht die beiden Keimzelltypen gleich zahlreich aktiv sind. Bei isogamem Verhalten der beiden Komplexe liegen die Dinge so, wie schon früher erörtert wurde (vergl. oben S. 151). Sind bei einer halb heterogamen Form die Eizellen zu $50 \%$ a und $\mathrm{zu} 50 \% \mathrm{~b}$, und kommt im Pollen nur a in aktiver Form vor, so entstehen ebenfalls $50 \%$ lebensfähige Heterozygoten $\mathrm{a} b$ und $50 \%$ Homozygoten a a als taube Samen. Sind von dè Samenanlagen $80 \%$ a und $20 \% \mathrm{~b}$, im Pollen $50 \%$ a und $50 \% \mathrm{~b}$, so entstehen: $40 \%$ a a, $40 \%$ ab, $10 \%$ ba und $10 \% \mathrm{bb}$, also wieder $50 \%$ Heterozygoten und $50 \%$ absterbende Homozygoten; von den letzteren stellen $40 \%$ den einen und $10 \%$ den anderen Typus dar, aber nur wenn die Hemmung der Samen auf verschiedenem Stadium erfolgt, lassen die beiden Typen sich unterscheiden. Sind die Eizellen a häufiger als die Eizellen $b$, und ist der Pollen einförmig $\mathrm{b}$ (Typus von O. biennis), so sind die keimhaltigen Samen $a b$ häufiger als die tauben $b$ b. Sind die Eizellen a häufiger als die Eizellen $b$ und ist der Pollen einförmig a, so sind die keimhaltigen Samen ab seltener als die tauben a a (Typus von O. suaveolens). Herrscht bei Isogamie der Komplex a sowohl im Pollen wie in den Eizellen gegenüber $b$ vor, so sind die gesunden Heterozygoten seltener als die kranken Homozygoten; angenommen, in $O$. (biennis $\times$ Lamarckiana) fallax seien die Eizellen wie die Pollenkörner zu $80 \%$ velans und zu $20 \%$ rubens, so entstehen $16 \%$ velans $\cdot$ rubens, $64 \%$ velans $\cdot$ velans, $16 \%$ rubens $\cdot$ velans, $4 \%$ rubens $\cdot$ rubens, also im ganzen $32 \%$ gesunde fallax-Samen 
und $68 \%$ taube Homozygotensamen. - Bei heterogamem Verhalten beider Komplexe, wie bei O.muricata und der de Vriesschen O.biennis, können sämtliche Samen gesund sein, weil Homozygoten gar nicht zur Bildung kommen.

Aus einem von 1:1 abweichenden Verhältnis zwischen gesunden und tauben Samen auf eine Zahl von Keimzelltypen zu schließen, die größer ist als zwei, ist nach dem Vorausgehenden nicht zulässig. Eine solche Abweichung kann allerdings durch das Hinzutreten von Faktorenheterozygotie zur Komplexheterozygotie hervorgerufen werden. So scheint die rotnervige $O$. Lamarckiana, in der der Rotnervenfaktor nicht homozygotisch verwirklicht werden kann, weniger gesunde Samen zu haben als die weißnervige $(25-33 \%$ gegen $30-49 \%)$.

Bei experimentell erzeugten konstanten Bastardtypen macht ein sehr hoher Gehalt an gesunden Samen es wahrscheinlich, daß die Komplexe der betreffenden Form sich heterogam verhalten, Häufigkeit tauber Samen, daß die Komplexe isogam sind. Die sichere Entscheidung darüber, ob in einem Geschlecht mehr als ein Typus von Keimzellen aktiv ist, wird aber immer nur durch günstige Kreuzungen mit genotypisch gut bekannten Formen zu erbringen sein, d. h. durch Kreuzungen, in denen die bei Selbstbestäubung taube Samen ergebenden Keimzellen keimfähige Samen erzeugen.

Wir haben bis jetzt eine Erörterung der Tatsache unterlassen, daB auch $O$. Lamarckiana, trotzdem sie in beiden Geschlechtern zwei aktive Keimzelltypen erzeugt, auch noch zur Hälfte sterile Samenanlagen und Pollenkörner besitzt. Diese 50\% steriler Keimzellen können bei einer isogamen Form nicht das gleiche bedeuten wie bei den heterogamen Arten. Die Spaltung der Keimzellen muß bei O. Lamarckiana weiter gehen als bis zur Bildung von zwei Typen, wahrscheinlich treten vier gleich häufige Typen auf wie bei Dihybriden. Die eine Hälfte stellt schon im haploiden Zustand unverträgliche Anlagenkombinationen dar, die andere Hälfte kennen wir als velans und gaudens. Daß es aber auch so noch recht große Komplexe von Erbanlagen sein müssen, die bei der Aufspaltung im Zusammenhang bleiben, ist nicht zu bezweifeln. Doch entfernt sich $Q$. Lamarekiana von der Idealform einer streng digametischen Komplexheterozygote verhältnismäßig weit, was ja schon aus ihrer hohen Mutabilität hervorgeht. - Auch die anderen Sippen mit isogamen Komplexen, Arten wie Bastarde, sind auf sterile Pollenkörner und Samenanlagen zu untersuchen, wenn wir über die Zahl der Keimzelltypen einigermaßen sicher werden wollen. 


\section{Die Veränderung der artunterseheidenden Faktorenkomplexe in den Bastarden.}

Wir haben aus den Ergebnissen der Kreuzungen vielfach schließen dürfen, daß bei den Bastarden die Faktorenkomplexe annähernd im selben Zustand in den Keimzellen anzutreffen sind wie bei den ursprünglichen Arten. Aus der sesquireziproken Kreuzung O. (biennis $\times$ muricata) $\times$ biennis geht eine Form hervor, die ich von der ursprünglichen biennis nicht zu unterscheiden vermag, abgesehen von der Blütengröße. Die Kreuzung $O$. biennis $\times$ (biennis $\times$ Lamarckiana) laeta liefert eine so typische laeta, daß wir notwendig annehmen müssen, der Pollen der laeta stelle ziemlich genau den gaudens-Komplex der O. Lamarckiàna dar, dem die laeta ihre Entstehung verdankt. Das gleiche gilt von den entsprechenden Verbindungen der velutina und der fallax. Bei genauer Vergleichung stellen sich aber doch geringe Unterschiede etwa zwischen der ursprünglichen velutina and der aus $O$. biennis $\times$ velutina gewonnenen Form heraus, Unterschiede, die man wohl im Garten sehen, aber schwer beschreiben kann. Es macht also den Eindruck, als ob der velansKomplex durch sein Zusammenleben mit dem albicans-Komplex der biennis sich doch einigermaßen von dem Zustand entfernt hätte, in dem er sich in der Lamarckiana, mit gaudens verbunden, befand. DaB die Komplexe durch Kreuzung der stabilen Arten sehr oft in den gut zu definierenden Faktoren für die Nervenfarbe, für die Blütengröße, für die Statur verändert werden, brauchen wir nicht noch einmal auszuführen.

Auch im züchterischen Verhalten scheinen solche Veränderungen gar nicht selten sich zu offenbaren, besonders auffällig nach den Angaben von de Vries in den Verbindungen der O. muricata. Auf die Fälle, in denen nach den Protokollen von de Vries eine Form, die man als lebensfähig erwarten möchte, nicht aufzutreten scheint, möchte ich nicht eingehen. Aber für sicher verbürgt halte ich einen Fall, in dem ein Bastard, der direkt aus einer Art nicht zu gewinnen ist, auf dem Umweg über eine Kreuzung gewonnen werden kann. O. Lamarckiana $\times$ muricata liefert nämlich bei de Vries eine einzige gracilis-Form neben gelben absterbenden Keimlingen, während durch Kreuzung sowohl von O. (muricata $\times L a$ marckiana) laeta als von $O$. (muricata $\times$ Lamarckiana) velutina mit muricata $0^{7}$ ein gracilis-Typus konstruiert werden kann (vergl. oben S. 243); einer von diesen beiden Typen muß dem lebensunfähigen Zwilling der Kreuzung Lamarckiana $\times$ muricata entsprechen. Die neben der gracilis auftretende muricata (de Vries nennt sie coerulea) soll von der Mutterart beträcht- 
lich verschieden sein. Hier ist also eine Veränderung einerseits am rigens-Komplex, andrerseits am gaudens- (oder velans?-) Komplex sichergestellt: die rigens-Eizellen der Zwillingsbastarde geben mit dem nutans-Pollen der Mutterart nicht mehr die reine O. muricata, und die gaudens-Eizellen der laeta liefern mit curvans-Pollen eine lebensfähige Bastardform, nicht eine kranke wie die gaudens-Eizellen der O. Lamarckiana.

Eine tiefgehende Veränderung der Keimzellen im Bastard kommt darin zum Ausdruck, daß eine $\mathrm{F}_{2}$ überhaupt nicht erzogen werden kann, d. h. daß der Bastard bei Selbstbefruchtung steril ist, wie es oft genug bei den Önotheren allerdings nicht sehr häufig - vorkommt. Ob noch kranke Zygoten gebildet werden oder ob schon die Keimzellen untauglich sind, ist dabei von untergeordneter Bedeutung ${ }^{1}$ ). Der zweite Modus zeigt nur, daß schon die aus den Reifeteilungen hervorgehenden haploiden Biotypen, die Sporen oder günstigerenfalls die Prothallien, nngünstig konstituiert sind, macht aber natürlich die weitere experimentelle Analyse, die des Mittels der Kreuzung bedarf, unmöglich ${ }^{2}$ ). Wir wissen allerdings nicht, ob für die Sterilität eines Bastardes in einem gegebenen Fall die durch Umgruppierung der elterlichen Gene herbeigeführte Veränderung der genotypischen Konstitution seiner Keimzellen oder irgendwelche rein physiologischen, dem Phänotypus angehörenden und dann vielleicht irgendwie $\mathrm{zu}$ überwindenden Störungen verantwortlich zu machen sind. Wenn es aber auf keine Weise gelingt, von einem Bastard keimfähige Samen zu erhalten, müssen wir notwendig mit der Möglichkeit rechnen, daß unter den Keimzellen des Bastardes die Genotypen der elterlichen Keimzellen überhaupt nicht vertreten sind. Durch Kreuzung des Bastardes mit den Eltern oder mit anderen Arten läßt sich günstigenfalls die Veränderung der Hybridkeimzellen experimentell prüfen ${ }^{3}$ ). Der Bastard O.(Lamarckiana $\times$ muricata) gracilis hat bei Selbstbestänbang weder in de Vries' Kulturen noch in den meinigen jenals einen keimfähigen Samen gebracht; ansehnliche taube Samen werden gebildet. O.biennis dagegen wird durch den Pollen des genannten Bastardes zur Ausbildung großer keimhaltiger

1) Literatur bei Sirks, 1917.

2) So bei den sterilen Embryosäcken und Pollenkörnern, die nach Belling bei Stizolobium-Bastarden, neben gesunden Keimzellen, gebildet werden. Die einfachen Mendelschen Zahlenverhältnisse zwischen gesunden und kranken Keimzellen und bei der Vererbung der "Semisterilität" machen es hier aber doch zur Gewißheit, daß die Erscheinung genotypisch bedingt ist.

3) Wichtige Erfahrungen hierüber an Weizen-Roggen-Bastarden bei Jes enko, 1913. 
Samen veranlaßt. Bestäubung der gracilis mit dem Pollen anderer Formen ist noch auszuführen. - Warum meine 0 . (muricata $\times$ Lamarckiana) laeta, anders als bei de Vries, selbststeril war, ist noch nicht klar. Bei Selbstbestäubung trat überhaupt keine Befruchtung ein.

Eine bedeutsame Veränderung wäre es auch, wenn isogame Komplexe durch eine neue Verbindung in heterogame umgewandelt würden oder umgekehrt. Der zweite Fall liegt vielleicht bei den Bastarden zwischen O. biennis und muricata vor. Denn während die beiden Elterarten (biennis wenigstens in der holländischen Rasse) als heterogam fast nur gesunde Samen erzeugen, sind die Samen der Bastarde mindestens zur Hälfte taub, wie wenn untaugliche homozygotische Kombinationen gebildet würden. Die Erscheinung muß durch zweckdienliche Kreuzungen noch analysiert werden.

Nach den mitgeteilten Errfahrungen dürfen wir uns von dem Verhalten der jeweils paarweise zusammengekoppelten Komplexe wohl folgendes Bild machen. Zwischen den beiden Komplexen einer gegebenen "Art" besteht ein gewisses Gleichgewicht, das bei der Keimzellbildung im großen und ganzen festgehalten wird; davon rührt die hohe Konstanz her, die trotz Heterozygotie zur Erscheinung kommt. Die Elemente eines und desselben Komplexes, ins grob Morphologische übersetzt die den Komplex vererbenden Chromosomen, üben eine gewisse Anziehung aufeinander aus, und die Elemente des einen Komplexes stoßen die des anderen ab. Dafür gibt eine gute Illustration das Verhalten der O. biennis, in der der Rotfaktor des rubens-Komplexes von dem albicans-Komplex streng ferngehalten wird. Wird nun durch Kreuznng eine neue Verbindung von Komplexen hergestellt, so wird gewöhnlich das Gleichgewicht fürs nächste gestört sein und bei der Keimzellbildung des $\mathrm{F}_{1}$-Bastardes ein neues Gleichgewicht angestrebt werden. SolcheFaktoren, die zu beiden Komplexen gleiche "Affinität" haben, werden bald dem einen, bald dem anderen Komplex zugeteilt werden, sie werden mit Leichtigkeit von dem sie ursprünglich tragenden Komplex abgerissen und dem neuen Komplex angegliedert. Affinität soll nur ein handliches Wort für die unbekannten Momente sein, die den Faktorenaustausch bedingen; ob diese Momente chemischer Natur, in der Konstitution der Keimplasmen begründet, oder räumlicher Art, in der Struktur eines morphologisch definierten Vererbungsapparats gegeben sind, bleibt dabei offen. Bei ganz gleicher Affinität treten beide Bindungen des Faktors, die alte und die neue, in gleicher Häufigkeit auf, d. h. bei der Hälfte der Tetradenteilungen bleibt die alte Bindung erhalten, bei der andern Hälfte tritt die nene 
in Kraft. Falls die betreffenden Faktoren homozygotisch verwirklicht werden können, tritt bei Selbstbefruchtung der $F_{1}$ in der $F_{2}$ in bezug auf die betreffenden Faktoren normale Mendelspaltung zutage; sind die positiven Homozygoten nicht lebensfähig, dann ist die Spaltung nicht ganz typisch (so verhält sich bei der rotnervigen O. Lamarckiana von Heribert-Nilsson der Rotnervenfaktor). Bei den Önotheren kennen wir als mendelnde Faktoren vorzugsweise die Träger untergeordneter Charaktere, wie es Anthokyanbildung, Blütengröße, Statur sind. Wir sehen den Rotfaktor von rubens der biennis auf velans der Lamarckiana übergehen und aus der rotnervigen fallax in $\mathrm{F}_{2}$ Weißnerven herausspalten; wir finden bei Kreuzung von Arten mit verschieden großen Blüten regelmäßig Spaltung nach der Blütengröße; wir beobachten die Übertragung des Zwergfaktors von nanovelans der Lamarckiana-nanella auf albicans der biennis, auf rigens der muricata, auf Hookeri, und sehen die zunächst hochwüchsigen Bastarde in $\mathrm{F}_{2}$ homozygotische Zwerge abspalten. Nur die Abspaltung der rubrinervis aus O. (rubrinervis $\times$ biennis) subfallax ist ein Beispiel für mendelndes Verhalten der wichtigsten habitusbestimmenden Artmerkmale.

Gelegentlich bleibt derselbe Faktor, der in der einen Komplexverbindung mendelt, in einer anderen Verbindung fest an einen Komplex geknüpft. So lagert sich der Rotnervenfaktor $\mathrm{R}$ in der $O$. Lamarckiana bald an gaudens bald an velans an, und auch wenn R-velans mit r-albicans zu rotnerviger velutina vereinigt wird, pendelt er zwischen velans und albicans hin und her. Dagegen bleibt er in der rotnervigen laeta fest mit gaudens verbunden und geht nicht auf albicans über. Die Festigkeit der Bindung eines Faktors an einen gegebenen Komplex (wie gaudens) ist also keine konstante Größe, sondern sie hängt von der Beschaffenheit des mit dem Faktor nicht ausgestatteten antagonistischen Komplexes ab, oder der Grad der AbstoBung, die ein gegebener Komplex (wie albicans) auf einen Faktor ausübt, variiert je nach dem antagonistischen Träger des Faktors. Kurz, das Verhalten eines Faktors wird bestimmt durch das Verhältnis zu den beiden Komplexen, zwischen denen der Faktor zu wählen hat. Ja, nach den Erfahrungen von Bateson, Baur u. a. ist sogar zu erwarten, daß bei der Keimzellenbildung eines Bastards immer die elterlichen Faktorenkombinationen vor neuen Verbindungen bevorzugt werden, wenn schon einmal Ungleichheit der Chancen vorliegt, daß also Koppelung oder Abstoßung auftritt, je nach den Gametentypen, die in die Heterozygote eingegangen sind. Wenn das für unsere Objekte gilt, dann wird eine 
Faktorenbindung, die selten zu stande kommt (wie etwa die Kombinationen P-rubens und p-velans in der fallax, vergl. oben S. 248), auch selten wieder gelöst werden. Es gäbe dann überhaupt keine Affinität eines Faktors, die zu dem einen von zwei gegebenen Komplexen größer wäre als zu dem andern, sondern nur ein größeres oder geringeres Maß der Leichtigkeit, mit der der Austausch eines Faktors zwischen zwei gegebenen Komplexen in der einen wie in der umgekehrten Richtung sich vollzieht.

In den Kern der artunterscheidenden Anlagenkomplexe dringen die Austauschvorgänge bei den Önotheren im allgemeinen nicht ein ${ }^{1}$ ). Daß aber die Kreuzungen der $O$. rubrinervis sich vielfach anders verhalten, haben wir schon erwähnt, und nach den Angaben von de Vries über gewisse Kreuzungen von O. muricata mit Lamarckiana (vergl. S. 275) werden auch hier die im Bastard vereinigten Komplexe bei der Keimzellbildung weitgehend verändert. Augenscheinlich ist die $\mathrm{Zahl}$ der selbständig mendelnden Faktoren abhängig vlon dem Verhältnis der Komplexe, denen man die Möglichkeit gibt miteinander zu reagieren. Ein änßerster, bei den Önotheren vielleicht überhaupt nicht verwirklichter Grenzfall wäre ein Aufmendeln nach sämtlichen unterscheidenden Erbeinheiten bis auf den identischen Grundstock hinunter, den wir bei verwandten Sippen wohl annehmen dürfen. Das Extrem nach der andern Seite wäre eine absolute Abstoßung der zusammengebrachten Komplexe, so daß der Bastard von der ersten Generation an so konstant wäre wie die komplexheterozygotischen "Arten", durch deren Kreuzung er entstanden ist. Das gewöhnliche Verhalten der Önotheren ${ }^{2}$ ) dürfte ein mäßiges Aufspalten der $\mathrm{F}_{2}$ nach untergeordneten Merkmalen sein. Auch weiter abweichende seltene Typen, „Mutanten“, treten unter der $\mathrm{F}_{2}$ von Bastarden und bei Kreuzung von Bastarden miteinander oder mit den Eltern nach meinen Erfahrungen viel häufiger auf als bei Selbstbefruchtung der alten Arten. Durch Kreuzung wird also die Stabilität der Komplexe in der Regel doch recht tief erschüttert.

Zwischen spaltenden gleich Varietätmerkmalen und nicht spaltenden gleich Artmerkmalen können wir bei den Önotheren offensichtlich

1) Ähnliche Erfahrungen scheint Cook bei Baumwollspezieskreuzungen gemacht zu haben. Er schreibt (S. 242): „The contrasted characters of interspecific hybrids do not behave as independant Mendelian units, but tend to remain more or less united with others derived from the same parental stock."

2) Bei Erophila verna findet $\mathrm{Rosen}$ in $\mathrm{F}_{2}$ bald fast unübersehbare, bald mäBige bald sehr geringe Variation. 
nicht unterscheiden. Wenn wir einen Kern von nicht auseinander weichenden Erbanlagen als die Summe der Artcharaktere den leicht ablösbaren, selbständig mendelnden Einzelfaktoren gegenüberstellen möchten, so finden wir ja, daß der Kern verschiedene Ausdehnung hat je nach dem antagonistischen Komplex. Außerdem trifft es auch bei „intermediärer" Vererbung der "konstanten" Bastarde nicht zu, daß nach den Kernen der Komplexe keine Spaltung eintritt. Die Komplexe lösen sich ja in der Keimzellbildung voneinander und vereinigen sich wenigstens bei Isogamie in der Befruchtung bald zu Heterozygoten bald zu Homozygoten. Daß die Spaltung in der lebensfähigen Nachkommenschaft nicht sichtbar wird, ist für die Theorie des Mendelismus gleichgültig, macht aber die Heterozygotie erst zu einer dauernden, habituellen.

Von den in der $\mathrm{F}_{2}$-Generation auftretenden Typen wird ein Teil vielleicht in den späteren Generationen weitermendeln, ein anderer Teil (oder sollten es gelegentlich alle sein wie bei Erophiza nach Rosen?) erreicht vielleicht schon in der $\mathrm{F}_{2}$ den Zustand, auf den alle Typen bei Selbstbefruchtung hintreiben: Die Formen werden, die einen früher, die andern später, so konstant wie die zu der Kreuzung verwendeten Arten, weil zuletzt alle selbständig mendelnden Faktoren homozygotisch vertreten sind und die übrigen Gene bezw. höheren Einheiten von Erbanlagen trotz heterozygotischem Vorhandensein sich wieder zur selben Stabilität ins Gleichgewicht setzen, wie wir sie von älteren komplexheterozygotischen Formen kennen.

$\mathrm{Da} \beta$ bei diesen Vorgängen der Neukombination allerhand haploide Genotypen entstehen werden, die keine funktionsfähigen Prothallien liefern, und $d a ß$ in den lebensfähigen Sporenformen allerhand Anlagenkomplexe auftreten werden, die bald in homozygotischer Verwirklichung (wie der simple R-Faktor), bald in irgendwelchen heterozygotischen Verbindungen nur untaugliche Zygoten in ein kurzes Leben rufen, brauchen wir nicht zu betonen. Trotzdem kann die Zahl der aus einer Kreuzung hervorgehenden weiterlebenden Formen beträchtlich sein.

\section{IX: Kreuzung und Artentstehung.}

$\mathrm{DaB}$ zwei so verschiedene haploide Komplexe wie gaudens und velans in O. Lamarckiana, wie albicans und rubens in 0 .biennis, wie rigens und curvans in $O$. muricata einander ursprünglich jeweils gleich gewesen und innerhalb der reinen, homozygotischen Art allmählich oder plötzlich so ungleich geworden sein sollen, hat wenig Wahrscheinlichkeit. 
Viel wahrscheinlicher ist die Entstehung dieser dauernd heterozygotischen Sippen durch Bastardierung. Die Ausgangsformen dürften homozygotische Arten gewesen sein, wie sie unter den von de Vries verwendeten Materialien vielleicht die isogamen Typen O. Hookeri, Cockerelli und strigosa darstellen. Die Bastarde zwischen diesen Arten sind nach de Vries (1913, S. 60) mehr oder weniger intermediär und bei Selbstbefruchtung konstant, sie kehren nicht zu den Eltern zurück. Das heißt soviel wie, daß in ihren Keimzellen nur die ursprünglichen Komplexe aktiv werden, daß diese Komplexe aber auch nicht ganz unverändert geblieben. sind. Wären sie noch vollkommen intakt, so müßte die $\mathrm{F}_{2}$ der Bastarde wohl die Elternformen als lebensfähige Homozygoten abspalten, nur die Hälfte der Nachkommenschaft würde den Bastardtypus reproduzieren; die Heterozygotie wäre noch nicht habituell. Konstanz der intermediären Bastardform wäre freilich auch dadurch zu erzielen, daß die vorher isogamen Komplexe in der neuen, heterozygotischen Verbindung heterogam werden, aber damit wäre doch auch eine wesentliche Veränderung des haploiden Genotypus gegeben. Solche konstanten Bastarde müssen nun, falls sie isogam bleiben wie die Elternarten, bei Kreuzungen sich so verhalten wie $O$. Lamarckiana: bei Selbstbefruchtung werden sie etwa zur Hälfte taube Samen erzeugen, und bei Kreuzung mit einem neuen Komplex werden günstigenfalls in der ersten Generation Zwillinge sichtbar werden. Leider hat de Vries seine Bastarde zwischen den isogamen Arten nicht weiter gekreuzt. Die dringendste Unternehmung zur Klärung des OenotheraProblems werden aber fürs nächste diese Kreuzungen sein. Natürlich müssen auch einerseits solche Arten, die mit einiger Sicherheit als homozygotisch gelten können, und andererseits „konstante " Bastarde zwischen so beschaffenen Arten auf das Vorkommen von "Mutationen" geprüft werden. Vielleicht werden unter den Nachkommen der Bastarde Mutanten sichtbar, die sich bald dem einen, bald dem andern Elter nähern.

Ein guter Beleg für die Möglichkeit der Artentstehung bei den Önotheren durch Kreuzung ist die Aufdeckung des Verhältnisses zwischen o. biennis und suaveolens. Beide enthalten denselben Komplex albicans, aber in Verbindung mit zwei weit verschiedenen Komplexen, rubens dort flavens hier. Die beiden Arten können also als Bastarde einer Art a mit zwei verschiedenen Arten $b$ und $\mathrm{c}$ entstanden sein. Weiter sind der gaudens-Komplex der O. Lamarekiana und der rubens-Komplex der O. biennis zwar nicht ganz gleich, aber doch recht ähnlich und stammen vielleicht von einer und derselben Art her; durch die beiden Kreuzungen, von denen die eine die Lamarckiana, die andere die biennis geliefert 
hat, kann der ursprünglich gleiche Komplex sich ja nach zwei verschiedenen Richtungen verändert haben. Natürlich brauchen die eben genannten, und ebenso die anderen durch Züchtungen genauer bekannt gewordenen heterozygotischen Arten gar nicht unmittelbar aus homozygotischen Spezies hervorgegangen zu sein, sondern ihre Stammeltern können bereits Formen gewesen sein, die ihrerseits schon als Bastarde gebildet waren. Mehr als zwei Komplexe kann eine diploide Art nicht enthalten - bei einer tetraploiden gigas-Form, die nicht als Mutation bei Selbstbefruchtung, sondern infolge einer Bastardbefruchtung entstanden wäre, könnten allerdings vier verschiedenə Haploidkomplexe vertreten sein, bei einer semigigas-Form drei -, und ob diese beiden Komplexe ans zwei homozygotischen Arten, oder aus einer homo- und einer heterozygotischen, oder aus zwei heterozygotischen Formen stammen, ist ihnen nicht anzusehen. So könnęn O. suaveolens und Lamarckiana auch durch Kreuzung der biennis mit anderen Arten ins Leben gerufen worden sein; zu suaveolens müßte biennis dann Mutter, zu Lamarckiana könnte sie Vater gewesen sein. Eine solche Art der Entstehung der verbreitetsten Spezies würde auch die sonderbare Tatsache verständlich machen, daß weder $O$. Lamarckiana, noch biennis, noch muricata, noch suaveolens in Nordamerika unter den zahlreichen dort in wildem Zustand vorkommenden Formen haben entdeckt werden können ${ }^{1}$ ). Auch die Aussicht, eine der europäischen Spezies durch mehrfache Kreuzungen zwischen den in Amerika wild wachsenden Typen herzustellen, ist sicher sehr gering, weil die Wege, die zu der Bildung dieser Arten geführt haben, wahrscheinlich sehr verschlungen gewesen sind. Es kann ja auch ein seltener aus einem gar nicht mehr existierenden primären Bastard herausgespaltener Typus besonders lebenskräftig gewesen sein und sich über ein weites Gebiet ansgebreitet haben. Doch wird ein letztes Ziel, wie es sich Davis für $O$. Jamarckiana gesteckt hat, natürlich immer die Synthese solcher heterozygotischen Arten sein, von denen man annehmen kann, daß sie in historischer Zeit entstanden sind.

Für die Entstehungsgeschichte der holländischen O. Lamarckiana wäre es von großer Wichtigkeit zu wissen, ob die Art ursprünglich heterozygotisch-rotnervig gewesen ist wie die Rasse von HeribertNilsson. Eine Angabe von de Vries macht das sehr wahrscheinlich, nämlich die Beschreibung der zuerst beobachteten rubrinervis-Mutanten: "Eine schöne Art mit meist roten Blattnerven" (Mutationstheorie I,

1) De Vries 1914, S. 357. 
S. 161). Wenn die Mutante ursprünglich rotnervig war, wird auch die Stammform rote Nerven besessen haben, die von einer Kreuzung mit einer konstant rotnervigen Art, wie O. biennis, herrühren dürften.

Ein weiteres Problem neben dem der habituellen Heterozygotie ist das der Heterogamie (de Vries). Fürs erste wird zu prüfen sein, ob durch Verbindung zweier isogamen Formen, oder genauer zweier sich isogam verhaltenden Komplexe ein heterogamer Typus konstruiert werden kann. Unter den wenigen Kombinationen, die ich bis jetzt kenne, findet sich ein derartiger Fall nicht. Die Beobachtung, daß die de Vriessche 0 . biennis rein heterogam ist, während meine biennis Eizellen vom Pollentypus auch nur in geringer Zahl erzengt, kann so verstanden werden, daß die Heterogamie sich hier aus der isogamen Heterozygotie herausgebildet hat. Es könnte aber doch sein, daß gelegentlich zwei isogame, von verschiedenen homozygotischen Arten stammende Komplexe durch ihre Verbindung mit einem Schlag zu heterogamem Verhalten gebracht werden. Die konstanten Bastarde zwischen den isogam-homozygotischen Arten wie O. Hookeri, Cockerelli verdienen jedenfalls daraufhin geprüft $\mathrm{zu}$ werden.

Die $O$. Iamarckiana erscheint jetzt den anderen Spezies gegenüber gar nicht mehr merkwürdig. Die wesentlichste Abweichung von der gametischen Struktur der normalen, homozygotischen Arten, die dauernde Heterozygotie ohne Abspaltung lebensfähiger Homozygoten, findet sich bei einer ganzen Zahl von Arten, allerdings in der Form von reiner oder halber Heterogamie; und derselbe Modus von Heterozygotie ist das gewöhnliche Verhalten der experimentell hergestellten Artbastarde. Die heterogamen Arten wie O. muricata sind sogar noch viel merkwürdiger als O. Lamarckiana, deren isogame Heterozygotie erst den Schlüssel für das Verständnis der Heterogamie an die Hand gibt. Falls die Zurückführung der "Mutabilität" der O. Lamarckiana auf ihre Heterozygotie richtig ist, sind auch bei den anderen Arten Mutationen zu erwarten. Tatsächlich sind solche, von denen vor allem die Typen mit abweichender Blattform wichtig sind, bei einer ganzen Reihe von Arten schon beobachtet worden. De Vries stellt 1915 a, S. 183, folgende Liste zusammen: O. biennis L., O. biennis-Chicago de Vries, O. muricata L., O. atrovirens Bartl. (= cruciata de Vries), $O$. suaveolens Desf., O. grandiflora Ait., O. stenomeres Bartl. Dazu kommen nach weiteren Mitteilungen aus dem Jahre 1915 von Bartlett noch O. pratincola Bartl. und O. Reynoldsii Bartl., die de Vries in seine zweite Zusammenstellung der mutierenden Arten (1916 a) schon aufgenommen 
hat. Ob die Entstehung der gigas-, der lata- und der nanellaFormen mit der Heterozygotie unmittelbar etwas zu tun hat, ist noch am ehesten zweifelhaft. Von anderen Matationen aber, vor allem von den schmalblättrigen Typen, die so häufig in der Nachkommenschaft breitblättriger Formen auftreten, ist anzunehmen, daß sie durch Faktorenaustausch zwischen den Komplexen zustande kommen. De Vries hat zugegeben (1915 a, S. 180), daß O. Lamarckiana sich zum Studium der Mutationserscheinungen nicht besonders gut eigne, wenn die Hypothese der Heterozygotie sich bestätige, und er meint, O. biennis sei dafür geeigneter, weil nicht der geringste Zweifel an ihrer gametischen Reinheit bestehe. Die Begründung ist einigermaßen befremdend, weil de Vries selber die Erscheinungen entdeckt hat, die ihn zur Annahme der Heterogamie bei $O$. biennis zwangen. Und meine Rasse ist vollends, wenigstens was die Eizellen betrifft, im selben Sinne digametisch wie $O . \mathrm{La}$ marckiana. Allerdings sind gerade von $O$. biennis hauptsächlich solche Mutationen bekannt geworden, deren Zusammenhang mit der Heterozygotie weniger sicher ist: gigas und semigigas, lata, nanella. Eher könnten die blaßblütige Mutante sulfurea und die von Gates beobachteten Mutanten laevifolia und rubrinervis durch Mischung der Komplexe albicans und rubens zustande gekommen sein. Zuversichtlich zu erwarten sind weißnervige Mutanten, am ehesten unter den blaßblütigen; denn aus der Kreuzung biennis $\times$ suaveolens wissen wir, daß der Pollenkomplex rubens seinen Rotfaktor gelegentlich an albicans abgibt. Um die Mutationserscheinungen an einer von jedem Verdacht der Heterozygotie freien Form zu studieren, müßte man sich also an homozygotische Arten wie 0 . Hookeri halten.

Für die Önotheren scheint mir das Vorkommen konstanter Artbastarde - konstant wenigstens wenn wir uns an die tatsächlich zur Entwicklung kommenden Phänotypen halten - außer Zweifel gestellt zu sein. Ob die kaum jemals absolute Konstanz, die ja das Auftreten von "Mutationen" noch immer zuläßt, irgendwo schon in der ersten Generation erreicht wird, ist noch fraglich; von der zweiten oder einer späteren Generation an dürfte die Konstanz in günstigen Fällen schon ihren maximalen Endwert erreichen. Für gewisse Fragestellungen der Systematik, der Pflanzengeographie und auch der Deszendenzlehre genügt der Nachweis der praktischen Konstanz von Artbastarden. Ob die Konstanz im Lauf von Generationen durch typisches Aufspalten und allmähliches Homozygotischwerden herbeigefürt wird, oder von der ersten Generation an durch diploide Apogamie (vergl. Lotsy und besonders 
Ernst 1917), oder auf dem für die Önotheren klargelegten Weg, ist für die genannten Teildisziplinen von untergeordneterer Bedeutung. Die experimentelle Vererbungsforschung dagegen hat andere Ziele und stellt andere Fragen, und sie hat alle Angaben, daß typisch amphimiktische Spezieshybriden von der ersten oder zweiten Generation an konstant sein sollten, mit Mißtrauen betrachtet, aus dem Wunsche heraus, nur die eine Gesetzmäßigkeit der klaren Mendelspaltung in allen Kreuzungserscheinungen zu finden. Und tatsächlich haben die überzeugten Mendelianer, also die erfolgreichsten Führer der Vererbungsforschung, wenigstens bei den Önotheren mit ihrer zuversichtlichen Erwartung Recht behalten, daß hinter der Konstanz, wenn sie praktisch irgendwo verwirklicht sei, doch irgend eine Art von verkappter Mendelspaltung stecken müsse. Die Erscheinungen der Spaltung werden nur verdunkelt durch verschiedene Formen der auf Kreuzung folgenden Sterilität, deren Wesen Bateson das dunkelste aller genetischen Phänomene genannt hat.

Ob der Vererbungsmodus, den wir bei den Artbastarden in der Gattung Oenothera finden, weitere Verbreitung hat, darüber werden wir wohl in Bälde unterrichtet sein. Am nächsten liegt es, in der Verwandtschaft der Önotheren, etwa in der Gattung Epilobium, Umschau zu halten, und sonst überall da, wo Bastarde von hoher Konstanz vorkommen.

\section{Zusammenfassung der wesentlichen Ergebnisse.}

Die untersuchten Oenothera-Arten, nämlich $O$. Lamarckiana, biennis, muricata, suaveolens, sind sämtlich habituell komplex-heterozygotisch, d.h. sie bilden dauernd zwei weit versehiedene Typen von Keimzellen, die sich wahrscheinlich in zahlreichen, aber fest verketteten, nicht unabhängig mendelnden Faktoren unterscheiden. Homozygotisch ist keiner dieser je paarweise vereinigten Komplexe von Erbanlagen existenzfähig. Wenn Homozygoten gebildet werden, erscheinen sie als bald früher bald später gehemmte Embryonen in tauben Samen.

Die beiden Typen von Keimzellen treten innerhalb desselben Geschlechts auch bei Isogamie (de Vries) meist nicht in gleichen Zahlen aktiv auf. Im extremen Fall, bei Heterogamie (de Vries), ist ein Haploidkomplex nur in den Embryosäcken und der andere nur in den Pollenzellen aktiv. Der jeweils inaktive Komplex liegt in Form von abortierenden Embryosäcken bezw. Pollenkörnern vor. Die Heterogamie 
ist ein Spezialfall der Komplexheterozygotie und von der isogamen Ausprägung verschieden durch das selektive Fehlschlagen von Keimzellen, das an die Stelle des Fehlschlagens von Homozygoten tritt.

O. Tamarckiana besteht aus zwei Komplexen, die wir velans und gaudens genannt haben und die beide in den Eizellen wie im Pollen etwa gleich häufig sind. Die Art ist isogam, weil Eizellen wie Pollen dityp sind, ihre Strukturformel ist velans $90^{\top} \cdot$ gaudens $90^{7}$. Der Komplex velans vererbt schmale Blätter und Anthokyanbildung an den Kelchblättern und in den Haarbasen am Stengel und an den Fruchtknoten (rote Tupfen). Der Komplex gaudens vererbt breite Blätter, grünen Kelch und farblose Haarbasen.

o. muricata ist streng heterogam; die Eizellen sind monotyp und stellen den Komplex rigens dar, der Pollen ist ebenfalls monotyp und repräsentiert den Komplex curvans. Die Formel ist also rigens 9 - curvans $\sigma^{\top}$. Der Komplex rigens überträgt aufrechte Sprosse und rote Tupfen, curvans vererbt nickende Sproßgipfel, die in den bekannten Verbindungen sich dominant verhalten.

O. biennis ist in der von mir kultivierten Rasse halbheterogam. Der Weißnervigkeit vererbende Komplex albicans ist auf die Eizellen beschränkt, verhält sich heterogam, der Rotnervigkeit übertragende Komplex rubens ist isogam, denn er kommt in dem monotypen Pollen und in einem kleinen Teil der Eizellen aktiv vor. Die Formel der Art ist albicans + . rubens $9 \sigma^{7}$.

O. suaveolens ist ebenfalls halbheterogam und hat die Formel

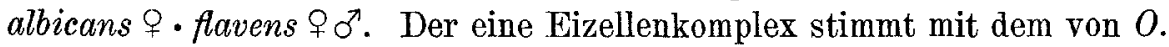
biennis anscheinend überein. Der Komplex flavens überträgt breite, mehr oder weniger gelblichgrüne Blätter und sehr schlanke Früchte. In den ditypen Eizellen ist der Komplex favens häufiger als albicans, im Pollen fehlt albicans in aktivem Zustand vollständig.

Nicht lebensfähige Homozygoten, also aus genotypischer Ursache taube Samen, kommen nur dort vor, wo die Eizellen dityp sind, bei strenger Heterogamie (O. muricata) fehlen sie. Zweierlei Homozygoten sind bei der isogamen $O$. IJamarckiana anzunehmen, ein homozygotischer Typus bei den halb heterogamen Arten O. biennis (rubens - rubens) und O. suaveolens (flavens flavens).

Bei Kreuzungen zwischen den Arten ist die erste Generation einförmig, wenn monotype Eizellen mit monotypem Pollen verbunden werden. Die $F_{1}$ ist zweiförmig, wenn ditype Keimzellen mit monotypen, und vierförmig, wenn ditype Keimzellen mit ditypen verbunden werden. In 
günstigen Fällen sind alle Kombinationen lebensfähig, in anderen treten gewisse heterozygotische Typen als nicht ergrünende, sehr früh absterbende Keimlinge oder gar nur als taube Samen mit winzigen Embryonen in die Erscheinung. Die Arten, die bei Selbstbestäubung zahlreiche taube Samen erzeugen, weil ihre Samenanlagen dityp sind, bringen in solchen Kreuzungen, die unter den Keimpflanzen oder noch später mehrere Bastardtypen erkennen lassen, fast lauter keimfähige Samen hervor.

Reziproke Kreuzungen zwischen zwei heterogamen Arten oder zwischen einer heterogamen und einer isogamen Art können keine identischen Bastarde geben, weil eine heterogame Art als Vater ganz andere Erbanlagen überträgt denn als Mutter (de Vries). Reziproke Verbindungen isogamer Arten bezw. isogamer Komplexe liefern annähernd identische Bastarde.

Einförmig ist die $\mathrm{F}_{1}$-Generation der Kreuzung O. muricata $\times$ biernis der Bastard hat die Formel rigens - rubens.

Einförmig scheint die $\mathrm{F}_{1}$ der Kreuzung $O$. Lamarckiana $\times$ biennis; Lebensfähig ist nämlich nur der Bastard fallax $=$ velans $\cdot$ rubens, die Kombination gaudens - rubens ist durch taube Samen vertreten.

Bei der Keimung zweiförmig ist die $\mathrm{F}_{1}$ der Kreuzung O. Lamarckiana $\times$ muricata. Lebensfähig ist der Bastard gracilis $=v e$ lans (?) - curvans, auf sehr frühem Stadium stirbt die Kombination gaudens (?) - curvans. Ebenso verhält sich die Kreuzung O. biennis $X$ muricata; die lebensfähige gracilis-Form ist albicans curvans; die Verbindung rubens • curvans ist wohl noch keimfähig, die Keimlinge ergrünen aber nicht.

Zwei lebensfähige Bastardformen, Zwillingsbastarde, treten in folgenden Kreuzungen auf: 0 . muricata $\times$ Lamarckiana liefert velutina $=$ rigens $\cdot$ velans und laeta $=$ rigens $\cdot$ gaudens. O. biennis $\times$ suaveolens liefert albicans $\cdot$ flavens $=$ suaveolens (suavis) und rubens . flavens $=$ flava. O. suaveolens $\times$ biennis liefert albicans $\cdot$ rubens $=$ biennis (redempta) und flavens $\cdot$ rubens = flava. Die flava -Typen der beiden reziproken Kreuzungen sind identisch. O. Lamarckiana $\times$ suaveolens liefert velans $\cdot$ flavens $=$ suavi-velutina und gaudens $\cdot$ flavens.$=$ suavi-laeta .

Aus drei lebensfäligen Bastardformen besteht die $\mathrm{F}_{1}$ der Kreuzung O. biennis $\times$ Lamarckiana. Es treten auf: albicans $\cdot$ velans $=$ velutina, albicans $\cdot$ gaudens $=$ laeta, rubens $\cdot$ velans $=$ fallax, diese mit der auf reziprokem Wege gewonnenen fallax identisch. Die vierte Kombination rubens - gaudens ist nur durch taube Samen vertreten. 
Vier lebensfähige Formen setzen die $F_{1}$ der Kreuzung $O$. suaveolens $\times$ Lamarckiana zusammen, nämlich flavens $\cdot$ velans $=$ suavivelutina, flavens $\cdot$ gaudens = suavi-laeta (diese beiden mit den Zwillingen der reziproken Kreuzung identisch), albicans $\cdot$ velans $=$ bienni-velutina, albicans $\cdot$ gaudens $=$ bienni-laeta (diese beiden mit den Zwillingen aus $O$. biennis $\times$ Tamarckiana identisch).

Die artunterscheidenden Faktorenkomplexe bleiben in den Keimzellen der Bastarde in ihrem Hauptbestand meistens unverändert. Nur in bezug auf gewisse untergeordnete Merkmale tritt bei den im übrigen konstanten Bastardrassen in $\mathrm{F}_{2}$ fast immer Mendelsche Spaltung ein, nämlich nach der Nervenfarbe, wenn ein weißnerviger und ein rotnerviger Komplex verbunden worden sind, nach der Blütengröße, nach der Griffellänge. Faktorenaustausch kann auch zwischen einem aktiven und einem inaktiven Keimzelltypus stattfinden.

$\mathrm{Ob}$ ein Faktor mendelt oder mit dem ihn tragenden Komplex fest im Zusammenhang bleibt, hängt von der Beschaffenheit des antagonistischen Komplexes ab.

Auch das Verhältnis der Komplexe zum Geschlecht der Keimzellen bleibt in den Bastarden im allgemeinen dasselbe wie in den Arten. Ein isogamer Komplex bleibt isogam, ein heterogamer bleibt heterogam. Bei den meisten hergestellten Bastarden sind die Bedingungen für die Bildung von Homozygoten bei Selbstbefruchtung gegeben, weil die Keimzellen wenigstens in einem Geschlecht dityp zu sein pflegen, die Zahl der tauben Samen ist deshalb meistens beträchtlich. Die Konstanz der Artbastarde in unserer Gruppe beruht demnach nur zu einem geringen Teil auf der Wiederherstellung eines homozygotischen Zustandes, zur Hauptsache darauf, daß jeweils nur eine heterozygotische Kombination zugelassen wird und die Kombinationen, die in bezug auf den Kern der Anlagenkomplexe homozygotisch sind, entweder (bei Heterogamie) sich gar nicht bilden können oder (bei Isogamie) nicht lebensfähig sind, genau wie bei den zu den Kreuzungen verwendeten heterozygotischen Arten.

Sind die im gleichen Geschlecht aktiven Komplexe einer Art durch Kreuzung mit einer anderen Art voneinander getrennt, auf ein Paar von Zwillingsbastarden verteilt, so kann durch Kreuzung der Zwillinge die Art wieder hergestellt werden. So gelingt die Synthese der 0 . Iamarckiana aus den Zwillingen $O$. (biennis $\times$ Lamarckiana) laeta und velutina.

Im übrigen geben die Bastarde bei Kreuzung mit Arten oder mit anderen Bastarden ein- bis vierförmige Nachkommenschaft, je nach dem heterogamen oder isogamen Verhalten der Komplexe. 
Ausnahmsweise reißt sich ein Faktor, der sonst an den zugehörigen Komplex fest gebunden ist, bei der Keimzellbildung eines Bastardes von seinem Komplex los und geht auf den antagonistischen Komplex über. So verhält sich in seltenen Fällen der Faktor, der die Rotfärbung der Haarbasen bedingt, bei dem Bastard $O$. (Lamarckiana $\times$ biennis) fallax und reziprok.

Die Variabilität aller Zahlenverhältnisse zwischen den Kombinationen ist zum Teil wohl darauf zurückzuführen, daß Pollenzellen, die verschiedene haploide Genotypen darstellen, verschiedene und von den Außenbedingungen in verschiedener Weise beeinflußte Keimungs- und Wachstumsgeschwindigkeit haben können, auch wenn sie im selben Pollensack entstanden sind.

Es wird die Vermutung ausgesprochen, daß die in einer Art jeweils verbundenen Komplexe allgemein nicht absolut stabil sind, sondern gelegentlich Faktoren miteinander austauschen, und daß ein Teil der ans $O$. Lamarckiana und anderen komplexheterozygotischen Arten hervorgehenden „Mutanten" durch solchen Faktorenaustausch zwischen den Komplexen entsteht.

Auf dem angedeuteten Wege dürfte die Mutante rubrinervis entstanden sein. Sie unterscheidet sich von $O$. Lamarckiana in beiden Komplexen. Der velans-Komplex ist sehr wenig modifiziert, aber doch nicht ganz unverändert. Statt des gaudens-Komplexes enthält $O$. rubrinervis den Komplex subvelans, der etwa in der Mitte zwischen gaudens und velans steht. Mit den beiden Komplexen der O. biennis liefern beide Komplexe der 0 . rulrinervis lebensfähige Verbindungen: Die Kreuzung 0 .rubrinervis $\times$ biennis gibt fallax $=$ velans $\cdot$ rubens und die sehr ähnliche subfallax $=$ subvelans $\cdot$ rulbens, die Kreuzung $O . b i$ ennis $\times$ rubrinervis gibt velutina $=$ albicans $\cdot$ velans, die sehr ähnliche subvelutina $=$ albicans $\cdot$ subvelans, weiter fallax $=$ rubens $\cdot$ velans und subfallax $=$ rubens $\cdot$ subvelans. Die Kreuzung 0 . rubrinervis $\times$ Lamarckiana zeigt, daß auch der velans-Komplex etwas abgeändert ist. Denn die beiden Bastardformen, die aus der Krenzung hervorgehen, sind mit den Elterarten nicht identisch; subvelans - velans ist blanda, nicht rubrinervis, und die Verbindung velans - gaudens ist der O. Tamarckiana zwar sehr ähnlich, aber doch nicht ganz gleich; subvelans.gaudens scheint nicht lebensfähig zu sein.

Von der Mutante 0 . Lamarckiana-nanella ist vorläufig nur so viel zu sagen, daß der Zwergcharakter dem velans-Komplex zukommt und über die im gaudens-Komplex vererbte hohe Statur dominiert; denn von den Zwillingsbastarden treten nur die velutina-Formen als Zwerge auf, nicht die laeta-Formen. In Verbindung mit den Komplexen anderer 
Arten (z. B. muricata) ist aber das Zwergmerkmal rezessiv, Zwerge können also erst in der zweiten Bastardgeneration als Homozygoten auftreten. Der Zwergfaktor gehört demnach in diesen Verbindungen zu den mendelnden Faktoren, während er in der O. Lamarckiana-nanella nicht von velans auf gaudens übergeht. - Ebensogut oder noch besser verständlich sind die Erscheinungen, wenn wir annehmen, daß der Zwergcharakter immer rezessiv ist, $\mathrm{da} B$ er dem gaudens-Komplex der $O$. Lamarckiana immer angehört und gewöhnlich nicht, aber doch gelegentlich auf velans übergeht.

Für O. Lamarckiana-gigas wird die experimentell leicht zu prüfende Hypothese aufgestellt, daß ihre Keimzellen die Konstitution (velans + gaudens) haben. Das Ausbleiben der laeta-velutina-Spaltung in der Kreuzung mit O. biennis ๆ wäre damit erklärt.

Bei der Rückkreuzung gewisser Bastarde mit den Elterarten treten Erscheinungen auf, die auf eine tiefere Veränderung der ursprünglichen Komplexe in der neuen, durch Kreuzung herbeigefürten Verbindung hinweisen. Vor allem ist gelegentlich eine Verbindung eines Komplexes lebensfähig, wenn der betreffende Komplex aus einem Bastard stammt, während dieselbe Verbindung nicht verwirklicht werden kann, wenn der Komplex der Art entnommen wird. Ebenso kann umgekehrt eine aus der Art in lebensfähiger Form zu gewinnende Verbindung gelegentlich aus dem Bastard nicht gewonnen werden.

Diese Erfahrungen legen die Aufstellung folgender Hypothese über die Entstehung der komplexheterozygotischen Arten nahe. Das Ausgangsmaterial sind homozygotische Arten wie O. Hookeri, Cockerelli. Durch Kreuzung zweier solcher Arten entsteht dann und wann ein Bastard, in dessen Keimzellen die beiden vereinigten Komplexe durch Faktorenaustausch so verändert werden, daß die Komplexe nicht mehr in homozygotischer Form lebensfähig sind, daß also die Elterarten nicht aus dem Bastard herausspalten können. Vertragen sich die bei der Keimzellbildung modifizierten Komplexe auch in heterozygotischer Verbindung nicht mehr miteinander, so ist der Bastard selbststeril und kann sich nicht erhalten. Gewöhnlich aber liefern bei den Önotheren die Keimzellen der $\mathrm{F}_{1}$ eine lebensfähige, bald mehr bald weniger vielförmige heterozygotische Nachkommenschaft, und damit ist der Bestand einer oder mehrerer dauernd heterozygotischer Formen gesichert. Durch weitere Kreuzungen zwischen schon heterozygotischen Formen entstehen weitere Scharen von neuen, untereinander teilweise wenig verschiedenen heterozygotischen Arten.

München-Zamdorf, im Januar 1917. 


\section{Nachschrift.}

Nach der Absendung des Manuskripts sind mir noch zwei Mitteilungen von Davis (1916 a und b) zugegangen, und auch von de Vries ist ein neuer Beitrag erschienen (1917). In Fubnoten babe ich auf diese drei Arbeiten sehon an verschiedenen Stellen Bezug genommen.

Davis ist es in Verfolgung seines alten Ziels gelungen, durch Synthese einen sehr Lamarckiana-ähnlichen Typus zu gewinnen, den er neo-Lamarckiana nennt. In der primären Kreuzung ist $O$. franciscana die Mutter, mit schmalen Blättern, roten Haarpolstern, rotstreifigen Kelchen, großen langgriffeligen Blüten; biennis ist Vater. Das stimmt mit den Ergebnissen unserer analytischen Versuche über die Beschaffenheit der Komplexe velans und gaudens aufs beste überein. Die $\mathrm{F}_{1}$ der $\mathrm{Kreuzung}$ spaltet stark, die eigentliche neo-Lamarckiana ist erst in $\mathrm{F}_{\mathrm{s}}$ entstanden und ist noch nicht konstant, sondern spaltet bei Selbstbestäubung noch immer franciscana-ähnliche (homozygotische?) Typen $a b$; bei Kreuzung mit $O$. biennis $O$ und mit $O$. biennis-Chicago $O$ liefert sie Zwillinge. Davis, der seit dem Erscheinen meiner ersten Mitteilang die tanben Samen berücksichtigt, bringt die Inkonstanz der gewonnenen Form mit ihrem hohen Gehalt an keimfähigen Samen $\left(87 \%\right.$ in $\left.\mathrm{F}_{3}\right)$ in Beziehung und sucht nun nach Typen mit geringerer Fruchtbarkeit, die vielleicht konstant werden. Seine Versuche bewegen sich also genau in der Richtung, die auch mir als die aussichtreichste erseheint.

Auch de Vries nimmt jetzt an, daß $O$. Lamarckiana dauernd zwei Typen von Keimzellen bildet, die er laeta und velutina nennt und die in homozygotischer Kombination taube Samen erzeugen. Der velutina-Typus (unser velans-Komplex) soll durch primäre Mutation aus laeta (unserem gaudens-Komplex) entsprungen sein, und O. Lamarckiana ist, weil aus einer mutierten und einer nicht mutierten Keimzelle der hypothetischen homozygotischen Stammart hervorgegangen, eine „Halbmutante“. Als Vollmutante gehört zu ihr die homozygotische(?) Mutation velutina, die de Vries als Abkömmling der Lamarckiana vor kurzem aufgefunden hat.

Die Frage, wie die Lamarckiana entstanden sein mag, ist wie alle derartigen historischen Fragen im strengen Sinn nicht exakt lösbar. Aber geben wir einmal zu, $\mathrm{da} B$ der velutina-Komplex infolge einer spontanen Abänderung von laeta ins Leben getreten sei, und daß gleichzeitig, ebenfalls durch Mutation, sowohl laeta wie velutina einen "letalen Faktor" erworben haben, der ihnen die Möglichkeit homozygotischer Existenz raubte, so ist die Lamarckiana eben doch nicht mehr und nicht weniger als ein heterozygotisches Wesen, das verschiedene Keimzellen immer erzeugen $\mathrm{mu} B$, nicht infolge einer seltsamen Mutabilität unter gewissen Bedingungen erzeugen kann. De Vries nennt das dauernde Auftreten von velutina- neben laela-Keimzellen. „sekundäre Mutation“, und zwar im Anschluß an Bartlett (1915) sekundäre "Mlassenmutation". Ich kann nicht finden, dab zwischen diesem Vorgang und monohybrider Mendelspaltung ein Unterschied besteht.

Im übrigen sieht de Vries in der Bastardierung der Lamarckiana ein Mittel, die beiden Komplexe in Form von Zwillingsbastarden getrennt zu studieren, und er hat auch schon begonnen, die Mutanten im selben Sinn zu analysieren, wie es in den oben mitgeteilten Versuchen geschehen ist. Bei seiner unvergleichlichen Erfahrung wird er uns sicher in Kürze die Aufk]ärung der wichtigsten Matantentypen bescheren.

Ulm, im September 1917. 


\section{Zitierte Literatur.}

De Vries, H. Die Mutationstheorie. 1. Bd. 1901, 2. Bd. 1903.

- Über doppeltreziproke Bastarde von Oenothera biennis L. und O. muricata L. Biolog. Centralblatt, 1911, Bd. 31, S. 97.

- Gruppenweise Artbildung. Berlin 1913.

- The probable origin of Oenothera Lamarckiana Ser. Bot. Gaz. 1914, vol. 59, p. 345.

- 1915 a. The coefficient of mutation in Oenothera biennis L. Bot. Gaz. 1915, vol. 59 , p. 169 .

- 1915 b. Über künstliche Besehleunigung der Wasseraufnahme in Samen durch Druck. Biolog. Centralblatt, 1915, Bd 35, S. 161.

- 1915 c. Über amphikline Bastarde. Berichte der Deutsch. Bot. Gesellschaft, 1915, Bd. 33, S. 461.

- 1915 d. Oenothera gigas nanella, a Mendelian mutant. Bot. Gaz. 1915, vol. 60, p. 337.

- 1916 a. Die endemischen Pflanzen von Ceylon und die mutierenden Önotheren. Biolog. Centralblatt, 1916, Bd. 36, S. 1.

- 1916 b. Gute, harte und leere Samen von Oenothera. Zeitschr. f. ind. Abst.- und Vererbungslehre, 1916, Bd. 16, S. 239.

- Halbmutanten und Zwillingsbastarde. Berichte der Deutsch. Bot. Gesellschaft, 1917, Bd. 35, S. 128.

Atkinson, G. F. Sorting and blending of "unit characters" in the zygote of Oenothera with twin and triplet hybrids in the first generation. Zeitschr. f. ind. Abst.- und Vererbungslehre, 1916, Bd. 16, S. 193.

Bartlett, H. H. Twelve elementary species of Onagra. Cybele Columbiana, 1914, vol. 1, p. 37.

- Additional evidence of mutation in Oenothera. Bot. Gaz., 1915, vol. 59, p. 81.

- Mass mutation in Oenothera pratincola. Bot. Gaz., 1915, vol. 60, p. 425.

Bateson, W. .Mendels Vererbungstheorien. Übersetzt von A. Winckler. Leipzig 1914.

Baur, E. Einführung in die experimentelle Vererbungslehre. Berlin, 1. Auflage 1911, 2. Auflage 1914.

Belling, J. The mode of inheritance of semi-sterility in the offspring of certain hybrid plants. Zeitschr. f. ind. Abst.- und Vererbungslehre, 1914, Bd. 12, S. 303.

Cook, O. F. Mendelism and interspecific hybrids. Amer. Naturalist, 1913, vol. 47, p. 239.

Correns, C. Scheinbare Ausnahmen von der Mendelschen Spaltungsregel für Bastarde. Berichte der Deutsch. Bot. Gesellschaft, 1902, Bd. 20, S. 159.

Davis, B. M. 1910 a. Cytological studies on Oenothera. II. The reduction division of Oenothera biennis. Annals of Bot., 1910, vol. 24, p. 631 .

- 1911 a. III. A comparison of the reduction divisions of Oenothera Lamarckiana and $O$. gigas. Ebenda, 1911, vol. 25, p. 941.

$-1910 \mathrm{~b}$. Genetical studies on Oenothera. I. Notes on the behavior of certain hybrids of Oenothera in the first generation. Amer. Naturalist, 1910, vol, 44, p. 108.

- 1911 b. II. Some hybrids of 0 . biennis and grandiflora that resemble O. Lamarckiana. Ebenda, 1911, vol. 45, p. 193.

- 1912. III. Further hybrids of $O$. biennis and $O$. grandiflora that resemble O. Lamarckiana. Ebenda, 1912, vol. 46, p. 377. 
Dayis, B. M. 1913. IV. The behavior of hybrids between 0 . biennis and 0 . grandiflora in the second and third generations. Ebenda, 1913, vol. 47, p. 449.

- 1914. V. Some reciprocal crosses of Oenothera. Zeitschr. f. ind. Abst.- und Vererbungslehre, 1914, Bd. 12, S. 169.

- 1915 a. A method of obtaining complete germination of seeds in Oenothera and of recording the residue of sterile seed-like structures. Proceed. of the National Academy of Sciences, 1915, vol. 1, p. 360 .

- $1915 \mathrm{~b}$. The test of a pure species of Oenothera. Proceed. of the American Philosophical Society, 1915, vol. 54, p. 226.

- 1916 a. Hybrids of Oenothera biennis and $O$. franciscana in the first and second generations. Genetics, 1916, vol. 1, p. 197.

- $1916 \mathrm{~b}$. Oenothera neo-Lamarckiana, hybrid of 0 . franciscana Bartl. $\times 0$. biennis $L$. Amer. Naturalist, 1916, vol. 50, p. 688.

East, E. M. Inheritance of flower size in crosses between species of Nicotiana. Bot. Gaz. 1913, vol. 55, p. 177.

Ernst, A. Experimentelle Erzeugung erblicher Parthenogenesis. Zeitschr. f. ind. Abst.und Vererbungslehre, 1917, Bd. 17, S. 203.

Feder]ey, H. Das Verhalten der Chromosomen bei der Spermatogenese der Schmetterlinge Pygaera anachoreta, curtula und pigra sowie einiger ihrer Bastarde. Ein Beitrag zur Frage der konstanten intermediären Artbastarde. Zeitschr. f. ind. Abst.- und Vererbungslehre, 1913, Bd. 9, S. 1.

- Chromosomenstudien an Mischlingen 1, II, III. Referat von Tischler in Zeitschr. f. ind. Abst.- und Vererbungslehre, 1917, Bd. 18, S. 62.

Gates, R. R. Tetraploid mutants and chromosome mechanisms. Biolog. Centralblatt, 1913, Bd. 33, S. 92.

Gates, R. R., and Thomas, N. A cytological study of Oenothera mut. lata and Oe. mut. semilatia in relation to mutation. The quarterly Journal of Microscopical Science, 1914, vol. 59, p. 523.

Geerts, J. M. Beiträge zur Kenntnis der Cytologie und der partiellen Sterilität von Oenothera Lamarckiana. Recueil trav. bot. néerland. 1909, vol. 5, p. 93.

Haase-Bessell, Gertraud. Digitalisstudien I. Zeitschr. f. ind. Abst.- und Vererbungslehre, 1916, Bd. 16, S. 293.

Heribert-Nilsson, N. Pollenslangarnas tillväxthastighet hos Oenothera Lamarckiana och gigas. Botaniska Notiser, 1911, p. 19.

- Die Variabilität der Oenothera Lamarckiana und das Problem der Mutation. Zeitschr. f. ind. A bst.- und Vererbungslehre, 1912, Bd. 8, S. 89.

- Die Spaltungserscheinungen der Oenothera Lamarckiana. Lunds Universitets Årsskrift, 1915 , Bd. 12, Nr. 1.

- Eine mendelsche Erklärung der Verlustmutanten. Berichte der Deutsch. Bot. Gesellschaft, 1916, Bd. 34, S. 870.

Honing, J. A. Die Doppelnatur der Oenothera Lamarckiana. Zeitschr. f. ind. Abst.und Vererbungslehre, 1911, Bd. 4, S. 227.

Jeffrey, E. C. Spore conditions in hybrids and the mutation hypothesis of de Vries. Bot. Gaz., 1914, vol. 58, p. 322.

Jesenk 0, J. Über Getreide-Speziesbastarde (Weizen-Roggen). Zeitschr. f. ind. Abst.und Vererbungslehre, 1913, Bd. 10, S. 311. 
Johannsen, W. Elemente der exakten Erblichkeitslehre. 2. Aufl. Jena 1913.

Jost, L. Über die Selbststerilität einiger Blüten. Botan. Zeitung, 1907, Jahrg. 65, S. 77. Klebahn, H. Formen, Mutationen und Kreuzungen bei einigen Önotheren aus der Lüneburger Heide. Jahrb. d. Hamburg. Wissensch. Anstalten, Bd. 31, 3. Beiheft, 1914.

Lehmann, E. Über Bastardierungsuntersuchungen in der Veronica-Gruppe agrestis. Zeitschr. f. ind. Abst.- und Vererbungslehre, 1914, Bd. 13, S. 88.

Lotsy, J. P. Kreuzung oder Mutation die mutmaßliche Ursache der Polymorphie? Zeitschr. f. ind. Abst.- und Vererbungslehre, 1915, Bd. 14, S. 204.

Mac Dougal, D. T., Vail, Shull and Small. Mutants and hybrids of the Oenotheras. Carnegie Inst. of Washington, 1905, Publ. No. 24.

Renner, O. Befruchtung und Embryobildung bei Oenothera Lamarckiana und einigen verwandten Arten. Flora, 1914, Bd. 107, S. 115.

- Die tauben Samen der Önotheren. Berichte der Deatsch. Bot. Gesellschaft, 1916, Bd. 34 , S. 858.

Rosen, F. Die Entstehung der elementaren Arten von Erophila verna. Cohns Beitr z. Biologie d. Pfl., 1911, Bd. 10, S. 379.

Saunders, E. R. On the mode of inheritance of certain characters in double-throwing stocks. A reply. Zeitschr. f. ind. Abst.- und Vererbungslehre, 1913, Bd. 10, S. 297.

Sirks, J. M. Stérilité, auto-inconceptibilité et différenciation sexuelle physiologique. Arch. néerland. d. sc. exact. et natur., série $B, 1917$, t. 3, p. 205.

Stomps, Th. Über den Zusammenhang zwischen Statur und Chromosomenzahl bei den Önotheren. Biolog. Centralblatt, 1916, Bd. 36, S. 129.

Tanaka. Occurrence of different systems of gametic reduplication in male and female hybrids. Zeitschr. f. ind. Abst.- und Vererbungslehre, 1915, Bd. 14, S. 12.

Tischler, G. Neuere Arbeiten über Oenothera. Sammelreferat. Zeitschr. f. ind. Abst.und Vererbungslehre, 1911., Bd. 5, S. 324.

- Chromosomenzahl, -Form und Individualität im Pflanzenreiche. Progr. rei bot., 1915, Bd. 5, S. 164.

Tschermak, A. v. Über das verschiedene Ergebnis reziproker Kreuzungen von Hühnerrassen und über dessen Bedeutung für die Vererbungslehre (Theorie der Anlagenschwächung oder Genasthenie). Biolog. Centralblatt, 1917, Bd. 37, S. 217.

Winkler, Hans. Über die experimentelle Erzeugung von Pflanzen mit abweichenden Chromosomenzahlen. Zeitschr. f. Bot., 1916, Bd. 8, S. 417. 